\title{
Analyse alter DNA zur Ermittlung von Heiratsmustern in einer frühmittelalterlichen Bevölkerung
}

\author{
Dissertation zur Erlangung des Doktorgrades \\ der Mathematisch-Naturwissenschaftlichen Fakultäten \\ der Georg-August-Universität zu Göttingen
}

\author{
vorgelegt von \\ Julia Gerstenberger \\ aus Osnabrück
}

Göttingen 2002 
D7

Referent:

Prof. Dr. B. Herrmann

Korreferent:

Prof. Dr. W. Engel

Tag der mündlichen Prüfungen: $\quad$ 24. April 2002 
1 EINLEITUNG 1

1.1 Rekonstruktion von Heiratsverhalten ........................................................ 1

1.1.1 Heiratsregeln .............................................................................. 1

1.1.2 Die frühmittelalterliche Bevölkerung von Weingarten................................ 2

1.2 Verwandtschaftsfeststellung innerhalb der Historischen Anthropologie .............. 4

1.2.1 Molekularer Nachweis von Verwandtschaft durch Analyse alter DNA....... 5

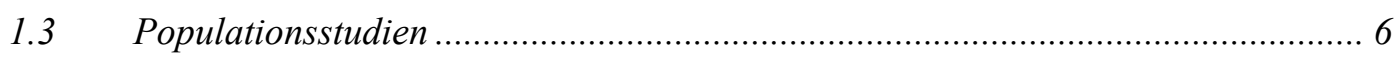

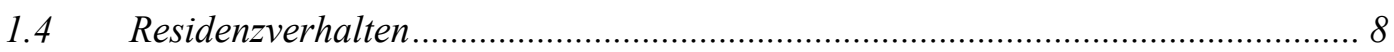

1.4.1 Nachweis des Residenzverhaltens durch Analyse molekularer Marker ........ 9

1.5 Ehe und Heiratsregeln: Externe Erkenntnisse ................................................. 10

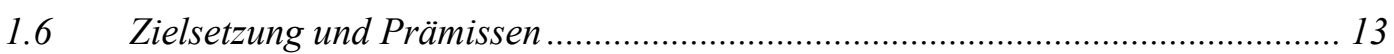

2 MATERIAL ......................................................................................................... 15

$2.1 \quad$ Die alamannische Gesellschaft ........................................................ 15

2.1.1 Reihengräber- und Beigabensitte ..................................................... 15

2.1.2 Sozialstruktur der merowingerzeitlichen Gesellschaft ........................... 17

2.1.3 Rückschlüsse auf die Sozialstruktur anhand archäologischer Quellen ........ 18

2.2 Der Fundort Weingarten .................................................................... 20

$2.3 \quad$ Skelett- und Grabfunde ................................................................. 22

3 METHODEN ............................................................................................ 28

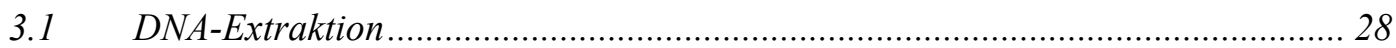

3.1.1 Probenentnahme und -vorbereitung ............................................... 28

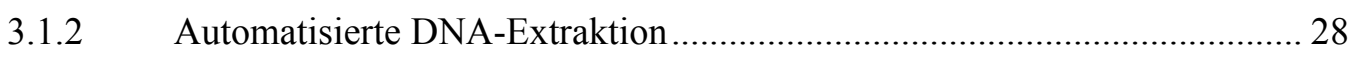

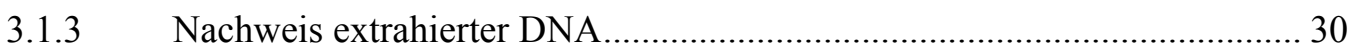

3.1.4 Zusätzliche Aufreinigung von Extrakten ............................................... 31

3.2 DNA-Amplifikation: Polymerase Chain Reaction (PCR)................................ 32

3.2.1 Kontaminationsprävention und Authentifizierung.................................. 33

3.2.1.1 Kontaminationsvermeidung.......................................................... 34

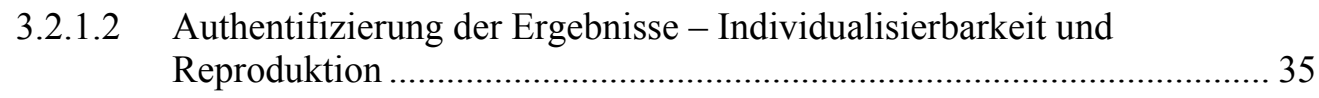

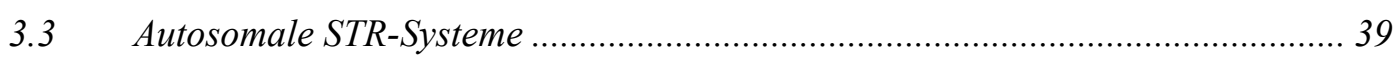

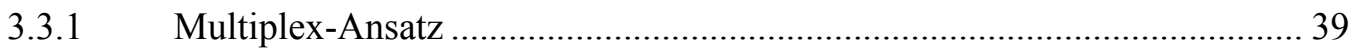

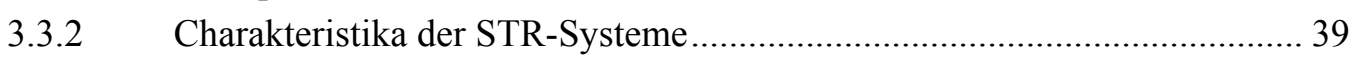

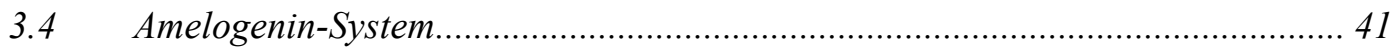

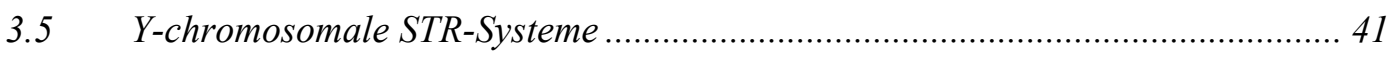

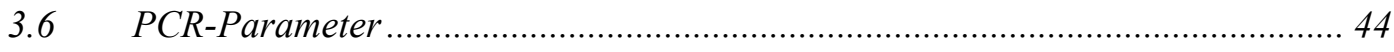

3.6.1 AmpFlSTR Profiler Plus PCR Amplification Kit.................................. 44

3.6.2 Y-STR-Systeme: Quadruplex-PCR ..................................................... 44

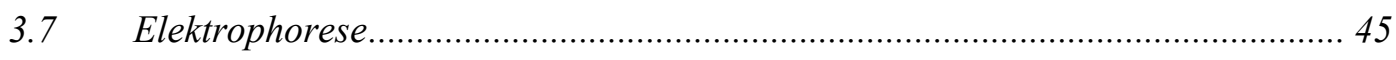

3.7.1 Agarose-Gelelektrophorese ...................................................... 45 
3.7.2 Denaturierende Polyacrylamid-Gelektrophorese (PAGE) ........................... 45

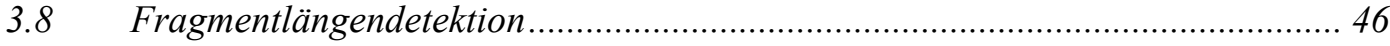

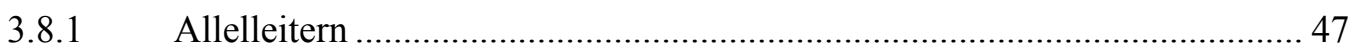

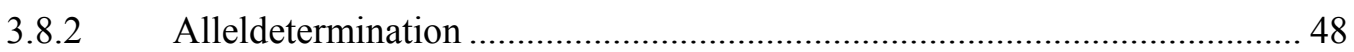

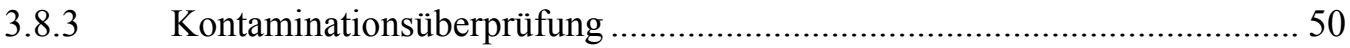

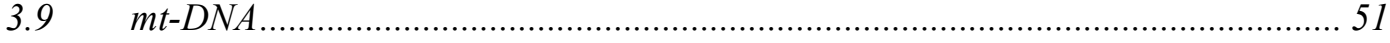

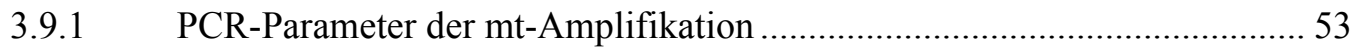

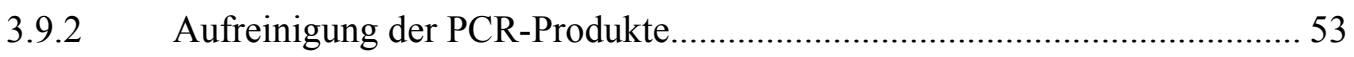

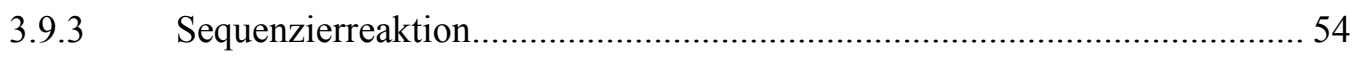

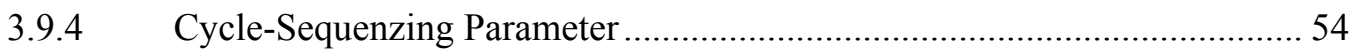

3.9.5 Sequenzierung mit der Kapillar-Elektrophorese.......................................... 55

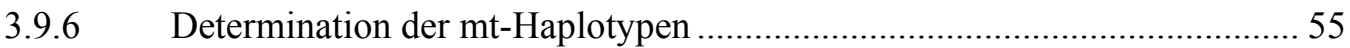

4 POPULATIONSGENETISCHE PARAMETER .......................................................5 57

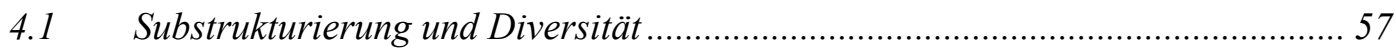

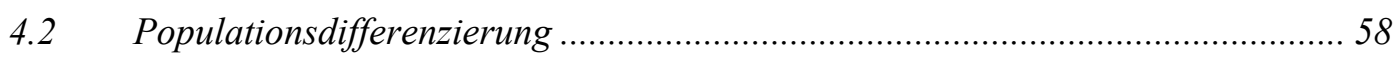

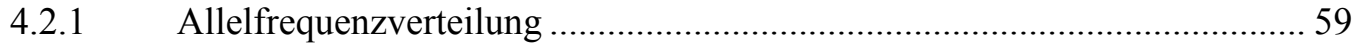

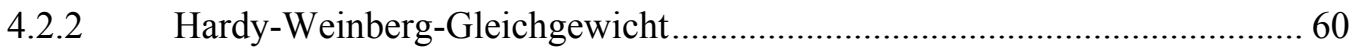

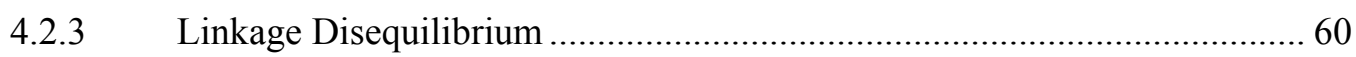

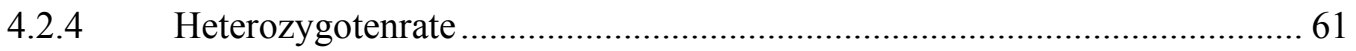

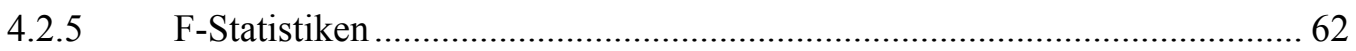

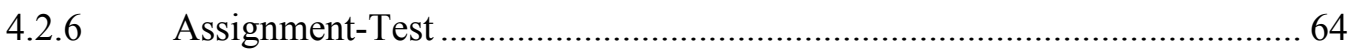

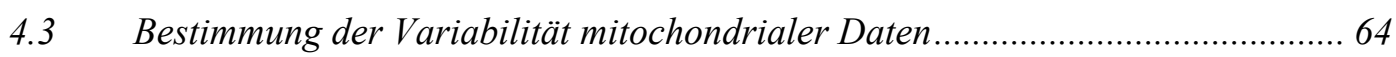

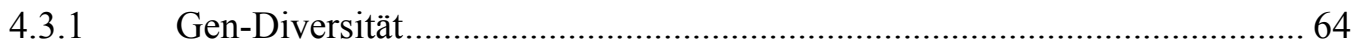

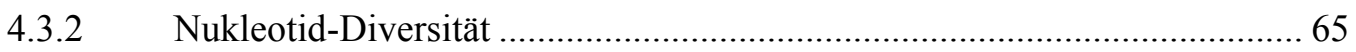

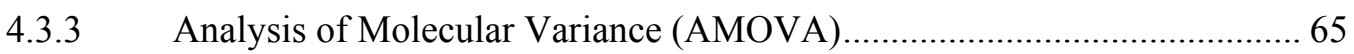

4.3.4 Exakter Test zur Populationsdifferenzierung.................................................. 66

4.4 Determination von Residenzverhalten .......................................................... 67

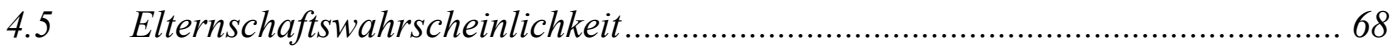

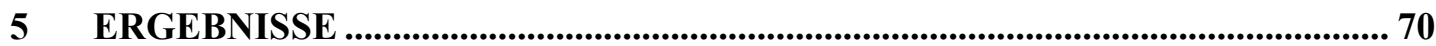

5.1 Deskription der Typisierungsergebnisse …....................................................... 70

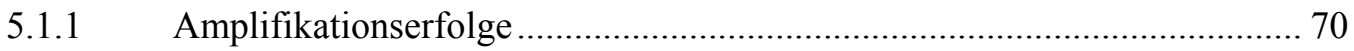

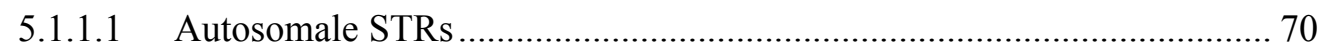

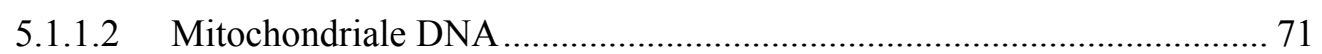

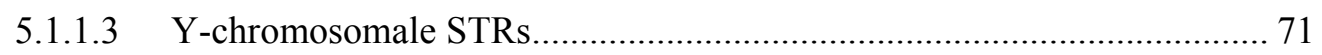

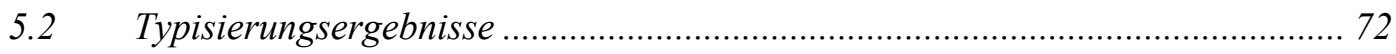

5.2.1 Ergebnisse der Amplifikation autosomaler STRs...................................... 72

5.2.1.1 Darstellung von Genotypisierungen ………........................................... 73

5.2.2 Ergebnisse der Y-chromosomalen STR-Typisierungen ............................. 78

5.2.3 Ergebnisse der Analyse mitochondrialer DNA ........................................... 80

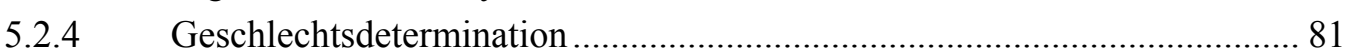


5.3 Vergleich der sozialen Ranggruppen durch Analyse der chromosomalen

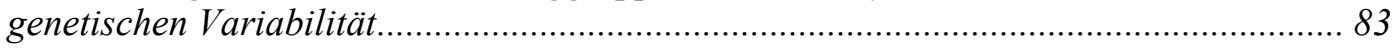

5.3.1 Vergleich der Datensätze autosomaler STRs............................................ 83

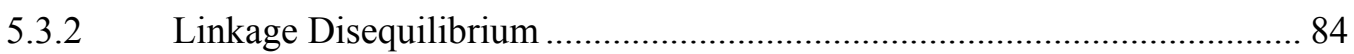

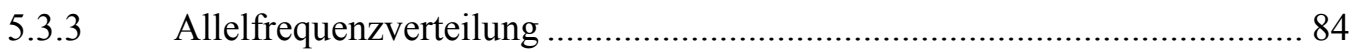

5.3.3.1 Historische vs. rezente Stichprobe......................................................... 84

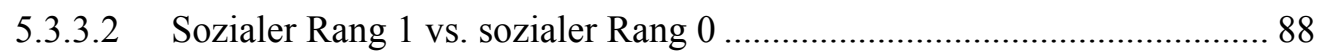

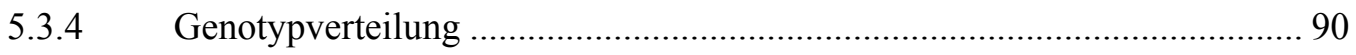

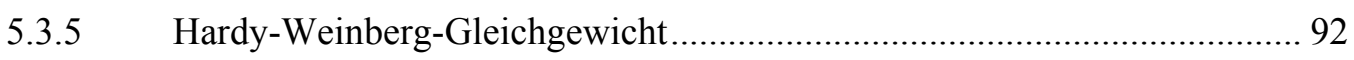

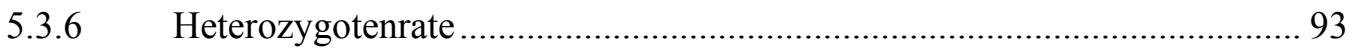

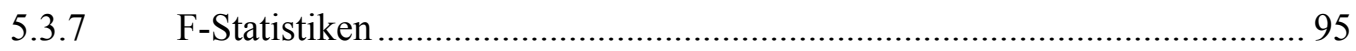

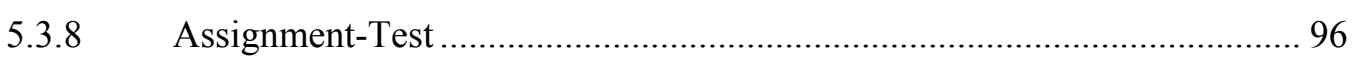

$5.4 \quad$ Vergleich der sozialen Ranggruppen durch Analyse mitochondrialer Sequenzen 98

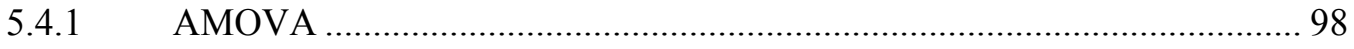

5.4.2 Exakter Test zur Überprüfung von Populationsunterschieden .................... 99

5.4.3 Vergleich innerhalb der Subgruppen ...................................................... 99

5.4.4 Zusammenfassung der Ergebnisse des Gruppenvergleichs ..................... 100

5.5 Determination von Residenzverhalten ......................................................... 100

5.5.1.1 mt-Variabilität im Geschlechtervergleich........................................... 103

5.5.1.2 Y-STR-Variabilität vs. männliche mt-Variabilität ................................ 103

5.6 Genealogische Verwandtschaftsbeziehungen .................................................. 104

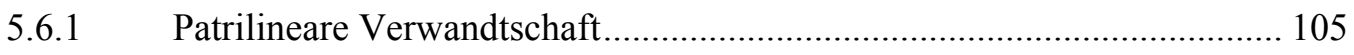

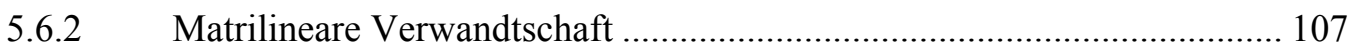

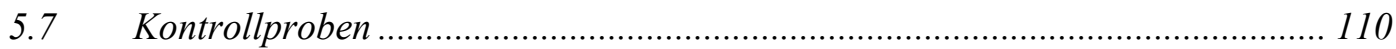

5.7.1 Autosomale und Y-chromosomale STRs.................................................. 110

5.7.1.1 Blind- und Leerkontrollen .............................................................. 113

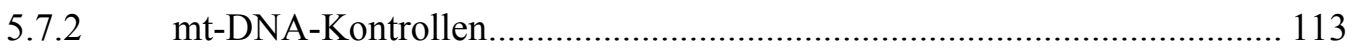

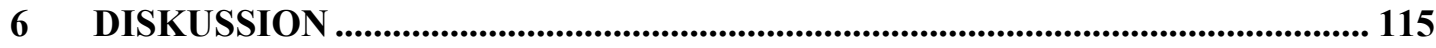

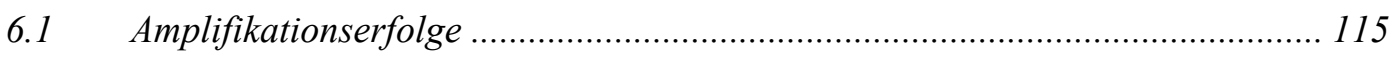

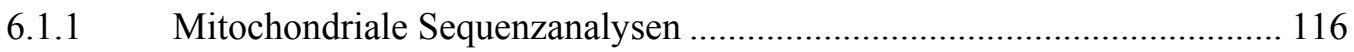

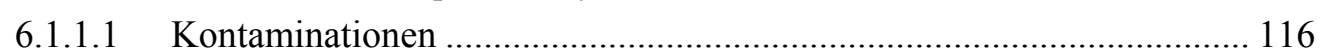

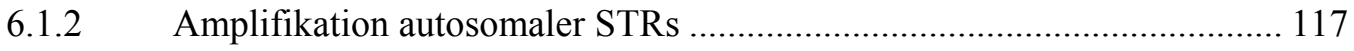

6.1.3 Amplifikation Y-chromosomaler STRs ................................................ 118

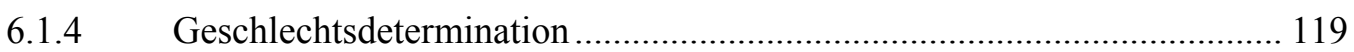

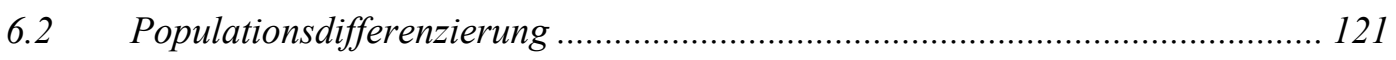

6.2.1 Ergebnisse der statistischen Tests ............................................................ 122

6.2.2 Familienzugehörigkeit und Sozialstatus ............................................ 125

6.2.3 Genetische Homogenität der Weingartner Bevölkerung .......................... 126

6.2.4 Mitochondriale Sequenzdiversität .................................................. 127

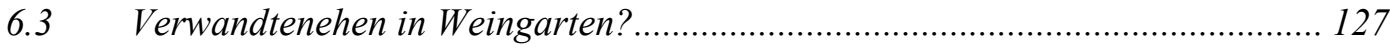

6.4 Residenzverhalten der Weingartener Bevölkerung …................................... 128 
6.4.1 mt-Variabilitäten im Geschlechtervergleich ............................................ 129

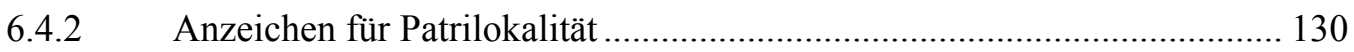

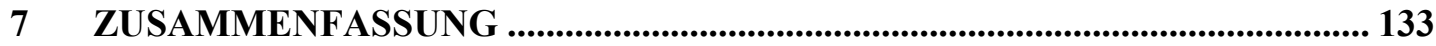

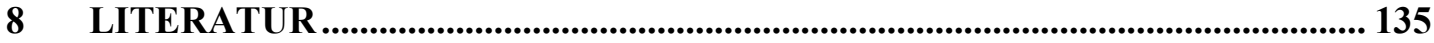

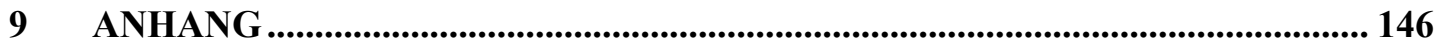

9.1 Einheiten und Abkürzungen ………........................................................... 146

9.2 Geräte, Chemikalien, Kits und Computersoftware .......................................... 147

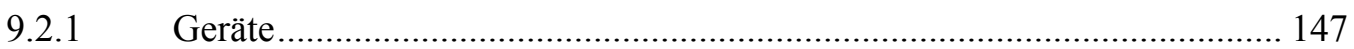

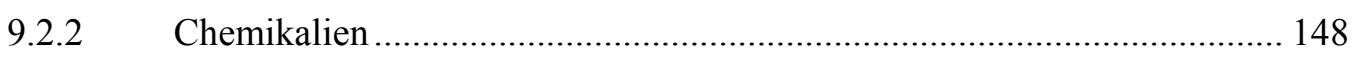

9.2.3 Einwegmaterialien und Hilfsmittel ........................................................ 149

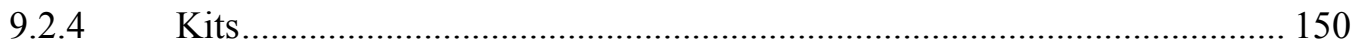

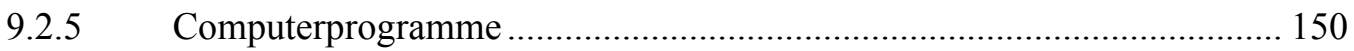

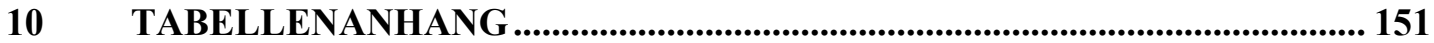




\section{$1.1 \quad$ Rekonstruktion von Heiratsverhalten}

Mit der vorliegenden Arbeit wird zum ersten Mal eine zahlenmäßig bedeutsame historische Bevölkerungsstichprobe der Analyse genetischer Marker unterzogen, die regelhaft in Studien zur molekularen Charakterisierung von Populationen verwendet werden. Durch die dargestellten Untersuchungen sollen Aussagen über die soziale Struktur und damit über die Lebensverhältnisse einer frühmittelalterlichen Population erhalten werden. Verfolgt wird dabei die Frage nach den in dieser Gemeinschaft vorherrschenden Heiratsmustern. Durch Analyse molekularer Marker wird es möglich, auch solch unmittelbare kollektive Verhaltensweisen und soziale Handlungen wie die Heiratsbräuche einer Population nachzuweisen, sofern diese Gebräuche über einen längeren Zeitraum von einem Großteil der Bevölkerung befolgt wurden. Daraus könnte sich die Aufklärung eines komplexen Sozialverhaltens einer historischen Populationen ergeben und damit ein Beitrag zur Ergründung der Geschichte der gesellschaftlich wichtigen Institution Ehe geleistet werden.

\subsubsection{Heiratsregeln}

Die Regelung der Sexualpartnerbeziehung ist in vielen Gesellschaften durch die Ehe institutionalisiert. Die Universalität der Ehe innerhalb verschiedener Gemeinschaften, Kulturen und Zeiten basiert vermutlich auf den vielgestaltigen sozialen und persönlichen Funktionen und Bedürfnissen, die durch die Ehe strukturiert werden. Dazu gehören primär Fortpflanzung, Versorgung der Nachkommen und deren rechtliche Anerkennung, Sanktionierung der Sexualität, Verteilung der Aufgaben zwischen den Geschlechtern und Produktion von Gütern (Barnard \& Good 1984). Eine weitere wichtige Funktion der Ehe dürfte darüber hinaus auch die Etablierung dauerhafter sozio-politischer und ökonomischer Allianzen zwischen sozialen Gruppen sein. Die eheliche Verbindung von zwei Individuen wird über eine umfangreiche Anzahl an Konventionen und Normen geregelt. $\mathrm{Zu}$ diesen gesellschaftlichen Übereinkünften gehört die Festlegung des 
Kreises der als Heiratspartner geeigneten und ungeeigneten Individuen, wobei hier vor allem die Verwandtschaftskategorie und Zugehörigkeit zu einer sozialen Schicht, Klasse oder Kaste ausschlaggebende Kriterien sind.

\subsubsection{Die frühmittelalterliche Bevölkerung von Weingarten}

Bei der untersuchten Bevölkerung handelt es sich um eine Stichprobe der frühmittelalterlichen Population von Weingarten. Das zur Siedlung gehörende Reihengräberfeld mit den Bestattungen von etwa 900 die Bevölkerung repräsentierenden Skelettindividuen weist einen Belegungszeitraum vom frühen 6. bis ins späte 7. Jahrhundert auf (Neuffer 1975). Die Auswahl dieser Nekropole als Untersuchungs-Population gründet darauf, daß die Weingartener Bevölkerung dem archäologischen Befund nach eine soziale Stratifizierung aufweist. Für die merowingerzeitliche Reihengräberfeldkultur, zu der die Weingartener Nekropole zu zählen ist, wird gemeinhin angenommen, daß durch das Beigabeninventar der Gräber der Rang und soziale Status der Toten angezeigt wird (Christlein 1991; Härke 1990; Robb et al. 2001). Es wird die Auffassung vertreten, daß das Auffinden von reich und einfach ausgestatteten Individuen innerhalb eines Gräberfeldes Zeugnis einer sozial stratifizierten Bevölkerung ist (Solberg 1985). Die überlieferten schriftlichen Quellen der Merowingerzeit, worunter vor allem Gesetzestexte aus dieser Zeitstellung zu verstehen sind, reflektieren eine solche Einteilung der Bevölkerung. Die archäologische Forschung versucht, diese historisch definierten Gruppen mit den durch die Grabbeigaben determinierten Gruppen in Einklang zu bringen. So ergeben sich für die Weingartener Bevölkerung zwei Subgruppen, die anhand der Grabbeigaben zwei unterschiedlichen sozialen Rängen zugeordnet sind (Roth \& Theune 1995; Schutkowski et al. 1999).

Es besteht die Frage, ob die Stratifizierung dieser Gesellschaft auf sozialem Niveau sich auch in einer genetischen Substrukturierung der Weingartener Bevölkerung widerspiegelt. So soll es eines der Ziele der vorliegenden Arbeit sein, zu untersuchen, ob die in der Bevölkerung festgestellten Sozialgruppen eine genetische Grundlage haben. Um eine etwaige Manifestation molekularer Unterschiede 
zwischen Individuen verschiedenen Sozialranges festzustellen, werden Informationen verwendet, die sich aus der Analyse polymorpher Abschnitte der DNA ergeben, und die dazu genutzt werden können, Individuen und Populationen zu charakterisieren. Durch Untersuchung dieser Marker läßt sich im Intra- und InterGruppenvergleich überprüfen, ob genetische Unterscheidungen aufzeigbar sind. Durch Vergleiche zwischen den Sozialgruppen soll geklärt werden, ob die augenscheinlich vorhandene kulturelle Verschiedenheit der Individuen biologische Voraussetzungen hat (Herrmann 2001).

$\mathrm{Zu}$ zeigen wäre also, ob die zwei in der Bevölkerungsstichprobe determinierten Ranggruppen aus Individuen bestehen, die sich genetisch voneinander differenzieren. Dies könnte auf die Existenz kultureller Regeln, wie z.B. sozial festgelegter Heiratsvorgaben, hinweisen, die Beziehungen zwischen bestimmten Individuen ausschließen. In Gemeinschaften mit präskriptiven Heiratsordnungen, in denen der Kreis der geeigneten Heiratskandidaten strikt vorgeschrieben ist, können die Eignungskriterien z.B. auf Zugehörigkeit zu einer Verwandtschafts- oder Lokalgruppe beruhen. Entscheidend kann auch die ethnische Zugehörigkeit, der Sozialstatus oder Besitzstand sein. Diese sozial determinierten Paarungsschranken können eine genetische Substrukturierung der Population zur Folge haben (Reddy et al. 2001; Zhivotovsky et al. 2001; Bamshad et al. 1998).

Basieren könnten mögliche genetische Unterschiede auf Prozessen der Besiedlungsgeschichte Südwestdeutschlands ab dem 3. Jh. n. Chr., da diese Region seit Aufgabe des Obergermanischen-Rätischen Limes zum Siedlungsgebiet germanischer Stämme geworden war, die unter dem Namen „Alamannen“ zusammengefaßt wurden (Geuenich 1997). Dabei ist zumindest aufgrund archäologischer Daten nicht zu klären, ob und in welchen Ausmaß die zum Teil romanisierte ehemalige Bevölkerung dieser Gebiete im Lande verblieb und inwieweit eine Assimilierung zwischen ihnen und den zugewanderten Bevölkerungsgruppen stattfand (Schach-Dörges 1997). Eine bereits länger zurückliegende, von Huber (1967) anhand des Materials des Gräberfeldes Weingarten durchgeführte anthropologische Studie legt nahe, daß zwischen den archäologisch erkennbaren Sozialgruppen morphologische Unterschiede feststellbar seien. Der Autor ordnet dabei die sich durch Reichtum der Grabbeigaben und 
Körperhöhe auszeichnenden Individuen als die Zugewanderten ein, während er in den Unbewaffneten mit geringerer Körperhöhe die Angehörigen der vorgermanischen Bevölkerung identifiziert zu haben glaubt.

\section{$1.2 \quad$ Verwandtschaftsfeststellung innerhalb der Historischen Anthropologie}

Die Untersuchung historischer Skelettfunde mit molekularen Analysetechniken eröffnet einzigartige Möglichkeiten, Wissen über die Lebensumstände menschlicher Populationen vergangener Zeiten $\mathrm{zu}$ erlangen. Durch die Untersuchung der genetischen Ausstattung von Skelettindividuen aus archäologischen Fundkontexten lassen sich molekulare Zugänge $\mathrm{zu}$ den Grundthemen der Historischen Anthropologie finden: Über die Identifikation von Individuen und Verwandtschaftsfeststellung auf der familiären Ebene und im besonderen durch die Erfassung verwandtschaftlicher Strukturen ganzer Bevölkerungsgruppen kann die Rekonstruktion sozio-ökonomischer Parameter erreicht werden. Durch die Anwendung von molekularen Techniken auf historisches Untersuchungsmaterial können komplexe Zusammenhänge des Sozialverhaltens frühzeitlicher Populationen nachvollziehbar werden, deren Offenlegung auf anderem Wege - durch das Studium herkömmlicher Quellen der Archäologie und Geschichtswissenschaften - nicht zu erreichen wäre (Perez-Lezaun et al. 1999; Herrmann et al. 2001; Williams et al. 2002).

Ein Hauptinteresse der Historischen Anthropologie liegt in der Ergründung der sozialen Aspekte der menschlichen Existenz. Dies läßt sich über die Untersuchung von Verwandtschaftsbeziehungen erreichen, was letztendlich zur Klärung der Organisation sozialer Gruppen beiträgt. Eine der grundlegenden Annahmen ist dabei, daß Verwandtschaft einen der bedeutsamsten Faktoren darstellt, aufgrund dessen sich soziale Beziehungen zwischen Individuen determinieren. Es existieren verschiedene Prinzipien, auf denen Verwandtschaftsbeziehungen basieren. Zum einen die biologische, auf Konsanguinität beruhende Verwandtschaft, und im 
weiteren solche Beziehungen, die aus der Verbindung durch Heirat (Affinalität; Verschwägerung) entstehen ${ }^{1}$.

\subsubsection{Molekularer Nachweis von Verwandtschaft durch Analyse alter DNA}

Konsanguine, richtiger, genetische Verwandtschaftsbeziehungen zwischen Individuen sind ganz offensichtlich durch DNA-Analyse zu überprüfen, da die Nukleinsäuren Träger der Erbinformation sind. Durch die Anwendung der PCR (engl. Polymerase Chain Reaction) können auch geringste Mengen an DNA der Analyse zugeführt werden. Da so der Zugang $\mathrm{zu}$ der in Skelettüberresten gespeicherten DNA-Information gegeben ist (aDNA, ancient DNA vgl. Herrmann \& Hummel 1993), besteht die Möglichkeit, die in der Forensik bereits seit längerem etablierte Feststellung von Verwandtschaft auf molekularer Basis auch auf historische Individuen anzuwenden, deren körperliche Überreste das Untersuchungssubstrat der Historischen Anthropologie darstellen.

So lassen sich direkte Eltern-Kind-Verwandtschaften durch die Determination des genetischen Fingerabdrucks nachweisen, der durch die Analyse von STRs (Short Tandem Repeats) erstellt wird (Gill et al. 1994; Hummel \& Herrmann 1997; Gerstenberger et al. 1999). Bei den STRs handelt es sich um längenvariable DNAAbschnitte, deren Aufbau durch die tandemartige Wiederholung einer Basensequenz von 2-6 bp Länge gekennzeichnet ist (Weber \& May 1989; Litt \& Luty 1989). Die Bestimmung von Allelen unterschiedlicher STR-Loci ermöglicht die Erstellung eines Allelprofils, das für ein Individuum charakteristisch ist (Edwards et al. 1991; Jeffreys \& Pena 1993). Durch den kodominanten Vererbungsweg dieser genetischen Marker läßt der Vergleich der Allelmuster zwischen Individuen Aussagen über die Existenz unmittelbarer Verwandtschaftsverhältnisse zu.

Eine Einordnung von Individuen in Abstammungsgruppen kann aber selbst dann vorgenommen werden, wenn keine Vermutungen zur Elternschaft bestehen, bzw. diese Individuen nicht zur Untersuchung vorliegen (Schultes 2000; Corach et al.

\footnotetext{
${ }^{1}$ Eine dritte Möglichkeit der verwandtschaftlichen Verbindung, die nicht unerwähnt bleiben soll, sind sogenannte fiktive Verwandtschaftsbeziehungen, die z.B. auf Adoption oder Patenschaft beruhen.
} 
1997). Diese weiter gefaßte Einteilung gelingt über die Untersuchung von Y-chromosomalen Markern und Bereichen der mitochondrialen DNA. Hiermit werden die zwei Abschnitte des Genoms erfasst, die im Gegensatz zum Großteil der DNA-Information nur uniparental, also nur durch ein Elternteil weitergegeben werden. Das mitochondriale Genom, das keinerlei rekombinatorischen Vorgängen unterliegt, wird ausschließlich über die mütterliche Linie vererbt und eignet sich somit zur Einordnung von Individuen in maternale Abstammungslinien (Jehaes et al. 1998; Stone et al. 2001; Weichhold et al. 1998). Die Y-chromosomalen Sequenzen, die über die väterliche Linie weitergegeben werden und abgesehen von den subtelomerischen Regionen ebenfalls von der Rekombination ausgeschlossen sind, dienen dementsprechend der Determination von paternalen Deszendenzgruppen (Foster et al. 1998).

\section{$1.3 \quad$ Populationsstudien}

Eine der Zielsetzungen der aDNA-Forschung liegt in der Einbeziehung größerer Bevölkerungsgruppen in die Analyse, da so die Rekonstruktion von Populationsstrukturen und Migrationsbewegungen historischer Bevölkerungen erreicht werden kann.

Das Prinzip molekularer Studien auf Populationsebene besteht darin, durch geeignete Merkmale Bevölkerungsgruppen genetisch $\mathrm{zu}$ charakterisieren, um somit Unterschiede und Ähnlichkeiten $\mathrm{zu}$ anderen Bevölkerungen herauszustellen. So werden schließlich Rückschlüsse auf die zwischen Populationen bestehenden Beziehungen möglich. Hierfür werden dieselben polymorphen genetischen Marker analysiert, die auch zur Feststellung von Verwandtschaft auf der familiären Ebene verwendet werden. Populationsgenetische Studien beruhen demnach zum einen auf Analyse der autosomalen STRs. Deren potentiell große Allelanzahl pro Genort und die damit verbundene hohe genetische Diversität eignen sie im hohen Maße auch für die Determination der genetischen Variabilität ganzer Bevölkerungsgruppen. Zurückgegriffen wird in weitem Ausmaß auch auf die Analyse von Sequenzpolymorphismen der nicht-codierenden Bereiche der Kontrollregion des Mitochondriums, die aufgrund einer erhöhten Mutationsrate ebenfalls hochvariabel 
sind und sich so zur Populationsdifferenzierung anbieten (Meyer et al. 1999; Stoneking 2000). Gleichfalls verwendet werden Y-chromosomale STRs, die, ähnlich wie die autosomalen STRs, eine hohe Variabilität aufweisen und damit zur Unterscheidbarkeit von Bevölkerungsgruppen geeignet sind (Jobling \& Tyler-Smith 1995; Roewer et al. 1996; Perez-Lezaun et al. 1997). Durch den Nachweis und Vergleich von Häufigkeiten und Variabilitäten der genannten genetischen Marker innerhalb und zwischen Bevölkerungen lassen sich Einblicke gewinnen, in welcher Art und Weise sich Populationen vergrößert, geographisch verteilt und vermischt haben. Diese Ergebnisse in Verbindung mit historischen, archäologischen und linguistischen Erkenntnissen können zur Aufklärung von Bevölkerungsgeschichte im weitesten Sinne beitragen (Owens \& King 1999; Renfrew 2001; Brown \& Pluciennik 2001).

Zahlreiche Studien untersuchen an Rezentstichproben die Muster der genetischen Variabilität von Bevölkerungen, um so schließlich die historischen Prozesse der Besiedlung und Bevölkerungsentwicklung $\mathrm{zu}$ rekonstruieren, die sich in den spezifischen Verteilungsmustern widerspiegeln (Jorde et al. 2000; Hammer et al. 1997; Comas et al. 1998; Poloni et al. 1997; Ritte et al. 1993; Sajantila et al. 1996).

Mit der Entwicklung von Methoden, die den Zugang zu der im Skelettmaterial gespeicherten genetischen Information gestatten, hat in den vergangenen Jahren aber auch die Anzahl der Studien zugenommen, die sich der Untersuchung (prä)historischer Bevölkerungen widmen. Bis jetzt stand auch bei der molekularen Bearbeitung größerer Skelettkollektive aus archäologischen Fundkontexten die Beantwortung bevölkerungsgeschichtlicher Fragen im weiteren Sinne im Vordergrund. So wurde durch die Analyse mitochondrialer DNA der Versuch unternommen, Besiedlungsprozesse und Migrationsmuster vor allem des amerikanischen Kontinents zu rekonstruieren (Stone \& Stoneking 1998; Kaestle \& Smith 2001; Gonzalez-Oliver et al. 2001; Parr et al. 1996; Merriwether et al. 1994). Mehrere Studien zeigen durch Analyse historischer Skelettüberreste, die Relevanz von aDNA Untersuchungen für die Klärung der Herkunft moderner asiatischer Populationen (Oota et al. 1999; Wang et al. 2000; Horai et al. 1991). Andere Studien 
versuchen durch aDNA-Analyse direkte Einsichten in die sozialen Systeme historischer Bevölkerungsgruppen zu gewinnen (Shinoda \& Kanai 1999; Shinoda \& Kunisada 1994; Oota et al. 1995). Hervorzuheben ist eine Studie von Bramanti et al. (2000b) zu Wanderungsbewegungen in einer frühneuzeitlichen Gesellschaft, die auf der Analyse autosomaler STRs beruht und somit als einzige die Informationen nuklearer DNA nützt. Ebenso bemerkenswert ist die Studie von Schultes (Schultes 2000), der genetische Typisierungen an einem bronzezeitlichen Skelettkollektiv vornimmt und in seine Untersuchungen sowohl mitochondriale als auch chromosomale Marker einbezieht.

\section{$1.4 \quad$ Residenzverhalten}

Die Analyse der genetischen Zusammensetzung der historischen Stichprobe des Gräberfeldes von Weingarten soll weitere Hinweise auf das in dieser Gesellschaft womöglich angewandte Heiratsverhalten erbringen. Neben den Heiratsordnungen, die bestimmen, zwischen welchen Personen Eheschließungen stattfinden dürfen, legen die Wohnfolgeordnungen (Residenzregeln) schließlich fest, an welchem Ort ein Individuum nach seiner Heirat lebt (Vivelo 1981; Schmitz 1964). So tragen die von einer Gemeinschaft ausgeübten Heiratssitten letztlich zur räumlichen Versetzung von Individuen bei. Zumindest für einen der Partner ist die Eheschließung mit der Verlegung des Wohnortes, also mit der Aufnahme einer neuen Residenz verbunden. Somit macht die Heiratsmigration einen großen Teil der kleinräumigen Bevölkerungsbewegungen aus (Schmidt 1989; Lehmkühler 1991).

Zwei Hauptformen der Residenzordnung sind dabei die patrilokale Residenz und die matrilokale Wohnfolgeordnung. Patrilokale Residenz verpflichtet ein verheiratetes Paar, auf dem Gebiet oder nahe bei der Gruppe des Ehemanns zu wohnen, während matrilokale Residenz die Aufnahme der Wohnung bei der Familie der Frau bedeutet (Levi-Strauss 1981). 


\subsubsection{Nachweis des Residenzverhaltens durch Analyse molekularer Marker}

Bei Einhaltung bestimmter Heiratsgebräuche über Generationen hinweg ist zu erwarten, daß sich dieses Verhalten im Genpool der Population widerspiegeln wird. Die Vorgehensweise beim Nachweis von Heiratsmustern über molekulare Analysen liegt darin, die zwei Abschnitte des Genoms zu untersuchen, deren Vererbung an nachkommende Generationen nur durch eines der Geschlechter übernommen wird, die Y-chromosomalen und mitochondrialen DNA-Abschnitten. Praktiziert eine Gemeinschaft Patrilokalität, sollte die Diversität des mitochondrialen Genpools ansteigen, da Genfluß zwischen verschiedenen Populationen stattfindet, der von den weiblichen, in die Gemeinschaften einheiratenden Individuen getragen wird. Im Gegensatz dazu sollte der Y-chromosomale Genpool weniger variabel sein, da aufgrund des Heiratsmusters keine weiteren oder nur wenige Y-Sequenzen in die Population gelangen. Ein Vergleich der Diversitäten des spezifisch männlichen und weiblichen Genpools kann somit Aufschluß über ein Verhalten geben, das in den sozialen Vorstellungswelten der betreffenden Gesellschaft tief verwurzelt ist.

Diese Herangehensweise der molekularen Überprüfung des Residenzverhaltens hat sich bereits an rezenten Populationen bewährt. Oota et al. (2001) zeigen so für verschiedene patrilokale bzw. matrilokale Populationen, daß die Variabilität der mtDNA und der Y-Sequenzen mit der von der jeweiligen Gemeinschaft eingehaltenen Wohnfolgeordnung korreliert. Ähnliches demonstrieren Untersuchungen an Beduinenstämmen des Sinais, hier werden die niedrigeren Variabilitäten der YSequenzen im Vergleich $\mathrm{zu}$ denen der mitochondrialen Abschnitte durch die traditionell praktizierte männliche Polygamie und patrilokale Exogamie der Stammesgemeinschaften erklärt (Salem et al. 1996). Indem alte DNA aus Skelettmaterial untersucht werden kann, besteht die Aussicht, durch die Analyse der paternalen und maternalen Marker und den anschließenden Vergleich ihrer Diversitäten, Hinweise auf das angewandte Residenzverhalten der frühmittelalterlichen Bevölkerung von Weingarten zu erhalten und zu überprüfen, ob die festgestellten sozialen Ranggruppen sich in ihrem Heiratsverhalten unterscheiden lassen. 


\subsection{Ehe und Heiratsregeln: Externe Erkenntnisse}

Im folgenden schließt sich ein kurzer Überblick der Erkenntnisse zum Themenbereich Ehe und Heirat in der frühmittelalterlichen Gesellschaft an, die anhand archäologischer und historischer Forschungsergebnisse vorliegen.

Der Begriff „Ehe“ ist in der älteren germanischen Rechtssprache nicht bekannt. Interessant ist aber ein Vergleich der in den nordgermanischen Sprachen für Ehe gebrauchten Lexeme. Die einzelnen Wortbelege beschreiben unterschiedliche Aspekte des Begriffs Ehe, von denen Beck (1986) folgende benennt: das Abschließen eines Vertrages, das Zahlen eines Brautpreises und - interessant für die Frage der Wohnfolge - die Weggabe der Frau in eine andere Gemeinschaft.

Trotz des Fehlens eines unmittelbaren Terminus für die Ehe bestanden feste Regeln, die diese besondere Verbindung von Mann und Frau ordneten.

So existierten verschiedene Formen der Ehe, wobei die sogenannte Muntehe (,munt “ $=$ Rechtsgewalt) die offiziellere Form der Ehe ist, der eine Absprache mit dem Brautvater und eine Verlobungszeit vorausgeht. Mit der Eheschließung wird die Rechtsgewalt über die Frau, die bis dahin der Vater innehatte, an den Ehemann übertragen. Verbunden mit der Muntehe ist auch die Zahlung einer Brautpreises, der allerdings allein der neugegründeten Familie zur Verfügung steht. Bei der zur Muntehe im Gegensatz stehenden Friedelehe (ahd. friudila „Freundin“, „Geliebte“) entfällt die Übertragung der Munt, noch wird eine Brautgabe verlangt (Schulze 1986; Siegmund 1998a). Anscheinend stand hier eher der Wunsch nach ehelicher Verbindung der beiden Partner im Vordergrund, eine materielle Absicherung der Frau wie bei der Muntehe war aber nicht gegeben.

Weitere Reglementierungen bestimmten, welche Partner miteinander die Ehe eingehen durften. So existierte in der merowingerzeitlichen Gesellschaft anscheinend ein überraschend striktes Inzesttabu (vgl. hierzu vor allem de Jong 1989). Heirat innerhalb eines bestimmten Kreises von Verwandten schien untersagt zu sein. Bis zum 6. Jahrhundert schloß sich eine Heirat bis zum dritten Verwandtschaftsgrad aus. Wichtig ist dabei die Kenntnis um den Verwandtschaftsbegriff der Germanen, der vom römischen System abwich. Im römischen Verwandtschaftsverständnis war ein Kind primär mit seinen Eltern verwandt. Verwandtschaftsgrade (gradus) wurden 
nach der Anzahl der Zeugungen berechnet, die zwischen ego und dem betreffenden Verwandten lagen. Das bedeutet z.B., daß eine Person mit seinen Geschwistern als im zweiten Grad verwandt galt: Der erste Verwandtschaftsgrad besteht dabei zwischen Eltern und ego, der zweite Grad ergibt sich zwischen Eltern und Geschwistern (Goody 1983). Im germanischen System der Verwandtschaftsbestimmung wurde eine andere Einteilungsweise verfolgt. Das Individuum galt als primär mit seinen Geschwistern verwandt. Vom Individuum ausgehend, wurden die Verwandtschaftsgrade (generatio) generationsweise gezählt, wobei die Anzahl der Generationen gezählt wurde, die zwei verwandte Individuen von ihrem letzten gemeinsamen Vorfahren trennen. Während also zwischen einem Individuum und seinen Geschwistern eine Verwandtschaft der ersten Generation vorlag, wurde es mit seinen Onkeln, Tanten, Cousins und Cousinen ersten Grades als in der zweiten Generation verwandt betrachtet (vgl. Abbildung 1.1).

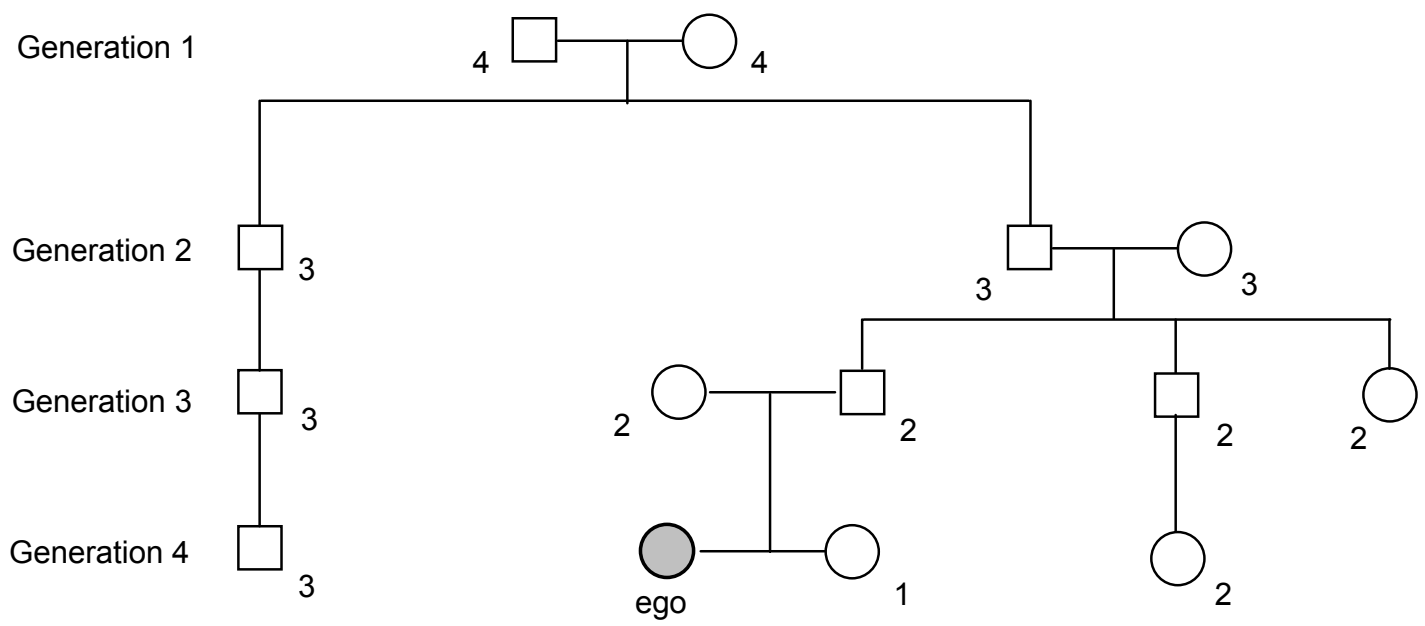

Abbildung 1.1: Schema zum germanischen Verwandtschaftssystem. Die an den Stammbaumsymbolen verzeichneten Zahlen geben den Grad der Verwandtschaft bezogen auf ego an. Der Verwandtschaftsgrad berechnet sich aus der Anzahl der Generationen, die verwandte Individuen vom letzten gemeinsamen Vorfahren trennen. Eheschließungen bis einschließlich zum dritten Grad der Verwandtschaft war nach germanischer Rechtsauffassung untersagt (Siegmund 1998a). Schema nach Goody (1983).

Bei der Einteilung der Verwandtschaftsverhältnisse galt dabei in beiden Systemen das Prinzip der kognaten (bilinealen) Deszendenz, was bedeutet, daß sowohl Individuen der mütterlichen als auch der väterlichen Seite als verwandt gelten. Geht man von einem Verbot der Eheschließung zwischen Individuen bis einschließlich 
zum 3. Verwandtschaftsgrad aus, umfaßt dies z.B. auch Cousins und Cousinen nicht nur des ersten, sondern auch des zweiten Grades. Hier wird also ein relativ großer Personenkreis von zum Teil nur sehr entfernt verwandten Individuen als potentielle Ehepartner ausgeschlossen. Das Unterfangen, außerhalb dieses Verwandtschaftskreises einen (Fortpflanzungs)-Partner $\mathrm{zu}$ finden, stieß auf Hindernisse, die Siegmund (1998a) in seinen Betrachtungen zum Frauenraub während der Merowingerzeit ausführlich darstellt.

Innerhalb der eigenen Siedlung angemessene Heiratspartner $\mathrm{zu}$ finden, stellt Siegmund als eher unwahrscheinlich dar. Begründet wird dies durch die von vornherein geringe Einwohnerzahl der Siedlungsplätze, die im Durchschnitt vermutlich bei 40 Individuen lag. Donat \& Ulrich (1971) gehen davon aus, daß ein Gehöft von einer 20-30 Mitglieder umfassenden Großfamilie bewohnt wurde, was aber auch Knechte und Mägde mit deren Familien einschloß. Aus der Lex Salica läßt sich schlußfolgern, daß die erwachsenen Söhne mit ihren Familien im Hofverband lebten (Njeussychin 1961), so daß davon ausgegangen werden kann, daß die Individuen der Siedlung fast ausnahmslos in einem Verwandtschaftsverhältnis miteinander standen. Im weiteren kann angenommen werden, daß von den Bewohnern über die Hälfte nicht im heiratsfähigen Alter waren (Siegmund 1998a). Da Eheschließungen zwischen Freien und Unfreien zum Standesverlust des Höherstehenden führten, kann ebenfalls davon ausgegangen werden, daß solche Verbindungen eher vermieden wurden, so daß auch diese Personen als potentielle Heiratskandidaten ausschieden, was den Kreis der Ehekandidaten weiterhin einschränkte.

Demnach dürfte es also schwer, wenn nicht teilweise praktisch unmöglich gewesen sein, in der eigenen Siedlung legitime Heiratspartner zu finden. So müßte sich die Ehepartnersuche auf mehr oder weniger weit entfernte Siedlungen konzentriert haben. Siegmund (1998a) geht davon aus, daß es im Umkreis von $30 \mathrm{~km}^{2}$ nur schwerlich gelungen ist, auf nicht-verwandte heiratsfähige Individuen zu treffen, was dafür spricht, daß räumlich sehr weit gefaßte Heiratskreise existiert haben müssten. Daß diese „Brautschau“ in fremden Siedlungen auch auf die gewaltsame Entführung 
von Frauen hinauslaufen konnte, belegen Gesetzestexte des Pactus Legis Salicae, in dem für den Raub freier Frauen hohe Strafen festgelegt sind (Siegmund 1998a).

Inwieweit diese aus archäologischen und historischen Quellen zu ziehenden Annahmen der historischen Realität entsprechen, bedarf weiterer Überprüfungen, hier kann die Analyse alter DNA eine wichtige Rolle spielen. Exogamie, im Sinne von Heirat außerhalb der Lokalgruppe, ist als eine besondere Form der Mobilität in den schriftlichen Quellen der Merowingerzeit nur für die herrschenden Dynastien und den Hochadel belegt. Das Vorhandensein von artifiziellen Schädeldeformationen und ungewöhnlichen, milieufremden Trachtenausstattungen belegt das Auftreten von Fremd-,,Importen“ von Individuen zwar auch archäologisch (Werner 1970), es dürfte sich hier aber um Einzelfälle handeln.

\subsection{Zielsetzung und Prämissen}

Inwieweit sind aber Heiratskreise für den Großteil der ,gemeinen“ Bevölkerung zu fassen? Herrschte Patrilokalität oder gibt es Anzeichen von Matrilokalität? Sind die proklamierten Inzuchttabus eingehalten worden, oder lassen sich nicht dennoch Verbindungen zwischen verwandten Individuen nachweisen? Haben zwischen den beiden Sozialgruppen Heiratsbeziehungen bestanden oder handelt es sich bei der frühmittelalterlichen Gesellschaft Weingartens um eine isogame Gemeinschaft, wobei Isogamie Heiratsbeziehungen beschreibt, in denen die aus einer stratifizierten Gesellschaft stammenden Ehepartner derselben sozialen Gruppe angehören. Bei Überprüfung auf Heiratsbeziehungen zwischen den Sozialrängen, basierend auf dem Nachweis genetischer Unterschiede zwischen den Gruppen, muß als Prämisse angenommen werden, daß Sozialstatus durch Geburt prädisponiert ist und mit dem Sozialrang übereinstimmt, den das Individuum zum Zeitpunkt des Todes innehat. Ohne eine solche, von den genetischen Informationen unabhängige externe Setzung, ist ein Vergleich von genetischen Gruppenstrukturen nicht möglich. Zu beachten ist, daß diese Ausgangshypothese zwei Annahmen beinhaltet: das Vorhandensein von sozialen Unterschieden und die Beibehaltung des individuellen Sozialranges von Geburt an bis zum Tod. Andernfalls wäre bei einem Ergebnis, daß eine genetisch 
nicht-differenzierte Gesellschaft nahe legt, nicht zu unterscheiden, ob dieses Ergebnis darauf zurückzuführen ist, daß zwischen den Sozialgruppen Heiratsbeziehungen bestehen, oder ob nachgewiesene Homogenität der Gruppen lediglich darauf basiert, daß Rangzugehörigkeit im Gegensatz zu der unveränderlichen individuellen genetischen Merkmalsausprägung nicht durch Geburt festgelegt, sondern wandelbar ist. Durch Veränderung des Sozialrangs im Leben könnte sich eine artifizielle „Vermischung“ ergeben, die unabhängig von der genetischen ist.

Siegmund (1998) sieht die Frage der Festlegung des Sozialranges als nicht geklärt an, und meint: ,...it is an outstanding question whether any status was fixed by birth.“ (S. 177). Christlein (1991) schließt eine Prädisponierung des Sozialranges nicht aus, und verweist darauf, daß die Überschneidung morphologischer Verschiedenheiten der Skelette und der Unterschied in Grabbeigaben, „immer wieder“ für frühmittelalterliche Gräberfelder zu beobachten seien und dies „doch nur...auf die tatsächliche Verbindung von Waffenausstattung mit einem durch Geburt und/oder Lebensweise errungenen sozialen Status zurückzuführen“ sei (S. 19).

Es wird versucht, diesen Fragestellungen durch DNA-Typisierung der frühmittelalterlichen Population von Weingarten nachzugehen und die Ergebnisse anschließend unter Einbeziehung von Erkenntnissen und Informationen beteiligter Disziplinen, wie z.B. der Archäologie und Geschichtsforschung, zu diskutieren. 


\section{MATERIAL}

Untersuchungsmaterial dieser Arbeit ist eine Stichprobe von 161 Individuen des frühmittelalterlichen Gräberfeldes von Weingarten (Baden-Württemberg). Dieses Reihengräberfeld aus der Merowingerzeit (5.-8. Jh.) ist mit ca. 900 aufgefundenen Bestattungen nicht nur das größte im süddeutschen Raum, sondern stellt aufgrund der kontinuierlichen Belegung vom Anfang des 6. Jahrhunderts bis zum Ende des 7. Jahrhunderts auch eine wichtige archäologische Quelle für die Erforschung der Besiedlungs- und Sozialgeschichte dieser Region und Zeit dar (Neuffer 1975). Der umfassenden Darstellung des untersuchten Skelettmaterials geht zur Einführung eine ausführlichere Erläuterung der alamannischen Bestattungssitten und Gesellschaftsordnung voraus.

\subsection{Die alamannische Gesellschaft}

\subsubsection{Reihengräber- und Beigabensitte}

Die Sitte der Totenverbrennung, deren Wurzeln noch in der angenommenen Ursprungsheimat der Alamannen an mittlerer Elbe und Havel zu suchen sind, (Christlein 1991; Schach-Dörges 1997) wurde durch den Übergang zur Erdbestattung abgelöst. Im südwestdeutschen Einwanderungsgebiet kam es im späten 4. und 5. Jahrhundert zur allmählichen Herausbildung der Reihengräbersitte. Im Gegensatz zu den bis dahin üblichen Einzelgrabanlagen wurden nun in geringer Entfernung zu den jeweiligen Siedlungen größere Gräberfelder angelegt, auf denen alle Mitglieder der Gemeinschaft bestattet wurden. Im Laufe des 6. und 7. Jahrhunderts war die Körperbestattung der Toten auf Reihengräberfeldern weithin üblich. Zu Beginn des 8. Jahrhunderts schließlich kam es zur Auflösung der großen Ortsgräberfelder, da die Kirche als Institution nun das Sepulturrecht an sich zog (Siegmund 2000).

Die Zahl der Bestattungen pro Gräberfeld hing von der Größe der zugehörigen Siedlung und deren Gründungszeitpunkt $\mathrm{ab}$ und konnte in Einzelfällen bis zu 1000 Individuen umfassen. Anscheinend wurde ein Begräbnisplatz ausschließlich 
von den Bewohnern einer einzigen Siedlung genutzt (Stork 1997). Bei der Belegungsart der Reihengräberfelder galt offenbar eine gewisse Reglementierung. Im Hinblick auf den Bestattungsplatz orientierte man sich bei der Anlage neuer Gräber augenscheinlich in erster Linie an der Lage des zuletzt bestatteten Toten. Dadurch wäre praktisch so gut wie immer ausgeschlossen, daß Individuen eines Familienverbandes gemeinsam und nebeneinander an einem Ort des Friedhofes bestattet wurden (Christlein 1991). Durch diese Belegungstradition erklärt sich ferner die zum Teil auf engem Raum konzentrierte, in Reihen und typischer West-OstAusrichtung erfolgte Belegungsweise, auf die der Begriff „Reihengräberzivilisation“ gründet.

Dem Bestattungszeremoniell kam während der Merowingerzeit eine große Bedeutung zu. Besonders zu beachten ist dabei die Beigabensitte, d.h. der Brauch, den Verstorbenen persönliche Habe ins Grab beizulegen. Da das Individuum in der Anschauung der Zeit nach seinem Tode als Rechtsperson weiterlebte, hatte es, so Christlein (1991), dementsprechend Anrecht darauf, mitsamt den Gegenständen bestattet zu werden, die zum Erhalt seiner rechtlichen Persönlichkeit notwendig waren. Durch Tracht, Schmuck und Waffenausstattung konnte der Habitus des jeweiligen Individuums auch im Jenseits dargestellt werden. Diese Rechtsvorstellung scheint zu einer konsequent ausgeübten Beigabensitte geführt zu haben (Christlein 1991).

So lassen sich in Männergräbern - allerdings in zeitlich, sozial und ethnisch variierender Zusammensetzung - folgende Beigabenensembles beobachten: Fast stets ist der Leibgürtel zu finden, an dem das einschneidige Hiebschwert, der Sax, befestigt war. Diese Waffe findet sich in Alamannien fast in jedem zweiten Männergrab (Martin 1997) und kann so als Zeichen des wehrfähigen, zum Tragen von Waffen berechtigen Mannes angesehen werden. Die Spatha, das zweischneidige Langschwert, ist eher als Abzeichen von Macht und Wohlstand zu sehen, denn als eine tatsächlich im Kampf zum Einsatz kommende Waffe. Weitere Angriffswaffen, die sich regelhaft in merowingerzeitlichen Gräbern finden, sind Streitaxt, Ango (ein spezieller Typ des Speeres), Beil, Lanze, Pfeil und Bogen sowie Schutzbewaffnung wie Schild, seltener Helm und Panzer. 
In Frauengräbern finden sich die metallenen Bestandteile von Trachtenschmuck wie Fibeln, Gürtelgehänge, Wadenbinden, Schuhbesätze, Schnallen sowie Arm- und Fingerringe, Nadeln, Perlenketten und im besonderen auch Amulette verschiedenster Art. Unter anderem lassen sich auch häusliche Gerätschaften, wie zum Beispiel Spinnwirteln, Schlüssel, Weinsiebe oder Webschwerter nachweisen. Darüber hinaus sind in vielen Gräbern weitere Beigaben wie Gefäße aus Holz, Ton oder Glas zu finden, in denen den Toten Speisen und Getränke mitgegeben wurden.

Auch Kinder waren von der Beigabensitte nicht ausgeschlossen, es galten jedoch einige Besonderheiten für die Bestattung jüngerer Individuen. So erhielten Jungen erst im Alter von 12-15 Jahren (mit Einsetzen der Rechtsmündigkeit) umfangreichere Waffenausrüstungen, wenn auch quantitativ geringere als Erwachsene. Häufig finden sich Pfeilspitzen in Gräbern älterer Jungen (infans II), die sonst eher selten als Grabbeigaben zu beobachten sind (vgl. dazu auch Siegmund 1998a). Bereits ab dem 6. Lebensjahr lassen sich jedoch sowohl der Sax als auch weitere Waffen in einigen Jungengräbern finden, obgleich die Kinder physisch nicht zum Führen dieser Waffen in der Lage waren. Selbst in Kleinstkindergräbern sind noch Saxe und Beile in Miniaturformat aufgefunden worden.

Bei den Mädchengräbern fällt auf, daß diese meist lediglich die „Grundausstattung“ aufweisen, und so nur Fibeln, Gürtelgehänge und Perlen zu finden sind. Allerdings heben sich die Bestattungen von Kindern aus wahrscheinlich wohlhabenderen Familien dadurch ab, daß sie durchaus das gesamte Schmuck-Repertoire oder den kompletten Waffensatz enthalten, was sonst nur Erwachsenengräbern vorbehalten ist.

\subsubsection{Sozialstruktur der merowingerzeitlichen Gesellschaft}

Charakteristisch für die alamannische Gesellschaft ist ihre Staffelung nach Rängen, wobei „Rang“ die Position innerhalb der sozialen Hierarchie wiedergibt. So gibt z.B. der Pactus Alamannorum aus dem späten 6. Jahrhundert eine Vorstellung der Rangunterschiede innerhalb der Gesellschaft. In diesen sogenannten leges, den Niederschriften der germanischen Stammesrechte, ist festgesetzt, daß die Tötung 
oder Verletzung eines Menschen durch das Zahlen einer Buße („Wergeld“) geahndet wird. Deren Höhe richtete sich dabei nach dem sozialen Rang der geschädigten Person. Aus diesen Quellen geht hervor, daß in der merowingerzeitlichen Gemeinschaft folgende Gruppierungen existierten: Abhängige, Hörige und Sklaven (servi), Halbfreie oder Freigelassene (liten oder laten) und Freie (liberi oder ingenui). Darüber hinaus gab es nicht nur Unterschiede zwischen Freien und Unfreien, auch innerhalb der Freien herrschten Rangabstufungen: Minderbemittelte oder schlichte Freie (baro minoflidis), Freie mittleren Standes (medianus alamannus) und Freie hohen Standes (primus alamannus). Diese Einteilung gilt sowohl für Männer und Frauen als auch für Kinder (Steuer 1997; Siegmund 1998b).

Nach Steuer (1984) soll ein prägnantes Merkmale der alamannischen Gesellschaft sein, daß es keine feste Zugehörigkeit von Familien $\mathrm{zu}$ einem rechtlich streng determinierten Stand gab. Vielmehr bestimmte sich die Position in der Gemeinschaft nach den innerhalb dieser Gemeinschaft erbrachten Leistungen und wohl auch nach wirtschaftlichen Besitz. Steuer (1984) bezeichnet die alamannische Gesellschaft daher als eine „offene Ranggesellschaft“ ohne festgefügte Schichten. Der Glaube, daß gesellschaftlichen Unterschiede auch im Jenseits nicht hinfällig würden, könnte nach Christlein (1991) einer der Beweggründe gewesen sein, einen Toten mitsamt allen Insignien seiner gesellschaftlichen Stellung zu bestatten, die seinen im Leben eingenommen Status unmißverständlich anzeigte. Das Ende der Beigabensitte zum Ende des 7. Jahrhunderts ist nach Steuer (1997) nicht allein auf verändertes Totenbrauchtum im Zuge der Christianisierung zurückzuführen, sondern geht bezeichnenderweise auch mit der Auflösung der alten Sozialstrukturen und der Entstehung eines Adels als Geburtsstand einher. Grabbeigaben wurden mithin überflüssig, da die Ranghöhe einer Familie nun festgeschrieben war und sich auf andere Weise manifestierte.

\subsubsection{Rückschlüsse auf die Sozialstruktur anhand archäologischer Quellen}

Für die archäologische Forschung stellen die zahlreichen Grabfunde der Merowingerzeit ein wichtiges Substrat dar. Obwohl stets mit einschränkenden Nebenbemerkungen versehen, wird in vielen Abhandlungen und Untersuchungen davon 
ausgegangen, daß sich unter Umständen anhand des Grabinventars und auch aus den Beobachtungen zur Aufwendigkeit des Grabbaus Angaben zum sozialen Rang eines Individuums machen lassen (Dommasnes 1982; Robb et al. 2001; Härke 1992; Solberg 1985; Christlein 1991). Aus der Evaluation der Beigaben und dem Vergleich innerhalb der Gesamtpopulation der Bestatteten lassen sich möglicherweise Rückschlüße über die Sozialstruktur der zugehörigen historischen Siedlung ziehen. $\mathrm{Zu}$ einfache Schlussfolgerungen sind jedoch nicht statthaft, denn es läßt sich zum Teil in Frage stellen, ob anhand der Grabausstattung tatsächlich auf einen durch Geburt und/oder Lebensweise erworbenen sozialen Status rückzuschließen ist. Unter Umständen bestimmt eher der Besitzstand eines Individuums die Güte und Quantität der Grabbeigaben als ein davon vielleicht unabhängiges rechtlich-soziales Gliederungssystem der Gesellschaft. So tendieren viele Untersuchungen zu einer sozial neutraleren, eher auf den materiellen Wert abzielenden Einteilung der Grabinventare in sogenannte „Qualitätsgruppen“ (Christlein 1991). Hier wird eine Gruppierung der Beigaben aufgrund ihrer qualitätsmäßigen Zusammensetzung versucht. Indem eine Kombination von verschiedenen Merkmalen betrachtet wird, kann eine Einteilung in vier verschiedene Stufen (A-D) vorgenommen werden, die von ,arm“ bis „ungewöhnlich reich“ variiert. Es lassen sich somit Personengruppen bestimmen, die in etwa den gleichen Besitzstand aufweisen. Ob diese Qualitätsstufen letztendlich auch mit gesellschaftlichen Rangpositionen verknüpft werden dürfen, ob also Individuen des gleichen Besitzstandes auch einem einheitlichen rechtlichsozialen Stand angehören, bleibt ungewiß(Steuer 1982; Pader 1982).

Nicht zu vergessen ist im Zusammenhang von Sozialrang und Beigabeninventar der Aspekt des Grabraubes und die damit verbundenen möglichen Auswirkungen auf das Beigabenspektrum. Die Sitte des Grabraubes ist ein nicht zu unterschätzendes Phänomen und kann für fast jedes Gräberfeld nachgewiesen werden. Siegmunds (2000) Ansicht nach sind mehr als ein Drittel aller aufgefundenen Gräber beraubt, so daß Grabraub, obwohl unter strenger Strafe stehend (Steuer 1982), als eine weit verbreitete soziale Praxis gelten kann. Die mögliche Beeinträchtigung der archäologischen Quellenlage durch die Beraubung der Gräber muß also bei der Zuordnung von Individuen zu bestimmten Qualitätsstufen bzw. Sozialrängen beachtet werden. 
Die in diesem Kapitel dargestellten Einschränkungen sollte aber nicht dazu führen, von einer - zumindest vorsichtigen - Rekonstruktion einer frühmittelalterlichen Sozialstruktur anhand der Grabinventare gänzlich abzulassen, die dementsprechend auch für das untersuchte Gräberfeld Weingarten vorgenommen wurde.

\section{$2.2 \quad$ Der Fundort Weingarten}

Bei dem untersuchten Skelettmaterial handelt es sich um Grabungsfunde des frühmittelalterlichen Reihengräberfeldes Weingarten (Kr. Ravensburg), BadenWürttemberg. Das Gräberfeld gehört vermutlich zu der 1036 erstmals erwähnten Siedlung Altdorf (die schließlich nach dem Kloster Weingarten umbenannt wurde) und liegt von deren früheren Ortskern ca. $700 \mathrm{~m}$ entfernt (Roth \& Theune 1995). Da die ursprünglich zum Gräberfeld gehörende frühmittelalterliche Siedlung unter neueren Bauten liegen dürfte, sind - wie in vielen Fällen - keinerlei Angaben zu Siedlungsbefunden möglich. Eine Vorstellung der Topographie der frühmittelalterlichen Siedlung gibt Abbildung 2.1.

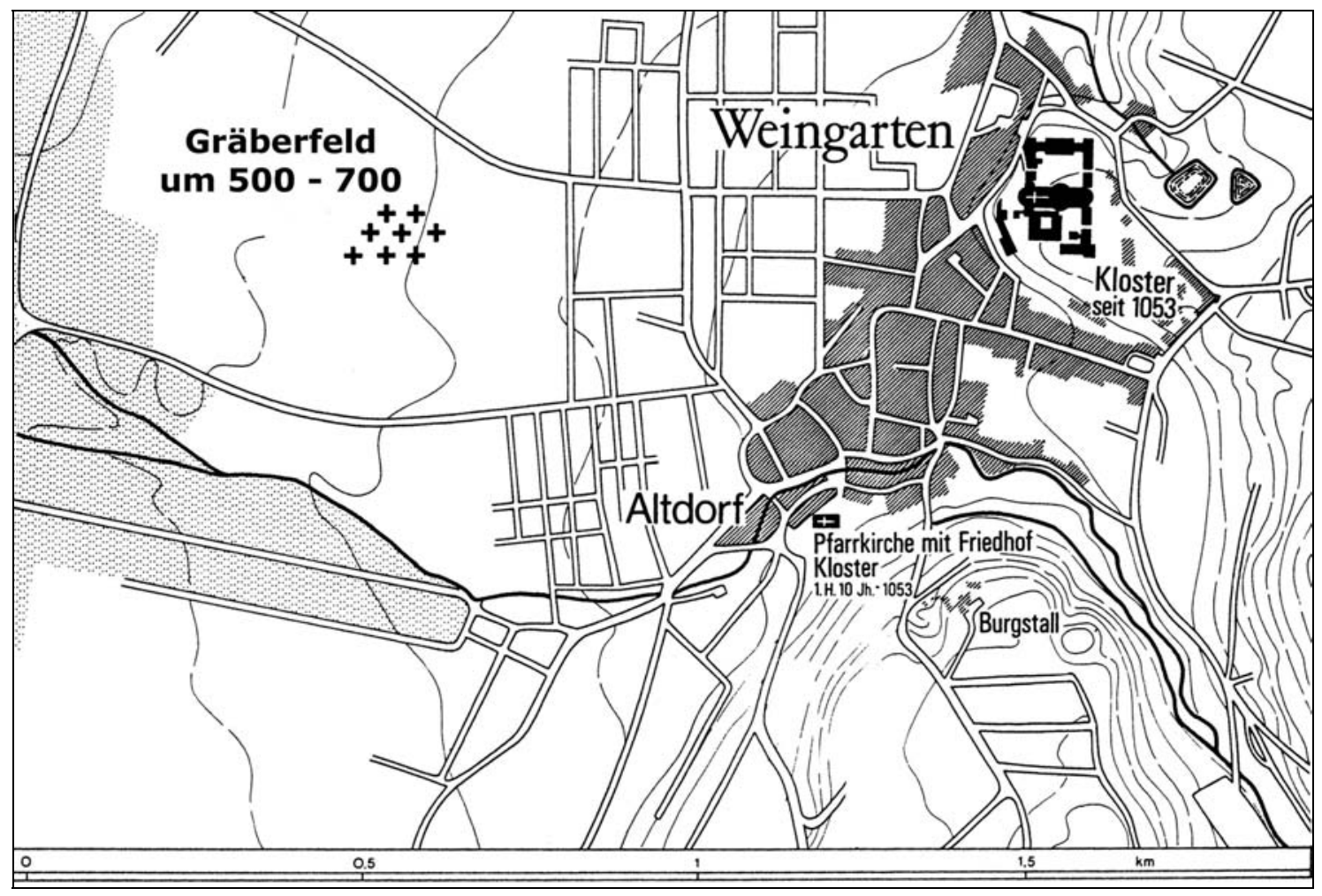

Abbildung 2.1:. Historische Topographie von Weingarten (Neuffer 1975) 
Die Grabungsarbeiten, die vom Staatlichen Amt für Denkmalpflege Tübingen durchgeführt wurden, begannen 1954, nachdem man bei Erschließungsarbeiten auf Gräber gestoßen war. 1957 wurden die Grabungstätigkeiten eingestellt. Das Weingartener Gräberfeld umfaßt insgesamt 801 Bestattungen, allerdings ist anzumerken, daß durch die vorhergehenden Bauarbeiten schätzungsweise 100 Gräber unbemerkt zerstört worden waren. Auch während der archäologischen Grabungen, die zum Teil als Notbergungen vonstatten gehen mussten, kam es zu weiteren Störungen der Gräber. Dies und auch der generelle Bodenaufbau sind die Gründe, weswegen Angaben zum Grabbau und zum Teil auch zu den Grabinventaren nicht immer vollständig sind. Der Untergrund besteht aus einem stark geröllhaltigen Geschiebeboden (Korngröße 1-4 cm), was die Beobachtung und letztendlich die Dokumentation der Grabgruben sehr erschwerte (Roth \& Theune 1995). Aus den schlechten Bodenverhältnissen ergibt sich auch, daß Anzeichen der Beraubung, sonst durchaus erkennbar, nur schwer nachzuweisen sind (Roth 1977; Roth 1977). Möglicherweise ist auch der allgemein schlechte Erhaltungszustand der Skelette auf das ungünstige Bodenmilieu zurückführen. Darüber hinaus fehlt ein Plan, in dem sämtliche freigelegten Gräber eingetragen sind; der vorhandene Lageplan verzeichnet nur etwa die Hälfte der Bestattungen. So lassen sich weder Angaben über die genaue Ausdehnung des Gräberfeldes machen, noch ist es möglich, z.B. Belegungslücken zu definieren oder die genaue Belegungsabfolge zu rekonstruieren. Festzustellen ist, daß sich die frühesten Bestattungen im südwestlichen Teil des Friedhofes befinden, mit fortdauernder Belegung erweiterte sich die Nekropole in nordöstliche Richtung, die letzten Gräber befinden sich im östlichen Abschnitt des Begräbnisfeldes (Neuffer 1975). Durch die mangelnde Dokumentation ist leider auch nicht mehr feststellbar, ob es separate Familien- oder Sippenbestattungsplätze gab, oder ob ungewöhnliche Grabbauten, wie z.B. Hügelaufschüttungen, existierten, die das Begräbnis von Personen anzeigen, die unter Umständen einer Siedlungs-Elite zugeordnet werden könnten. Die beobachteten Bestattungen finden sich zwischen 0,20 m bis 2,00 $\mathrm{m}$ unter der für die damaligen Bauzwecke abgeschobenen Oberfläche. 
In ihrem Beitrag zu Einwohnerzahlen und Siedlungsgröße der Merowingerzeit versuchen Donat \& Ullrich (1971) eine Schätzung der durchschnittlichen Bevölkerungszahl auch für den Weingartener Siedlungsplatz. Diese Schätzung ergibt sich aus der Anzahl der Gräber und dem Belegungszeitraum und berücksichtigt außerdem die Anzahl der nicht bestatteten Individuen der Alterklassen infans I/II - juvenis. So läßt sich für Weingarten eine durchschnittliche Bevölkerungszahl von 191 Individuen ermitteln, was eine im Vergleich mit anderen Siedlungen sehr hohe Anwohnerzahl darstellt und noch einmal auf die große Bedeutung des Weingartener Gräberfeldes hinweist, da es eine außergewöhnlich bevölkerungsreiche Siedlung repräsentiert.

\section{$2.3 \quad$ Skelett- und Grabfunde}

Auch die Gräber der Weingartener Nekropole folgen der für die Merowingerzeit charakteristischen Beigabensitte. Nur 92 der 801 Gräber sind als inventarlos vermerkt. Obwohl Weingarten als einer der größten Reihengräberfriedhöfe im süddeutschen Raum gilt, ist die Ausstattung der Gräber nicht als außergewöhnlich reich anzusehen (Christlein 1991). Im Gegensatz zu Friedhöfen, wie z.B. Kirchheim/Ries oder Fridingen, Kr. Tuttlingen, die aus derselben Zeitstellung stammen, fehlen hier prunkvoll ausgestatte Gräber (Adelsbestattungen) gänzlich. Vor allem die Männergräber entsprechen dem üblichen Bewaffnungs- und Ausstattungsschema (Neuffer 1975). Eine Einteilung der Weingartener Individuen hinsichtlich ihrer Zugehörigkeit $\mathrm{zu}$ verschiedenen Rängen wurde von Helmut Roth vorgenommen (Schutkowski et al. 1999). Aufgrund ihrer Grabbeigabenausstattung sind die Individuen entweder dem Rang 0 (niederer sozialer Rang) oder dem Rang 1 (höherer sozialer Rang) zugeordnet worden.

In den folgenden Abbildungen 2.2 - 2.5 sind beispielhaft Grabzeichnungen mit den vorgefundenen Grabinventaren von vier Individuen dargestellt, die dem Fundkatalog der Weingartener Ausgrabung (Roth \& Theune 1995) entnommen sind. Hierbei handelt es sich um zwei Frauen- und zwei Männergräber mit jeweils einem Repräsentanten aus dem sozial niedrigeren Rang 0 und aus der sozial höheren Gruppe, dem Rang 1. 


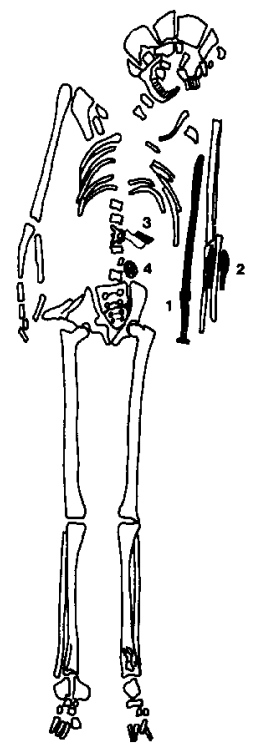

Abbildung 2.2: Grab 303. Männliches Individuum des niederen sozialen Ranges (Rang 0). Alter: adult. Grabtiefe $160 \mathrm{~cm}$. Grabinventar: Sax, zwei Pfeilspitzen, Feuerzeug und -stahl, Flintabschlag, Schnalle, Messer. Aus Roth \& Theune (1995)

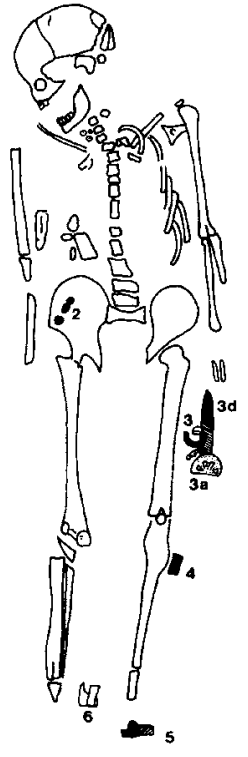

Abbildung 2.4: Grab 141. Weibliches Individuum des niederen sozialen Ranges (Rang 0). Alter: adult. Grabtiefe $120 \mathrm{~cm}$. Grabinventar: Glas-Perlenkette, Schnalle, Gürtelgehänge, bronzene Zierscheibe, Bronze-Ringe, Messer, Schuhschnallengarnitur, Schnallenbeschlag, Riemenzunge, Tierknochen (Rind). Aus Roth \& Theune (1995).

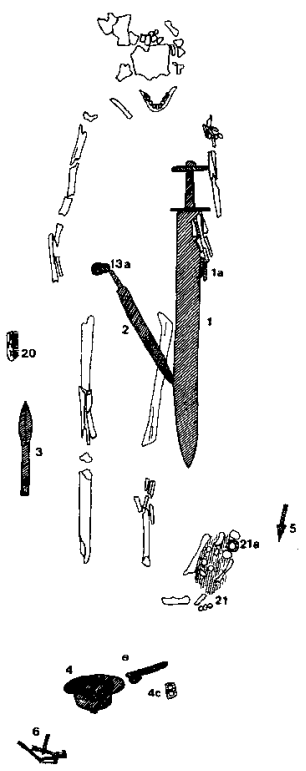

Abbildung 2.3: Grab 619. Männliches Individuum des höheren sozialen Ranges (Rang 1). Alter: adult. Grabinventar: Spatha mit Silberstreifentauschierung, Sax, Lanze, Schildbuckel, Schildfessel, Schnallen, Pfeilspitzen, Trense, silbertauschierte Gürtelgarnitur, Feuerstahl, Messer, Kamm, Ringe, Tierknochen (Schwein, Hund, Teilskelett eines enthaupteten Pferdes). Aus Roth \& Theune (1995).

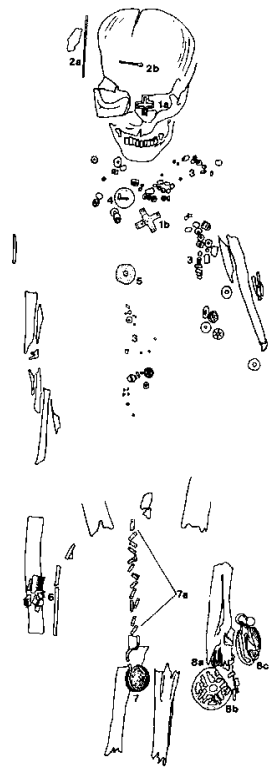

Abbildung 2.5: Grab 615. Weibliches Individuum des höheren sozialen Ranges (Rang 1). Alter: matur. Grabinventar: Goldblattkreuze, Nadeln aus Bronze und Silber, Perlenkette, Goldscheibenfibel, Scheibenfibel, Kamm, Bergkristallkugel, Silberbleche, Bügelschere, Zierscheibe, Muschel (Cypraea tigris) Schnallen, Ringe, Messer, Schabmesser, Textilfragmente, Tierknochen, Eierschalen. Aus Roth \& Theune (1995). 
Die anthropologische Untersuchung der Skelettindividuen wurden von Neil Huber und Joachim Wahl (Landesdenkmalamt Baden-Württemberg) durchgeführt, wobei in der vorliegenden Arbeit auf die neueren Ergebnisse der Geschlechts- und Altersbestimmungen von Wahl zurückgegriffen wird.

Die Proben wurden seit ihrer Bergung vor etwa 48 Jahren und nach eingehenden Untersuchungen im Alamannen-Museum in Weingarten eingelagert und dort im Ossuar bei Raumtemperatur aufbewahrt. Aus dem Skelettkollektiv wurde eine Stichprobe von 161 Individuen entnommen, die bereits im Rahmen einer früheren Studie zur Analyse von Ernährungsgewohnheiten ausgewählt wurden (Schutkowski et al. 1999). Hierbei wurden von den 81 nicht-adulten Individuen der Gesamtpopulation 25 Individuen beprobt, die aufgrund ihres Erhaltungszustandes zur Probenentnahme zur Verfügung standen. Die restlichen 136 erwachsenen Individuen stellen einen repräsentativen Ausschnitt des Weingartener Gräberfeldes dar, der ohne Berücksichtigung archäologischer Informationen (Roth \& Theune 1995) nach dem Zufallsprinzip ausgewählt wurde. 83 dieser Individuen sind dem niederen sozialen Rang zugeordnet, während für 77 der Individuen Zugehörigkeit zum höheren sozialen Rang vermutet wird.

Von den im Weingartener Alamannen-Museum aufbewahrten Individuen wurden, soweit vorhanden, jeweils 1-2 Zähne entnommen. Diese wurden entweder mit der Hand oder mit einer Zange aus dem Kiefer gelöst, wobei nur Zähne ausgewählt wurden, die keinerlei Anzeichen von Karies aufwiesen. Knochenproben wurden lediglich von den Individuen entnommen, von denen keinerlei Zahnmaterial vorlag. In diesen Fällen wurde mit Hilfe einer Diamantsäge (Dentalbohrer K10) vorzugsweise aus einem Langknochenelement eine ca. $1 \mathrm{~g}$ schwere Probe entnommen. Alle Probenstücke wurden in sterile Falcon-Tubes überführt. Eine Konkordanzliste des Probenmaterials ist in der folgenden Tabelle 2.1 wiedergegeben. 
Tabelle 2.1: Auflistung der für die Untersuchungen ausgewählten Weingartener Individuen. Zum Teil waren die Zahnproben mit Wachs oder Klebstoff auf Pappkarton befestigt, bzw. in die Zahnfächer des Kiefers geklebt. Diese Proben sind in der folgenden Tabelle mit der Zustandsbeschreibung „Geklebt“ gekennzeichnet. Aufgeführt sind ebenfalls die anhand der archäologischen und anthropologischen Untersuchungen festgelegten Geschlechtsbestimmungen. Unsichere Determinationen, auch beim Individualalter, sind mit '?' gekennzeichnet. Der jeweilige Sozialrang ist durch '1' oder '0' gekennzeichnet, wobei '0' dem niedrigeren sozialen Rang entspricht, während '1' Zugehörigkeit zum höheren sozialen Rang bedeutet.

\begin{tabular}{|c|c|c|c|c|c|c|}
\hline $\begin{array}{c}\text { Grab } \\
\text { Nr. }\end{array}$ & $\begin{array}{c}\text { Geschlecht } \\
\text { (archäologisch) }\end{array}$ & $\begin{array}{c}\text { Geschlecht } \\
\text { (anthropologisch) }\end{array}$ & Skelettelement & Zustand & Individualalter & Rang \\
\hline 51 & $?$ & $?$ & 26 & Geklebt & iuv & 0 \\
\hline 52 & $\mathrm{~m}$ & $?$ & 37,47 & Geklebt & inf II-juv & 0 \\
\hline 65 & $?$ & ? & 23 & Geklebt & inf I/II (ca.6) & 0 \\
\hline 66 & $\mathrm{w}$ & $?$ & Femur (1) & & $?$ & 1 \\
\hline 79 & $?$ & $\mathrm{w}$ & 36 & & fad & 0 \\
\hline 99 & $\mathrm{~m}$ & $\mathrm{~m}$ & Radius & & mat & 0 \\
\hline 111 & $\mathrm{w}$ & $\mathrm{w}$ & 48,47 & & $\mathrm{ad}$ & 1 \\
\hline 113 & $\mathrm{w}$ & $\mathrm{w}$ & 43 & & mmat-smat & 1 \\
\hline 115 & $\mathrm{~m}$ & $\mathrm{~m}$ & 47 & Geklebt & sad & 0 \\
\hline 119 & $\mathrm{w}$ & $\mathrm{w}$ & 28,25 & & mmat-smat & 1 \\
\hline 125 & $\mathrm{w}$ & $\mathrm{w} ?$ & 36,65 & Geklebt & $\inf$ II (7-8) & 1 \\
\hline 130 & $?$ & $\mathrm{w}$ & 17,18, Femur & Geklebt & mad-sad & 0 \\
\hline 134 & $\mathrm{~m}$ & $?$ & 27,16, Femur & Geklebt & sad-fmat & 0 \\
\hline 136 & $\mathrm{~m}$ & $?$ & 16,17 & Geklebt & $\mathrm{ad}$ & 1 \\
\hline 141 & w & $\mathrm{w}$ & 37,47 & & $\mathrm{ad}$ & 0 \\
\hline 144 & $\mathrm{~m}$ & $\mathrm{~m} ?$ & 16,17 & Geklebt & sad-mmat & 0 \\
\hline 153 & w & $\mathrm{w}$ & 21 & Geklebt & fmat-mmat & 1 \\
\hline 157 & $\mathrm{w}$ & $\mathrm{w}$ ? & 44 & & smat-sen & 0 \\
\hline 161 & $\mathrm{w}$ & w? & Femur & & $\mathrm{ad}$ & 1 \\
\hline 163 & $\mathrm{~m}$ ? & $\mathrm{m}$ & 37 & & fad & 0 \\
\hline 164 & $?$ & $\mathrm{~m}$ ? & 47 & & fad & 0 \\
\hline 165 & $\mathrm{~m}$ & $?$ & Femur & & $\mathrm{ad}$ & 1 \\
\hline 167 & $\mathrm{~m}$ & $\mathrm{~m}$ & 33,34 & Geklebt & mmat & 1 \\
\hline 173 & w & w & 17 & & $\mathrm{fad}$ & 0 \\
\hline 175 & $\mathrm{w}$ & $\mathrm{w}$ & 18,28 & Geklebt & fad-mad & 0 \\
\hline 178 & $\mathrm{w}$ & $\mathrm{w}$ & 45 & & fad & 1 \\
\hline 179 & w & $\mathrm{w}$ ? & 18 & Geklebt & $\mathrm{ad}$ & 1 \\
\hline 182 & $\mathrm{~m}$ & $\mathrm{~m}$ & 33,45 & & fad-mad & 0 \\
\hline 184 & w & $\mathrm{w}$ & Femur & & fmat & 0 \\
\hline 186 & $\mathrm{~m}$ & $\mathrm{~m}$ ? & 18 & & mmat & 0 \\
\hline 194 & $\mathrm{w}$ & $\mathrm{w}$ & 37,36 & & $\mathrm{sad}$ & 1 \\
\hline 196 & $?$ & w & 47,44 & & sad & 0 \\
\hline 199 & $\mathrm{w}$ & $?$ & 36 & & $\inf$ II $(9-10)$ & 0 \\
\hline 201 & $\mathrm{~m}$ & $\mathrm{~m}$ & Femur (1) & & mad-sad & 1 \\
\hline 202 & $\mathrm{~m}$ & $\mathrm{~m}$ & 38,16 & & fmat-mmat & 1 \\
\hline 204 & $\mathrm{~m}$ & $?$ & 46,47, Femur & Geklebt & inf II-juv & 0 \\
\hline 206 & $\mathrm{w}$ & $\mathrm{w}$ & 47,18 & Geklebt & fad & 0 \\
\hline 208 & $?$ & $\mathrm{~m} ?$ & 45,27 & & $\mathrm{fad}$ & 0 \\
\hline 211 & $?$ & $\mathrm{~m}$ & 16 & & mad-fmat & 0 \\
\hline 214 & $\mathrm{w}$ & $?$ & 16 & & $\inf$ II (6-7) & 1 \\
\hline 221 & $?$ & $\mathrm{w}$ & 37 & Geklebt & mad & 0 \\
\hline 226 & $?$ & $?$ & 35 & & inf II & 0 \\
\hline 227 & $\mathrm{~m}$ & $\mathrm{~m} ?$ & 28,17 & & sad-fmat & 1 \\
\hline 228 & $\mathrm{w}$ & $\mathrm{w}$ & 45 & & smat-sen & 0 \\
\hline 231 & $\mathrm{~m}$ & $\mathrm{~m}$ & 48 & & sad-fmat & 0 \\
\hline 232 & $\mathrm{~m}$ & $\mathrm{~m} ?$ & 48 & & fad & 1 \\
\hline 233 & $\mathrm{w}$ & $\mathrm{m} ?$ & 55 & & $\inf I$ (ca. 3) & 1 \\
\hline 234 & $\mathrm{w}$ & $\mathrm{w}$ & Femur & & sad & 0 \\
\hline
\end{tabular}




\begin{tabular}{|c|c|c|c|c|c|c|}
\hline $\begin{array}{c}\text { Grab } \\
\text { Nr. }\end{array}$ & $\begin{array}{c}\text { Sex } \\
\text { (archäologisch) }\end{array}$ & $\begin{array}{c}\text { Sex } \\
\text { (anthropologisch) }\end{array}$ & Skelettelement & Zustand & Individualalter & Rang \\
\hline 238 & $\mathrm{~m}$ & $\mathrm{~m}$ & 17 & & juv-fad & 1 \\
\hline 241 & w & w & 3 Zähne & & sad & 1 \\
\hline 243 & w & ? & 3 Zähne & & $\inf I(2-4)$ & 1 \\
\hline 244 & $\mathrm{~m}$ & $\mathrm{~m} ?$ & Femur & & fad & 1 \\
\hline 253 & $\mathrm{~m}$ & $\mathrm{~m}$ & 47,48, Femur & Geklebt & $\mathrm{ad}$ & 1 \\
\hline 256 & $\mathrm{~m}$ & $\mathrm{~m}$ & 3 Zähne & & fad-mad & 1 \\
\hline 257 & $\mathrm{~m}$ & $\mathrm{~m}$ & 47, Femur & & $\mathrm{fad}$ & 1 \\
\hline 258 & $\mathrm{w}$ & $\mathrm{w}$ & 1 Zahn (OK) & Geklebt & mad-sad & 0 \\
\hline 259 & $\mathrm{w}$ & $?$ & 37 & & sad-fmat & 0 \\
\hline 260 & w & ? & 55 & Geklebt & $\inf$ II (8-10) & 1 \\
\hline 270 & $\mathrm{~m}$ & $\mathrm{~m}$ & 37,18 & & sen & 0 \\
\hline 271 & $\mathrm{w}$ & $\mathrm{w}$ & 17 & & fad & 1 \\
\hline 272 & w & $\mathrm{w}$ & 48,45 & & fad-mad & 1 \\
\hline 275 & $\mathrm{~m}$ & $?$ & 47,46, Femur & Geklebt & sad & 1 \\
\hline 278 & $?$ & $\mathrm{w}$ & 38 & & sad-fmat & 0 \\
\hline 282 & $\mathrm{~m}$ & $\mathrm{~m}$ & 17,27 & & mad-sad & 0 \\
\hline 283 & $\mathrm{~m}$ & $\mathrm{~m}$ & 34,43 & & $\operatorname{mad}$ & 1 \\
\hline 293 & $\mathrm{w}$ & $\mathrm{w}$ & 48 & & smat-sen & 0 \\
\hline 298 & $\mathrm{~m}$ & $\mathrm{~m}$ & 2 Zähne & & smat & 0 \\
\hline 303 & $\mathrm{~m}$ & $\mathrm{~m}$ & 23,18, Femur & & mmat & 0 \\
\hline 313 & $\mathrm{w}$ & $\mathrm{w} ?$ & 37,38 & Geklebt & $\mathrm{fad}$ & 1 \\
\hline 322 & $?$ & $\mathrm{~m}$ & Zahn & & sen & 0 \\
\hline 323 & $\mathrm{~m}$ & $\mathrm{~m} ?$ & 21 & Geklebt & sad-fmat & 1 \\
\hline 326 & $\mathrm{~m}$ & $\mathrm{~m}$ & 46,45 & & smat & 0 \\
\hline 330 & $\mathrm{~m}$ & $\mathrm{~m}$ & 4 Zähne & & mad-sad & 1 \\
\hline 332 & $\mathrm{~m}$ & $?$ & Femur & & $\mathrm{ad}$ & 1 \\
\hline 335 & $\mathrm{~m}$ & $\mathrm{~m}$ & Humerus & & fmat-mmat & 1 \\
\hline 342 & $\mathrm{~m}$ & $\mathrm{~m}$ & 28,36 & & mat & 1 \\
\hline 344 & $\mathrm{w}$ & $\mathrm{w} ?$ & 47 & & fmat-mmat & 1 \\
\hline 348 & $?$ & $\mathrm{w}$ & 37,38 & & fmat-mmat & 0 \\
\hline 359 & $\mathrm{~m}$ & $\mathrm{~m}$ & 37,38 & & fmat & 1 \\
\hline 363 & $?$ & $\mathrm{~m}$ & 37 & & mad-sad & 0 \\
\hline 374 & $\mathrm{w}$ & w & 38, Ulna & & sad & 0 \\
\hline 376 & $\mathrm{~m}$ & $?$ & 35,36 & Geklebt & $\inf$ II (9-10) & 0 \\
\hline 377 & $\mathrm{~m}$ & $?$ & 37 & Geklebt & sad & 1 \\
\hline 379 & $\mathrm{~m}$ & $\mathrm{~m}$ & 25 & & mmat & 0 \\
\hline 385 & $\mathrm{~m}$ & $\mathrm{~m}$ & 38,25 & & $\operatorname{mad}$ & 1 \\
\hline 395 & $\mathrm{w}$ & $\mathrm{w}$ & 48,44 & & $\mathrm{ad}$ & 1 \\
\hline 397 & $?$ & $?$ & 15,37 & & $\inf$ II (10-11) & 0 \\
\hline 399 & $\mathrm{~m}$ & $\mathrm{~m}$ & 38, Femur & & $\mathrm{ad}$ & 1 \\
\hline 405 & $\mathrm{w}$ & $?$ & 17 & & mat & 0 \\
\hline 406 & $\mathrm{~m}$ & $?$ & 27,26 & & $\inf$ II (12-13) & 1 \\
\hline 408 & $\mathrm{w}$ & $\mathrm{w}$ & 47 & & ad & 0 \\
\hline 409 & $\mathrm{~m}$ & $\mathrm{~m}$ & 36,47 & & fad & 1 \\
\hline 411 & $\mathrm{w}$ & w & 45,34 & & smat & 0 \\
\hline 414 & $\mathrm{w}$ & w & 38 & & $\operatorname{mad}$ & 1 \\
\hline 417 & $?$ & w & 36,47 & & sad & 0 \\
\hline 426 & $\mathrm{~m}$ & $\mathrm{~m}$ & Femur & & fad-mad & 0 \\
\hline 441 & $?$ & $\mathrm{w}$ & 47,45 & & mad-sad & 0 \\
\hline 442 & $\mathrm{~m}$ & $\mathrm{~m}$ & 38,36 & & $\operatorname{mad}$ & 0 \\
\hline 443 & $\mathrm{w}$ & $?$ & 43 & Geklebt & $\inf$ II (11-13) & 0 \\
\hline 456 & $\mathrm{w}$ & $\mathrm{w}$ & 16 & & sad-fmat & 0 \\
\hline 461 & w & $\mathrm{w} ?$ & Femur & & erwachsen & 1 \\
\hline 464 & $\mathrm{w}$ & $\mathrm{w}$ & 36,37 & & smat-sen & 1 \\
\hline 469 & $?$ & $\mathrm{~m}$ & Femur & & mad-sad & 0 \\
\hline 478 & $\mathrm{~m}$ & $\mathrm{~m}$ & 27,28, Femur & & sad & 1 \\
\hline
\end{tabular}




\begin{tabular}{|c|c|c|c|c|c|c|}
\hline $\begin{array}{l}\text { Grab } \\
\text { Nr. }\end{array}$ & $\begin{array}{c}\text { Sex } \\
\text { (archäologisch) }\end{array}$ & $\begin{array}{c}\text { Sex } \\
\text { (anthropologisch) }\end{array}$ & Skelettelement & Zustand & Individualalter & Rang \\
\hline 480 & $\mathrm{~m}$ & $\mathrm{~m}$ & 46,47 & & fad & 0 \\
\hline 485 & $?$ & $\mathrm{~m}$ & 13 & & sad & 0 \\
\hline 487 & w & w? & Zahn & & erwachsen & 1 \\
\hline 488 & $\mathrm{~m}$ & $\mathrm{w}$ ? & 16 & & mad & 0 \\
\hline 491 & $?$ & $?$ & 36 & Geklebt & $\inf$ II (8-9) & 0 \\
\hline 500 & $\mathrm{~m}$ & $\mathrm{~m}$ & $45 ; 46$ & & sad & 1 \\
\hline 505 & $?$ & $\mathrm{w}$ & 46,47 & & sad-fmat & 0 \\
\hline 507 & $\mathrm{w}$ & $\mathrm{w}$ & 47 & & $\mathrm{fad}$ & 1 \\
\hline 517 & $?$ & $\mathrm{~m} ?$ & 16, Femur & Geklebt & $\inf$ II (ca. 10) & 0 \\
\hline 551 & $\mathrm{w}$ & $\mathrm{w}$ & 27 & & $\mathrm{fad}$ & 0 \\
\hline 556 & $\mathrm{w}$ & $\mathrm{w}$ & 37 & & sad & 1 \\
\hline 562 & $?$ & $\mathrm{~m}$ & 37,47 & & sad & 0 \\
\hline 565 & $\mathrm{~m}$ & $\mathrm{~m}$ & Zahn & & sad-fmat & 1 \\
\hline 567 & w & $\mathrm{w}$ & 16,17 & & $\mathrm{fad}$ & 1 \\
\hline $568 \mathrm{~A}$ & $?$ & $\mathrm{w}$ & Zahn (UK) & & smat-sen & 0 \\
\hline 577 & $\mathrm{w}$ & $?$ & 44 & & mat & 1 \\
\hline 580 & w & $\mathrm{w}$ & 37 & & fad & 1 \\
\hline 586 & $?$ & $\mathrm{w}$ & Zahn (OK) & & $\operatorname{mad}$ & 0 \\
\hline 590 & $\mathrm{~m}$ & $\mathrm{~m}$ & 17,13 & & ad-mat & 1 \\
\hline 610 & $\mathrm{~m}$ & $\mathrm{~m}$ & 26 & & mat & 0 \\
\hline 612 & $\mathrm{~m}$ & $\mathrm{~m}$ & 36 & & erwachsen & 1 \\
\hline 615 & $\mathrm{w}$ & $?$ & 27 & & mat & 1 \\
\hline 616 & $\mathrm{~m}$ & $\mathrm{~m} ?$ & 23 & Geklebt & sad & 1 \\
\hline 619 & $\mathrm{~m}$ & $\mathrm{~m} ?$ & 46,47 & & $\mathrm{ad}$ & 1 \\
\hline 620 & $\mathrm{w}$ & $?$ & 35 & & $\mathrm{ad}$ & 1 \\
\hline 625 & $\mathrm{~m}$ & $\mathrm{~m} ?$ & 37, Femur & & juv-fad (ca. 20) & 0 \\
\hline 631 & $\mathrm{~m}$ & $\mathrm{~m}$ & 26, Femur & & fmat & 0 \\
\hline 636 & $\mathrm{~m}$ & $\mathrm{~m}$ & 16 & & fmat & 1 \\
\hline 641 & $?$ & $\mathrm{~m}$ & 43 & & fmat & 0 \\
\hline 644 & $\mathrm{~m}$ & $\mathrm{~m} ?$ & 37,38 & & fad & 0 \\
\hline 647 & $\mathrm{w}$ & $?$ & 36,26 & & juv-fad (18-20) & 0 \\
\hline 655 & $?$ & $\mathrm{~m}$ & 46,47 & & fmat & 0 \\
\hline 658 & $\mathrm{~m}$ & $\mathrm{w}$ & 36 & & mmat & 0 \\
\hline 668 & $\mathrm{w}$ & $\mathrm{w}$ & 17 & & $\mathrm{ad}$ & 1 \\
\hline 689 & $\mathrm{~m}$ & $\mathrm{~m}$ & 18 & & sad & 0 \\
\hline 696 & $\mathrm{~m}$ & $\mathrm{~m}$ & 46, Femur & & sad & 1 \\
\hline 697 & $?$ & $\mathrm{w}$ & 46,24 & & fad-mad & 0 \\
\hline 699 & $\mathrm{w}$ & $\mathrm{w}$ & 38 & & mmat & 0 \\
\hline 702 & $\mathrm{w}$ & $?$ & 84 & Geklebt & $\inf I(2-4)$ & 1 \\
\hline 704 & $?$ & $\mathrm{~m}$ & 48 & & sad-fmat & 0 \\
\hline 705 & $\mathrm{~m}$ & $?$ & 64 & & $\inf I(1-2)$ & 0 \\
\hline 715 & $\mathrm{w}$ & $?$ & 54 & Geklebt & $\inf I(3-4)$ & 1 \\
\hline 724 & $\mathrm{w}$ & $?$ & 62 & & $\inf$ II (7-8) & 1 \\
\hline 743 & $?$ & $\mathrm{~m}$ & 47,48 & & mad-sad & 0 \\
\hline 748 & $\mathrm{~m}$ & $\mathrm{~m}$ & 46, Femur & & fmat & 1 \\
\hline 757 & $\mathrm{~m}$ & $\mathrm{~m}$ & 37,38 , Femur & & mmat-smat & 1 \\
\hline 758 & $?$ & $\mathrm{~m}$ & 45 & & sad & 0 \\
\hline 763 & $\mathrm{~m}$ & $?$ & Zahn & & $\operatorname{infl}(5-6)$ & 1 \\
\hline 775 & $\mathrm{w}$ & $?$ & 85 & & $\inf I I(8-9)$ & 1 \\
\hline 778 & $\mathrm{w}$ & $\mathrm{w} ?$ & 36 & & $\inf$ II (10-12) & 1 \\
\hline 779 & $?$ & $\mathrm{~m} ?$ & 83 & & $\operatorname{infI}(4-5)$ & 0 \\
\hline 781 & $\mathrm{~m}$ & $\mathrm{~m}$ & 14,16, Femur & & mad-sad & 1 \\
\hline 785 & $\mathrm{~m}$ & $\mathrm{~m}$ & 48, Femur & & fad & 0 \\
\hline 790 & $\mathrm{w}$ & $\mathrm{w}$ & 26 & & sen & 1 \\
\hline 796 & $\mathrm{w}$ & $?$ & 36 & & $\inf \mathrm{I} / \mathrm{II}(5-7)$ & 1 \\
\hline 799 & $?$ & $\mathrm{~m}$ & 47 & & sad & 0 \\
\hline
\end{tabular}




\subsection{DNA-Extraktion}

\subsubsection{Probenentnahme und -vorbereitung}

Das im Weingartener Alamannen-Museum aufbewahrte Probenmaterial ist seit der Bergung vor ca. 50 Jahren zahlreichen Untersuchungen unterzogen worden. Insbesondere die Zähne waren Objekte eingehender Analysen. Da durch einfache Berührung Zellen des Bearbeiters, die amplifizierbare DNA enthalten, auf einem Objekt zurückbleiben können (Findlay et al. 1997; Zamir et al. 2000), musste der Entfernung eventuell der Probenoberfläche anhaftender Fremd-DNA besondere Beachtung zukommen. Aus diesem Grunde wurde etwa 1,5 mm der Oberflächen der Zähne und Knochenfragmente sehr sorgfältig mit einer Fräse (Dremel Multi 395) entfernt. Anschließend wurden die Proben einer UV-Licht Bestrahlung bei $\lambda=254 \mathrm{~nm}$ (30 W/30 min) ausgesetzt, wobei die Entfernung der Proben zur Lichtquelle etwa $5 \mathrm{~cm}$ betrug. UV-Licht dieser Wellenlänge induziert in der oberflächlichen DNA die Bildung von Pyrimidindimeren; derartig geschädigte DNA kann nicht mehr als Template für eine Amplifikation dienen (Cone \& Fairfax 1993).

Um eine optimale Oberflächenvergrößerung zu erreichen, wurde das Zahn- und Knochenmaterial zunächst in einem Stahlmörser grob zerkleinert und dann in einer Kugelschwingmühle (MM2, Retsch) bis zum Erreichen einer pulvrigen Konsistenz zermahlen. Bis zur weiteren Verarbeitung wurde das Skelettmaterial bei $-20^{\circ} \mathrm{C}$ eingelagert.

\subsubsection{Automatisierte DNA-Extraktion}

Eine möglichst hohe DNA-Ausbeute ist das Ziel jeder DNA-Extraktion. Dies gilt im besonderen für die Arbeit mit alter DNA. Dennoch scheinen gerade bei der Analyse von aDNA aus Knochenmaterial häufig Extraktionsprotokolle Anwendung zu finden, die aufgrund ihrer ungenügenden Anpassung an die speziellen Anforderungen dieses Probenmaterials nur suboptimale Ausbeuten erzielen, da sie nicht in der Lage sind, die Nukleinsäuren aus der Matrix des Hartgewebes herauszulösen (Müller 2000). 
Wird z.B. auf die Verwendung von Phenol verzichtet, kann dies zur Folge haben, daß die Proteine der Zellkernwand nur ungenügend denaturiert werden. Nicht nur aus diesem Grund ist die Durchführung einer Phenol-Chloroform-Extraktion bei der Untersuchung bodengelagerten Skelettmaterials angezeigt: Zugleich ist bei Anwendung dieser Methode die Entfernung von Humin- und Fulvinsäuren gewährleistet, bodenimmanente Verbindungen, die bei Verbleib im DNA-Extrakt die Amplifikation massiv inhibieren oder gar unterbinden.

In dem hier angewandten Protokoll erfolgte zunächst eine Demineralisierung des Probenmaterials: Jeweils 0,3 g des Knochen- bzw. Zahnpulvers wurden mit 1,5 ml 0,5 M EDTA ( $\mathrm{pH} 8.3$ ) versetzt und für $24 \mathrm{~h}$ bei RT in einem Rotationsgerät inkubiert. Das chelatbildende EDTA löst die $\mathrm{Ca}^{2+}$ - Ionen aus dem die anorganische Matrix bildenden Hydroxylapatit der Hartgewebe. Die dort eingebundenen Zellen und Zellfragmente gehen in die wässrige Phase über. Diese wurde anschließend durch Zentrifugation (4000U/min, 4 min, Eppendorf Zentrifuge 5415 C) von den Knochen- bzw. Zahnpulverresten abgetrennt. Der so gewonnene Überstand wird in die folgende Phenol-Chloroform- Extraktion eingesetzt.

Im ersten Schritt der automatisierten Extraktion wird durch die Zugabe des proteolytisch aktiven Enzyms Proteinase K eine Zelllyse bewirkt. Diesem folgt die Ausschüttlung des Zell-Lysates mit einem Phenol-Chloroform-Gemisch und damit eine Denaturierung vorhandener Proteine. Abschließend kommt es in Anwesenheit von Isopropanol und Natriumacetat zur Fällung der Nukleinsäuren. Zur Unterstützung der Präzipitation der DNA wird zusätzlich eine SilikatpartikelSuspension (Glasmilch ${ }^{\mathrm{TM}}$, QBioGene) zugegeben, an die die DNA adsorptiv bindet. Die vom Extraktor (Nucleinsäuren-Extraktor Typ 341A, Applied Biosystems) durchgeführten Schritte sind im folgenden aufgeführt. In den acht gläsernen Probenbehältnissen (Vesseln) des Geräts werden die Proben weitestgehend ohne manuellen Eingriff automatisch extrahiert.

- Beschickung der Vessel mit 1,3 - 1,8 ml Ampuwa ${ }^{\circledR}$

- Manuelle Zugabe von 1,3 ml des Überstandes aus dem Dekalzifikationsschritt

Zugabe von 38 - $650 \mu 1$ Proteinase K-Lösung $(20 \mathrm{mg} / \mathrm{ml})$ 
- $\quad 1 \mathrm{~h}$ Inkubation bei $60^{\circ} \mathrm{C}$ unter permanenter Durchmischung

- Zugabe von 2,7 - 3,5 ml Phenol / Chloroform / Wasser Gemisch (70\%)

- 6 min Durchmischung bei RT

- 8 min Phasentrennung bei $60^{\circ} \mathrm{C}$

- Abzug der organischen Phase und der Interphase

- Zugabe von 4,0 - 5,3 ml Chloroform (100\%)

- 6 min Durchmischung bei RT

- 8 min Phasentrennung bei $60^{\circ} \mathrm{C}$

- Abzug der organischen Phase

- Zugabe von 64 - $120 \mu 12$ M Natriumacetat-Puffer $(\mathrm{pH}=4,5)$

- Zugabe von 2,8 - 3,8 ml Isopropanol

- 75 s Durchmischung

- Einsetzen einer Filtervorrichtung mit Teflonmembran (Präzipitette)

- $\quad$ Manuelle Zugabe von $5 \mu$ Glasmilch GM $^{\mathrm{TM}}$

- 10 min Durchmischung bei RT

- Abzug der Flüssigkeit durch die Teflonmembran

- Zugabe von 2,8 - 3,8 ml Ethanol (80\%)

- 5 min Durchmischung bei RT

- Abzug des Ethanols durch die Teflonmembran

- Manuelle Entnahme der Teflonmembran

Der auf der Teflonmembran gesammelte Glasmilch-DNA-Komplex wurde mit 80\% Ethanol von der Membran gewaschen. Nach anschließender Zentrifugation (6000U/min, 4 min, Eppendorf Zentrifuge 5415 C) erfolgt eine Dekantierung des Überstandes. Das Glasmilch-DNA-Pellet wurde getrocknet, in $50 \mu 1$ Ampuwa $^{\circledR}$ eluiert und bis zum Verbrauch bei $-20^{\circ} \mathrm{C}$ tiefgefroren.

\subsubsection{Nachweis extrahierter DNA}

Zur Überprüfung des Extraktionserfolges und um die Qualität von DNA in den Extrakten $\mathrm{zu}$ kontrollieren, erfolgte eine elektrophoretische Auftrennung von Probenextrakt auf einem Agarosegel. Auf diese Weise lassen sich Aussagen über 
Molekulargewichtszusammensetzung und eventuell im Extrakt verbliebene Inhibitoren machen.

Die Auftrennung erfolgte auf ca. 4 mm dicken 2,5\%igen Agarosegelen, die 1: 3000 mit Ethidiumbromid (1\% w/v) vorgefärbt waren. Als Puffersystem wurde 1x TBE Puffer verwendet (90 mM Tris, pH 8,3; 90 mM Borsäure; 2,5 mM EDTA).

$10 \mu \mathrm{l}$ des DNA-Extraktes, jeweils versetzt mit $2 \mu \mathrm{l}$ Schwerelösung $(40 \% \mathrm{w} / \mathrm{v}$ Saccharose; 0,25\% w/v Bromphenolblau, Ampuwa ${ }^{\circledR}$ ), wurden auf das Gel aufgetragen. Ein Längenstandard wurde zur Orientierung auf jedem Gel mitgeführt (1 KbDNA-ladder [Life Technologies] Konzentration 0,1 ng/ $\mu$ l). Die Laufzeit betrug $40 \mathrm{~min}$ bei $80 \mathrm{~V}, 14 \mathrm{~cm}$. Die durch den interkalierenden Farbstoff Ethidiumbromid angefärbte DNA wird durch UV-Lichtbestrahlung bei $\lambda=254 \mathrm{~nm}$ sichtbar gemacht und auf Polaroid ${ }^{\mathrm{TM}}$-Film 667 (s/w) dokumentiert.

Die gelelektrophoretische Auftrennung der DNA-Extrakte ermöglicht Aussagen über die Ausbeute an DNA und deren Degradierungszustand. Hochmolekulare DNA, charakterisiert durch Fragmente von über 1000 bp, stammt in der Regel von Mikroorganismen, die das Skelettmaterial unter der Liegezeit invadiert haben. Humane DNA-Fragmente, die sich aus historischen Skelettmaterial extrahieren lassen, zeigen zumeist Basenpaarlängen, die 350 bp nicht überschreiten. Nur unter günstigen Umständen gelingt es, aus überdauertem Hartgeweben längere DNA-Fragmente nachzuweisen, die probenendogen sind (Haack et al. 2000). Die Provenienz der DNA ist anhand des Agarosegelbildes jedoch nicht zu klären und läßt sich erst durch die Amplifikation mit speziesspezifischen Primern überprüfen.

\subsubsection{Zusätzliche Aufreinigung von Extrakten}

Mit Hilfe der Agarose-Gelelektrophorese lassen sich auch im Extrakt verbliebene inhibitorische Substanzen, wie z.B. Huminstoffe, sichtbar machen, da diese bei UVLicht-Durchstrahlung im Gegensatz zur orange-rot fluoreszierenden DNA eine blaugrüne Färbung aufweisen (Francalacci 1995). Für diese Extrakte und in Fällen, in denen eine Inhibition der Amplifikation durch das Fehlen von Produkten und PrimerDimeren nahelag, erfolgte eine zusätzliche Entfernung von inhibierenden Stoffen durch die Verwendung des Wizard PCR Prep DNA Purification Systems 
(Promega). Verunreinigungen des Extrakts werden über die Gelmatrix der Reinigungssäulen des Kits ausgewaschen. Die zurückgehaltene DNA wird anschließend in Ampuwa ${ }^{\circledR}$ eluiert. Folgende Schritte wurden durchgeführt:

- Elution der DNA von der Glasmilch bei $50^{\circ}$ für $5 \mathrm{~min}$

- Zentrifugation (14.000U/min, $20 \mathrm{sec}$, Eppendorf Zentrifuge $5415 \mathrm{C}$ )

- Abtrennung des Überstandes, überführen in $2 \mathrm{ml}$ Eppendorf-Gefäß

- Zugabe von $50 \mu \mathrm{l}$ Direct Purification Puffer (Promega)

- $\quad$ Kurze Durchmischung (Vibrofix VF1)

- Zugabe von $1 \mathrm{ml}$ Wizard Prep PCR Preps Resin (Promega)

- Kurze Durchmischung

- Flüssigkeit mit Hilfe einer Einmalspritze $(2 \mathrm{ml})$ durch die mit Gelmatrix gefüllten Minisäulen (Wizard Minicolum, Promega) drücken

- Waschung der Säule mit $2 \mathrm{ml} \mathrm{80 \%} \mathrm{Isopropanol}$

- Restliche Flüssigkeit abzentrifugieren (14.000U/min, 20sec).

- Trocknung der Säulenmatrix für $10 \mathrm{~min}$ bei RT

- Zugabe von $50 \mu 1$ Ampuwa ${ }^{\circledR}, 1$ min inkubieren

- Überführen der Säule in neues Eppendorf-Gefäß

Abzentrifugation (14.000U/min, $20 \mathrm{sec})$

Das so gewonnene Eluat wird bis zur weiteren Verwendung bei $-20{ }^{\circ} \mathrm{C}$ gelagert.

\subsection{DNA-Amplifikation: Polymerase Chain Reaction (PCR)}

Studien an alter DNA zur Rekonstruktion historischer Zusammenhänge, die von der

Klärung individueller Verwandtschaft bis hin $\mathrm{zu}$ Untersuchungen von Populationsursprüngen reichen, haben in den letzten Jahren zunehmend an Bedeutung gewonnen (Kaestle \& Smith 2001; Schultes 2000; Hauswirth et al. 1994; Wang et al. 2000; Bramanti et al. 2000a). Dazu beigetragen hat im großen Maße die Möglichkeit, durch die Polymerase Kettenreaktion (Saiki et al. 1985; Mullis \& 
Faloona 1987) gezielt kleinste Mengen relativ kurzer DNA-Abschnitte mit einer hohen Spezifität in vitro enzymatisch zu vervielfältigen.

Die hohe Sensibilität der PCR macht die Methode für die Analyse von DNA aus bodengelagertem Skelettmaterial besonders geeignet: Aus $1 \mathrm{~g}$ rezenten menschlichen Knochens lassen sich wenige $\mu \mathrm{g}$ DNA extrahieren. Bodengelagerter Knochen dagegen enthält etwa $1 \%$ der Menge an DNA, die in Rezentmaterial zu erwarten ist (Lambert 1998). Hinzu kommt, daß die vielfältigen physikalischen, chemischen und biogenen Faktoren des Liegemilieus meist zu einer raschen Degradierung der DNAMoleküle beitragen (Eglinton \& Logan 1991). Unter günstigen Bedingungen -trockenes, kühles Milieu, neutraler pH-Wert, Abwesenheit von Mikroorganismen(Burger et al. 1999) ist es jedoch möglich, daß DNA über einen langen Zeitraum hinweg in den Hartgeweben erhalten bleibt und amplifikationsfähige Fragmente selbst noch nach bis zu 100. 000 Jahren nachzuweisen sind (Krings et al. 1997).

\subsubsection{Kontaminationsprävention und Authentifizierung}

Der immensen Sensibilität der PCR-Methode ist aber auch ihre hohe Anfälligkeit für Kontaminationen zuzuschreiben, was dazu geführt hat, daß zum Teil die Authentizität von Ergebnissen, die auf der Analyse von alter DNA beruhen, angezweifelt wird (Hofreiter et al. 2001; Handt et al. 1994; Kolman \& Tuross 2000; Cooper \& Wayne 1998). Die Autoren verweisen auf das hohe Kontaminationsrisiko durch allgegenwärtige rezente menschliche DNA. Dies bringt die unbedingte Notwendigkeit mit sich, Ergebnisse, die auf der Amplifikation endogener ProbenDNA beruhen, gegen falsch-positive Ergebnisse abzugrenzen, die sich aus der Amplifikation dieser kontaminierenden modernen DNA ergeben. Sind diese Bedenken im Hinblick auf einige Studien unter Umständen berechtigt (Zischler et al. 1995; Scholz et al. 2001) steht jedoch außer Frage, daß zum einen verschiedene wirksame Methoden zur unmittelbaren Kontaminationsvermeidung bestehen, die im folgenden vorgestellt werden. Zum anderen läßt sich die Authentifizierung von aDNA Ergebnissen durch besondere Strategien des Versuchsdesigns erreichen, die ebenfalls im nachstehenden Kapitel beschrieben werden. 


\subsubsection{Kontaminationsvermeidung}

Bei der PCR handelt es sich um einen kompetitiven Prozess, in dem präferentiell intakte Zielsequenzen amplifiziert werden. Alte DNA liegt charakteristischerweise nur noch in einem stark degradierten Zustand vor. Während der Liegezeit kommt es unter anderem durch hydrolytische Reaktionen zu Basenverlusten, die Folge der damit einhergehenden reduzierten Stabilität des DNA-Moleküls ist ein vermehrtes Auftreten von Strangbrüchen (Lindahl 1993). Aufgrund dieser Fragmentierungprozesse ist die Anzahl intakter, amplifizierbarer DNA-Abschnitte im Probenmaterial nur gering. Bei der Amplifikation von aDNA besteht daher die Gefahr, daß die moderne kontaminierende DNA, obgleich meist ebenfalls im Spurenbereich vorliegend, im Gegensatz zur Proben-DNA im größeren Maße intakte Zielsequenzen aufweist, weswegen sie unter Umständen bevorzugt amplifiziert wird (Handt et al. 1994; Kolman \& Tuross 2000). So kann es zu einer Überlagerung der stark degradierten Ziel-DNA durch die kontaminierende DNA kommen. Ist darüber hinaus keine endogene Proben-DNA im PCR-Ansatz vorhanden, kann es durch Amplifikation der Kontaminations-DNA zu falsch-positiven Ergebnissen kommen (Kitchin et al. 1990).

Obwohl die Möglichkeiten zum Eintrag von Kontaminationen vielfältig sind, kann die Kontaminationsrate durch geeignete Vorkehrungsmaßnahmen weitestgehend eingeschränkt werden. Im folgenden sind die potentiellen Hauptquellen der Kontamination und die angewandten Gegenmaßnahmen dargestellt:

Kontaminationen durch rezente DNA aus der Umgebung, übertragen unter anderem durch Hautschuppen oder Speichel (Kitchin et al. 1990). Um dieser vermutlichen Hauptkontaminations-Quelle entgegenzuwirken, wurden während sämtlicher Schritte der Proben- und Extrakt-Behandlung Gesichtsmaske, Haarhaube und Einmalhandschuhe getragen. Auch der Ansatz aller Reagenzien erfolgte unter Einhaltung dieser Vorkehrungsmaßnahmen.

Kontamination der Probenoberfläche. Um durch vorherige Bearbeiter auf die Probenoberfläche eingetragene DNA $\mathrm{zu}$ entfernen, wurde die gesamte Oberflächen der Proben abgetragen (siehe Probenvorbereitung). 
Eintrag von amplifizierter DNA aus vorhergehenden PCR-Reaktionen: „carry over"-Kontaminationen (Kwok 1990). Dieser Kontaminationseintrag wurde durch eine strikte räumliche Trennung von Prä- und Post-PCR-Arbeiten verhindert. Während die Probenvorbereitung, DNA-Extraktion und PCRAnsatz in einem Arbeitsraum durchgeführt wurden, fanden die Amplifikationen in einem gesonderten Labor statt. Die Analyse der Amplifikationsprodukte wurde in einem dritten Arbeitsraum durchgeführt. Laborgerätschaften und Reagenzien waren fest den verschiedenen Labors zugeordnet. Nach Arbeiten in den Bereichen mit hoher PCR-ProduktKonzentration wurde das Prä-PCR-Labor an diesem Tag nicht mehr betreten, da unvermeidlich an der Kleidung anhaftende Amplifikationsprodukte so in diesen Raum übertragen würden.

- Kreuzkontamination durch Übertragung von DNA zwischen den Proben während der Bearbeitung. Derartige Kontaminationen wurden ausgeschlossen, indem sämtliche Werkzeuge und Apparaturen, die mit einer Probe in Berührung gekommen waren, vor der nächsten Benutzung gründlich mit Wasser, Aceton und einer Extran-Lösung gereinigt wurden. Alle Arbeitsflächen wurden ebenfalls vor und während der Arbeitsschritte wiederholt durch Reinigung mit Wasser und Extran-Lösung gesäubert.

Eintrag von kontaminierender Rezent-DNA durch Laboreinwegmaterialien und Laborgeräte in PCR-Ansätze (Schmidt et al. 1995; Hauswirth et al. 1994). Um Kontaminationen dieser Art vorzubeugen, wurden sämtliche Probenbehältnisse und Einwegmaterialien, die bei der Durchführung der Extraktionen und Amplifikationen verwendet wurden, für eine Dauer mit UV-Licht bei $\lambda=254 \mathrm{~nm}$ bestrahlt ( $30 \mathrm{~W}, 30 \mathrm{~min}, 5 \mathrm{~cm}$ Abstand). Sämtliche Laborgerätschaften wurden einer Reinigung in einer Extranlösung mit einer anschließenden Säurebehandlung unterzogen.

\subsubsection{Authentifizierung der Ergebnisse - Individualisierbarkeit und Reproduktion}

Auch bei strikter Einhaltung des im vorangehenden Kapitel angeführten Maßnahmenkatalogs ist eine vollständige Vermeidung des Eintrags von 
Kontaminationen nicht zu erreichen. Besonders für den Aspekt der herstellerseitigen Verunreinigung der PCR-Gefäße lassen sich kaum befriedigende Lösungen finden. Stichprobenweise wurden in den einzelnen PCR-Läufen ein bis zwei No-Template Kontrollen mitgeführt. Diese Leerkontrollen beinhalten sämtliche Komponenten des Reaktionsansatzes, werden jedoch ohne Zugabe von DNA dem PCR-Vorgang unterzogen. Diese Kontrollen können aber nur der Überprüfung der Reaktionschemikalien und der für die Kontrollproben verwendeten Reaktionsgefäße dienen, sind jedoch nicht geeignet, etwaige Kontamination der Proben durch die verschiedenen Bearbeiter zu überprüfen (Kolman \& Tuross 2000). Deswegen kommt der Authentifizierung der Ergebnisse mit Hilfe des Versuchsdesigns eine besondere Bedeutung zu. Es gilt, genetische Marker zu finden, die in der Lage sind, zwischen den historischen Proben und jeglicher potentieller moderner Kontamination zu diskriminieren. Diese Voraussetzung ist bei der mitochondrialen DNA-Analyse von historischen Neuwelt-Populationen relativ leicht erfüllt, da deren polymorphe Sequenzen sich deutlich von europäischen Populationen unterscheiden, so daß Kontaminationen etwa durch Bearbeiter einfacher festzustellen sind. Diese Situation ist jedoch atypisch für Analysen an menschlicher aDNA, da meist die jeweilige historische Population und die als putative Kontaminationsquelle geltende moderne Population, aus der die Bearbeiter stammen, weitestgehend genetisch identisch sind.

Es müssen deswegen Loci gewählt werden, die aufgrund ihrer hohen Variabilität innerhalb der Bevölkerung zu individualisierbaren Ergebnissen führen. Handelt es sich dabei um authentische Allelergebnisse des Individuums, so sollten diese in weiteren Analysegängen reproduziert werden können. Treten nicht-reproduzierbare Ergebnisse auf, was auf Kontaminationen schließen läßt, kann anhand des ermittelten Genotyps der Kontaminationsverursacher unter Umständen zurückverfolgt werden. Weiterführend sollten diese polymorphen Loci in einer Multiplex-PCR kombiniert werden, was bedeutet, daß mehrere Systeme gleichzeitig in einer einzigen Reaktion amplifiziert werden. Je mehr Loci untersucht werden, desto höher wird der sogenannte Diskriminationsindex (DI). Dieser Wert gibt die Wahrscheinlichkeit an, mit der zwei Individuen, die zufällig aus einer Population ausgewählt wurden, übereinstimmende Genotypen aufweisen (Jones 1972). Der DI ergibt sich aus 1-pM, wobei pM die Matching Probability darstellt. Für die Berechung des pM-Wertes 
werden die jeweiligen Allel-Frequenzen verwendet. Bei der Analyse mehrerer Loci kann die kombinierte Matching Probability durch einfache Multiplikation der Einzelwerte ermittelt werden. Durch die Verknüpfung nur weniger polymorpher STR-Loci läßt sich bereits eine an Individualisierung heranreichende Zuordnungswahrscheinlichkeit erreichen. Durch die Analyse mehrerer polymorpher STR-Systeme ist damit die Erstellung eines individual-spezifischen Fingerprints gegeben. Darin liegt die Möglichkeit zur Selbstkontrolle der Experimente hinsichtlich etwaig auftretender Kontaminationen und zur letztlichen Authentizitätsabklärung der Ergebnisse (Hummel et al. 2000).

Bei der Analyse degradierter DNA aus historischem Skelettmaterial läßt sich in der Regel aus einer einzigen Amplifikation nicht das vollständige genetische Profil des beprobten Individuums erheben. Allein die Kombination der Ergebnisse mehrerer PCRs erlaubt die Erstellung des charakteristischen Allelprofils. Gleichzeitig kann verhindert werden, daß vermeintliche Allele typisiert werden, die lediglich auf einmaligen Artefaktbildungen während der PCR beruhen. Dazu gehören unter anderem die sogenannten „stutter bands" oder "shadow bands“, die zuerst von Hauge \& Litt (1993) beschrieben wurden. Hierbei werden während der PCRAmplifikation Banden gebildet, die eine Repeateinheit kürzer, in selteneren Fällen auch eine Einheit länger, als das eigentliche authentische Allel sind. Als Ursache für diese Stotterbanden wird der ,slipped strand“" Mechanismus angenommen (Hite et al. 1996; Kimpton et al. 1993). Hierbei kommt es durch partielle Denaturierung des Primer-Template-Komplexes während des Elongationsschrittes der PCR zu einem Verrutschen des Templates relativ zum neu-synthetisierten Strang. In der Regel weisen Stotterbanden eine deutlich schwächere Signalintensität auf als die Produkte der Originalallele (Lygo et al. 1994; Urquhart et al. 1995), so daß sie leicht zu identifizieren sind. Bei der Analyse degradierter DNA ist jedoch oft zu beobachten, daß Stotterprodukte in gleicher Menge wie die eigentlichen Allelfragmente entstehen, bzw. diese hinsichtlich der Quantität sogar übertreffen (Odelberg \& White 1993) und folglich nicht von vornherein als Artefakte erkannt werden können. Stotterartefakte treten nach Clayton et al. (1998) vor allem bei der gleichzeitigen Amplifikation mehrerer STR-Systeme in Multiplexansätzen auf. Ein weiteres 
bekanntes Problem bei der Analyse alter DNA, das bei nur einmaliger Amplifizierung zu Fehltypisierungen führen kann, ist der Ausfall eines Allels (,allelic dropout“) (Kimpton et al. 1993; etc). Bei Nicht-Wiederholung der Reaktion kann so fälschlicherweise ein homozygotes Ergebnis angenommen werden.

Einige Autoren empfehlen dringend, die Analysen in einem zweiten unabhängigen Labor zu wiederholen, um so vor allem bei menschlichen Proben eine Reproduktion und somit Bestätigung der Ergebnisse zu erhalten (Krings et al. 1997; Cooper \& Poinar 2000; Hofreiter et al. 2001). Durch diese Vorgehensweise läßt sich jedoch nur überprüfen, ob die Ergebnisse lediglich auf systematischen, laborinternen Kontaminationen beruhen. Dies kann jedoch ebenfalls erreicht werden, wenn die Einzel-Ergebnisse jeder PCR jeweils miteinander und mit den genetischen Profilen der Labormitarbeiter verglichen werden. Andere Kontaminationseinträge, die das Ergebnis ebenfalls verfälschen, lassen sich durch Reproduktionen in einem zweiten Labor nicht besser nachweisen als es eine Wiederholung im selben Labor auch gewährleistet. So lassen sich durch den Abgleich jedes Einzel-Ergebnisses der Multiplex-Reaktionen mit allen anderen Proben-Resultaten zum einen Kreuzkontaminationen detektieren und zum anderen durch einem Vergleich mit den Fingerprints der Labormitarbeiter Kontaminationen durch den Eintrag moderner Bearbeiter-DNA detektieren (Hummel et al. 2000; Bramanti et al. 2000a). Die wiederholte Durchführung von Multiplex-Reaktionen garantiert darüber hinaus die Aufdeckung von zufälligen, unspezifischen Kontaminationen (z.B. durch werkseitige Kontaminationen der Einwegmaterialien, (Schmidt et al. 1995), da diese Ergebnisse nicht reproduzierbar sind. Nur Ergebnisse, die durch mehrere PCR-Ergebnisse, die auf der Amplifikation von mindestens zwei unterschiedlichen Extraktionen beruhen, können als authentisch angesehen werden. Um die Einhaltung der Laborstandards zu überprüfen, beteiligt sich das Labor jährlich an den deutschen Ringversuchen der Europäischen DNA Profiling Gruppe (EDNAP). 


\subsection{Autosomale STR-Systeme}

\subsubsection{Multiplex-Ansatz}

Um einen großen Durchsatz an Proben möglichst effizient zu bearbeiten, wurde in der forensischen Analytik die Entwicklung von Multiplex-PCR Systemen vorangetrieben. So existieren neben dem AmpF/Profiler Plus Kit, der neun STRSysteme beinhaltet, weitere Kits, wie das PowerPlex16 System (Promega Cooperation) und der AmpFlSTR Identifiler (Applied Biosytems), die 15 STRs und das Amelogenin System in einer einzigen Reaktion amplifizieren (Finis 2001). Vorteile dieser Kits liegen in der erhöhten Effizienz, dem verminderten Probenverbrauch, der Verringerung des Proben-Handlings und der damit verbundenen Reduktion von Laborfehlern.

Zur Generierung des individual-spezifischen genetischen Fingerprints wurde der AmpFlSTR Profiler Plus PCR Amplification Kit (PE Applied Biosystems) verwendet, der in einer Reaktion neun verschiedene STR-Systeme und das geschlechtsanzeigende Amelogenin-System amplifiziert und in zahlreichen forensischen und populationsgenetischen validiert wurde (Anslinger et al. 2001a; Neuhuber et al. 1999; Han et al. 2000, Lederer et al. 2001; Gusmao et al. 2000). Darüber hinaus hat sich die Anwendung des Profiler Kits schon in mehreren Studien an (prä)historischem Skelettmaterial hervorragend bewährt (Bramanti et al. 2000a; Hummel et al. 2000; Schultes 2000).

\subsubsection{Charakteristika der STR-Systeme}

Die im AmpFlSTR Profiler Plus Kit vorhandenen STR-Systeme erfüllen die folgenden, für populationsgenetische Studien wie auch für die forensische Anwendung relevanten Charakteristika:

- Geringe Länge der Allele: Das größte Profiler-STR-System weist eine maximale Allel-Länge von $341 \mathrm{bp}$ auf, was der Analyse degradierter DNA entgegenkommt. Der begrenzte Allelumfang pro System reduziert allelicdropout Ereignisse, was durch präferentielle Amplifizierung der jeweiligen kürzeren Allele hervorgerufen werden kann (Clayton et al. 1998). 
- $\quad$ Hohe Heterozygotenrate in der Bevölkerung (>70\%).

- Hoher Diskriminierungsindex (DI) (Jones 1972). In Verbindung mit der Heterozygotenrate determiniert sich hierdurch die Wertigkeit eines Merkmalsystems. So läßt sich für jedes System die Matching Probability (pM) berechnen, womit die Wahrscheinlichkeit angegeben wird, daß zwei nichtverwandte Individuen in dem untersuchten System die gleichen Merkmale aufweisen. Der Wert errechnet sich aus der Summe der quadrierten Häufigkeiten der in dem System gegebenen Phänotypen. Der pM-Wert sollte möglichst niedrig sein $(<0,1)$ (Gill et al. 1996). Der DI ergibt sich aus 1-pMgesamt.

- Die verwendeten Loci liegen auf verschiedenen Chromosomen, um die stochastische Unabhängigkeit zu gewährleisten.

- Die Kernmotive der Systeme sind Tetranukleotidrepeats. Diese sind im Gegensatz zu Dinukleotidrepeats weniger anfällig für das Phänomen des Polymerase-Slippage während der Amplifikation, so daß das Auftreten von Stotterartefakten vermindert wird.

Tabelle 3.1: Informationen über die Systeme des AmpFlSTR Profiler Plus PCR Amplification Kits.

\begin{tabular}{|c|c|c|c|c|c|c|}
\hline Locus & $\begin{array}{l}\text { Längen- } \\
\text { bereich } \\
\text { [bp] }\end{array}$ & $\begin{array}{l}\text { Dye- } \\
\text { Label }\end{array}$ & $\begin{array}{l}\text { Anzahl } \\
\text { Allele* }\end{array}$ & $\begin{array}{c}\text { Diskriminanz- } \\
\text { stärke** }\end{array}$ & $\begin{array}{l}\text { Beobachtete } \\
\text { Heterozygoten } \\
\text {-rate }\left[\mathbf{H}_{\text {obs }}\right]^{* *}\end{array}$ & $\begin{array}{c}\text { Erwartete } \\
\text { Heterozygoten } \\
\text {-rate }\left[\mathbf{H}_{\mathrm{exp}}\right]^{* *}\end{array}$ \\
\hline D3S1358 & $114-142$ & 5-FAM & 8 & 0,91 & 0,79 & 0,78 \\
\hline VWA & 157-197 & 5-FAM & 11 & \multirow{2}{*}{0,94} & 0,74 & 0,82 \\
\hline FGA & 219-267 & 5-FAM & 14 & & 0,87 & 0,87 \\
\hline D8S1179 & $128-168$ & JOE & 12 & 0,96 & 0,84 & 0,79 \\
\hline D21S11 & $189-243$ & JOE & 22 & \multirow{2}{*}{0,92} & 0,88 & 0,84 \\
\hline D18S51 & $247-255$ & JOE & 22 & & 0,88 & 0,88 \\
\hline D5S818 & 273-341 & NED & 10 & 0,95 & 0,68 & 0,71 \\
\hline D13S317 & $206-234$ & NED & 8 & \multirow{2}{*}{0,97} & 0,74 & 0,77 \\
\hline D7S820 & 258-294 & NED & 10 & & 0,83 & 0,81 \\
\hline Amelo. & 106,112 & JOE & $X, Y$ & 0,86 & - & - \\
\hline
\end{tabular}

*Angaben sind dem AmpFlSTR Profiler Plus PCR Amplification Kit Manual entnommen. **Angaben entstammen Studien an einer rezenten bayerischen Populationsstichprobe (Anslinger et al. 2001a).

Die kombinierte Matching Probability liegt bei ca. $1 \times 10^{-11}$. 


\subsection{Amelogenin-System}

Die molekulare Geschlechtsbestimmung wird durch die Amplifikation eines Abschnitts des auf den Geschlechtschromosomen lokalisierten Amelogenin-Gens vorgenommen. Vermehrt wird dabei eine single-copy Sequenz aus dem ersten Intron des Gens, die einen Längenpolymorphismus zwischen den Geschlechtschromosomen aufweist (Sullivan et al. 1993). Während die Sequenz auf dem Y-Chromosom 112 Basenpaare aufweist, umfaßt die Sequenz auf dem X-Chromosom aufgrund einer 6 bp Deletion nur 106 Basenpaare. Eine Geschlechtsdiagnose unter Verwendung des oben beschriebenen Primerpaares erlaubt dementsprechend sowohl den positiven Nachweis für das weibliche, als auch für das männliche Geschlecht. Das Amelogenin-System ist Bestandteil des AmpFlSTR Profiler Plus Kits.

\subsection{Y-chromosomale STR-Systeme}

Bei den Y-chromosomalen STR-Systemen handelt es sich um Mikrosatelliten, die in ihrer Struktur den autosomalen STRs gleichen (Caglia et al. 1998). Durch die Lokalisation in der nicht-pseudoautosomalen Region des Y-Chromosoms sind die Sequenzen von der Rekombination ausgeschlossen und werden daher im Prinzip unverändert als Haplotypen weitervererbt. Die Analyse von Y-STRs ist nicht nur in der Forensik, z.B. bei Vaterschaftstests, ein wertvolles Analysewerkzeug. Aufgrund ihres haploiden Zustandes und der ausschließlichen Vererbung über paternale Linien können Y-Haplotypen auch bei Studien hilfreich sein, die sich mit evolutionären oder populationshistorischen Fragestellungen beschäftigen (Zerjal et al. 1997; Sajantila et al. 1996; Ritte et al. 1993; Salem et al. 1996).

Im Gegensatz zu den autosomalen STRs ist eine Individualisierung einer Probe durch die Analyse von Y-Haplotypen nicht möglich. Sämtliche Individuen, die Mitglieder einer Patrilinie sind, weisen denselben Haplotypen auf. Zudem ist die Variabilität der Y-chromosomalen STRs aufgrund der fehlenden Rekombinationsvorgänge und der im Gegensatz zu den autosomalen Chromosomen geringen Anzahl begrenzt (Jobling \& Tyler-Smith 1995). Dies führt dazu, daß auch nicht-verwandte Individuen durchaus dengleichen Haplotypen aufweisen können. Wie auch im Fall der autosomalen STRs kann hier ein Höchstmaß an Unterscheidung erreicht werden, 
indem mehrere Marker mit ausreichender Diskriminanzstärke gleichzeitig untersucht wurden.

Folgende vier Tetranukleotid-STR-Systeme, für die bereits forensische Validierungsstudien vorliegen, wurden für die Untersuchungen in einer MultiplexPCR kombiniert:

\section{DYS19}

Die verwendeten Primer weisen folgende Sequenzen auf (Roewer et al. 1996):

Primer A: $\quad$ 5' - CTACTGAGTTTCTGTTATAGT- 3'

Primer B: $\quad$ 5'- ATGGCATGTAGTGAGGACA- 3'

Der Primer A ist am 5' - Ende mit dem Farbstoff 6-FAM markiert.

Die insgesamt zehn nachgewiesenen Allele sind in Tabelle 3.2 aufgeführt.

Tabelle 3.2: Allele des Locus DYS19 (Kayser et al. 1997; de Knijff et al. 1997) und Allelfrequenzen (Daten basieren auf den Untersuchungen einer bayerischen Populationsstichprobe (Anslinger et al. 2000)).

\begin{tabular}{ccc}
\hline $\begin{array}{c}\text { Allel } \\
\text { (Anzahl der Repeateinheiten) }\end{array}$ & $\begin{array}{c}\text { Fragmentlänge } \\
{[\mathrm{bp}]}\end{array}$ & Allelfrequenzen \\
\hline 10 & 174 & 0.000 \\
11 & 178 & 0.000 \\
12 & 182 & 0.000 \\
13 & 186 & 0.059 \\
14 & 190 & 0.549 \\
15 & 194 & 0.185 \\
16 & 198 & 0.132 \\
17 & 202 & 0.079 \\
18 & 206 & 0.000 \\
19 & 210 & 0.000 \\
\hline
\end{tabular}

\section{DYS390}

Die Primersequenzen lauten nach Kayser et al. (1997):

Primer A: 5' - TATATTTTACACATTTTTGGGCC - 3'

Primer B: $\quad$ 5'- TGACAGTAAAATGAACACATTGC - 3'

Der Primer A ist am 5 '- Ende zu Detektionszwecken mit dem Fluoreszenzfarbstoff HEX markiert. 
Die nachgewiesenen zehn Allele sind in Tabelle 3.3 aufgeführt.

Tabelle 3.3: Allele des Locus DYS390 (Kayser et al. 1997; de Knijff et al. 1997) und Allelfrequenzen (Daten basieren auf den Untersuchungen einer bayerischen Populationsstichprobe (Anslinger et al. 2000)).

\begin{tabular}{ccc}
\hline $\begin{array}{c}\text { Allel } \\
\text { (Anzahl der Repeateinheiten) }\end{array}$ & $\begin{array}{c}\text { Fragmentlänge } \\
{[\mathrm{bp}]}\end{array}$ & Allelfrequenzen \\
\hline 18 & 191 & 0.000 \\
19 & 195 & 0.000 \\
20 & 199 & 0.000 \\
21 & 203 & 0.000 \\
22 & 207 & 0.145 \\
23 & 211 & 0.284 \\
24 & 215 & 0.317 \\
25 & 219 & 0.205 \\
26 & 223 & 0.006 \\
27 & 227 & 0.000 \\
\hline
\end{tabular}

\section{DYS389I/II}

Der Vorteil dieses Systems liegt darin, daß durch die Verwendung nur eines Primers zwei STR-Systeme amplifiziert werden können, die, da sie unabhängig voneinander mutieren, als zwei unabhängige Y-STR-Systeme betrachtet werden können. Bei der Amplifikation werden zwei Produkte verschiedener Größe (DYS389I und DYS389II) generiert, was darin begründet liegt, daß die Annealstelle des ForwardPrimers und der folgende STR-Abschnitt dupliziert vorliegen, während die Primersite des Backward-Primers nur einmal vorkommt. Als Folge werden zwei Produkte gebildet, von denen das längere zwei STR-Bereiche enthält, das kürzere nur einen (Kayser et al. 1997).

Der Primer A entspricht der bei Kayser et al. (1997) und de Knijff et al. (1997) veröffentlichten Sequenz. Der untere Primer ist modifiziert, woraus eine Produktverkürzung um 94 bp resultiert. Hiermit wird die Amplifikation degradierter DNA gewährleistet (Schultes et al. 1999).

Primer A: $\quad$ 5' - CCAACTCTCATCTGTATTATCTAT - 3'

Primer B: $\quad$ 5' - TTATCCCTGAGTAGTAGAAGAAT - 3'

Der Primer A ist zu Detektionszwecken am 5'- Ende mit dem Farbstoff HEX markiert. 
Tabelle 3.4: Allele des Locus DYS389I/II und Allelfrequenzen (Daten basieren auf den Untersuchungen einer bayerischen Populationsstichprobe (Anslinger et al. 2000)). Die Angaben zur Fragmentlänge entsprechen den Daten bei Kayser et al. (1997), sind jedoch um jeweils 94 bp verkürzt (Schultes et al. 1999).

\begin{tabular}{ccc}
\hline $\begin{array}{c}\text { Allel } \\
\text { (Anzahl der Repeateinheiten) }\end{array}$ & $\begin{array}{c}\text { Fragmentlänge } \\
{[\mathrm{bp}]}\end{array}$ & Allelfrequenzen \\
\hline System DYS389I & 145 & \\
10 & 149 & 0.000 \\
11 & 153 & 0.000 \\
12 & 157 & 0.211 \\
13 & 161 & 0.708 \\
14 & 165 & 0.070 \\
15 & 169 & 0.000 \\
16 & & 0.000 \\
System DYS389II & 261 & \\
26 & 265 & 0.000 \\
27 & 269 & 0.000 \\
28 & 273 & 0.165 \\
29 & 277 & 0.456 \\
30 & 281 & 0.238 \\
31 & 285 & 0.125 \\
32 & 289 & 0.000 \\
33 & 293 & 0.000 \\
34 & & 0.000 \\
\hline
\end{tabular}

\subsection{PCR-Parameter}

\subsubsection{AmpFISTR Profiler Plus PCR Amplification Kit}

Die PCR wurde in einem $25 \mu 1$ Ansatz durchgeführt, der $10 \mu 1$ AmpFlSTR PCR Reaction Mix ${ }^{\mathrm{TM}}, 5 \mu \mathrm{A}$ AmpFlSTR Profiler Plus Primer Set ${ }^{\mathrm{TM}}$ und 2.5 U AmpliTaq Gold $^{\mathrm{TM}}$ enthielt. Der Einsatz des DNA-Extrakts variierte zwischen $10 \mu \mathrm{lbzw} .5 \mu 1$ DNA-Extrakt, wobei das Endvolumen durch Auffüllen mit der entsprechenden Menge Ampuwa ${ }^{\circledR}$ (Fresenius) erreicht wurde.

Cyclebedingungen: $11 \mathrm{~min} 30 \mathrm{sec}$ bei $94^{\circ} \mathrm{C}$ (Aktivierung der hitzeinduzierten TaqPolymerase AmpliTaq Gold ${ }^{\mathrm{TM}}$ ), $94^{\circ} \mathrm{C} 1 \mathrm{~min}, 59^{\circ} \mathrm{C} 1 \mathrm{~min}, 72^{\circ} \mathrm{C} 1 \mathrm{~min}, 45$ Zyklen und abschließende $45 \mathrm{~min}$ bei $60^{\circ} \mathrm{C}$.

\subsubsection{Y-STR-Systeme: Quadruplex-PCR}

$50 \mathrm{mM} \mathrm{KCl}, 10 \mathrm{mM}$ Tris- $\mathrm{HCl}, 2.0 \mathrm{mM} \mathrm{MgCl} 2,175 \mu \mathrm{M}$ dNTPs, je $0,1 \mu \mathrm{M}$ Primer DYS19, DYS390 und DYS389I/II, $6 \mu \mathrm{l}$ aDNA Extrakt, 2.5 U AmpliTaqGold ${ }^{\mathrm{TM}}$ Polymerase. 
Cyclebedingungen: $11 \mathrm{~min} 30 \mathrm{sec}$ bei $94^{\circ} \mathrm{C}$ (Aktivierung der hitzeinduzierten TaqPolymerase AmpliTaq Gold ${ }^{\mathrm{TM}}$ ) 55 Zyklen: $94^{\circ} \mathrm{C} 1 \mathrm{~min}, 51^{\circ} \mathrm{C} 1 \mathrm{~min}, 72^{\circ} \mathrm{C} 1 \mathrm{~min}$

\subsection{Elektrophorese}

\subsubsection{Agarose-Gelelektrophorese}

Wegen ihrer geringen Trennschärfe ist die Agarose-Gelelektrophorese ungeeignet für eine STR-Alleldetermination. Eine Auftrennung von PCR-Produkten auf Agarosegelen dient lediglich der Überprüfung des Amplifikationserfolges. Des weiteren läßt sich anhand der Bandensignalstärken im Agarosegel eine Abschätzung über die in die Polyacrylamid-Gelektrophorese (PAGE) einzusetzende Menge an PCR-Produkt vornehmen.

Die elektrophoretische Auftrennung der PCR-Produkte auf Agarosegelen erfolgte analog der Auftrennung der DNA-Extrakte (vgl. 3.2.3).

\subsubsection{Denaturierende Polyacrylamid-Gelektrophorese (PAGE)}

Um eine Alleldetermination durchführen zu können, erfolgte eine Auftrennung der Amplifikationsprodukte durch eine Polyacrylamid-Gelelektrophorese. Die hohe Trennschärfe dieser Auftrennungsmethode ermöglicht die bei STR-Analysen unabdingbare exakte Fragmentlängenbestimmung der PCR-Produkte. Verwendet wurden 6\% denaturierende (8 M Urea) Polyacrylamidgele, die folgende Zusammensetzung besaßen:

$15 \mathrm{~g} \quad$ Urea

4,5 ml Acrylamidlösung (40\%ige Lösung aus Acrylamid, Bisacrylamid 29:1)

$3 \mathrm{ml}$ 10x TBE-Puffer $(900 \mathrm{mM}$ Tris, $\mathrm{pH}=8.3$; $900 \mathrm{mM}$ Borsäure, $25 \mathrm{mM}$ EDTA)

$12 \mathrm{ml}$ Aqua bidest

Nach Lösung der Urea folgte eine Vakuumfiltration durch einen Filter der Porengröße 0,2 $\mu \mathrm{m}$. Die Lösung wurde mit $90 \mu \mathrm{l}$ APS (10\%ige (w/v) Lösung) und $12 \mu 1$ TEMED versetzt und anschließend zwischen zwei fluoreszenzfreie Glasplatten 
gegossen. Nach einer ca. zweistündigen Polymerisierungszeit war das Gel verwendungsbereit.

Für die Analyse wurden 0,25 $\mu \mathrm{l}$ Längenstandard $\operatorname{GS} 350$ ROX ( 2 fmol), $2 \mu \mathrm{l}$ Formamid und 0,5 $\mu$ Ladepuffer (50 mg/ml Dextran blau, $25 \mathrm{mM}$ EDTA) mit einem Aliquot des zu untersuchenden PCR-Produkts versetzt. Die einzusetzende Produktmenge richtete sich nach der Signalstärke der produktspezifischen Banden im Agarosegel und lag zwischen $0,1-1,5 \mu$. Die Ansätze wurden für 2 min bei $94^{\circ} \mathrm{C}$ denaturiert und bis zum Beladen des Gels auf Eis gelagert.

Die PCR-Produkte wurden für $3 \mathrm{~h}$ bei $30 \mathrm{~W}$ in einem 373A stretch Sequenzer (Applied Biosystems) elektrophoretisch aufgetrennt Die Laufstrecke betrug $12 \mathrm{~cm}$. Als Elektrodenpuffer diente 1×TBE Puffer (90 mM Tris, pH 8.3; 90 mM Borsäure; 2,5 mM EDTA).

\subsection{Fragmentlängendetektion}

Zur Aufnahme der Rohdaten tastet ein Argonlaser das Gel senkrecht zur Laufrichtung ab. Den Detektionsbereich des Lasers passierende DNA-Fragmente werden zur Aussendung einer charakteristischen Fluoreszenzstrahlung angeregt, welche nach Fokussierung durch eine Linse ein aus vier verschiedenen Filtern bestehendes Filterrad passiert. Ein Photomultiplier wandelt das Signal nach Messung der Intensität in ein digitales Signal um, und überträgt es auf einen Computer (Quadra 650, Apple Computer Inc.), der die Daten mit Hilfe der Software (672 GENESCAN-Collection [Applied Biosystems]) verarbeitet.

Die Weiterverarbeitung der Daten erfolgte durch die Software 672 GENESCAN ${ }^{\top M}$-Analysis 2.0.2, die, gemäß den zuvor vom Anwender festgestellten Parametern, eine Fragmentlängenbestimmung durchführt.

Bei den Parametern handelt es sich um Angaben bezüglich des verwendeten Geltyps, der Trennstrecke und der gewählten Methode zur Berechnung der Fragmentlängen. Des weiteren muß die Untergrenze der in die Berechnung eingehenden Fluoreszenzintensitäten festgelegt werden. 
Die Längenbestimmung der DNA-Fragmente erfolgt mit Hilfe des spurinternen Standards GS350 ROX unter Verwendung der Local Southern Methode (Elder \& Southern 1987). Hierbei wird die reziproke Beziehung zwischen Länge und Mobilität eines Fragments ausgenutzt. Eine Gruppe von jeweils drei Standardfragmenten bekannter Länge, die sich in der Nachbarschaft des zu determinierenden Fragments befinden, werden zur Generierung einer Kalibrierungskurve herangezogen. Aus den gemittelten Werten ergibt sich dann die Größe der zu berechnenden Bande.

Die GENESCAN Software erlaubt die Darstellung der Ergebnisse in Form eines Gelbildes, einer Datenliste und durch ein Elektropherogramm. Letzteres stellt die im Gelbild als Banden erscheinenden Fragmente als Kurvenerhebung (Peak) dar. Deren Höhe, angegeben in dimensionslosen Fluoreszenzeinheiten, korreliert mit der Intensität der Banden, wodurch Rückschlüße auf das relative Mengenverhältnis der amplifizierten Fragmente zu ziehen sind (Clayton et al. 1998). Jede Spur und somit jede Probe ist einzeln darstellbar, möglich ist aber auch die gemeinsame Projektion von mehreren Spuren in einem Elektropherogramm (Ziegle et al. 1992).

\subsubsection{Allelleitern}

Grundsätzlich wird durch die oben beschriebene Methode die direkte Längenbestimmung eines Fragments möglich, indem die Basenpaaranzahl, basierend auf den Fragmentlängen des spurinternen Standards, mit Hilfe der Local Southern Methode errechnet wird. Aufgrund von Unterschieden in der Gelzusammensetzung können im Inter-Gelvergleich z.T. erhebliche Unterschiede in den Längenangaben von Produkten derselben Probe auftreten, so daß die ermittelten Fragmentgrößen nicht direkt zur Bezeichnung der Allele herangezogen werden können (Fregeau \& Fourney 1993; Kimpton et al. 1993; Ziegle et al. 1992; Lygo et al. 1994).

Zur eindeutigen Alleldetermination werden daher allelische Leitern verwendet. Hierbei handelte es sich um Vergleichsstandards, erstellt aus den in einer Population vorkommenden Allelen des jeweiligen Polymorphismus. Im verwendeten AmpFlSTR Profiler Plus Kit werden Allelleitern aller Systeme bereitgestellt. Durch Übereinanderlegen einer Probenspur und des Elektropherogramms der Allelleitern können, die Allele der Probe zweifelsfrei bestimmt werden. 
Für die Determinierung der Ychromosomalen Allele wurden für jedes System Allelleitern angefertigt, wobei die DNA mehrerer Individuen bekannten Genotyps gepoolt wurde. Zur vorbehaltlosen Bestimmung eines Allels sollte der Unterschied zwischen Probenfragment und Allelleiter nicht größer als 0,5 bp sein (Smith 1995).

\subsubsection{Alleldetermination}

Die eindeutige Identifikation von Allelen wird zum Teil durch das Auftreten von Artefaktprodukten erschwert. Zu diesen Phänomenen zählen bei der Amplifikation von alter und damit degradierter DNA vor allem die Stotterereignisse und das Auftreten von allelic dropouts, welche bereits in Abschnitt 3.2.1.3 beschrieben wurde. Aufgrund der Beobachtung, daß bei der Amplifikation von degradierter DNA Stotterprodukte entstehen können, die die eigentlichen Allelfragmente hinsichtlich der Quantität sogar übertreffen (Odelberg \& White 1993), darf bei der Auswertung also nicht automatisch das Kriterium gelten, lediglich die zwei höchsten Peaks des Elektropherogramms als authentische Probenallele anzunehmen, da es so zu einer falschen Alleltypdetermination kommen kann.

Bei der Bestimmung des Alleltyps einer Probe wurde deswegen ein von Schultes (1997) entwickeltes Auswertungsverfahren angewendet, das den aufgeführten speziellen Amplifikationseigenschaften von aDNA und dem Auftreten von sporadischen Kontaminationen Rechnung trägt. Durch die Standardisierung der Auswertungskriterien und durch die Festlegung von Richtwerten wird eine objektive Analyse der Ergebnisse ermöglicht.

Wichtig ist die Unterscheidung zwischen der Einzelbestimmung, die die Auswertung einer Amplifikation umfaßt und der abschließenden Bestimmung des Genotyps der Probe, in die die Ergebnisse aller Amplifikationen einfließen.

In den Einzelbestimmungen gilt es abzuwägen, welche der auftretenden Produktpeaks die authentischen Allele darstellen und welche Peaks lediglich das Resultat von Artefaktereignissen sind. Prinzipiell werden dabei die höchsten Allelpeaks als authentische Allele angenommen. Alle weiteren Peaks, die im Elektropherogramm eine geringere Höhe aufweisen, fließen entweder als unsichere Allele in die Einzelbestimmung mit ein (Ergebnis wird dabei in Klammern 
angegeben) oder werden als Artefaktprodukte sofort ausgeschlossen. Die aufgestellten Entscheidungskriterien beruhen auf den Studien zur Entstehung von Stotterbanden, die zum einen besagen, daß ein Slippage-Ereignis statistisch seltener auftreten sollte als die fehlerlose Synthese eines Tochterstranges (Lygo et al. 1994; Hite et al. 1996) und im weiteren, daß Stotterprodukte meist kürzer sind, als das mit ihnen assoziierte tatsächliche Allel (Hite et al. 1996; Walsh et al. 1996). Dementsprechend gelten folgende Einteilungen:

- Als Allelsignale werden die Peaks aufgenommen, die innerhalb der direkt an sie angrenzenden Bereiche von einer Wiederholungseinheit die stärksten Signalintensitäten aufweisen.

- Peaks, die diesen Allelsignalen vorangehen und um die Hälfte kleiner als diese sind, werden als Artefaktsignale angesehen. Sind Peaks eine Repeateinheit länger als das Allelsignal, werden sie erst dann als Artefaktsignal angesehen, wenn sie nur $20 \%$ der Höhe des vorangehenden Allelsignals aufweisen.

○ Peaks, die aufgrund ihrer Größe keiner dieser Gruppen zuzuordnen sind, werden als unsichere Allelsignale bezeichnet.

Im Gegensatz zur Arbeit mit rezenter DNA ist bei der Analyse von aDNA eine einmalige Durchführung der Amplifikation nicht ausreichend. So sind aufgrund des allelic dropout Phänomens mindestens fünf Amplifikationen (Gagneux et al. 1997; Schmerer et al. 1997) notwendig, um ein falsch-homozygotes Ergebnis auszuschließen.

Aber auch angesichts der auftretenden Stotterbanden sind mehrere Einzelbestimmungen die Voraussetzung zur Bestimmung des Genotyps einer Probe. Bei der zusammenfassenden Betrachtung der Einzelbestimmungen bleiben Diskrepanzen zwischen den Ergebnissen nicht aus. Es muß deswegen von der Hypothese ausgegangen werden, daß die in den Einzelergebnissen am häufigsten bestimmten Allele auch den authentischen Allelen des untersuchten Individuums entsprechen (Burger 1997). Bevor ein Allel in die abschließende Genotypisierung aufgenommen wird, müssen folgende Bedingungen erfüllt sein: 
- Das Allel muß mindestens zweimal aus einer Einzelbestimmung als Allelsignal hervorgegangen sein. Dabei müssen die PCR-Ergebnisse aus zwei unabhängigen Extraktionen generiert worden sein. Bei Reproduktion aus nur einem Extrakt wird das Allel in Klammern aufgenommen.

- Ein homozygoter Genotyp wird nur dann angenommen, wenn in mindestens drei Amplifikationen ausschließlich das jeweilige Allel detektiert werden konnte.

○ In Fällen, in denen mehr als zwei Fragmente als potentielle Allele in Frage kommen, kann keine abschließende Genotypisierung durchgeführt werden. In diesem Fall werden die möglichen Allele in Klammern gestellt aufgeführt.

○ Einzelergebnisse, die lediglich in zwei - drei Systemen ein Ergebnis zeigen, wurden nicht in die Gesamtbestimmung miteinbezogen, selbst wenn die Ergebnisse scheinbar stimmig mit den weiteren Amplifikationsergebnissen waren. Diese Ergebnisse können unter Umständen auch das Resultat von sporadisch auftretenden Kontaminationen sein.

\subsubsection{Kontaminationsüberprüfung}

Jedes Einzelresultat wurde durch Anwendung des Programms „aDNA-Typing“ (MoReData) daraufhin überprüft, ob das Ergebnis möglicherweise auf der Amplifikation einer Kontamination basiert. Innerhalb dieses, speziell für diese Arbeit konzipierten Softwareprogramms, sind in einer Datenbank sowohl alle Fingerprints der Labormitarbeiter, sowie auch die für die Weingartener Individuen determinierten Allel-Profile gespeichert. Mit Hilfe dieses Programms lassen sich Übereinstimmungen zwischen zwei Datensätzen feststellen. Dabei ist es möglich, auch eine gewisse, frei wählbare Fehlertoleranz einberechnen zu lassen. Das Programm akzeptiert auch die Eingabe von unvollständigen Datensätzen.

Bei der Einzelüberprüfung wird ein Datensatz ausgewählt, dessen Allelkombination dann mit den gespeicherten Datensätzen auf etwaige Übereinstimmungen überprüft wird. So lassen sich zum einen mögliche Kreuzkontaminationen durch andere Proben, zum anderen etwaige Kontaminationen durch Rezent-DNA der Bearbeiter feststellen, womit verhindert wird, daß auf Kontaminationen beruhende Alleldaten als falsch-positive Ergebnisse in die Analyse miteinfließen. Sämtliche für die Weingartener Individuen determinierten Allelprofile wurden anhand des Programms auf die oben genannten Eintragsmöglichkeiten von Kontaminationen überprüft. 
In Fällen, in denen das Ergebnis einzelner Amplifikation eklatant von den restlichen Einzelresultaten abweicht, jedoch keine Übereinstimmung mit den in der Datenbank gespeicherten Allelprofil erhalten wird, kann davon ausgegangen werden, daß dieses Resultat zwar durch eine Kontamination hervorgerufen wurde, deren Urheber jedoch nicht festzustellen ist. Diese Ergebnisse gehen ebenfalls nicht in die Endauswertung ein.

\section{$3.9 \quad$ mt-DNA}

Die Analyse der mitochondrialen DNA eignet sich besonders für die Untersuchung alter DNA; im Gegensatz zum chromosomalen DNA-Satz, der pro Zelle zweimal vorhanden ist, liegt das mitochondriale Genom bis zu 500-2000 in der Zelle vor, was die Chancen erhöht, auch in degradierten Material noch mt-DNA zu finden ist. So hat die Untersuchung von mt-DNA den Zugang zu forensischen Fällen eröffnet (Holland et al. 1998; Anslinger et al. 2001b). Darüber hinaus beschäftigen sich jedoch auch die meisten Arbeiten, deren Untersuchungsobjekt (prä)historische DNASequenzen darstellen, mit der Analyse mitochondrialer DNA (Krings et al. 1997; Oota et al. 1995; Krings et al. 1997; Hauswirth et al. 1994). Die prinzipielle Limitation bei der Analyse von mt-DNA ist die nicht-gewährleistete definitive Identifizierungsmöglichkeit, die nur die Analyse autosomaler DNA bietet. Zum einen gleichen sich maternal verwandte Individuen, zum anderen ist die Individualisierbarkeit der mitochondrialen Sequenzen aufgrund der geringeren Variabilität mt-DNA-Abschnitte generell eingeschränkter. Die Wahrscheinlichkeit einer zufälligen Übereinstimmung zwischen zwei unverwandten Individuen ist relativ groß.

Die Kontrollregionen des Mitochondriums, der einzige nicht für Gene kodierende Abschnitt der mt-DNA, beinhaltet die beiden hypervariablen Regionen I und II, die zusammen insgesamt 610 bp umfassen (Parsons \& Coble 2001). Die Sequenzen dieser Regionen weisen hohe Variabilität innerhalb der Bevölkerung auf, was auf einer höheren Mutationsrate beruht, gegeben durch die Tatsache, daß die nichtkodierenden Regionen einem geringeren funktionalen Zwang unterliegen. Um 
Unterschiede zwischen Individuen festzustellen, werden deswegen stets Bereiche aus diesen Regionen untersucht.

Die Amplifizierung eines 610 bp langen Fragments ist bei der Untersuchung alter DNA meist nicht gegeben, da diese häufig in kleinere Abschnitte fragmentiert vorliegt. Mit der Einbeziehung einer größeren Region erhöht sich aber die Wahrscheinlichkeit, interindividuelle Unterschiede festzustellen. Für die Untersuchung eines möglichst langen Bereichs wurde im Rahmen einer weiteren Arbeit zur Typisierung alter DNA (Schultes 2000) eine Multiplex-Reaktion entwickelt, in der gleichzeitig drei Fragmente generiert werden, die einen Großteil (etwa zwei Drittel) der sequenzpolymorphismenreichen Region abdecken. Der Effekt der Zusammenfassung von Bereichen aus den hypervariablen Regionen I und II des Mitochondriums liegt in der Steigerung der Diskriminanzstärke. Im folgenden werden die Sequenzen der drei verwendeten Primerpaare vorgestellt (die Bezeichnungen geben die Position auf dem Mitochondrium des 3'-Endes des Primers an):

\section{Locus A:}

H16233: $\quad 5^{`}$ - ACA GCA ATC AAC CCT CAA CTA TCA - 3‘

L16317: $\quad$ 5` - TGT GCT ATG TAC GGT AAA TGG CTT - 3`

\section{Locus B:}

H16048: $\quad$ 5‘ - TTC ATG GGG AAG CAG ATT TGG - 3‘

L16173: $\quad$ 5‘ - ATG GGG AGG GGG TTT TGA TGT GG - 3‘

\section{Locus C:}

H149: $\quad 5^{\star}-$ CTG TCT TTG ATT CCT GCC TCA T $-3^{\star}$

L323: $\quad 5^{`}-$ AGA TGT GTT TAA GTG CTG TGG C - 3`

Die Primer amplifizieren Fragmente der Länge von 131 bp (A), 168 bp (B) und 217 bp (C). Bei besonders guter Erhaltung der untersuchten DNA wird noch ein viertes Fragment amplifiziert, das eine Länge von 312 bp (D) aufweist. Das 
letztgenannte Produkt entsteht durch die enge Nachbarschaft der Loci A und B und wird durch die Primer H16048 und L16317 amplifiziert. Zusätzlich zu den Sequenzen der Fragmente A und B wird hier ebenfalls der zwischen den Fragmenten liegende Bereich vervielfältigt.

\subsubsection{PCR-Parameter der mt-Amplifikation}

Amplifikationen erfolgten im $50 \mu$-Ansatz und enthielten: $10 \mathrm{mM}$ TRIS-HCl (GeneAmp 10xPCR Puffer II, PE Applied Biosystems), $2 \mathrm{mM} \mathrm{MgCl}_{2}, 175 \mu 1$ dNTPs, $0.14 \mu \mathrm{M}$ je Primer H16233 und L16317, $0.18 \mu \mathrm{M}$ je Primer H16048 und L16175, $0.22 \mu \mathrm{M}$ je Primer H149 und L323, 10 bzw. $5 \mu$ DNA-Extrakt, 2,5 U AmpliTaq Gold (PE Applied Biosystems).

Cyclebedingungen: Initialschritt von $11 \mathrm{~min}$ bei $94^{\circ} \mathrm{C}: 94^{\circ} \mathrm{C} 1 \mathrm{~min}, 56^{\circ} \mathrm{C} 1 \mathrm{~min}, 72^{\circ}$ 1 min für 45 Zyklen.

\subsubsection{Aufreinigung der PCR-Produkte}

Für einen Einsatz in die Sequenzierreaktion müssen die mitochondrialen DNAFragmente von den übrigen Komponenten des PCR-Reaktionsgemisches abgetrennt werden. Zur Aufreinigung wird dabei der QIAquick PCR Purification Kit (Qiagen) verwendet, der PCR-Produkte, die größer als $100 \mathrm{bp}$ sind, von überschüssigen Primern, Nukleotiden und der Polymerase trennt. Nach Versetzung des PCRAnsatzes mit $150 \mu \mathrm{l}$ Puffer wird die Probe auf die QIAquick Spinsäule aufgetragen. Hierbei bindet die DNA auf der Silikamembran; Oligonukleotide, die kürzer als $100 \mathrm{bp}$ sind (z.B. Primer), werden auf der Membran jedoch nicht gebunden. Nach Abzentrifugation des Überstandes folgte eine Waschung der DNA mit $750 \mu 1$ PEPuffer. Nach erneuter Zentrifugation wird der Überstand abermals verworfen. Die DNA wird schließlich mit HPLC-Wasser eluiert, wobei das Ausgangsvolumen des PCR-Produktes $(40 \mu 1)$ beibehalten wurde. 


\subsubsection{Sequenzierreaktion}

Die hier verwendete sogenannte Cycle-Sequencing Reaktion geht auf die Sequenzier-Methode nach Sanger zurück, die im wesentlichen auf der enzymatischen Kopierung des zu sequenzierenden DNA-Stranges mit einer DNA-Polymerase basiert (Sanger et al. 1977). Es werden die drei PCR-Temperaturschritte von Denaturierung, Annealing und Elongation durchgeführt. Da nur ein Strang generiert werden soll, wird die PCR nur mit einem der beiden Primer durchgeführt. Bei Verwendung des oberen Primers wird damit der obere Strang sequenziert (forward), beim unteren Primer entsprechend der komplementäre Strang (reverse).

Für die Sequenzierreaktion wurde der BigDye ${ }^{\mathrm{TM}}$ Kit (Applied Biosystems) verwendet. Das Reaktionsgemisch des Kits enthält neben Polymerase, Tris-HCL, $\mathrm{MgCl}$ und dNTPs auch fluoreszenzfarbstoffenmarkierte Didesoxynukleotide (ddNTPs), deren Einbau in den neu zu synthetisierenden DNA-Strang einen Kettenabbruch bewirkt. Bei der Elongation werden neben den unmarkierten dNTPs an zufälligen Positionen auch ddNTPs eingebaut, die eine weitere Extension des Stranges unterbinden. So entsteht während der Reaktion eine Population von teilweise aufsynthetisierten DNA-Molekülen, die in der Länge variieren und am 3'-Ende jeweils mit einem der vier farbmarkierten ddNTPs enden. Die so markierten DNA-Fragmente wurden mit einem Kapillar-Sequenzierer (Applied Biosystems) elektrophoretisch der Größe nach aufgetrennt, die markierten ddNTPs werden dabei von einem Laser detektiert. Da jede Base mit einem anderen Farbstoff markiert ist, kann diese Analyse in einem Reaktionsansatz durchgeführt werden.

\subsubsection{Cycle-Sequenzing Parameter}

Der Ansatz bestand aus $4 \mu \mathrm{l}$ BigDye $^{\mathrm{TM}}$ Ready Reaction Mix, 0,06 $\mu \mathrm{M}$ je Primer und 4-6 $\mu$ l PCR-Produkt (je nach Signalstärke der Produkte auf dem Agarosegel). Cyclebedingungen: $30 \sec 96^{\circ} \mathrm{C}, 15 \sec 58^{\circ} \mathrm{C}, 4 \min 60^{\circ} \mathrm{C}, 25$ Zyklen.

Die Produkte der Cycle-Sequenzing Reaktion werden durch die Zugabe von $50 \mu 1$ 95\% EtOH und $2 \mu 13 \mathrm{M} \mathrm{NaAc}(\mathrm{pH} 4,6)$ ausgefällt und zur Pelletierung zentrifugiert (14000U/min, $30 \mathrm{~min}$, Eppendorf Zentrifuge 5402). Das DNA-Pellet wurde anschließend mit 70\% EtOH gewaschen und erneut zentrifugiert (1400U/min, 
15 min, Eppendorf Zentrifuge 5402). Nach Trocknung wurde es tiefgefroren und erst vor dem Einsatz in das Sequenzier-Gerät in $10 \mu \mathrm{l}$ HPLC-Wasser aufgenommen. $4 \mu 1$ dieses Ansatzes wurden mit $16 \mu 1$ HPLC-Wasser versetzt und zur Sequenzierung in das Autosampler-Tray des Sequenzierers eingesetzt.

\subsubsection{Sequenzierung mit der Kapillar-Elektrophorese}

Bei der Kapillar-Elektrophorese (ABI Prism 310 Genetic Analyzer) dient eine mit Polymer (POP 6, Applied Biosystems) gefüllte Glaskapillare als Trennmedium. Die in Puffer aufgenommene DNA wird elektrokinetisch in diese Kapillare injiziert und der Größe nach aufgetrennt. Während der Elektrophorese werden die an den 3'Enden der Stränge befindlichen fluoreszenzmarkierten ddNTPs von einem Laser angeregt, das emittierte Licht wird von einer CCD-Kamera registriert und von der Analyse-Software (ABI Prism Sequencing Analysis ${ }^{\mathrm{TM}}$ 3.0, Applied Biosystems) ausgewertet. Die Absorptionsspektren der vier Farbstoffe unterscheiden sich so weit voneinander, daß sie bei Anregung durch den Laser vier photometrisch eindeutig erfassbare Einzelsignale ergeben.

Das Analyse-System gibt die entsprechende Sequenz in Form eines Elektropherogramms wieder, hier sind die Signale der ddNTPs als verschiedenfarbige Peaks dargestellt, die den gemessenen Fluoreszenz-Ausbeuten entsprechen. Die Elektropherogramme lassen ein nachträgliches Editieren insbesondere von unsicheren Sequenzbereichen zu. Eine weitere Bearbeitung der Proben erfolgte mit dem Softwarepaket „DNAStar“, das einen Abgleich der ProbenSequenzen mit Vergleichssequenzen zuläßt.

\subsubsection{Determination der mt-Haplotypen}

Da die softwaregesteuerte Basenbestimmung oft nicht fehlerfrei durchgeführt wurde, erfolgte für alle Sequenzen eine Überprüfung und Editierung durch die Bearbeiterin. Für die Bestimmung der Basenabfolge galten folgende Kriterien. Traten deutliche Unterpeaks auf (über 30\% der Höhe des Hauptpeaks), wurde der IUBBuchstabencode verwendet. Bei uncharakteristischem Erscheinungsbild der Peaks 
wurde diese Base als Artefaktereignis determiniert und nicht in die Bestimmung miteinbezogen.

Als Einzelergebnis galten die jeweils aus einem Ansatz hervorgegangenen drei Fragmente. Nur wenn zumindest zwei der Abschnitte sequenzierbar waren, ging das Ergebnis in die Auswertung ein. Auch hier galt das Kriterium der Reproduzierbarkeit, was bedeutet, daß ein Ergebnis aus zwei unabhängigen Extraktionen generiert werden musste, um als authentisches Ergebnis zu gelten. 


\section{POPULATIONSGENETISCHE PARAMETER}

\subsection{Substrukturierung und Diversität}

Eine der theoretischen Grundannahmen der Populationsgenetik liegt in der Zugrundelegung von panmiktischen Populationen, was bedeutet, daß unter den Mitgliedern dieser Gemeinschaften eine theoretisch gleiche Paarungswahrscheinlichkeit besteht. Obwohl dies in einigen Fällen womöglich zutrifft, sind die Populationen fast aller Organismen doch unterteilt in kleinere Subpopulationen in Form von Herden, Kolonien, Rudeln oder Schwärmen, zwischen denen Zufallspaarungen nur noch in eingeschränkter Form vorkommen (Hartl \& Clark 1997).

Auch menschliche Populationen sind in derartige Subpopulationen unterteilt, zwischen denen es unter Umständen nur noch im begrenzten Umfang zur Fortpflanzung kommt. Das Zustandekommen solcher Unterteilungen ist häufig durch die räumliche Separation der jeweiligen Populationen begründet, auch linguistische Unterschiede zwischen Gruppen können Zufallspaarungen einschränken (Stenico et al. 1996). Eine Trennung in Subgruppen kann darüber hinaus auch auf dem Vorhandensein von sozialen Schichten, Klassen oder Kasten basieren, die eine Verbindung zwischen Individuen unterschiedlicher Gruppenzugehörigkeit untersagen. So können kulturelle Regeln, wie z.B. sozial festgelegte Heiratsvorgaben existieren, die Beziehungen zwischen Individuen ausschließen und damit die Untergruppierung einer Population hervorrufen (Reddy et al. 2001; Bamshad et al. 1998).

Je nachdem, wie restriktiv die aus den genannten Gründen hervorgerufene Trennung der Population ist, kommt es $\mathrm{zu}$ einer deutlichen Abnahme oder sogar zum vollständigen Erliegen des Genflusses zwischen den Subgruppen. So kann sich eine genetische Differenzierung innerhalb der Gruppen einstellen, was bedeutet, daß eine voneinander abweichende Ausbildung von Allelfrequenzen stattfindet, die die Subpopulationen schließlich unterscheiden. Die Ursache der Ausbildung genetischer Differenzierung kann darin liegen, daß natürliche Selektionsfaktoren bestimmte Genotypen in den verschiedenen Subpopulationen bevorzugen, andererseits kann die Differenzierung lediglich auf zufälligen Prozessen bei der Vererbung der Allele 
basieren oder aber durch die zufällige unterschiedliche Verteilung der Allele in den jeweiligen Gründerpopulation hervorgerufen werden.

Die Muster der genetischen Variabilität zwischen und auch innerhalb von Populationen spiegeln historische Prozesse wider. Deswegen gilt den Verteilungsmustern genetischer Diversität in Bevölkerungen in Evolutionsstudien ein Hauptinteresse. Ebenso sind sie Schwerpunkt in forensischen Untersuchungen und in Studien zur Verteilung von genetisch veranlagten Krankheiten (Jorde et al. 2000). Die Studien zur genetischen Variabilität beruhen unter anderem auf Untersuchungen von Merkmalen wie Protein-Polymorphismen, Blutgruppen und craniometrischen Maßen. Heutzutage dominieren in Populationsstudien aber die Analysen von mitochondrialen, Y-chromosomalen und autosomalen DNA-Polymorphismen (Merriwether et al. 1991; Hammer et al. 1997; Jorde et al. 1995).

Vor allem die bereits vorgestellten Short Tandem Repeats (STRs) bieten sich zum Populationsvergleich an, die sich als hochpolymorphe und hochevolvierende Marker vorzüglich für den Nachweis von Substrukturierungen in einer Bevölkerung eignen. Durch den kodominanten Vererbungsweg der STRs wird es möglich, die Heterozygotenrate innerhalb einer Population anzugeben und mögliche Abweichungen vom Hardy-Weinberg-Gleichgewicht zu detektieren. Weitere genetische Marker, die in Kombination mit STRs oder für sich in Populationsstudien verwendet werden, sind die hochvariablen Bereiche der Kontrollregion des Mitochondriums, die aufgrund der maternalen Vererbungsweise mitochondrialer DNA die Rekonstruktion von Matrilinien ermöglichen. Daneben werden immer häufiger Y-STRs verwendet, die, abgesehen von ihrem ausschließlich paternalen Vererbungsweg, mit den autosomalen STRs zu vergleichen sind.

\subsection{Populationsdifferenzierung}

Es existieren verschiedene Methoden und Strategien zur Auswertung genetischer Daten, die schließlich Aussagen über das Ausmaß der Substrukturierung einer Population zulassen. So werden in dieser Arbeit die festgestellten Allel-Verteilungen untersucht und geprüft, ob sich die Weingartener Population im Hardy-WeinbergGleichgewicht und im Linkage Equilibrium befindet. Um die Effekte und das 
Ausmaß der Populationsstrukturierung innerhalb der Untersuchungspopulation zu bestimmen, werden außerdem die F-Statistiken von Wright verwendet. Durch ebenfalls durchgeführte Assignmentkalkulationen kann die Wahrscheinlichkeit der Zugehörigkeit eines Individuums zu einer bestimmten Sozialgruppe abgeschätzt werden.

Zur Berechung dieser Größen wurden verschiedene Computerprogramme verwendet, die speziell für die Analyse von Populationsdaten entwickelt wurden. Das für die Berechnung der Grunddaten verwendete Programm „GENEPOP 3.3“ (Raymond \& Rousset 1995b) hat sich auch bei der Bearbeitung von unvollständigen Datensätzen als robust und zuverlässig erwiesen (Bramanti et al. 2000a). Zur Analyse der mitochondrialen Daten wurde die Software „ARLEQUIN Ver. 2.000“ (Schneider et al. 2000) verwendet, welche Intra- und Interpopulationsvergleiche anhand von Haplotypvergleichen vornimmt. Um die Populationszugehörigkeit der Individuen zu untersuchen, wurde das Programm „WHICHRUN“ (Banks \& Eichert 2000) eingesetzt, daß anhand von Multilocus-Genotypdaten die Zuordnung von Individuen vornimmt. Alle drei Programme sind im Internet frei erhältlich (sog. Freeware).

Im folgenden werden die angewandten statistischen Verfahrensweisen und Methoden kurz vorgestellt. Bei allen statistischen Tests wurde als Signifikanzniveau ein Wert von $\alpha=0,05$ festgelegt.

\subsubsection{Allelfrequenzverteilung}

Eine der ersten Überprüfungen, die beim Vergleich von Populationen vorgenommen werden sollten, gilt der Frage, ob die betreffenden Gruppen Abweichungen in ihrer Allelfrequenzverteilung zeigen. Die Bewertung der Unterschiede in der Häufigkeitsverteilung der Allele wird durch das Programm GENEPOP über die Bildung von Kontingenztabellen und einer Abschätzung des p-Wertes für jeden einzelnen Locus und über alle Loci durch Fishers Exakten Test unter Verwendung der Markov-Chain-Methode (1000 Iterationen) erreicht.

Die Prüfung, ob die Genotyp-Verteilung zwischen den jeweiligen Gruppen identisch ist, wurde durch Kontingenztabellen vorgenommen. Eine Abschätzung des p-Wertes 
wird dabei durch die Anwendung des log-Likelihood Exakten Test (Goudet et al. 1996) unter Verwendung der Markov-Chain-Methode durchgeführt.

\subsubsection{Hardy-Weinberg-Gleichgewicht}

Die Überprüfung des Hardy-Weinberg-Gleichgewichtes (HW-Gleichgewicht) ist eine grundlegende Vorbedingung für weitere genetische Tests, bei denen Genotypfrequenzen in die Berechnungen eingehen.

Signifikante Abweichungen der Allelhäufigkeiten von den Erwartungswerten der Hardy-Weinberg-Proportion deuten auf bestimmte Mechanismen bei der AllelRekombination hin. So kann zum Beispiel das Vorhandensein von nicht miteinander paarenden Subpopulationen innerhalb der untersuchten Population, die deutlich voneinander abweichende Allelfrequenzen aufweisen, $\mathrm{zu}$ einer Abnahme der Heterozygosität im Vergleich zur erwarteten Heterozygosität führen (WahlundEffekt). Werden jene Subpopulationen aber einzeln untersucht, weisen sie keine Abweichungen vom Hardy-Weinberg-Gleichgewicht auf.

Der Test zur Überprüfung des HW-Gleichgewichts innerhalb der Weingartener Bevölkerungsstichprobe wurde für jeden Locus unter Verwendung von Fishers Exaktem Test durchgeführt, die Abschätzung des p-Wertes wurde durch Anwendung der Markov-Chain-Methode ermittelt. Dabei wurden die Tests mit alternativen $\mathrm{H}_{1}$ durchgeführt, zum einen zur Überprüfung auf Heterozygoten-Überschuß, zum anderen auf Heterozygoten-Mangel. Auch hier wurden die Tests zunächst für jeden einzelnen Locus und im folgenden für alle Loci (Multilocus oder globaler Test) durchgeführt, wobei die Unabhängigkeit der Loci zugrundegelegt wird. In allen Fällen wurde eine ausreichend große Anzahl (1000) Iterationen bei der MarkovChain-Methode angesetzt (Guo \& Thompson 1992).

\subsubsection{Linkage Disequilibrium}

Es wurde überprüft, ob innerhalb der Genotypkonstellationen der untersuchten Stichprobenindividuen bestimmte Allele verschiedener Loci überzufällig häufig miteinander kombinieren, was auf ein Linkage Disequilibrium (LD) hinweisen 
würde. Ein signifikantes Kopplungsungleichgewicht läßt sich für Loci nachweisen, die physikalisch nah beieinander liegen. Da die verwendeten autosomalen STRs auf verschiedenen Chromosomen lokalisiert sind, sollte dies als Grund für ein Linkage Disequilibrium auszuschließen sein. Allerdings kann das Auftreten eines LDs auch ein Artefakt der Tatsache sein, daß die untersuchte Population in Subpopulationen aufgeteilt ist, die unterschiedliche Allelfrequenzen besitzen (Wilson \& Goldstein 2000; Pritchard \& Rosenberg 1999). Die Prüfung, ob ein Linkage Disequilibrium besteht, wurde mit Hilfe des GENEPOP-Programmes durchgeführt. Hierbei kommt Fishers Exakter Test unter Verwendung der Markov-Chain-Methode basierend auf Kontingenztabellen zum Einsatz, wobei eine Überprüfung für alle Locus-Paare stattfindet.

\subsubsection{Heterozygotenrate}

Es werden verschiedene Maße für die Heterozygotenrate $[\mathrm{H}]$ verwendet. $\mathrm{H}_{\mathrm{obs}}$ beschreibt den beobachteten Anteil der Heterozygoten in einer Population. $\mathrm{H}_{\exp }$ ist die nach der Hardy-Weinberg-Proportion erwartete Heterozygotie und gilt als Diversitätsmaß. Durch den Vergleich der beiden Werte wird überprüft, ob in der Population signifikante Abweichungen im Hinblick auf die Häufigkeit heterozygoter Individuen bestehen. Ist der Anteil der Heterozygoten bei der Mehrzahl der Genorte geringer als erwartet, so kann dies ein Hinweis auf Inzuchtprozesse sein. Der Berechnung der erwarteten Heterozygoten-Rate $\left(\mathrm{H}_{\text {exp }}\right)$ liegt folgende Formel zugrunde:

$H_{\text {exp }}=1-\sum_{i=j}^{k} p_{i}^{2}$

$\mathrm{H}_{\text {exp }}=$ erwartete Heterozygotenrate; $\mathrm{k}=$ Anzahl der Allele, $\mathrm{p}_{\mathrm{i}}=$ Frequenz des $\mathrm{i}^{\mathrm{t}}{ }^{\text {ten }}$ von $\mathrm{k}$ Allelen

Die durchschnittliche Heterozygotenrate ist der Durchschnittswert über alle untersuchten Loci. Sie berechnet sich wie folgt (Nei 1987): 
$H=\sum_{j=1}^{l} \frac{h_{j}}{l}$

$\mathrm{h}_{\mathrm{j}}=$ Heterozygotenrate für den $\mathrm{j}$-ten Locus; $1=$ Zahl der Loci; $\mathrm{j}=$ Locus

\subsubsection{F-Statistiken}

Um die Effekte zu quantifizieren, die zur Verringerung des Heterozygotenanteils in einer strukturierten Bevölkerung führen, werden die von Wright (1965) definierten F-(Fixation)-Indices verwendet.

Eine strukturierte Population läßt sich in drei verschiedene Komplexitätsebenen aufteilen: Individuen (I), Subpopulationen (S), und die Gesamtpopulation (T), die alle Subpopulationen zusammenfasst. Die Heterozygotenraten auf den einzelnen Levels sind:

$\mathbf{H}_{\mathbf{I}}$ : Individuelle Heterozygosität. Beobachtete Heterozygotenrate $\left(\mathrm{H}_{\mathrm{obs}}\right)$ in einer Subpopulation.

$\mathbf{H}_{\text {S: }} \quad$ Erwartete Heterozygotenrate $\left(\mathrm{H}_{\mathrm{exp}}\right)$ in einer zufallspaarenden Subpopulation.

$\mathbf{H}_{\mathbf{T}}$ : Erwartete Heterozygotenrate in der Gesamtpopulation, die sich unter der Annahme ergeben würde, daß zwischen den Individuen der gepoolten Subpopulationen Zufallspaarungen stattfinden.

Diese verschiedenen Heterozygotenraten werden verwendet, um die drei F-Indices zu berechnen, die Informationen über die Struktur einer Population geben können.

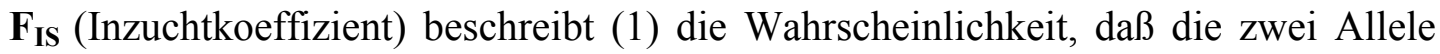
eines Locus in einem Individuum identischen Ursprungs (autozygot), also auf einen einzigen Vorfahren zurückzuführen sind oder (2) den Anteil der Reduktion der Heterozygotie eines Individuums, der begründet ist durch das non-random mating Verhalten der Subpopulation, der es angehört. Negative $F_{I S}-$ Werte zeigen einen 
Heterozygotenüberschuß an (Outbreeding), während positive Werte bedeuten, daß entgegen der nach HW-Gleichgewicht erwarteten Heterozygotenrate ein Heterozygotendefizit besteht, was auf Inzucht-Prozesse zurückzuführen ist. $F_{I S}$ läßt sich folgendermaßen darstellen:

$$
F_{I S}=1-\frac{H_{o b s}}{H_{\exp }}
$$

$\mathrm{H}_{\mathrm{obs}}=$ beobachtete Heterozygotenrate, $\mathrm{H}_{\mathrm{exp}}=$ erwartete Heterozygotenrate

oder

$F_{I S}=\frac{H_{S}-H_{I}}{H_{S}}$

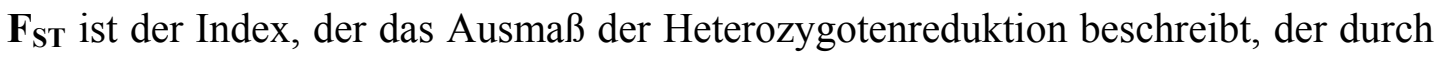
Substrukturierungen innerhalb der Population verantwortet wird. Dieser Wert ist ein oft gebrauchtes Maß für die Beschreibung der genetischen Variabilität zwischen den Subgruppen einer Populationen. Ein Wert von 0 bedeutet, daß eine panmiktische Population vorliegt, in der keine Substrukturierung herrscht. Die genetische Diversität der Bevölkerung liegt bei $0 \%$. Ein Wert von 1 bedeutet, daß eine gänzliche Substrukturierung der Population mit vollständiger (100\%) genetischer Differentiation besteht. $\mathrm{F}_{\mathrm{ST}}$-Werte bis 0.05 zeigen vernachlässigbare genetische Differentiation an, während Werte $>0.25$ schon eine sehr große Differentiation innerhalb der analysierten Population bedeuten (Hartl \& Clark 1997). F ST $_{\text {steht }}$ mithin auch für Ausmaß von Genfluß zwischen Populationen: $F_{\mathrm{ST}}=1$ zeigt an, daß kein Genfluß besteht, während $\mathrm{F}_{\mathrm{ST}}=0$ bedeutet, daß es zwischen den Gruppen zum Genaustausch kommt. $\mathrm{F}_{\mathrm{ST}}$ berechnet sich aus:

$$
F_{S T}=\frac{H_{T}-H_{S}}{H_{T}}
$$


F IT: Gesamtinzuchtkoeffizient eines Individuums im Vergleich zur Gesamtpopulation. Hierbei werden beide Effekte, die zu einer Reduktion der Heterozygotenrate führen können, wie nicht-zufälliges Fortpflanzungsverhalten innerhalb der Subpopulation $\left(\mathrm{F}_{\mathrm{IS}}\right)$, sowie die mögliche Substrukturierung der Bevölkerung $\left(\mathrm{F}_{\mathrm{ST}}\right)$ beachtet. $\mathrm{F}_{\mathrm{IT}}$ ist allerdings ein selten benutztes Maß.

$$
F_{I T}=\frac{H_{T}-H_{I}}{H_{T}}
$$

\subsubsection{Assignment-Test}

Durch das Programm WHICHRUN (Banks \& Eichert 2000) wird die log-Likelihood der Zugehörigkeit eines Individuums $\mathrm{zu}$ einer definierten Population bestimmt. Hierbei wird berechnet, wie groß die Wahrscheinlichkeit ist, daß ein individueller Genotyp in den jeweiligen zu vergleichenden Herkunftspopulationen auftritt. Diese Genotypfrequenz wird unter Zugrundelegung der verschiedenen Populationsallelfrequenzen berechnet. Der Vergleich dieser Werte führt zu einem Zuordnung jedes Individuums zu einer der Vergleichspopulationen. Darüber wird es möglich, Migranten zu identifizieren, ethnische Zuordnungen zu treffen oder die Durchmischung von Populationen zu überprüfen (Davies et al. 1999).

\subsection{Bestimmung der Variabilität mitochondrialer Daten}

\subsubsection{Gen-Diversität}

Der zur Beschreibung der genetischen Variabilität zwischen Populationen unter Verwendung von haploiden Daten verwendete Parameter wird als gene diversity $(\mathrm{H})$ bezeichnet (Nei 1987). Es ist gleichzusetzen mit der Heterozygotenrate für diploide Daten. $\mathrm{H}$ wird definiert als Wahrscheinlichkeit, daß zwei zufällig aus einer Stichprobe ausgewählte Haplotypen unterschiedlich sind. Die Gen-Diversität berechnet sich folgendermaßen (Nei 1987): 
$\widehat{H}=\frac{n}{n-1}\left(1-\sum_{i=1}^{k} p_{i}^{2}\right)$

$\mathrm{n}=$ Anzahl der Individuen, $\mathrm{k}=$ Anzahl der Haplotypen $\mathrm{p}_{\mathrm{i}}=$ Frequenz des $\mathrm{i}^{\text {ten }}$ Haplotypen

\subsubsection{Nukleotid-Diversität}

Die Nukleotid-Diversität definiert die Wahrscheinlichkeit, daß zwei zufällig ausgewählte homologe Nukleotide unterschiedlich sind. Dieses Maß dient der Überprüfung der Diversität von mitochondrialen Sequenzen und beschreibt die durchschnittliche Anzahl der Nukleotidunterschiede des jeweiligen sequenzierten Bereichs zwischen zwei zufällig ausgesuchten Proben einer Population. Die Nukleotid-Diversität ist gleichzusetzen mit der Heterozygotenrate auf dem Nukleotidlevel (Nei 1987).

\subsubsection{Analysis of Molecular Variance (AMOVA)}

AMOVA steht für „Analysis of Molecular Variance“ und ist eine Methode zur Untersuchung genetischer Variabilität innerhalb von Populationen. Die AMOVA (Excoffier et al. 1992) basiert auf der Analyse von Unterschieden zwischen Haplotyp-Paaren und generiert Angaben zur genetischen Varianz, die sich durch die Haplotyp-Diversität innerhalb und zwischen Populationen begründet. Die in der AMOVA gewählte Herangehensweise berücksichtigt die Anzahl der Mutationen zwischen Haploytpen. Für die Durchführung der AMOVA wurde das Softwareprogramm ARLEQUIN (Schneider et al. 2000) verwendet.

Innerhalb der AMOVA wird durch vorherige Definition von Populationsgruppen eine genetische Struktur definiert, die zur Überprüfung ansteht. Eine hierarchische Analyse der Varianz unterteilt die Gesamtvarianz in Varianzkomponenten, die durch Inter-Individuelle und/oder Inter-Populations Unterschiede verursacht werden.

Die Gesamtvarianz $\left(\sigma^{2}\right)$ ist die Summe aus den einzelnen Varianzkomponenten, die sich erklären aus: 
Variabilität der Haplotypen innerhalb einer Population $\left(\sigma_{\mathrm{c}}{ }^{2}\right)$

Variabilität der Haplotypen zwischen Populationen einer Bevölkerung $\left(\sigma_{\mathrm{b}}{ }^{2}\right)$ und

Variabilität der Haplotypen zwischen Bevölkerungen $\left(\sigma_{\mathrm{a}}^{2}\right)$

Die Kovarianzen werden verwendet, um $\Phi$-Statistiken zu berechnen, die Wrights FStatistiken (Wright 1951; Cockerham 1973) entsprechen. Der Signifikanztest der Varianzkomponenten erfolgt über einen Vergleich der beobachteten Werte mit denen einer Nullverteilung. Letztere wird mittels einer 1000 Permutationen umfassenden Bootstrap-Prozedur generiert.

\subsubsection{Exakter Test zur Populationsdifferenzierung}

Es wird ein exakter Test zur Feststellung von Unterschieden zwischen den Subgruppen auf Grundlage der mt-Haplotyp-Frequenzen durchgeführt. Dabei wird die Hypothese der zufälligen Verteilung der $k$ verschiedenen Haplotypen zwischen $r$ Populationen überprüft (Raymond \& Rousset 1995a). Dieser Test verläuft analog Fishers Exaktem Test in einer $2 \times 2$ Kontingenztafeln, die erweitert ist $\mathrm{zu}$ einer $\mathrm{r} \times \mathrm{k}$ Kontingenztafel. Die p-Wert Bestimmung erfolgt über die Anwendung der MarkovChain-Methode. 


\subsection{Determination von Residenzverhalten}

Für die Determination der Heiratsmuster eignet sich ein Vergleich der Variabilitäten Y-chromosomaler Sequenzen mit denen der mitochondrialen Regionen, wobei Vergleiche innerhalb und zwischen Gruppen durchgeführt werden können (vgl. Kapitel 1.4). Die Zusammenhänge werden durch folgende Tabellen verdeutlicht.

Tabelle 4.1: Darstellung der Zusammenhänge der Y-chromosomalen und mitochondrialen Variabilitäten bei patrilokalen Residenzverhalten.

\begin{tabular}{lcc}
\hline Patrilokalität & Zwischen Gruppen & Innerhalb einer Gruppe \\
\hline Variabilität & & \\
\hline $\mathrm{mt} / \mathrm{Y}$-STR & mt-Variabilität $<$ Y-Variabilität & mt-Variabilität $>$ Y-Variabilität \\
\hline
\end{tabular}

Tabelle 4.2: Darstellung der Zusammenhänge der Y-chromosomalen und mitochondrialen Variabilitäten bei matrilokalen Residenzverhalten.

\begin{tabular}{lcc}
\hline Matrilokalität & Zwischen Gruppen & Innerhalb einer Gruppe \\
\hline Variabilität & & \\
\hline $\mathrm{mt} /$ Y-STR & mt-Variabilität $>$ Y-Variabilität & mt-Variabilität $<$ Y-Variabilität \\
\hline
\end{tabular}

Dieser Vergleich zwischen den beiden paternal und maternal vererbten Markern des Genoms ist notwendig, um dem Ausmaß der jeweiligen Diversität einen Bezugsrahmen zu geben und dadurch die Größenordnung der Diversität abschätzen zu können. Die Determination von Matrilokalität kann allerdings auch durch die alleinige Analyse von mitochondrialen Sequenzen gelingen, wobei hier ein Vergleich zwischen den Geschlechtern stattfinden muß. In diesem Fall sollten sich die weiblichen Individuen einer Gruppe im Hinblick auf ihr mitochondriales Erscheinungsbild homogener zeigen, als die männlichen Individuen der Gemeinschaft. Ergibt sich die in der folgenden Tabelle dargestellte Beziehung des Ausmaßes der mitochondrialen Variabilität zwischen den Geschlechtern, kann auf die Ausübung von matrilokalen Residenzverhalten geschlossen werden. 
Tabelle 4.3: Darstellung der Zusammenhänge der mitochondrialen Variabilitäten zwischen den Geschlechtern bei matrilokalen Residenzverhalten.

\begin{tabular}{lcc}
\hline Matrilokalität & Zwischen Gruppen & Innerhalb einer Gruppe \\
\hline$m t$-Variabilität $[V]$ & & \\
\hline & $\mathrm{V}_{\text {weiblich }}>\mathrm{V}_{\text {männlich }}$ & $\mathrm{V}_{\text {weiblich }}<\mathrm{V}_{\text {männlich }}$ \\
\hline
\end{tabular}

Dahingegen ist der Nachweis von Patrilokalität nur durch den Vergleich mitochondrialer Variabilitäten schwer $\mathrm{zu}$ erreichen, denn in diesem Fall unterscheidet sich die Variabilität der mitochondrialen Sequenzen zwischen Männern und Frauen wahrscheinlich nicht. Praktiziert eine Gesellschaft Patrilokalität, verlassen die Frauen ihre Geburtsgruppe, um die postnuptiale Residenz bei der Familiengruppe des Ehemanns aufzunehmen. Hervorgerufen durch die bereits in den Generationen davor eingeheirateten Frauen (also durch das Hinzukommen von mtLinien), dürfte zwar die Diversität der mitochondrialen Sequenzen zwischen den weiblichen Individuen innerhalb der patrilokalen Gruppe einen gewissen Grad erreichen. Diesem Wert fehlt aber ein Vergleichsmaß. Es ist zu beachten, daß die mitochondriale Diversität der Männer ähnliche Quantitäten erreichen wird, wie die der Frauen, da sich in der männlichen mt-Diversität lediglich die der weiblichen Individuen der Mütter-Generation widerspiegelt, womit der Bezugsrahmen für eine Abschätzung der Unterschiede fehlt.

Es ist lediglich anzunehmen, daß die Diversität zwischen den Gruppen hinsichtlich der mitochondrialen-DNA geringer ist, als innerhalb der Gruppe. Entscheidend ist der Fakt, daß sich Patrilokalität, im Gegensatz zu Matrilokalität, bei der Untersuchung der mitochondrialen Diversität nicht explizit nachweisen läßt und sich vor allem auch nicht von endogamischen Vorgängen innerhalb der Population unterscheiden läßt (Williams et al. 2002).

\subsection{Elternschaftswahrscheinlichkeit}

Während durch den Abgleich der STR-Daten von putativen Eltern- und KindIndividuen ein Ausschluß der Elternschaft praktisch unwiderlegbar festzustellen ist, kann ein direkter Beweis für Elternschaft nicht erbracht werden. Ist jedoch aufgrund der Datenlage eine auf genetischer Verwandtschaft beruhende Beziehung in Betracht 
zu ziehen, können nur Wahrscheinlichkeits-Abschätzung angegeben werden (Pena \& Chakraborty 1994). Dabei wird die Wahrscheinlichkeit berechnet, daß ein Individuum, das aufgrund seiner genetischen Merkmale nicht von vornherein als Elter ausgeschlossen werden kann, tatsächlich als Vater (oder Mutter) in Betracht zu ziehen ist. Dieser Wahrscheinlichkeits-Wert ist relativ einfach unter Kenntnis der in der jeweiligen Population vorhandenen Allelfrequenzen zu berechnen und steigert sich mit der Anzahl der untersuchten Merkmalssysteme. Es läßt sich ein Likelihoodquotient (oder Paternitätsindex [PI]) bilden, der die Wahrscheinlichkeiten gegenüberstellt, daß es sich bei dem Putativelternteil tatsächlich um den biologischen Vater (biologische Mutter) handelt oder aber um eine nichtverwandte, zufällig aus der Population ausgewählte Person (Brenner 1993; Gerstenberger et al. 1999). 


\section{$5 \quad$ ERGEBNISSE}

\subsection{Deskription der Typisierungsergebnisse}

\subsubsection{Amplifikationserfolge}

\subsubsection{Autosomale STRs}

Insgesamt wurden an 161 Individuen des Gräberfeldes Weingarten molekulare Untersuchungen vorgenommen. Zur Feststellung des autosomalen STR-Fingerprints und zur molekularen Geschlechtsbestimmung wurde eine Probe jedes Individuum zunächst der Multiplex-Amplifikation mit dem AmpFlSTR Profiler Plus Kit unterzogen. Nach dem Ausgang dieser Amplifikation richtete sich die weiterführende Bearbeitung: Proben, die nach der Durchführung einer zweiten Amplifikation kein Ergebnis zeigten, wurden von weiteren Analysen ausgenommen. 121 Proben wurden in PCRs zur Determinierung des jeweiligen mitochondrialen DNA-Typus eingesetzt. 76 Proben wurden außerdem der Amplifikation mit den beschriebenen Y-chromosomalen Markern unterzogen.

Bei Amplifikation der autosomalen STRs ließen sich für 63 Proben (39\%) Allelprofile erhalten, die die Datengrundlage für die durchgeführten populationsgenetischen Analysen bildeten. Hiervon waren insgesamt 24 Proben in vier bis sechs Systemen typisierbar. 28 Proben waren in sieben bis neun Systemen auswertbar. Für 11 Proben ließ sich ein kompletter, alle zehn Systeme umfassender Fingerprint erhalten.

Für 25 Proben ergaben sich nur in ein bis drei Systemen reproduzierbare Ergebnisse, was für Analysen im Sinne der Verwandtschaftsfeststellung und für die weiteren populationsgenetischen Untersuchungen nicht als ausreichende Datengrundlage gelten kann. Für 73 Proben konnte keines der zehn Systeme nachgewiesen werden. Diese insgesamt 98 Proben (61\%) sind als nicht erfolgreich typisiert zu bezeichnen. 


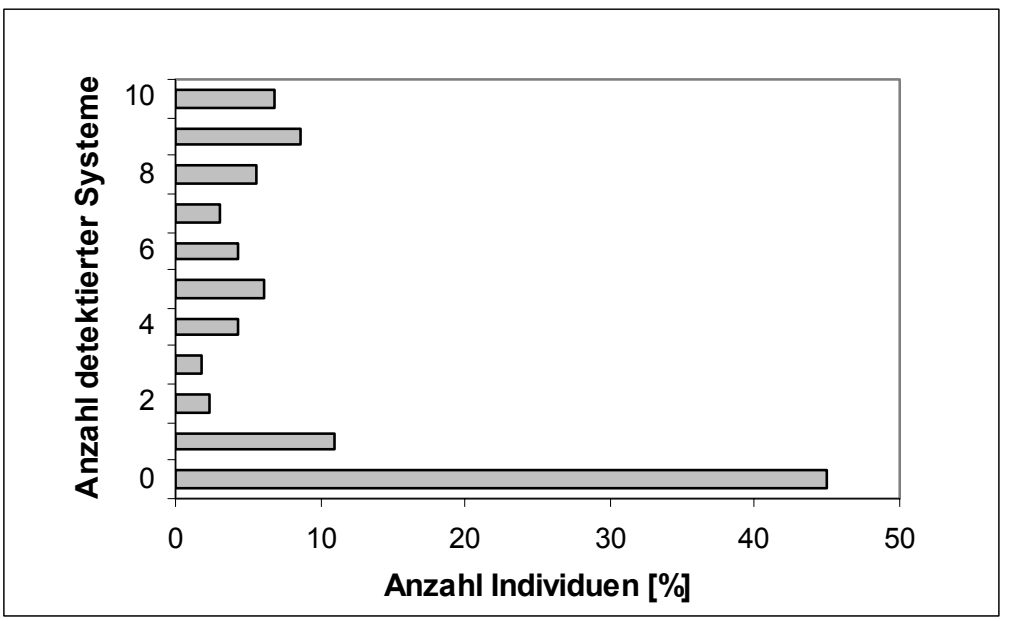

Abbildung 5.1: Darstellung der Anzahl detektierter autosomaler STRSysteme.

\subsubsection{Mitochondriale DNA}

Die Amplifikation der mitochondrialen Marker hat die Vermehrung von drei unterschiedlich langen Fragmenten aus den hypervariablen Kontrollregionen HVRI und HVRII des Mitochondriums zum Ziel. Durch diesen Multiplex-Ansatz läßt sich eine Authentifizierung der Ergebnisse erreichen, da hiermit eine erhöhte Individualisierbarkeit der Resultate gewährleistet ist. Für 83 Individuen (68\%) gelang die Amplifikation und Sequenzierung aller drei angestrebten Bereiche, wobei die Ergebnisse hier durch wiederholte PCRs unter Verwendung von DNA aus unabhängigen Extraktionen reproduzierbar waren und somit bestätigt wurden. Für 11 weitere Proben gelang die Amplifikation des dritten und längsten Fragments nur in Einzelfällen, so daß hier die Vorgabe der Ergebnisbestätigung durch Reproduktion nicht erfüllt wurde. Dennoch war in diesen Fällen eine vorsichtige Zuweisung des mt-Typus möglich, da bereits durch die Analyse der ersten beiden Fragmente eine Determinierung eines sich von den Sequenzabfolgen der übrigen Individuen unterscheidenden mt-Typus erreichbar war.

\subsubsection{Y-chromosomale STRs}

76 Individuen, die aufgrund der anthropologischen und/oder archäologischen Geschlechtsdeterminierung als männlich betrachtet wurden und weitere Individuen, bei denen aufgrund der Amelogenin-Ergebnisse innerhalb der AmpFlSTR Profiler 
Plus Kit PCR auf das Vorhandensein amplifizierbarer Y-chromosomaler-DNA zu schließen war, wurden der Amplifikation mit den beschriebenen vier Y-STRMarkern unterzogen. Hierbei waren für 30 Proben Ergebnisse zu erhalten. Typisierbar für mindestens drei Systeme waren 22 Proben-Individuen.

In der nachfolgenden Tabelle 5.1 sind die Erfolgsquoten der analysierten DNASysteme zusammengefaßt.

Tabelle 5.1: Amplifikationserfolge der drei untersuchten genetischen Markersysteme. Als erfolgreiches Analyseergebnis wird im Falle der autosomalen STRs die Typisierung von mindestens vier Systemen verstanden. Bei den mitochondrialen Sequenzen ist mit einem erfolgreichen Ergebnis die Sequenzierung aller drei amplifizierten mt-Bereiche gemeint. Bei der Amplifikation der Y-STRs müssen mindestens drei der vier Systeme reproduziert nachgewiesen sein.

\begin{tabular}{|cccc|}
\hline & $\begin{array}{c}\text { Anzahl untersuchte } \\
\text { Individuen }\end{array}$ & $\begin{array}{c}\text { Erfolgreiche } \\
\text { Analyseergebnisse }\end{array}$ & Erfolgsquote [\%] \\
\hline Autosomale STRs & 161 & 63 & $39 \%$ \\
mt-Sequenzen & 121 & 83 & $68 \%$ \\
Y-STRs & 76 & 22 & $28 \%$ \\
\hline
\end{tabular}

\section{$5.2 \quad$ Typisierungsergebnisse}

\subsubsection{Ergebnisse der Amplifikation autosomaler STRs}

Alle 161 Proben wurden zur Erstellung eines individualspezifischen Allelprofils einer Multiplex-Amplifikation mit den zehn im AmpFlSTR Profiler Plus Kit enthaltenen Systemen unterzogen. Hierdurch wird zum einen die Datengrundlage für den populationsgenetischen Gruppenvergleich geschaffen, daneben wird durch die Individualisierbarkeit der Ergebnisse aber auch deren Authentifizierung erreicht. Für jedes Proben-Individuum wurden mindestens 1-2 Extraktionen mit darauffolgender Amplifikation durchgeführt. Ergab sich hierbei ein positives Ergebnis, wurden weitere Extraktionen und Amplifikationen durchgeführt, um so über die Einzelergebnissen zu einer abschließenden Genotypisierung des Individuums zu gelangen. 


\subsubsection{Darstellung von Genotypisierungen}

Die Vorgehensweise bei der abschließenden Endtypisierung einer Probe ist in den folgenden Tabellen 5.2 und 5.3 exemplarisch für eine sehr gut amplifizierbare Probe (Individuum 619) sowie für eine weniger erfolgreiche Probe (Individuum 134) dargestellt.

Im Falle des Individuums 619 wurden insgesamt sechs Extraktionen und zwölf Amplifikationen durchgeführt. Während die erste Extraktion augenscheinlich erfolglos war, wurden in den folgenden Reaktionen sehr gute Ergebnisse erzielt, die zur Darstellung der bei der Genotypbestimmung einer Probe unerläßlichen Abwägungen dienen soll.

Allelausfälle: In einigen Amplifikationen der Probe 619 ist es offenbar zum Ausfall eines Allels gekommen (Reaktion 9.25a und 17.S1 in den Systemen VWA und FGA). Dadurch, daß für diese Systeme in den übrigen Amplifikationen heterozygote Ergebnisse erhalten werden, kann eindeutig erkannt werden, daß es sich in den angesprochenen PCR-Reaktionen nur um stochastische Ausfälle eines Allels handelt. Im System D7S820, in dem es trotz des anscheinend guten Erhaltungszustand der Proben-DNA wahrscheinlich aufgrund der Länge des Systems (max. 294 bp) in einzelnen Fällen zum vollständigen Ausfall beider Allele kommt, lassen sich in den ergebniszeigenden Amplifikationen nur Signale für jeweils ein Allel detektieren, die sich in der Endtypisierung aber zu einem heterozygoten Alleltyp zusammenfügen.

Unsichere Allelbestimmungen: In Klammern angegebene Allele (siehe Ergebnisse im System D5S818) zeigen an, daß nicht eindeutig zu unterscheiden ist, ob es sich hierbei um Artefaktsignale im Sinne von Stotterprodukten handelt, oder ob die detektierten Fragmente als authentische Probensignale zu werten sind. Durch die Wiederholung der Amplifikationen wird deutlich, daß sowohl das Allel 9 als auch das Allel 10 die probenendogenen Allele darstellen.

Homozygotes Ergebnis: Die alleinige Detektierung des Allels 30 im System D21S11 in zehn Amplifikationen spricht eindeutig für einen homozygoten Alleltyp des Individuums in diesem System. Die einmalige Feststellung des Alleles 26 ist vermutlich auf ein Artefaktereignis während der Amplifikation bzw. während der Datengenerierung des Sequenzier-Geräts zurückzuführen. 
Die Authentizität der Ergebnisse wird auch dadurch belegt, daß reproduzierbare Ergebnisse aus zwei verschiedenen Skelettelementen desselben Individuums zu erhalten sind.

Tabelle 5.2: Überblick über die Einzeltypisierungsergebnisse von Individuum 619 und die sich daraus ergebende abschließende Genotyp-Bestimmung. In Klammern angegebene Allele deuten auf eine unsichere Allelbestimmung hin.

\begin{tabular}{|c|c|c|c|c|c|c|c|c|c|c|}
\hline EX/PCR & Amelo & D3S1358 & VWA & FGA & D8S1179 & D21S11 & D18S51 & D5S818 & D13S317 & D7S820 \\
\hline Z1 1.1a & $/$ & $/$ & $/$ & $/$ & $/$ & $/$ & $/$ & $/$ & $/$ & $/$ \\
Z1 1.1b & $/$ & $/$ & $/$ & $/$ & $/$ & $/$ & $/$ & $/$ & $/$ & $/$ \\
Z1 3.2a & $\mathrm{XY}$ & $14 / 18$ & $17 / 19$ & $20 / 22$ & $12 / 14$ & $26 / 30$ & 13 & $9 /(10) /(11)$ & $/$ & $/$ \\
Z1 3.2b & $\mathrm{XY}$ & $14 / 18$ & $17 / 19$ & $20 / 22$ & $12 / 14$ & 30 & $/$ & $9 /(10)$ & $(10) / 11$ & $/$ \\
Z1 3.3a & $\mathrm{XY}$ & $14 / 18$ & $17 / 19$ & 22 & $12 / 14$ & 30 & $13 / 17$ & $9 / 10$ & 11 & $(10) / 11$ \\
Z1 3.3b & $\mathrm{XY}$ & $14 / 18$ & $17 / 19$ & $20 / 22$ & $12 / 14$ & 30 & $13 / 17$ & $(9) / 10$ & 11 & 11 \\
Z1 9.25a & ü.a.* & $14 / 18$ & 17 & 20 & $/$ & 30 & $15 / 17$ & $/$ & 10 & 10 \\
Z1 9.25b & ü.a.* & $14 / 18$ & $17 / 19$ & $20 / 22$ & $12 / 14$ & 30 & $/$ & $9 / 10$ & 10 & 11 \\
Z1 17.S1 & $\mathrm{XY}$ & $14 / 18$ & 17 & 22 & $12 / 14$ & 30 & $/$ & 9 & 10 & $/$ \\
Z1 17.S2 & $\mathrm{XY}$ & $14 / 18$ & $17 / 19$ & $20 / 22$ & $12 / 14$ & 30 & $/$ & $9 /(10)$ & $10 / 11$ & $/$ \\
Z2 38.58 & $\mathrm{XY}$ & $14 / 18$ & $17 / 19$ & $20 / 22$ & $12 / 14$ & 30 & $/$ & $9 / 10$ & $10 / 11$ & $/$ \\
Z2 30.63 & $\mathrm{XY}$ & $14 / 18$ & $17 / 19$ & $/$ & $11 / 12 / 14$ & 30 & $/$ & $(9) / 10$ & 10 & $/$ \\
\hline Genotyp & $\mathrm{XY}$ & $\mathbf{1 4 / 1 8}$ & $\mathbf{1 7 / 1 9}$ & $\mathbf{2 0 / 2 2}$ & $\mathbf{1 2 / 1 4}$ & $\mathbf{3 0 / 3 0}$ & $\mathbf{1 3 / 1 7}$ & $\mathbf{9 / 1 0}$ & $\mathbf{1 0 / 1 1}$ & $\mathbf{1 0 / 1 1}$ \\
\hline
\end{tabular}

* Die Bezeichnung ü.a. steht für ,über-amplifiziert“ und zeigt an, daß, verursacht durch einen Überschuß an Produkt, die bei der Datenerfassung generierten Fluoreszenz-Signale zu stark waren, um eine Auswertung zuzulassen. Z1=Zahn 46, Z2=Zahn 47.

In Tabelle 5.3 sind die Ergebnisse der Einzelamplifikationen und das Ergebnis der Genotypisierung der Probe 134 dargestellt. An diesem Beispiel wird deutlich, daß eine Feststellung des Allelprofils auch bei Proben mit weniger guten DNAErhaltungsgrad möglich ist. Allerdings muß gerade in diesen Fällen unter Kenntnis des Amplifikationsverhaltens alter DNA sorgsam abgewogen werden, welche Ergebnisse in die abschließende Genotypisierung einfließen. So kommt es im System D3S1358 aufgrund von Stotterereignissen in drei Amplifikationen zur Generierung des Allels 17. Durch das Auftreten des Alleles 16 in den übrigen Reaktionen, kann aber dieses Allel als das authentische angenommen werden. Im System VWA ist eine Festlegung auf zwei Allele nicht möglich, so daß in die Endtypisierung alle drei detektierten Allele aufgenommen werden. Dieses Ergebnis kann nicht in den populationsgenetischen Gruppenvergleich eingehen, ist aber zur Feststellung von konkreter Verwandtschaft verwendbar. Im System FGA wird trotz des Auftretens der 
Allele 21 und 23 in zwei der acht durchgeführten Reaktionen ein homozygotes Ergebnis 22/22 angenommen. Sowohl das Produkt, das 21 Wiederholungseinheiten aufweist, als auch das Produkt, das sich durch 23 Tetranukleotoideinheiten auszeichnet, ist als Stotterprodukt von Allel 22 erklärbar. Darüber hinaus ist das Allel 22 aus vier unabhängigen Extraktionen als singuläres Produkt generiert worden, wodurch die Aufnahme eines homozygoten Alleltyps gerechtfertigt ist. Im System D13S317 wurde dahingegen der Alleltypus 10/13 determiniert, obwohl das Allel 13 aus drei Extraktionen als einziges Signal nachwiesen werden konnte. Allerdings kommt es hier in zwei weiteren Amplifikationen, die auf zwei unabhängige Extraktionen zurückzuführen sind, auch zur Generierung des Alleles 10, das sich nicht als Stotterprodukt von Allel 13 erklären läßt. Aus diesem Grund werden beide Allele in die Endtypisierung aufgenommen. Im System D7S820 konnte das Allel 10 nur aus einer einzigen Extraktion nachgewiesen werden, wegen der mangelnden Reproduktion wird das Allel somit in der abschließenden Genotypisierung nur in Klammern aufgeführt.

Tabelle 5.3: Überblick über die Einzeltypisierungsergebnisse und die daraus resultierende Genotypisierung von Individuum 134. In Klammern angegebene Allele deuten auf eine unsichere Allelbestimmung hin. Sind drei Allele angegeben, war eine Festlegung auf zwei Allele nicht möglich.

\begin{tabular}{|c|c|c|c|c|c|c|c|c|c|c|}
\hline Ex/PCR & Amelo & D3S1358 & VWA & $F G A$ & D8S1179 & D21S11 & D18S51 & D5S818 & D13S317 & D7S820 \\
\hline Z1 12.27a & $X Y$ & $15 / 16$ & 15 & 21 & I & 1 & I & 1 & $13 / 14$ & 1 \\
\hline Z1 12.27b & $X Y$ & 1 & 1 & 22 & I & $29 / 30$ & I & I & 13 & 10 \\
\hline Z1 12.31a & $X Y$ & $15 / 16$ & $15 / 17 / 19$ & 22 & $11 / 13 /(14)$ & I & I & 11 & I & I \\
\hline Z1 12.31b & $X Y$ & 16 & 16 & 22 & $11 / 14$ & 30 & 1 & $11 /(12)$ & I & 10 \\
\hline Z1 21.39 & $X Y$ & $15 / 17$ & $15 / 18$ & $22 / 23$ & $11 / 14$ & 1 & 15 & 11 & I & 1 \\
\hline Z1 24.40 & $X Y$ & $15 / 17$ & 17 & 22 & $11 / 15$ & 28 & 1 & $8 /(10) / 11$ & $10 / 12$ & I \\
\hline Z1 24.42 & $X Y$ & $15 / 16$ & $14 / 16$ & I & $11 / 14$ & I & I & 1 & 1 & I \\
\hline Z1 28.46 & $x$ & 1 & 18 & I & 1 & I & I & I & I & I \\
\hline Z2 33.52 & $X Y$ & $15 / 16$ & $15 / 16 / 18$ & I & 11 & 30 & I & 12 & 13 & I \\
\hline Z2 34.53 & $X Y$ & $15 / 16$ & 18 & 1 & 1 & 29 & I & 12 & 13 & I \\
\hline Z2 41.59 & $X Y$ & $15 / 16$ & 1 & I & $11 / 14$ & 30 & I & 1 & 1 & I \\
\hline Z2 73.88 & $X Y$ & I & $(17) / 18$ & I & 1 & 1 & I & 1 & I & I \\
\hline Z2 85.97 & $X Y$ & 15 & $17 / 18$ & 22 & 13 & $(29) / 30$ & I & $10 /(11) / 12$ & 10 & 1 \\
\hline K 116.128 & $X Y$ & I & $15 / 18$ & 22 & $11 / 14$ & I & I & 11 & I & 12 \\
\hline Genotyp & $X Y$ & $15 / 16$ & $(15 / 17 / 18)$ & $22 / 22$ & $11 / 14$ & $29 / 30$ & I & $11 / 12$ & $10 / 13$ & (10) \\
\hline
\end{tabular}


In der folgenden Tabelle 5.4 sind die Ergebnisse der Genotypisierungen für die Individuen aufgeführt, die in mindestens vier Systemen für ein Allel reproduzierbare Resultate zeigten. Die Allelprofile dieser Proben-Individuen dienen im Subpopulationsvergleich als Datengrundlage. Die Ergebnisse der Einzel- und Endtypisierungen aller beprobten Weingartener Individuen finden sich im Tabellenanhang in Tabelle 10.3.

Tabelle 5.4: Ergebnisse der autosomalen Genotypisierungen der Weingartener Individuen. In Klammern angegeben sind unsichere Alleltypisierungen. In den Fällen, in denen drei Allele notiert sind, war eine Entscheidung, bei welchem der drei Allele es sich um ein Artefakt handelt und welche Signale die authentischen Allele repräsentieren, nicht eindeutig zu treffen. Allele, die nicht zu typisieren waren und Daten, die nicht den Reproduktionskriterien entsprachen, sind in dieser Tabelle durch "0" gekennzeichnet.

\begin{tabular}{|c|c|c|c|c|c|c|c|c|c|c|}
\hline Ind. & Sex & D3S1358 & D8S1179 & D5S818 & VWA & D21S11 & D13S317 & $F G A$ & D18S51 & $D 7 S 820$ \\
\hline 52 & $X Y$ & $15 / 16$ & $13 / 14$ & $11 / 12$ & $16 / 17$ & $29 / 30$ & $9 / 12$ & $22 / 23$ & $17 / 17$ & $10 / 0$ \\
\hline 115 & $X Y$ & $0 / 0$ & $14 / 0$ & $0 / 0$ & $17 / 0$ & $0 / 0$ & $0 / 0$ & $0 / 0$ & $15 / 0$ & $0 / 0$ \\
\hline 119 & $X X$ & $14 / 18$ & $10 / 13$ & $12 / 12$ & $16 / 18$ & $29 / 30$ & $11 / 11$ & $19 / 25$ & $17 / 0$ & $9 / 0$ \\
\hline 134 & $X Y$ & $15 / 16$ & $11 / 14$ & $11 / 12$ & $15 / 17 / 18$ & $29 / 30$ & $10 / 13$ & $22 / 22$ & $0 / 0$ & (10) \\
\hline 136 & $X Y$ & $15 / 17$ & $13 / 14$ & $11 / 12$ & $17 / 17$ & $29 / 30$ & $12 / 0$ & $19 / 27$ & $(14) /(17)$ & $(9) / 10$ \\
\hline 141 & $X Y$ & $15 / 15$ & $13 / 13$ & $11 / 12$ & $15 /(18)$ & $0 / 0$ & $12 / 12$ & $21 / 0$ & $0 / 0$ & $0 / 0$ \\
\hline 144 & $X Y$ & $14 / 17$ & $10 / 14$ & $11 / 12$ & $17 /(17)$ & $29 / 30$ & $13 / 13$ & $24 / 24$ & $13 / 14$ & $0 / 0$ \\
\hline 163 & $X Y$ & $16 / 0$ & $10 / 14$ & $12 / 0$ & $0 / 0$ & $0 / 0$ & $0 / 0$ & $0 / 0$ & $0 / 0$ & $0 / 0$ \\
\hline 164 & $X Y$ & $15 / 15$ & $13 / 15$ & $12 / 0$ & $18 / 0$ & $0 / 0$ & $0 / 0$ & $0 / 0$ & $0 / 0$ & $0 / 0$ \\
\hline 175 & $X(Y)$ & $15 / 17$ & $13 / 13$ & $13 / 0$ & $0 / 0$ & $0 / 0$ & $0 / 0$ & $25 / 0$ & $0 / 0$ & $0 / 0$ \\
\hline 182 & $X Y$ & $17 / 0$ & $13 / 0$ & $12 / 0$ & $0 / 0$ & $0 / 0$ & $0 / 0$ & $0 / 0$ & $15 / 15$ & $0 / 0$ \\
\hline 194 & $X X$ & $15 / 15$ & $10 / 12$ & $0 / 0$ & $0 / 0$ & $30 / 0$ & $0 / 0$ & $22 / 0$ & $(19) / 0$ & $10 / 0$ \\
\hline 196 & $X X$ & $15 / 18$ & $14 /(15)$ & $11 / 12$ & $14 / 16$ & $27 / 0$ & $0 / 0$ & $21 / 22$ & $17 / 17$ & $0 / 0$ \\
\hline 201 & I & $15 / 16$ & $11 / 13$ & $14 / 14$ & $0 / 0$ & $0 / 0$ & $0 / 0$ & $0 / 0$ & $0 / 0$ & $0 / 0$ \\
\hline 202 & $X Y$ & $15 /(15)$ & $12 / 14$ & $12 / 0$ & $16 / 19$ & $29 / 30$ & $0 / 0$ & $0 / 0$ & $18 / 0$ & $10 / 10$ \\
\hline 204 & $X Y$ & $15 / 16 / 17$ & $13 / 14$ & $11 / 13$ & $14 / 16 / 18$ & $29 / 30$ & $12 / 0$ & $22 / 0$ & $(13) /(17)$ & $10 / 10$ \\
\hline 208 & $X Y$ & $14 / 15$ & $11 / 13$ & $11 / 0$ & $0 / 0$ & $0 / 0$ & $9 / 12$ & $0 / 0$ & $0 / 0$ & $0 / 0$ \\
\hline 211 & $X Y$ & $15 / 15$ & $0 / 0$ & $12 / 0$ & $(14) / 0$ & $30 / 0$ & $0 / 0$ & $22 / 0$ & $0 / 0$ & $0 / 0$ \\
\hline 221 & $X Y$ & $16 / 0$ & $13 / 14$ & $11 / 12$ & $14 / 16$ & $30 / 30$ & $8 / 11$ & $19 / 21$ & $0 / 0$ & $0 / 0$ \\
\hline 227 & $X Y$ & $15 / 17$ & $13 / 14$ & $12 / 0$ & $19 / 0$ & $0 / 0$ & $0 / 0$ & $0 / 0$ & $0 / 0$ & $0 / 0$ \\
\hline 238 & $X Y$ & $15 / 15$ & $12 /(13)$ & $12 /(12)$ & $17 / 19$ & $30 / 31$ & $12 /(13)$ & $0 / 0$ & $15 / 15$ & (9) $/ 0$ \\
\hline 253 & $X Y$ & $15 / 17$ & $13 / 15$ & $12 / 12$ & $16 / 16$ & $29 / 30$ & $8 / 12$ & $22 / 0$ & $17 / 0$ & $11 / 0$ \\
\hline 256 & $X Y$ & $16 / 18$ & $0 / 0$ & $12 / 0$ & $14 / 0$ & $30 / 0$ & $12 / 0$ & $23 / 0$ & $0 / 0$ & $0 / 0$ \\
\hline 257 & $X Y$ & $18 / 0$ & $11 / 12 / 13$ & $0 / 0$ & $14 /(14)$ & $29 / 0$ & $0 / 0$ & $21 / 0$ & $14 / 0$ & $0 / 0$ \\
\hline 270 & $X Y$ & $17 /(17)$ & $10 / 12$ & $12 / 13$ & $15 / 17$ & $29 / 31.2$ & $10 / 12$ & $20 / 21$ & $16 / 0$ & $0 / 0$ \\
\hline 275 & $X Y$ & $15 / 16$ & $13 / 15$ & $11 / 12$ & $16 / 17$ & $30.2 / 0$ & $11 / 0$ & $22 / 0$ & $0 / 0$ & $11 / 0$ \\
\hline 278 & $X Y$ & $15 / 15$ & $12 /(14)$ & $(12) / 0$ & $(16) / 18$ & $30 / 0$ & $(8 / 12)$ & $22 / 22$ & $0 / 0$ & $9 /(10)$ \\
\hline 282 & $X Y$ & $16 / 18$ & $13 / 14 / 15$ & $11 /(12)$ & $14 / 20$ & $29 / 32.2$ & $11 / 13$ & $20 / 23$ & $0 / 0$ & $8 / 11$ \\
\hline 283 & $X Y$ & $15 / 17$ & $14 / 14$ & $11 / 12$ & $0 / 0$ & $29 / 0$ & $0 / 0$ & $0 / 0$ & $0 / 0$ & $0 / 0$ \\
\hline 303 & $X Y$ & $14 / 18$ & $13 / 14$ & $11 / 12$ & $17 / 17$ & $29 / 31.2$ & $12 / 0$ & $23 / 23$ & $0 / 0$ & $10 / 0$ \\
\hline
\end{tabular}


Fortsetzung Tabelle 5.4:

\begin{tabular}{|c|c|c|c|c|c|c|c|c|c|c|}
\hline Ind. & Sex & $D 3 S 1358$ & $D 8 S 1179$ & D5S818 & VWA & D21S11 & D13S317 & $F G A$ & D18S51 & D7S820 \\
\hline 326 & $X Y$ & $16 / 19$ & $11 / 15$ & $11 / 13$ & $17 / 18$ & $28 / 0$ & 10/12 & $19 / 22$ & $0 / 0$ & $10 / 0$ \\
\hline 330 & $X Y$ & $16 / 17$ & $13 / 14$ & $11 / 12$ & $14 / 17$ & $28 / 29$ & $11 / 13$ & $23 / 0$ & $12 / 19$ & $0 / 0$ \\
\hline 342 & $X Y$ & $15 /(17)$ & $10 / 15$ & $12 / 12$ & $16 / 17$ & $31.2 / 32.2$ & $13 / 14$ & $22 / 25$ & $14 / 0$ & $10 / 10$ \\
\hline 359 & $X Y$ & $15 / 16$ & $11 / 14$ & $11 / 13$ & $18 / 18$ & $28 / 29 / 30$ & $10 / 12$ & $21 / 23$ & $0 / 0$ & $0 / 0$ \\
\hline 363 & $X(Y)$ & $16 / 0$ & $14 / 0$ & $11 / 0$ & $17 / 0$ & $0 / 0$ & $0 / 0$ & $0 / 0$ & $0 / 0$ & $0 / 0$ \\
\hline 374 & $X Y$ & $15 / 16 / 17$ & $12 / 13 / 15$ & $9 / 11$ & $15 / 17 / 19$ & $28 / 30$ & $11 / 13$ & $20 / 24$ & $13 / 16$ & $12 / 0$ \\
\hline 385 & $X Y$ & 15/(15) & $12 / 14$ & $12 / 12$ & $18 / 19$ & $30 /(30)$ & $11 / 11$ & $22 / 23$ & $0 / 0$ & $0 / 0$ \\
\hline 399 & $X Y$ & $15 / 0$ & $9 /(13)$ & $12 / 0$ & $0 / 0$ & $0 / 0$ & $0 / 0$ & $0 / 0$ & $0 / 0$ & $0 / 0$ \\
\hline 409 & $X Y$ & $15 / 15$ & $13 /(13)$ & $11 / 12$ & $16 / 18$ & $30.2 / 31.2$ & $10 / 11$ & $21 / 22$ & $0 / 0$ & $10 / 12$ \\
\hline 414 & $X X$ & $17 / 17$ & $13 / 0$ & $10 / 11$ & $16 / 0$ & $31.2 / 0$ & $0 / 0$ & $0 / 0$ & $0 / 0$ & $0 / 0$ \\
\hline 442 & $X Y$ & $15 /(15)$ & $11 / 13$ & $12 /(12)$ & $0 / 0$ & $30 / 0$ & $13 / 0$ & $22 / 0$ & $0 / 0$ & $10 /(10)$ \\
\hline 464 & $X X$ & $(15) /(17)$ & $9 / 11$ & $11 / 12$ & $14 / 15$ & $0 / 0$ & $11 / 11$ & $21 / 21$ & $0 / 0$ & $0 / 0$ \\
\hline 478 & $X Y$ & $16 / 17$ & $11 / 13 / 14$ & $10 / 12$ & $(14) / 16$ & $30 / 0$ & $12 / 13$ & (21)22(25) & $12 / 14$ & $10 / 11$ \\
\hline 480 & $X Y$ & $15 / 17$ & $14 / 16$ & $11 / 13$ & 19/(19) & $29 / 29$ & $10 / 11 / 13$ & $22 / 23$ & $15 / 0$ & $10 / 11$ \\
\hline 488 & $X Y$ & $0 / 0$ & $13 / 0$ & $12 / 12$ & $0 / 0$ & $0 / 0$ & $11 / 0$ & $0 / 0$ & $0 / 0$ & $0 / 0$ \\
\hline 505 & $X(Y)$ & $15 / 16$ & $(14) /(14)$ & $(12) / 0$ & $(16 / 17)$ & $(30) /(31.2)$ & $(9 / 13)$ & $(21) / 24$ & $(12 / 13)$ & $(9) / 0$ \\
\hline 517 & $X Y$ & $16 / 17$ & $12 / 13$ & $12 / 12$ & $17 / 18$ & $30 / 32$ & $8 / 12$ & $25 / 0$ & $18 / 0$ & $10 / 10$ \\
\hline 567 & $X X$ & $17 / 18$ & $14 /(15)$ & $(9 /) 11 / 12$ & $(14)(15) 16 / 19$ & $30 / 32.2$ & $(12) / 0$ & $21 / 23 /(24)$ & $0 / 0$ & $(9) / 0$ \\
\hline 590 & $X Y$ & $0 / 0$ & $14 / 0$ & $11 / 12$ & $17 / 17$ & $0 / 0$ & $0 / 0$ & $0 / 0$ & $0 / 0$ & $0 / 0$ \\
\hline 610 & $X Y$ & $14 / 18$ & $10 / 11$ & $11 / 11$ & $15 / 16$ & $29 / 30$ & $14 / 0$ & $24 / 26$ & $0 / 0$ & $0 / 0$ \\
\hline 619 & $X Y$ & $14 / 18$ & $12 / 14$ & $9 / 10$ & $17 / 19$ & $30 / 30$ & $10 / 11$ & $20 / 22$ & $(13) / 17$ & $(10) / 11$ \\
\hline 620 & 1 & $18 / 0$ & $0 / 0$ & $0 / 0$ & $16 / 0$ & $0 / 0$ & $0 / 0$ & $24 / 0$ & $0 / 0$ & $0 / 0$ \\
\hline 631 & $X Y$ & $15 / 18$ & $11 / 12$ & $12 / 12$ & $15 / 16$ & $29 / 29$ & $8 / 12$ & $19 / 20$ & $0 / 0$ & $0 / 0$ \\
\hline 644 & $X Y$ & $15 / 18$ & $12 / 0$ & $9 / 12$ & $16 / 20$ & 29/31.2 & $9 / 11$ & $19 / 20$ & $0 / 0$ & $10 / 11$ \\
\hline 655 & $X Y$ & $13 / 16 / 17$ & $13 / 14$ & $12 / 0$ & $16 / 17 / 18$ & $30 / 0$ & $0 / 0$ & $21 / 0$ & $(19) / 0$ & $0 / 0$ \\
\hline 658 & $X Y$ & 18/(18) & $13 / 0$ & $0 / 0$ & $16 / 19$ & $0 / 0$ & $0 / 0$ & $22 / 23$ & $0 / 0$ & $0 / 0$ \\
\hline 668 & $x X$ & $14 / 15$ & $12 / 13$ & $13 / 13$ & $16 / 0$ & $0 / 0$ & $0 / 0$ & $21 / 22$ & $0 / 0$ & $0 / 0$ \\
\hline 696 & $X Y$ & $17 / 0$ & $13 / 15$ & $11 /(11)$ & $17 / 18$ & $28 / 29$ & $13 / 0$ & $19 / 23$ & $0 / 0$ & $0 / 0$ \\
\hline 697 & $X X$ & $15 / 18$ & $11 / 13$ & $(9) / 12$ & $16 / 16$ & $(26) / 30$ & $0 / 0$ & $22 /(23)$ & $0 / 0$ & $0 / 0$ \\
\hline 704 & $X Y$ & $15 / 16$ & $13 / 15$ & $12 / 13$ & $14 / 16$ & $31 / 31.2$ & $0 / 0$ & $20 / 22$ & $14 / 14$ & $12 / 0$ \\
\hline 748 & $X Y$ & $17 / 18$ & $10 / 13$ & $11 / 14$ & $16 / 17$ & $28 / 0$ & $(11) / 12$ & $20 / 24$ & $16 / 0$ & $(10) / 12$ \\
\hline 757 & $X Y$ & $15 / 18$ & $13 / 14$ & $11 / 0$ & $16 / 18$ & $31.2 / 0$ & $11 / 0$ & $21 / 22$ & $13 / 0$ & $11 / 11$ \\
\hline 781 & $X Y$ & $0 / 0$ & $0 / 0$ & $0 / 0$ & $0 / 0$ & $0 / 0$ & $11 / 0$ & $21 / 0$ & $15 / 0$ & $0 / 0$ \\
\hline 785 & $X Y$ & $15 / 16$ & $0 / 0$ & $9 / 12$ & $14 / 14$ & $32.2 / 0$ & $11 / 0$ & $0 / 0$ & $0 / 0$ & $0 / 0$ \\
\hline
\end{tabular}

Beim Vergleich der Amplifikationserfolge der einzelnen Systeme, dargestellt in Tabelle 5.5, wird deutlich, daß sich durch die Ergebnisse ein für die Amplifikation von alter DNA typisches Phänomen zeigen läßt: die Abnahme der Amplifikationserfolge innerhalb der größeren Systeme (im besonderen D18S51 und D7820). Für diese STR-Systeme, die eine Basenpaarlänge von über $250 \mathrm{bp}$ aufweisen, sind nur im deutlich geringeren Umfang Ergebnisse determiniert worden. 
Tabelle 5.5: Erfolgreich typisierte Allele pro STR-System in Abhängigkeit vom SystemGrößenumfang [bp]. Den Angaben liegen die 161 untersuchten Individuen des Weingartener Skelettkollektiv zugrunde.

\begin{tabular}{|c|c|c|}
\hline Locus & Längenbereich [bp] & Anzahl typisierbarer Allele \\
Amelogenin & 106,112 & 124 \\
D3S1358 & $114-142$ & 104 \\
D8S1179 & $128-168$ & 99 \\
D5S818 & $135-171$ & 100 \\
VWA & $157-197$ & 88 \\
D21S11 & $189-243$ & 75 \\
D13S317 & $206-234$ & 63 \\
FGA & $219-267$ & 80 \\
D18S51 & $273-341$ & 43 \\
D7S820 & $258-294$ & 37 \\
\hline
\end{tabular}

\subsubsection{Ergebnisse der Y-chromosomalen STR-Typisierungen}

Für 17 Individuen konnten spezifische Y-Haplotypen determiniert werden, wobei die Haplotypen dieser Individuen nicht zwingend durch vollständige Ergebnisse in allen vier verwendeten Systemen definiert sind. In einigen Fällen war trotz Typisierung von nur zwei Loci (vgl. z.B. Ind. 136 und 204, Tabelle 5.6) die Feststellung eines, das Individuum hinreichend gegen andere abgrenzenden Haplotyps möglich, da kein weiteres typisierbares Individuum die jeweilig determinierte Allelkombination aufwies.

Insgesamt wurden 16 verschiedene Y-Haplotypen definiert, wovon der als Haplotyp Y3 bezeichnete Y-Typ sicher von zwei Individuen geteilt wird (Individuum 270 und 409). Für 13 weitere Individuen war die Typisierung von mindestens zwei Y-STR-Systemen möglich. Anhand dieser Ergebnisse läßt sich für einige Individuen eine tentative Zuordnung $\mathrm{zu}$ einem der bereits definierten Haplotypen erreichen, dies gilt unter anderem für die Individuen 257, 282, 644, 757, die vermutlich dem Y-Haplotypen Y6 zuzuordnen sind. In diesen Fällen gelten die nicht-ermittelbaren Systeme weder als Übereinstimmung noch als Unterschied. Auch das Individuum 517 ist wahrscheinlich wie Individuum 221 dem Haplotypen Y1 zuzuordnen. In anderen Fällen ist die Zuordnung unsicherer: Für die Individuen 134, 359 und 658 kommt die Zugehörigkeit zum Haplotypen Y4 oder aber zum Haplotypen Y12 in Frage. Die eindeutige Zuordnung kann aufgrund des Ausfalls des 
Systems DYS19 nicht vorgenommen werden. Festzustellen ist, daß neun der gegeneinander abgrenzbaren Y-Haplotypen nur einmal in der untersuchten Bevölkerungsstichprobe auftreten.

Tabelle 5.6: Darstellung der Typisierungsergebnisse der Y-chromosomalen STRs und Zuordnung der Individuen zu den 16 determinierten Y-Haplotypen.

\begin{tabular}{|c|c|c|c|c|c|c|c|c|c|c|c|}
\hline Ind. & DYS19 & DYS38 & YS3 & DYS390 & Haplotyp & Ind. & DYS19 & DYS38 & DYS389II & DYS390 & Haplotyp \\
\hline 221 & 14 & 13 & 29 & 24 & Y1 & 136 & 15 & 15 & 0 & 0 & Y7 \\
\hline 517 & 14 & 13 & 0 & 24 & Y1? & 144 & 13 & 13 & 0 & 22 & Y8 \\
\hline 238 & 14 & 12 & 28 & 22 & Y2 & 202 & 15 & 12 & 0 & 23 & Y9 \\
\hline 303 & 14 & 12 & 0 & 22 & Y2/15? & 204 & 13 & 14 & 0 & 0 & Y10 \\
\hline 270 & 14 & 12 & 28 & 23 & Y3 & 227 & 15 & 12 & 0 & 22 & Y11 \\
\hline 409 & 14 & 12 & 28 & 23 & Y3 & 326 & 15 & 13 & 0 & 23 & Y12 \\
\hline 275 & 14 & 12 & 0 & 23 & Y3/15? & 330 & 13 & 13 & 0 & 24 & Y13 \\
\hline 704 & 14 & 12 & 0 & 23 & Y3/15? & 631 & 13 & 13 & 30 & 25 & Y14 \\
\hline 342 & 14 & 13 & 29 & 23 & Y4 & 655 & 14 & 12 & 30 & 0 & Y15 \\
\hline 134 & 0 & 13 & 29 & 23 & Y4/12? & 748 & 16 & 13 & 0 & 25 & Y16 \\
\hline 359 & 0 & 13 & 0 & 23 & Y4/12? & 374 & 0 & 13 & 29 & 0 & $?$ \\
\hline 658 & 0 & 13 & 0 & 23 & $Y 4 / 12 ?$ & 478 & 14 & 12 & 0 & 0 & $?$ \\
\hline 480 & 13 & 13 & 31 & 25 & Y5 & & & & & & \\
\hline 619 & 16 & 12 & 30 & 22 & Y6 & & & & & & \\
\hline 257 & 16 & 12 & 0 & 0 & Y6? & & & & & & \\
\hline 282 & 16 & 12 & 30 & 0 & Y6? & & & & & & \\
\hline 644 & 16 & 12 & 0 & 22 & Y6? & & & & & & \\
\hline 757 & 16 & 12 & 0 & 0 & Y6? & & & & & & \\
\hline
\end{tabular}

Die fett gedruckten Y-Haplotypen gelten als sicher gegeneinander abgrenzbare Y-Linien 


\subsubsection{Ergebnisse der Analyse mitochondrialer DNA}

Aus den hypervariablen Bereichen HVRI und II der Kontrollregion des Mitochondriums wurden drei Abschnitte amplifiziert und sequenziert, die zusammengenommen 380 Nukleotidpositionen umfassen. Das Vorhandensein von insgesamt 47 polymorphen Loci führte zur Definition von 50 gegeneinander abgrenzbaren mitochondrialen Sequenzen, die im folgenden als mt-Haplotypen bezeichnet werden.

Insgesamt 94 der Weingartener Individuen (45 aus Ranggruppe 1 und 49 aus Ranggruppe 0; 60 männliche und 34 weibliche Individuen,) waren den mt-Linien zuzuordnen. (Die Ergebnisse der Sequenzanalysen sind für alle Individuen in Tabelle 10.4 im Tabellenanhang dargestellt). Insgesamt existieren drei größere Matrilinien, deren spezifischer mt-Typ für mehrere Individuen nachgewiesen werden konnte. Der am häufigsten vertretene mt-Haplotyp (mt4) wird dabei von 13 Individuen geteilt. 32 Individuen besitzen singuläre mt-Haplotypen, die in der untersuchten Stichprobe kein weiteres Mal nachzuweisen sind. In sieben Fällen war die Zugehörigkeit von Individuen $\mathrm{zu}$ einer mt-Linie nicht einwandfrei festzustellen, da hier die Amplifikation eines der drei Fragmente kein Ergebnis erbrachte, hier ist nur eine tentative Zuordnung möglich. In Tabelle 5.7 ist die Verteilung der Individuen auf die nachgewiesenen Matrilinien aufgeführt. Tabelle 5.8 gibt die für jedes Individuum determinierte mt-Linie an.

Tabelle 5.7: Verteilung der Weingartener Individuen auf die 50 detektierten mt-Haplotypen.

\begin{tabular}{lcccccc}
\hline & $\begin{array}{c}\text { Singuläre mt- } \\
\text { Linien }\end{array}$ & $\begin{array}{c}2 \text { Ind./mt- } \\
\text { Linie }\end{array}$ & $\begin{array}{c}3 \text { Ind./mt- } \\
\text { Linie }\end{array}$ & $\begin{array}{c}7 \text { Ind./mt- } \\
\text { Linie }\end{array}$ & $\begin{array}{c}9 \text { Ind./mt- } \\
\text { Linie }\end{array}$ & $\begin{array}{c}13 \text { Ind./mt- } \\
\text { Linie }\end{array}$ \\
\hline Häufigkeit & 33 & 10 & 4 & 1 & 1 & 1 \\
\hline
\end{tabular}


Tabelle 5.8: Zuordnung der Weingartener Individuen zu den 50 definierten mt-Linien

\begin{tabular}{|c|c|c|c|c|c|}
\hline Ind. & mt-Linie & Ind. & mt - Linie & Ind. & mt - Linie \\
\hline 52 & $\mathrm{mt} 1$ & 175 & $\mathrm{mt} 10$ & 376 & mt29* \\
\hline 182 & $\mathrm{mt} 1$ & 202 & $\mathrm{mt} 10$ & 647 & $m t 29 *$ \\
\hline 221 & mt1 & 204 & $\mathrm{mt} 10$ & 696 & $\mathrm{mt} 29$ \\
\hline 256 & $\mathrm{mt1}$ & 385 & $\mathrm{mt} 10^{*}$ & 399 & $\mathrm{mt} 30$ \\
\hline 270 & mt1 & 409 & $\mathrm{mt} 10$ & 406 & $\mathrm{mt} 31$ \\
\hline 298 & mt1 & 551 & $\mathrm{mt} 10$ & 414 & $\mathrm{mt} 32$ \\
\hline 322 & $\mathrm{mt} 1$ & 689 & $\mathrm{mt} 10$ & 417 & $\mathrm{mt} 33$ \\
\hline 397 & $\mathrm{mt1}$ & 194 & $\mathrm{mt} 11$ & 441 & $\mathrm{mt} 34$ \\
\hline 715 & $\mathrm{mt1}$ & 196 & $\mathrm{mt} 12$ & 443 & $\mathrm{mt} 35$ \\
\hline 111 & $\mathrm{mt} 2$ & 757 & $\mathrm{mt} 12$ & 456 & $\mathrm{mt} 31$ \\
\hline 115 & $\mathrm{mt} 3$ & 206 & $\mathrm{mt} 13$ & 478 & $\mathrm{mt} 36$ \\
\hline 125 & $\mathrm{mt} 3$ & 208 & $\mathrm{mt} 14$ & 487 & $\mathrm{mt} 37$ \\
\hline 704 & $\mathrm{mt} 3$ & 303 & $\mathrm{mt} 14$ & 488 & $\mathrm{mt} 38$ \\
\hline 130 & $\mathrm{mt} 4$ & 214 & $\mathrm{mt} 15$ & 505 & $\mathrm{mt} 39$ \\
\hline 199 & $\mathrm{mt} 4$ & 227 & $\mathrm{mt} 16$ & 517 & $\mathrm{mt} 40$ \\
\hline 257 & $\mathrm{mt} 4$ & 232 & $\mathrm{mt} 17$ & 586 & $\mathrm{mt} 41$ \\
\hline 282 & $\mathrm{mt} 4$ & 644 & $\mathrm{mt} 17$ & 610 & $\mathrm{mt} 42$ \\
\hline 395 & $\mathrm{mt} 4$ & 238 & $\mathrm{mt} 18$ & 619 & $\mathrm{mt} 43$ \\
\hline 464 & $\mathrm{mt} 4$ & 556 & $\mathrm{mt} 18$ & 620 & $\mathrm{mt} 43$ \\
\hline 568 & $\mathrm{mt} 4$ & 241 & $\mathrm{mt} 19$ & 625 & $\mathrm{mt} 44$ \\
\hline 590 & $\mathrm{mt} 4$ & 243 & $m t 20^{*}$ & 658 & $\mathrm{mt} 45$ \\
\hline 612 & $\mathrm{mt} 4$ & 565 & $\mathrm{mt} 20$ & 668 & $\mathrm{mt} 46$ \\
\hline 631 & $\mathrm{mt} 4$ & 253 & $\mathrm{mt} 21$ & 699 & $\mathrm{mt} 47$ \\
\hline 697 & $\mathrm{mt} 4$ & 275 & $\mathrm{mt} 22$ & 724 & $\mathrm{mt} 42^{*}$ \\
\hline 781 & $\mathrm{mt} 4$ & 283 & $\mathrm{mt} 23$ & 748 & $\mathrm{mt} 42$ \\
\hline 785 & $\mathrm{mt} 4$ & 313 & $\mathrm{mt} 24$ & 796 & $\mathrm{mt} 48$ \\
\hline 134 & $\mathrm{mt5}$ & 326 & $\mathrm{mt} 25$ & 799 & $\mathrm{mt} 49$ \\
\hline 442 & $\mathrm{mt5}$ & 743 & $\mathrm{mt} 25^{*}$ & 164 & $\mathrm{mt} 50$ \\
\hline 136 & $\mathrm{mt} 6$ & 330 & $\mathrm{mt} 26$ & 179 & $\mathrm{mt} 50$ \\
\hline 141 & $\mathrm{mt} 7$ & 342 & $\mathrm{mt} 27$ & 344 & $\mathrm{mt} 50^{*}$ \\
\hline 144 & $\mathrm{mt} 8$ & 348 & $\mathrm{mt} 28$ & & \\
\hline 157 & $\mathrm{mt} 9$ & & & & \\
\hline 359 & $\mathrm{mt} 9$ & & & & \\
\hline
\end{tabular}

* Die Zugehörigkeit zur angegebenen mt-Linie ist aufgrund fehlender Sequenzierungsergebnisse des dritten Fragments nicht gänzlich abgesichert

\subsubsection{Geschlechtsdetermination}

Die Geschlechtsbestimmung der Individuen des Weingartener Gräberfeldes ist mit Hilfe von drei Methoden vorgenommen worden. So lagen bereits vor Beginn dieser Arbeit auf morphologischer Grundlage vorgenommene Geschlechtsbestimmungen der Skelettindividuen vor, zum anderen hatte von Seiten der bearbeitenden Archäologen eine Feststellung des Geschlechts stattgefunden, die sich an der Art der 
in den Gräbern gefundenen Beigaben orientierte. Im Rahmen der vorliegenden Arbeit erfolgte die Bestimmung des molekularen Geschlechts durch die Vermehrung eines Abschnitts des auf den Geschlechtschromosomen lokalisierten AmelogeninGens. Dieser Locus ist Bestandteil des AmpFlSTR Profiler Plus-Kits. In Tabelle 5.9 sind die Anzahlen der durch die verschiedenen Methoden geschlechtsbestimmten Individuen angegeben.

Tabelle 5.9: Anzahlen der Weingartener Individuen, deren Geschlecht anhand der drei angewandten Bestimmungsmethoden determinierbar war.

\begin{tabular}{|ccccc|}
\hline & unbestimmt & männlich & weiblich & bestimmbar [\%] \\
\hline Archäologisch & 33 & 67 & 61 & 79 \\
Anthropologisch & 34 & 56 (14 unsicher) & 47 (10 unsicher) & 63 \\
Molekular & 66 & 54 (12 unsicher) & 23 (6 unsicher) & 47 \\
\hline
\end{tabular}

Zwischen den drei Bestimmungsmethoden ergab sich für vier Individuen eine Diskordanz in Bezug auf die erhaltenen Geschlechtsdaten. In zwei dieser Fälle werden die Individuen dabei sowohl durch die archäologische als auch anhand der anthropologischen Bestimmung als weiblich determiniert, die Amplifikation der DNA weist diese Individuen jedoch aufgrund des Nachweises des Y-chromosomalen Fragments als männlichen aus. In zwei Fällen wurden Individuen durch die morphologische Analyse als männlich determiniert, während die molekularen Ergebnisse weibliches Geschlecht des Individuums nahegelegen.

Tab 5.10: Darstellung der Abweichungen in der Geschlechtsbestimmung der Weingartener Individuen zwischen den angewandten Untersuchungsmethoden.

\begin{tabular}{|cccc|}
\hline Individuum & $\begin{array}{c}\text { Archäologische } \\
\text { Determination }\end{array}$ & $\begin{array}{c}\text { Anthropologische } \\
\text { Determination }\end{array}$ & $\begin{array}{c}\text { Molekulare } \\
\text { Determination }\end{array}$ \\
\hline 141 & $\mathrm{w}$ & $\mathrm{w}$ & $\mathrm{m}$ \\
$\mathbf{3 7 4}$ & $\mathrm{w}$ & $\mathrm{w}$ & $\mathrm{m}$ \\
$\mathbf{2 2 1}$ & $?$ & $\mathrm{w}$ & $\mathrm{m}$ \\
$\mathbf{6 5 8}$ & $\mathrm{m}$ & $\mathrm{w}$ & $\mathrm{m}$ \\
\hline
\end{tabular}




\subsection{Vergleich der sozialen Ranggruppen durch Analyse der chromosomalen genetischen Variabilität}

Die Individuen der Weingartener Population sind durch das externes Kriterium der Grabinventare verschiedenen Gruppen zuzuordnen. Diese nach archäologischen Gesichtspunkten erfolgte Einteilung in zwei soziale Ranggruppen galt als Setzung für die durchgeführten genetischen Vergleichsuntersuchungen.

Durch den Vergleich der im weiteren als Subpopulationen aufgefassten Gruppen soll festgestellt werden, ob sich die Individuen der verschiedenen sozialen Ränge auch hinsichtlich ihrer genetischen Merkmalsausprägung unterscheiden, was in der Folge bedeuten würde, das es zwischen den Mitgliedern der beiden Gruppen nicht oder nur im geringen Ausmaß zu Fortpflanzungen gekommen ist. Als Grundlage der Analysen dienen die autosomalen STR-Datensätze und die Ergebnisse der Sequenzauswertungen der mitochondrialen DNA. Die Daten, die sich aus der Untersuchung der Y-chromosomalen Marker ergeben, waren aufgrund der geringen Stichprobengröße, zumindest für statistische Analysen, nicht verwertbar.

\subsubsection{Vergleich der Datensätze autosomaler STRs}

In der nachstehenden Tabelle 5.11 sind die deskriptiven Grunddaten zusammengefaßt, die sich durch die Analyse der autosomalen Mikrosatelliten innerhalb der beiden sozialen Ranggruppen der Weingartener Stichprobenpopulation ergeben haben. Angeführt ist die absolute Anzahl determinierter Chromosomen, was bedeutet, daß hier alle typisierten Allele angegeben sind, auch solche, die einer unvollständigen Typisierung entstammen, in der nur eines der beiden Allele des Locus bestimmbar war (z.B. 17/0). Dahingegen werden bei der Angabe der determinierten Genotypen nur jene Ergebnisse in Betracht gezogen, in denen beide Allele des Locus bestimmbar waren. Diese Unterscheidung ist wichtig, da in die nachfolgenden Berechungen nur die Daten vollständiger Genotypen Eingang finden. 
Tabelle 5.11: Vergleich der Grunddaten der autosomalen STRs für die beiden untersuchten Weingartener Sozialgruppen des höheren (Rang 1) und niederen Ranges (Rang 0). In die Anzahl der insgesamt determinierten Allele gehen auch solche Typisierungsergebnisse ein, in denen nur eines der beiden Allele des Locus bestimmbar war. In der Anzahl der heterozygoten und homozygoten Genotypen sind dagegen nur Typisierungen enthalten, für die beide Allele des Locus bestimmbar waren.

\begin{tabular}{l|cc|cc|cc|cc}
\hline \multicolumn{1}{|c|}{ Locus $^{1}$} & $\begin{array}{c}\text { Anzahl } \\
\text { determinierter Allele } \\
\text { insgesamt }\end{array}$ & $\begin{array}{c}\text { Nachgewiesene } \\
\text { Allele pro Locus }\end{array}$ & $\begin{array}{c}\text { Anzahl } \\
\text { heterozygoter } \\
\text { Genotypen }\end{array}$ & $\begin{array}{c}\text { Anzahl } \\
\text { homozygoter } \\
\text { Genotypen }\end{array}$ \\
\hline D3S1358 & 50 & 54 & 5 & 7 & 16 & 19 & 6 & 5 \\
D8S1179 & 47 & 52 & 7 & 7 & 20 & 19 & 1 & 3 \\
D5S818 & 47 & 53 & 6 & 4 & 21 & 16 & 8 & 6 \\
VWA & 43 & 45 & 6 & 7 & 13 & 15 & 5 & 5 \\
D21S11 & 35 & 40 & 7 & 7 & 11 & 13 & 2 & 3 \\
D135317 & 30 & 33 & 6 & 6 & 8 & 12 & 4 & 2 \\
FGA & 36 & 44 & 8 & 7 & 12 & 14 & 1 & 4 \\
D7S820 & 20 & 23 & 4 & 4 & 4 & 5 & 3 & 3 \\
D18551 & 18 & 19 & 6 & 6 & 4 & 3 & 1 & 4 \\
\hline
\end{tabular}

${ }^{1}$ Systeme aufgeführt nach Länge $[\mathrm{bp}]$

\subsubsection{Linkage Disequilibrium}

Wenn Analysen zur Häufigkeitsverteilung von Allelen vorgenommen werden, muß sichergestellt sein, daß die Genotypen der verwendeten Loci unabhängig voneinander vererbt werden. Abgesehen vom Locus D18S51, für den auf Grund der geringen Datenmenge eine Berechnung nicht möglich war, konnte für alle Locipaare gezeigt werden, daß keine allelische Assoziation zwischen den jeweiligen Systemen besteht (vgl. Tabelle 10.1 im Tabellenanhang).

\subsubsection{Allelfrequenzverteilung}

\subsubsection{Historische vs. rezente Stichprobe}

In der Abbildung 5.2 sind die Allelverteilungen in der Weingartener Gesamtpopulation den Allelfrequenzen einer rezenten deutschen Vergleichspopulation gegenübergestellt. Diese Überprüfung dient folgendem Zweck: 
Wie in Tabelle 5.5 dargestellt und wie sich vor allem auch in der Anzahl der typisierbaren Genotypen zeigt (vgl. Tabelle 5.11), lassen sich für die längeren STRSysteme geringere Amplifikationserfolge nachweisen, als für die kürzeren STRMarker. Zurückzuführen ist dies auf den hohen Fragmentierungsgrad der alten DNA, was das Vorhandensein von intakten Abschnitten, die eine gewisse Basenpaarlänge überschreiten, eher unwahrscheinlich macht. Es muß sichergestellt sein, daß es bei der Analyse der historischen Proben unter Umständen nicht zu einer technisch bedingten präferentiellen Amplifizierung der kleineren Fragmente eines jeweiligen Locus gekommen ist. Derartige Typisierungsfehler würden sich auf die statistische Auswertbarkeit des Datensatzes auswirken: die angezeigten Allelverteilungen könnten unter Umständen nicht-repräsentativ für die untersuchte historische Population sein. Aus diesem Grund ist ein Vergleich mit der Allelverteilung einer rezenten Bevölkerungsstichprobe angezeigt. Die Datengrundlage hierfür wurde durch die Genotypisierung von 66 nicht-verwandten Individuen aus verschiedenen Regionen Deutschlands geschaffen. Es handelt sich dabei um die Allelprofile von Mitarbeitern des Instituts für Zoologie und Anthropologie, deren genetische Fingerabdrücke als Vergleichskontrollen zur Feststellung etwaiger Kontaminationen erhoben wurden. Der Vergleich dieser Stichprobendaten mit publizierten Validitätsstudien an Stichproben rezenter Bevölkerungen (Anslinger et al. 2001a; Neuhuber et al. 1999) zeigen, daß mit der institutsinternen Datenbank eine repräsentative Stichprobe vorliegt. 

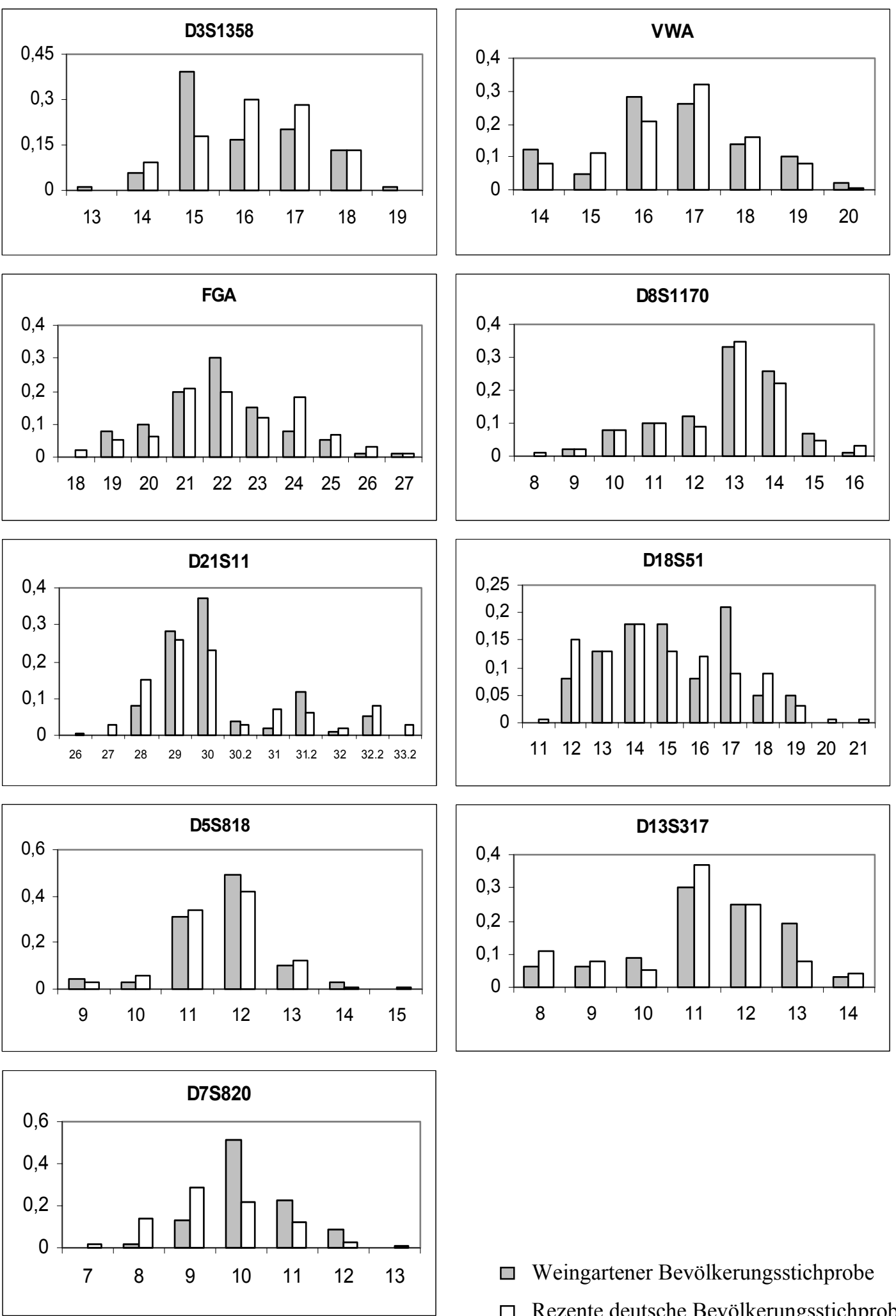

$\square$ Weingartener Bevölkerungsstichprobe

$\square$ Rezente deutsche Bevölkerungsstichprobe

Abbildung 5.2: Vergleich der Allelfrequenzen der neun autosomalen STR-Systeme zwischen der historischen Bevölkerungsstichprobe Weingartens und einer rezenten deutschen Bevölkerungsstichprobe. 
In der folgenden Tabelle 5.12 sind die p-Werte dargestellt, die sich bei der Überprüfung auf mögliche allelische Differenzierung zwischen der historischen und der rezenten Population ergeben. Beim Vergleich der Weingartener Gesamtpopulation mit der rezenten deutschen Vergleichspopulation ließ sich nur für das System D3S1358 ein p-Wert erhalten, der auf einen signifikanten Unterschied in der Allelfrequenzverteilung zwischen den Stichproben hinweist. Der globale Test unter Zusammenfassung aller Loci resultiert jedoch in einem $\mathrm{p}$-Wert oberhalb des Signifikanzniveaus, womit ein Unterschied in der Allelverteilung zwischen historischer und rezenter Bevölkerungsstichprobe zurückzuweisen ist. Die Allelfrequenzverteilung in der Weingartener Stichprobe ist also als repräsentativ anzusehen.

Tabelle 5.12: $\mathrm{p}$-Werte für den Vergleich zwischen der Weingartener Gesamtstichprobe und der rezenten Vergleichsstichprobe.

\begin{tabular}{|c|c|c|c|}
\hline & $\begin{array}{c}\text { WG-Gesamt } \\
\text { vs. } \\
\text { Rezent-Population }\end{array}$ & & $\begin{array}{c}\text { Anzahl der Allele } \\
n \\
\text { WG/Rezent }\end{array}$ \\
\hline Locus & $p$-Wert & S.E. ** & \\
\hline D3S1358 & $0,0036^{*}$ & 0,001 & $104 / 132$ \\
\hline VWA & 0,4657 & 0,011 & $88 / 132$ \\
\hline FGA & 0,3738 & 0,011 & $80 / 132$ \\
\hline D8S1179 & 0,9013 & 0,004 & $99 / 132$ \\
\hline D21S11 & 0,1656 & 0,007 & $75 / 132$ \\
\hline D18S51 & 0,7728 & 0,007 & $37 / 132$ \\
\hline D5S818 & 0,6186 & 0,010 & $100 / 132$ \\
\hline D13S317 & 0,3098 & 0,005 & $63 / 132$ \\
\hline D7S820 & 0,1152 & 0,006 & $43 / 132$ \\
\hline Multilocus & 0,0850 & & \\
\hline Multilocus (ohne D3S1358) & 0,4576 & & \\
\hline
\end{tabular}




\subsubsection{Sozialer Rang 1 vs. sozialer Rang 0}

In der folgenden Abbildung 5.3 ist die Verteilung der Allelfrequenzen zwischen den Weingartener Sozialgruppen dargestellt. Durch diesen Vergleich wird überprüft, ob es signifikante Abweichungen hinsichtlich der Allelverteilung zwischen den Subgruppen gibt. Eine Abweichung in den Häufigkeitsverteilungen würde dafür sprechen, daß zwischen den beiden Subgruppen eine Fortpflanzungsbarriere bestanden hat, die zur Herausbildung von unterschiedlichen Allelfrequenzen führte. 

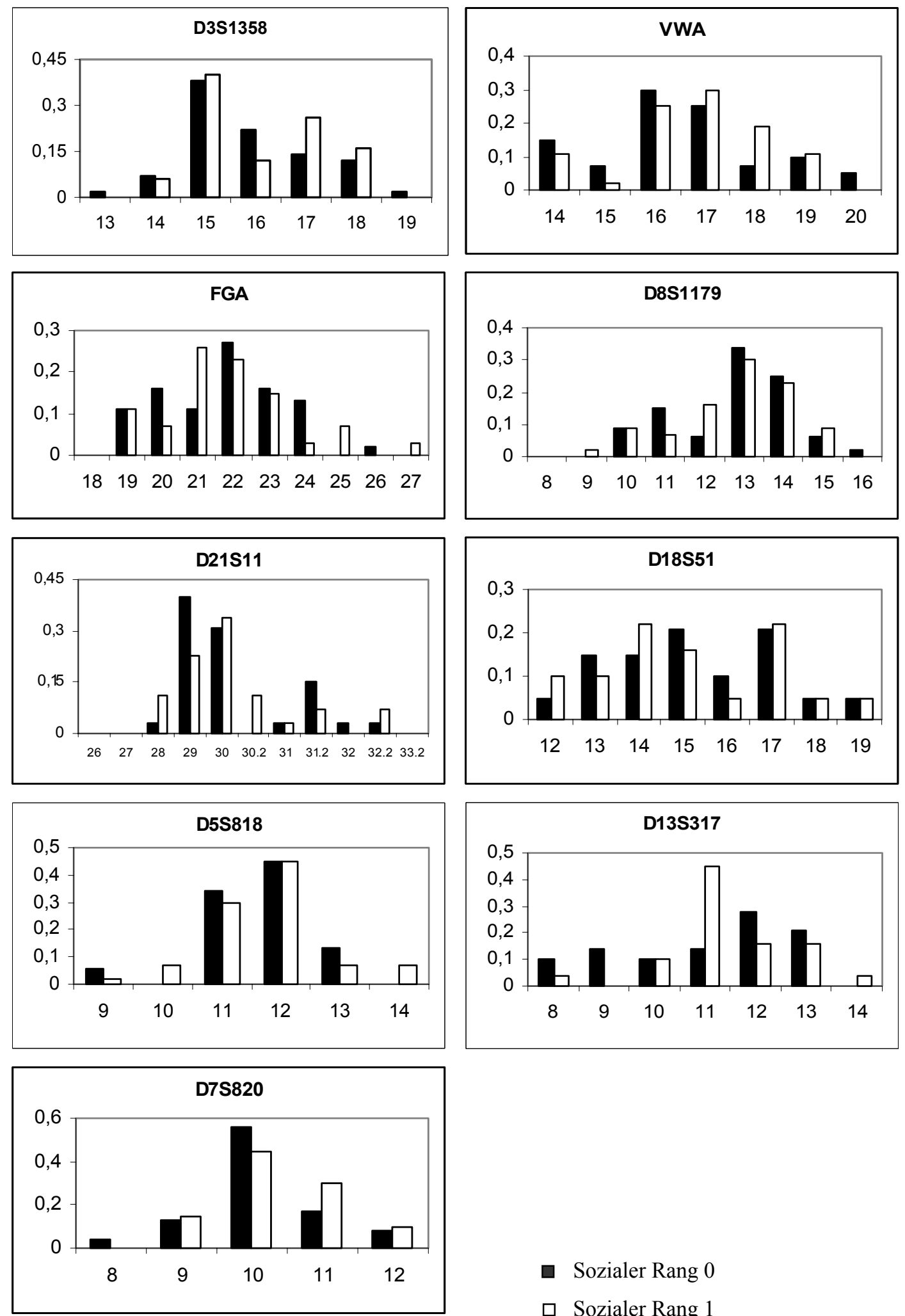

口 Sozialer Rang 0

$\square$ Sozialer Rang 1

Abbildung 5.3: Vergleich der Allelfrequenzen der neun autosomalen STR-Systeme zwischen den beiden Weingartener Sozialgruppen. 
In der folgenden Tabelle 5.13 sind die p-Werte zur Abschätzung der Unterschiede in der Allelverteilung zwischen den Weingartener Sozialgruppen Rang 1 und Rang 0 angegeben. Auch wenn die beiden Systeme D18S51 und D7S820 aufgrund der für sie vorliegenden geringen Stichprobengröße aus dieser Berechnung des p-Werts herausgenommen werden, bleibt der p-Wert auf einem nicht-signifikanten Niveau. Hiermit ist ein Unterschied in der Allelfrequenzverteilung der untersuchten Marker zwischen den beiden Sozialgruppen unwahrscheinlich, was ein Hinweis darauf ist, daß die Subgruppen voneinander nicht durch Paarungsschranken getrennt sind.

Tabelle 5.13: p-Werte für den Vergleich der Allelfrequenzen zwischen den sozialen Rängen R1 und R0.

\begin{tabular}{lccc}
\hline & $\begin{array}{c}\text { Rang } \\
\text { vs. } \\
\text { Rang } 0\end{array}$ & & $\begin{array}{c}\text { Anzahl der Allele } \\
n \\
R 1 / R 0\end{array}$ \\
\hline Locus & $p$-Wert & S.E. & \\
D3S1358 & 0,5158 & 0,008 & $50 / 54$ \\
VWA & 0,6656 & 0,007 & $43 / 45$ \\
FGA & 0,6454 & 0,008 & $36 / 44$ \\
D8S1179 & 0,7221 & 0,006 & $47 / 52$ \\
D21S11 & 0,6115 & 0,007 & $35 / 40$ \\
D18S51 & 1,0000 & 0,000 & $18 / 19$ \\
D5S818 & 0,1299 & 0,005 & $47 / 53$ \\
D13S317 & 0,2188 & 0,004 & $30 / 33$ \\
D7S820 & 0,8519 & 0,003 & $20 / 23$ \\
\hline Multilocus & $\mathbf{0 , 8 4 2 6}$ & \\
\hline Multilocus ohne D7820/D18S51 & $\mathbf{0 , 6 2 8 5}$ & & \\
\hline * Standard Error & & &
\end{tabular}

* Standard Error

\subsubsection{Genotypverteilung}

Im Zuge des Vergleichs zwischen den beiden definierten Subgruppen wurde ebenfalls getestet, ob eine mögliche Unterscheidung bezüglich der Genotypverteilung zwischen den sozialen Rängen besteht (vgl. Tabelle 5.14). Des weiteren wurde überprüft, ob eine Unterscheidung zwischen der historischen Gesamtpopulation und der rezenten Populationsstichprobe $\mathrm{zu}$ detektieren ist. Angegeben ist hierbei auch die Anzahl (n) der Genotypen, die in die Analyse 
eingegangen sind. Es zeigt sich ein ähnliches Ergebnis wie beim Vergleich der Allelfrequenzen. Beim Vergleich der historischen und der rezenten Probe ergibt sich im System D3S1358 ein p-Wert, der auf eine statistisch signifikante Abweichung hinweist, woraus sich begründet, daß bei der Berechnung des Gesamtwertes über alle Loci ein relativ niedriger $p$-Wert zu erhalten ist $(p=0,0847)$, der jedoch bei $p=0,4197$ liegt, wenn das System D3S1358 nicht in den globalen Test miteinbezogen wird.

Bei der Überprüfung auf Unterschiede hinsichtlich der Genotypverteilung zwischen den sozialen Ranggruppen, läßt sich aus dem globalen Test über alle Loci schließen, daß zwischen den untersuchten Subgruppen keine Unterschiede bestehen. Auch wenn die Systeme D7S820 und D18S51, für die sich nur eine reduzierte Anzahl von Genotypen aufweisen läßt und die deswegen möglicherweise nicht repräsentativ besetzt sind, aus der Berechnung hinausgenommen werden, wird das gesetzte Signifikanzniveau nicht unterschritten, so daß die Annahme bestehen bleibt, daß zwischen den Subgruppen keine Unterschiede bestehen.

Tabelle 5.14: p-Werte für den Vergleich der Genotyp-Verteilung zwischen den sozialen Rängen R1 und R0 und p-Werte, die sich für den Vergleich zwischen der Weingartener Gesamtpopulation und der rezenten Populationsstichprobe ergeben.

\begin{tabular}{|c|c|c|c|c|c|c|}
\hline & $\begin{array}{c}\text { Rang } 1 \\
\text { vs. } \\
\text { Rang } 0\end{array}$ & & $\begin{array}{c}\text { Anzahl } \\
\text { Genotypen } \\
\text { R1/RO }\end{array}$ & $\begin{array}{c}\text { WG-Gesamt } \\
\text { vs. } \\
\text { Rezent- } \\
\text { Population }\end{array}$ & & $\begin{array}{c}\text { Anzahl } \\
\text { Genotypen } \\
\text { WG/Rezent }\end{array}$ \\
\hline Locus & $p$-Wert & $S . E .{ }^{* *}$ & & $p$-Wert & S.E. ${ }^{* *}$ & \\
\hline D3S1358 & 0,7053 & 0,007 & $22 / 24$ & $0,0045^{*}$ & 0,001 & $46 / 66$ \\
\hline VWA & 0,5774 & 0,006 & $18 / 20$ & 0,5362 & 0,009 & $38 / 66$ \\
\hline FGA & 0,2881 & 0,006 & $13 / 18$ & 0,3277 & 0,008 & $31 / 66$ \\
\hline D8S1179 & 0,5679 & 0,006 & $21 / 22$ & 0,7943 & 0,005 & $43 / 66$ \\
\hline D21S11 & 0,3560 & 0,006 & $13 / 16$ & 0,2219 & 0,008 & $29 / 66$ \\
\hline D18S51 & 0,9150 & 0,002 & $5 / 7$ & 0,4945 & 0,011 & $12 / 66$ \\
\hline D5S818 & 0,1615 & 0,003 & $21 / 22$ & 0,7748 & 0,006 & $43 / 66$ \\
\hline D13S317 & 0,0766 & 0,003 & $12 / 14$ & 0,3344 & 0,009 & $26 / 66$ \\
\hline D7S820 & 1 & 0 & $7 / 8$ & 0,0811 & 0,004 & $15 / 66$ \\
\hline Multilocus & $\begin{array}{l}0,5617 \\
0,3078\end{array}$ & \multicolumn{2}{|c|}{$\begin{array}{c}\text { (ohne } \\
\text { D7S820/D18S51) }\end{array}$} & $\begin{array}{l}0,0847 \\
0,4195\end{array}$ & $\begin{array}{l}\text { (ohne } \\
\text { D3S1358) }\end{array}$ & \\
\hline
\end{tabular}

* signifikant bei $\alpha=0,05 \quad$ ** Standard Error 


\subsubsection{Hardy-Weinberg-Gleichgewicht}

Eine substrukturierte Bevölkerung kann durch die Fixation von Allelen in den jeweiligen Subpopulationen einen Heterozygoten-Mangel aufweisen und damit eine Abweichung vom Hardy-Weinberg-Gleichgewicht zeigen. Um dies zu überprüfen, wurde die Weingartener Gesamtstichprobe auf Einhaltung des HW-Gleichgewichts getestet.

Hierbei wurden gerichtete Tests durchgeführt, um deren Aussagekraft zu erhöhen. Im ersten Fall wurde die Alternativhypothese dahingehend formuliert, daß ein Heterozygotendefizit vorliegt. Bestünde die Weingartener Gesamtstichprobe aus zwei Subgruppen zwischen denen keine Zufallspaarungen stattfinden, würde dies unter Umständen dazu führen, daß in der Stichprobe, abweichend vom HWGleichgewicht, nur eine geringe Anzahl heterozygoter Individuen festzustellen sind.

Außerdem wurde ein gerichteter Test zur Überprüfung des Hardy-WeinbergGleichgewichts durchgeführt, in dem die Alternativ-Hypothese als Abweichung vom HW-Gleichgewicht aufgrund eines Heterozygoten-Überschusses formuliert wird. Dies hat einen methodischen Hintergrund: Aufgrund der strikten Kriterien, die bei der Untersuchung alter DNA für die Determination eines homozygoten Genotyps festgelegt sind (vgl. 3.8.2), kann es möglicherweise zu einer Unterrepräsentation homozygoter Allelausprägungen kommen.

In den im folgenden durchgeführten Tests, deren p-Wert Ergebnisse in Tabelle 5.15 aufgeführt sind, werden die Systeme D18S51 und D7820 aufgrund der reduzierten Anzahl von Genotypen aus der Berechnung des globalen p-Wertes ausgenommen. 
Tabelle 5.15: Angabe der p-Werte zu den gerichteten Tests auf Überprüfung des Hardy-WeinbergGleichgewichts innerhalb der Weingartener Gesamtpopulation.

\begin{tabular}{|c|c|c|}
\hline Locus & $\begin{array}{c}H W \text {-Gleichgewicht } \\
\text { (H } H_{1}=\text { Het. Defizit) }\end{array}$ & $\begin{array}{c}H W \text {-Gleichgewich } \\
\left(H_{1}=\text { Het. Excess) }\right.\end{array}$ \\
\hline D3S1358 & $0,6655 \pm 0,0132$ & $0,3379 \pm 0,0131$ \\
\hline VWA & $0,0743 \pm 0,0062$ & $0,9416 \pm 0,0055$ \\
\hline FGA & $0,4749 \pm 0,0152$ & $0,5301 \pm 0,0166$ \\
\hline D8S1179 & $0,9823 \pm 0,0025$ & $\mathbf{0 , 0 2 6 7 ^ { * }} \pm 0,0034$ \\
\hline D21S11 & $0,6069 \pm 0,0176$ & $0,3748 \pm 0,0181$ \\
\hline D5S818 & $0,0630 \pm 0,0045$ & $0,9320 \pm 0,0049$ \\
\hline D13S317 & $0,6319 \pm 0,0125$ & $0,3763 \pm 0,0110$ \\
\hline Globaler Test & $0,4699 \pm 0,0140$ & $0,5516 \pm 0,0152$ \\
\hline
\end{tabular}

Eine Abweichung der Weingartener Gesamtstichprobe vom Hardy-WeinbergGleichgewicht liegt weder bei Überprüfung auf Heterozygotendefizit noch auf -überschuß vor, werden alle untersuchten Loci gemeinsam betrachtet. Dies zeigt an, daß es keine Hinweise daraufhin gibt, daß es sich bei der Weingartener Bevölkerungsstichprobe um eine strukturierte Population handelt. Allerdings ergibt sich beim gerichteten Test auf Vorkommen eines Heterozygotenüberschusses für das System D8S1179 ein p-Wert von 0,0209, was auf ein überzufälliges Auftreten von Individuen mit heterozygoter Allelausprägung in diesem System hinweist.

\subsubsection{Heterozygotenrate}

Die genetische Diversität an jedem Locus wird über Vergleich der beobachteten Heterozygotenrate mit der im HW-Gleichgewicht erwarteten Heterozygotenrate überprüft. Angegeben wird in Tabelle 5.16 außerdem der F-(Inzuchtkoeffizient)Wert von Wright (Wright 1951) für jeden Locus und unter Zusammenfassung aller Loci, was Aussagen über das Paarungsverhalten innerhalb der Ranggruppen zuläßt. Als Inzucht oder Inbreeding wird Fortpflanzung zwischen Individuen verstanden, die gemeinsame Vorfahren aufweisen. Durch Inbreeding ändern sich nicht die Allelfrequenzen, jedoch aber die Genotypfrequenzen in der Population, die Heterozygotenrate nimmt durch Inzuchtprozesse innerhalb der Bevölkerung ab. Es wird in diesem Kontext die Abweichungen der beobachteten Genotypfrequenzen von 
den unter HW-Gleichgewicht erwarteten untersucht, die sich durch die nichtzufallsbedingte Verpaarung von Individuen ergibt. Der berechnete Wert F ist ein Maß für die Abweichung der Heterozygotenrate in der untersuchten Population, relativ zu einer panmiktischen Population, die die gleichen Allelfrequenzen aufweist. Es können sich verschiedene Ausprägungen des F-Wertes ergeben: In einer zufallspaarenden Population ergibt sich für F der Wert 0. F-Werte, die positiv sind, sprechen für bevorzugte Paarung mit verwandten Individuen, negative Werte dagegen für bevorzugte Auswahl von nicht-verwandten Individuen als Fortpflanzungspartner. Im folgenden werden die Systeme D18S51 und D7820 aufgrund der reduzierten Anzahl von Genotypen aus der Berechnung ausgenommen.

Tab. 5.16: Darstellung der Werte für die beobachtete $\left(\mathrm{H}_{\mathrm{obs}}\right)$ und die erwartete Heterozygotenrate $\left(\mathrm{H}_{\text {exp }}\right)$ für die sozialen Weingartener Subgruppen Rang 1 und Rang 0 und $\mathrm{H}_{\mathrm{obs}}$ und $\mathrm{H}_{\mathrm{exp}}$ für die gesamte Weingartener Populationsstichprobe unter Angabe des Inzuchtkoeffizienten F.

\begin{tabular}{l|ccc|ccc|ccc}
\hline & \multicolumn{3}{|c|}{ Rang 1 } & \multicolumn{3}{c|}{ Rang 0 } & \multicolumn{3}{c}{ WG-Gesamt } \\
\hline & $\mathrm{H}_{\text {obs }}$ & $\mathrm{H}_{\text {exp }}$ & $\begin{array}{c}\mathrm{F} \text { von } \\
\text { Wright }\end{array}$ & $\mathrm{H}_{\text {obs }}$ & $\mathrm{H}_{\text {exp }}$ & $\begin{array}{c}\mathrm{F} \text { von } \\
\text { Wright }\end{array}$ & $\mathrm{H}_{\text {obs }}$ & $\mathrm{H}_{\text {exp }}$ & $\begin{array}{c}\mathrm{F} \text { von } \\
\text { Wright }\end{array}$ \\
D3S1358 & 0,727 & 0,734 & $+0,009$ & 0,791 & 0,746 & $-0,060$ & 0,760 & 0,745 & $-0,020$ \\
VWA & 0,722 & 0,780 & $+0,074$ & 0,750 & 0,801 & $+0,063$ & 0,736 & 0,798 & 0,077 \\
FGA & 0,923 & 0,822 & $-0,122$ & 0,777 & 0,822 & $+0,053$ & 0,838 & 0,835 & $-0,003$ \\
D8S1179 & 0,952 & 0,795 & $-0,197$ & 0,863 & 0,777 & $-0,110$ & 0,906 & 0,791 & $-0,145$ \\
D21S11 & 0,846 & 0,786 & $-0,076$ & 0,812 & 0,709 & $-0,145$ & 0,827 & 0,756 & $-0,093$ \\
D5S818 & 0,619 & 0,683 & $+0,093$ & 0,727 & 0,653 & $-0,113$ & 0,674 & 0,672 & $-0,002$ \\
D13S317 & 0,666 & 0,733 & $+0,090$ & 0,857 & 0,818 & $-0,023$ & 0,769 & 0,801 & 0,03 \\
Multilocus & $\mathbf{0 , 7 7 9}$ & $\mathbf{0 , 7 6 1}$ & $\mathbf{- 0 , 0 2 3}$ & $\mathbf{0 , 7 9 6}$ & $\mathbf{0 , 7 6 0}$ & $\mathbf{- 0 , 0 4 7}$ & $\mathbf{0 , 7 8 7}$ & $\mathbf{0 , 7 7 1}$ & $\mathbf{- 0 , 0 2 0}$ \\
Ohne D8S1179 & $\mathbf{0 , 7 5 0}$ & $\mathbf{0 , 7 5 6}$ & $\mathbf{+ 0 , 0 0 7}$ & $\mathbf{0 , 7 8 5}$ & $\mathbf{0 , 7 5 8}$ & $\mathbf{- 0 , 0 3 5}$ & $\mathbf{0 , 7 6 7}$ & $\mathbf{0 , 7 6 8}$ & $\mathbf{0 , 0 0 1}$ \\
\hline
\end{tabular}

Zwischen den sozialen Rängen sind hinsichtlich der Locus-Diversität $\left(=\mathrm{H}_{\mathrm{exp}}\right)$ keine Unterschiede festzustellen.

Bei der Analyse über alle Loci ergibt sich in beiden Sozialgruppen ein negativer Wert für den Inzuchtkoeffizienten F. Dies würde dafür sprechen, daß in beiden Gruppen keine Zufallspaarungen stattfinden, sondern eine Strategie verfolgt wurde, die in der bewussten Auswahl von nicht-verwandten Individuen als Fortpflanzungspartner liegt. Diese Aussage steht jedoch unter gewissen Vorbehalten. Wird das System D8S1179, für das sich bei der Überprüfung des HW-Gleichgewicht eine überzufällig hohe Anzahl an heterozygoten Individuen feststellen ließ, aus 
diesem Grund von der Multilocus-Analyse ausgeschlossen und erfolgt die Berechnung nur mit den restlichen sechs Loci, läßt sich zumindest für die Ranggruppe 1 ein F-Wert erhalten, der nahe 0 liegt, was darauf hindeutet, daß hier eine zufallspaarende Population untersucht wurde. In der Ranggruppe 0 wird weiterhin ein negativer F-Wert erhalten, was auf Outbreeding-Verhalten hindeutet.

\subsubsection{F-Statistiken}

Die F-Statistiken werden zur Determinierung der Effekte herangezogen, die innerhalb einer Gesamtpopulation zur Abweichung vom Hardy-WeinbergGleichgewicht führen: Dies kann zum einen durch Substrukturierung der Population verursacht sein oder/und durch nicht zufallsbedingte Verpaarungen von Individuen innerhalb der Subpopulationen. Die F-Werte beschreiben ob und in welchem Ausmaß beide Effekte $\mathrm{zu}$ beobachten sind. Die Werte sind in Tabelle 5.17

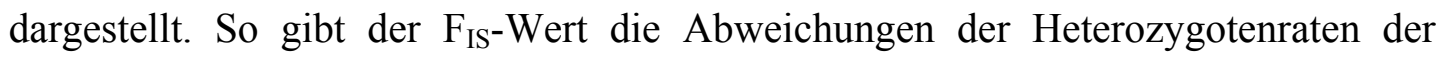
Individuen an, die auf das nicht-zufällige Paarungsverhalten innerhalb der Subpopulation zurückzuführen sind. Diese Abweichung kann in Form eines Heterozygoten-Defizits bestehen, was sich durch die überzufällig häufige Paarung zwischen nahe verwandten Individuen ergibt, also durch Inzuchtprozesse zu erklären ist. Ist die beobachtete Heterozygotenrate höher als die erwartete, ergibt sich ein negativer $\mathrm{F}_{\mathrm{IS}}$-Wert, was darauf zurückzuführen sein kann, daß Paarungen zwischen nicht-verwandten Individuen stattfinden (Outbreeding), die zum Beispiel aus entfernteren Populationen stammen. 
Tabelle 5.17: F-Statistiken für die sozialen Subgruppen der Weingartener Bevölkerungsstichprobe.

\begin{tabular}{lcc}
\hline \multicolumn{1}{c}{ Locus } & $F_{\text {IS }}$ & $F_{S T}$ \\
\hline D3S1358 & $-0,0049$ & $-0,0080$ \\
VWA & $+0,0960$ & $-0,0130$ \\
FGA & $+0,0136$ & $-0,0020$ \\
D8S1179 & $-0,1295$ & $-0,0076$ \\
D21S11 & $-0,0770$ & $+0,0079$ \\
D5S818 & $+0,0148$ & $-0,0110$ \\
D13S317 & $+0,0352$ & $+0,0471$ \\
\hline Gesamt & $-0,0094$ & $-0,0006$ \\
\hline Ohne & $+0,0160$ & $+0,0009$ \\
D8S1179 & & \\
\hline
\end{tabular}

$\mathrm{F}_{\mathrm{ST}}$ wird herangezogen, um das Ausmaß an genetischer Differenzierung zwischen Subpopulationen festzustellen. Ein $\mathrm{F}_{\mathrm{ST}}$-Wert um 0, wie er sich beim Vergleich der Weingartener Subpopulationen zeigt, steht für weitestgehende genetische Homogenität der untersuchten Stichprobe, damit für ein großes Maß an Genfluß und im Prinzip dafür, daß die Daten an einer Population erhoben wurde, die aus zufallspaarenden Individuen besteht, zwischen denen keine Paarungsschranken existieren.

Für die Weingartener Gesamtpopulation läßt sich unter Zugrundelegung aller Einzelwerte ein $\mathrm{F}_{\mathrm{IS}}-\mathrm{Werte}$ von $-0,0091$ erhalten. Wird allerdings das System D8S1179 aus den Berechnungen des Gesamtwertes ausgenommen, ergibt sich ein Wert, der positiv ist und bei 0,016 liegt, was bedeuten würde, das insgesamt die beobachteten Heterozygotenraten niedriger sind als die nach dem Hardy-WeinbergGleichgewicht erwarteten Heterozygotenraten. Dies spräche für das Vorkommen von Verpaarungen zwischen verwandten Individuen innerhalb des Weingartener Gesamtkollektives.

\subsubsection{Assignment-Test}

Im durchgeführten Assignment-Test werden die untersuchten Individuen einer der beiden Sozialgruppen zugeordnet, wobei als Entscheidungskriterium geprüft wird, wie wahrscheinlich das Auftreten des jeweiligen individualspezifischen Fingerprints 
in der einen oder anderen sozialen Ranggruppe ist. Als Basis dafür dienen die in den beiden Gruppen auftretenden Allelfrequenzen. In der Abbildung 5.4 ist in einer log-log Abtragung das Ergebnis dieses Tests graphisch dargestellt. Es wird hierbei deutlich, daß eine Trennung über die Genotypen nicht stattfindet, was in der Konsequenz bedeuten könnte, daß eine Vermischung zwischen den Individuen der Ranggruppen besteht.

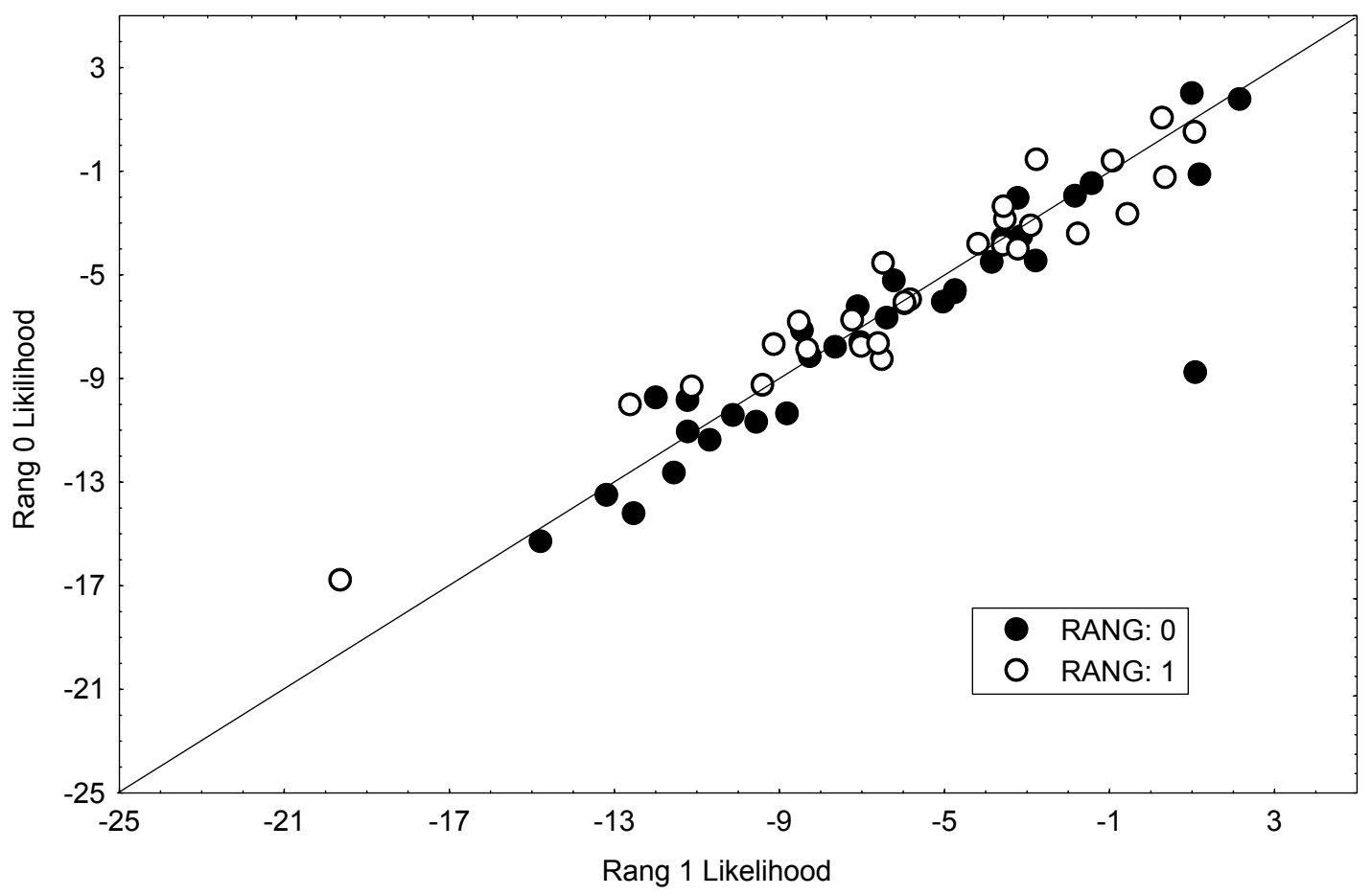

Abbildung 5.4 Zuordnung der Individuen zu den Subpopulationen Rang 1 und Rang 0 durch log-Likelihood Profile. Die Gleichheitslinien separiert die beiden Populationen. Individuen, die oberhalb dieser Linie liegen, sind aufgrund des Assignment-Tests der sozialen Gruppe Rang 0 zugeordnet, die darunter liegenden werden Rang 1 zugerechnet. 


\subsection{Vergleich der sozialen Ranggruppen durch Analyse mitochondrialer Sequenzen}

Zur Analyse der haploiden Datensätze wurde das Programm „ARLEQUIN“ (Schneider et al. 2000) verwendet. Dabei waren 365 der 380 Loci (=Nukleotide) in der AMOVA auswertbar, die restlichen Loci konnten aufgrund fehlender Daten nicht in die Auswertung einbezogen werden.

\subsubsection{AMOVA}

Für die mitochondrialen Daten wurde durch die AMOVA der Anteil der genetischen Varianz zwischen und innerhalb der Weingartener Subgruppen ermittelt und ein $\mathrm{F}_{\mathrm{ST}^{-}}$ Wert für das etwaige Ausmaß der Populationsstrukturierung berechnet. Die AMOVA-Statistiken sind in Tabelle 5.18 aufgeführt.

Tabelle 5.18: Anteile der Varianzkomponenten und der ermittelte $\mathrm{F}_{\mathrm{ST}}$-Wert für die Weingartener Stichprobe.

\begin{tabular}{c|ccccc}
\hline $\begin{array}{c}\text { Variabilitäts- } \\
\text { quelle }\end{array}$ & $\begin{array}{c}\text { Varianz- } \\
\text { komponenten }\end{array}$ & $\begin{array}{c}\% \\
\text { Variabilität }\end{array}$ & $F_{\text {ST }}$ & Probability & S.E. \\
\hline $\begin{array}{c}\text { Zwischen den } \\
\text { Subgruppen R1/RO }\end{array}$ & 0,01895 & 1,03 & 0,01027 & 0,11535 & 0,00812 \\
$\begin{array}{c}\text { Innerhalb der } \\
\text { Subgruppen R1/R0 }\end{array}$ & 1,82697 & 98,97 & & & \\
\hline
\end{tabular}

Durch Analyse der mitochondrialen Varianz in der Weingartener Gesamtstichprobe zeigt sich, daß nahezu die gesamte in der Population gezeigte Variabilität der mitochondrialen Sequenzen innerhalb der sozialen Subgruppen zu finden ist (98.97\%), während zwischen den Subgruppen nur geringe Unterschiede hinsichtlich der mitochondrialen Variabilität bestehen (1.03\%). Der $\mathrm{F}_{\mathrm{ST}}$-Wert liegt bei 0.01027 und ist nicht signifikant. Die Ergebnisse der AMOVA sind ein weiterer Hinweis darauf, daß es sich bei den untersuchten Ranggruppen nicht um zwei voneinander durch Paarungsschranken getrennte Subpopulationen handelt, sondern um eine homogene Bevölkerungsstichprobe. 


\subsubsection{Exakter Test zur Überprüfung von Populationsunterschieden}

Der Test nimmt als Nullhypothese Panmixie zwischen den Subgruppen an und untersucht, ob eine zufällige Verteilung der verschiedenen mt-Haplotypen zwischen den Gruppen vorliegt (Raymond \& Rousset 1995a; Goudet et al. 1996). Anhand des Testergebnisses ist davon auszugehen, daß sich die beiden untersuchten Weingartener Subgruppen aufgrund der mitochondrialen HaplotypFrequenzverteilungsmuster nicht voneinander differenzieren lassen.

Tabelle 5.19: Ergebnis des exakten Tests zur Überprüfung auf Populationsunterschiede.

\begin{tabular}{ccc}
\hline & Exakter p-Wert & S.E $^{*}$ \\
\hline Differentiations-Test zwischen & 0,58615 & $\pm 0,0251$ \\
sozialem Rang 1 und Rang 0 & & \\
\hline
\end{tabular}

* Standard Error

\subsubsection{Vergleich innerhalb der Subgruppen}

Für den Vergleich innerhalb der Subgruppen waren für beide Ranggruppen 368 von 380 Nukleotiden auswertbar. Aufgrund unzureichender Sequenz-Daten, die sich in dem Bereich des längsten (173 bp) amplifizierten Fragments ergaben, mussten in der Ranggruppe 0 die Haplotyp-Daten von sieben Individuen von der Analyse ausgenommen werden. Bei deren Mitführung wäre innerhalb des Auswertungsprogramms die Obergrenze unvollständiger Daten überschritten worden, was zur Nicht-Auswertung auch der restlichen Sequenzen geführt hätte. Die Resultate der intrapopulären Diversitäts-Analyse sind in der folgenden Tabelle 5.20 angegeben. 
Tabelle 5.20: Darstellung der molekularen Diversitäts-Indices der beiden untersuchten Ranggruppen.

\begin{tabular}{c|cc}
\hline & Rang 1 & Rang 0 \\
\hline Anzahl Individuen & 45 & 42 \\
Anzahl Haplotypen & 32 & 24 \\
Anzahl Loci & 380 & 380 \\
Anzahl verwendbarer Loci & 368 (mit weniger als 7\% & 368 (mit weniger als 7\% \\
fehlenden Daten) & fehlenden Daten) \\
Anzahl polymorpher Stellen & 37 & 26 \\
Gene Diversity & $0,9758 \pm 0,0127$ & $0,9408 \pm 0,0215$ \\
Nukleotid Diversität & $0,0122 \pm 0,0060$ & $0,0074 \pm 0,0047$ \\
Anzahl singulärer Linien & 18 & 14 \\
\hline
\end{tabular}

\subsubsection{Zusammenfassung der Ergebnisse des Gruppenvergleichs}

Die auf den Datensätzen der autosomalen STRs und der mitochondrialen Sequenzen beruhenden Analysen zeigen an, daß zwischen den archäologisch definierten Subgruppen keine genetisch nachweisbaren Unterscheidungen festzustellen sind. Vielmehr deuten alle Ergebnisse daraufhin, daß es sich bei der untersuchten Weingartener Populationsstichprobe um eine panmiktische Gemeinschaft von Individuen handelt, zwischen denen keine Paarungsschranken bestehen und innerhalb der unter Umständen verwandte Individuen zu Fortpflanzungspaaren zusammenfinden.

\subsection{Determination von Residenzverhalten}

Für die Determination des in einer Bevölkerung praktizierten postnuptialen Residenzverhaltens ist im Prinzip ein Vergleich der Variabilitäten von Y-STRs mit denen der mitochondrialen Sequenzen hervorragend geeignet (vgl. Kapitel 4.4). Hierbei werden die detektierten Variabilitäten der beiden paternal und maternal vererbten Marker zueinander in Bezug gesetzt. Da in der Weingartener Bevölkerungsstichprobe aufgrund der Amplifikationsausfällen der Y-chromosomalen STRs für diese Systeme eine nur geringe Datengrundlage vorliegt, wird die Rekonstruktion von Residenzmustern innerhalb der merowingerzeitlichen Population erschwert, da das erforderliche Bezugssystem nicht verfügbar ist. Zwar kann die 
Determination von Matrilokalität auch durch die alleinige Analyse von mitochondrialen Sequenzen gelingen, wobei dann ein Vergleich zwischen den Geschlechtergruppen stattfinden muß. Dahingegen stößt man beim Versuch des Nachweises von Patrilokalität an Interpretationsgrenzen (vgl. Kapitel 4.4).

Im folgenden wird ein Vergleich der relativen Datensätze auf rein deskriptiver Basis durchgeführt. Dabei wird auch eine Einbeziehung der Y-STR-Daten vorgenommen, die sich aufgrund der geringen Stichprobengröße anhand der verwendeten Statistiken nicht auflösen ließen. In Tabelle 5.21 sind die Zuordnungen der Weingartener Individuen $\mathrm{zu}$ den ermittelten maternalen und paternalen Linien dargestellt. Vervollständigt werden die Angaben durch das für die Individuen bestimmte Geschlecht und durch die Informationen zur sozialen Rangzugehörigkeit, die aufgrund der archäologischen Kriterien definiert wurde. 
Tabelle 5.21: Übersicht der Zugehörigkeiten der Weingartener Individuen zu den ermittelten mitochondrialen und Y-Linien unter Angabe von Rang und Geschlecht.

\begin{tabular}{|c|c|c|c|c|c|c|c|c|c|}
\hline Ind & Rang & mt-Linie & Y- Haplotyp & Sex & Ind & Rang & $m t$ - Linie & Y- Haplotyp & Sex \\
\hline 52 & 0 & $\mathrm{mt1}$ & & $\mathrm{m}$ & 232 & 1 & $\mathrm{mt} 17$ & & $\mathrm{~m}$ \\
\hline 182 & 0 & $\mathrm{mt} 1$ & & $\mathrm{~m}$ & 644 & 0 & $\mathrm{mt} 17$ & Y6? & $\mathrm{m}$ \\
\hline 221 & 0 & $\mathrm{mt1}$ & $\mathrm{Y} 1$ & $\mathrm{~m}$ & 238 & 1 & $\mathrm{mt} 18$ & Y2 & $\mathrm{m}$ \\
\hline 256 & 1 & $\mathrm{mt} 1$ & & $\mathrm{~m}$ & 556 & 1 & $\mathrm{mt} 18$ & & $w^{1}$ \\
\hline 270 & 0 & $\mathrm{mt} 1$ & Y3 & $\mathrm{m}$ & 241 & 1 & $\mathrm{mt} 19$ & & w \\
\hline 298 & 0 & $\mathrm{mt1}$ & & $\mathrm{m}^{1}$ & 243 & 1 & $\mathrm{mt} 20$ & & $w^{1}$ \\
\hline 322 & 0 & mt1 & & w & 565 & 1 & $\mathrm{mt} 20$ & & $m^{1}$ \\
\hline 397 & 0 & $\mathrm{mt} 1$ & & $?$ & 253 & 1 & $\mathrm{mt} 21$ & & $\mathrm{~m}$ \\
\hline 715 & 1 & $\mathrm{mt} 1$ & & $w^{1}$ & 275 & 1 & $\mathrm{mt} 22$ & Y3?Y15? & $\mathrm{m}$ \\
\hline 111 & 1 & $\mathrm{mt2}$ & & $w$ & 283 & 1 & $\mathrm{mt} 23$ & & $\mathrm{~m}$ \\
\hline 115 & 0 & $\mathrm{mt} 3$ & & $\mathrm{~m}$ & 313 & 1 & $\mathrm{mt} 24$ & & w \\
\hline 125 & 1 & $\mathrm{mt} 3$ & & w & 326 & 0 & $\mathrm{mt} 25$ & Y12 & $\mathrm{m}$ \\
\hline 704 & 0 & $\mathrm{mt} 3$ & Y3?Y15? & $\mathrm{m}$ & 743 & 0 & $\mathrm{mt} 25$ & & $\mathrm{~m}$ \\
\hline 130 & 0 & $\mathrm{mt} 4$ & & $\mathrm{~m} ?$ & 330 & 1 & $\mathrm{mt} 26$ & Y13 & $\mathrm{m}$ \\
\hline 199 & 0 & $\mathrm{mt} 4$ & & w & 342 & 1 & $\mathrm{mt} 27$ & Y4 & $\mathrm{m}$ \\
\hline 257 & 1 & $\mathrm{mt} 4$ & Y6? & $\mathrm{m}$ & 348 & 0 & $\mathrm{mt} 28$ & & w \\
\hline 282 & 0 & $\mathrm{mt} 4$ & Y6? & $\mathrm{m}$ & 376 & 0 & $\mathrm{mt} 29$ & & $\mathrm{~m}^{1}$ \\
\hline 395 & 1 & $\mathrm{mt} 4$ & & $\mathrm{~m} ?$ & 647 & 0 & $\mathrm{mt} 29$ & & w \\
\hline 464 & 1 & $\mathrm{mt} 4$ & & w & 696 & 1 & $\mathrm{mt} 29$ & & $m$ \\
\hline 568 & 0 & $\mathrm{mt} 4$ & & $w^{1}$ & 399 & 1 & $\mathrm{mt} 30$ & & $\mathrm{~m}$ \\
\hline 590 & 1 & $\mathrm{mt} 4$ & & $\mathrm{~m}$ & 406 & 1 & $\mathrm{mt} 31$ & & $\mathrm{~m}^{1}$ \\
\hline 612 & 1 & $\mathrm{mt} 4$ & & $?$ & 456 & 0 & $\mathrm{mt} 31$ & & $w^{1}$ \\
\hline 631 & 0 & $\mathrm{mt} 4$ & Y14 & $\mathrm{m}$ & 414 & 1 & $\mathrm{mt} 32$ & & w \\
\hline 697 & 0 & $\mathrm{mt} 4$ & & w & 417 & 0 & $\mathrm{mt} 33$ & & w \\
\hline 781 & 1 & $\mathrm{mt} 4$ & & $\mathrm{~m}$ & 441 & 0 & mt34 & & w \\
\hline 785 & 0 & $\mathrm{mt} 4$ & & $\mathrm{~m}$ & 443 & 0 & $\mathrm{mt} 35$ & & $w^{1}$ \\
\hline 134 & 0 & $\mathrm{mt5}$ & Y4?Y12? & $\mathrm{m}$ & 478 & 1 & $\mathrm{mt} 36$ & Y2?Y3?Y15? & $\mathrm{m}$ \\
\hline 442 & 0 & $\mathrm{mt5}$ & & $m$ & 487 & 1 & $\mathrm{mt} 37$ & & w \\
\hline 136 & 1 & $\mathrm{mt6}$ & Y7 & $\mathrm{m}$ & 488 & 0 & $\mathrm{mt} 38$ & & $\mathrm{~m}$ \\
\hline 141 & 0 & $\mathrm{mt} 7$ & & $\mathrm{~m}$ & 505 & 0 & $\mathrm{mt} 39$ & & $?$ \\
\hline 144 & 0 & $\mathrm{mt8}$ & Y8 & $\mathrm{m}$ & 517 & 0 & $\mathrm{mt} 40$ & Y1? & $\mathrm{m}$ \\
\hline 157 & 0 & $\mathrm{mt} 9$ & & w & 586 & 0 & $\mathrm{mt} 41$ & & $?$ \\
\hline 359 & 1 & $\mathrm{mt} 9$ & Y4?Y12 & $\mathrm{m}$ & 610 & 0 & $\mathrm{mt} 42$ & & $\mathrm{~m}$ \\
\hline 175 & 0 & $\mathrm{mt} 10$ & & $\mathrm{~m} ?$ & 724 & 1 & $\mathrm{mt} 42$ & & $w^{1}$ \\
\hline 202 & 1 & $\mathrm{mt} 10$ & Y9 & $\mathrm{m}$ & 748 & 1 & $\mathrm{mt} 42$ & Y16 & $\mathrm{m}$ \\
\hline 204 & 0 & $\mathrm{mt} 10$ & Y10 & $\mathrm{m}$ & 619 & 1 & $\mathrm{mt} 43$ & Y6 & $\mathrm{m}$ \\
\hline 385 & 1 & $\mathrm{mt} 10$ & & $m$ & 620 & 1 & $\mathrm{mt} 43$ & & $w^{1}$ \\
\hline 409 & 1 & $\mathrm{mt} 10$ & Y3 & $m$ & 625 & 0 & $\mathrm{mt} 44$ & & $\mathrm{~m}^{1}$ \\
\hline 551 & 0 & $\mathrm{mt} 10$ & & w & 658 & 0 & $\mathrm{mt} 45$ & Y4?Y12 & $\mathrm{m}$ \\
\hline 689 & 0 & $\mathrm{mt} 10$ & & $\mathrm{~m}$ & 668 & 1 & $\mathrm{mt} 46$ & & w \\
\hline 194 & 1 & $\mathrm{mt} 11$ & & w & 699 & 0 & $\mathrm{mt} 47$ & & $w^{1}$ \\
\hline 196 & 0 & $\mathrm{mt} 12$ & & w & 796 & 1 & $\mathrm{mt} 48$ & & w \\
\hline 757 & 1 & $\mathrm{mt} 12$ & Y6? & $m$ & 799 & 0 & $\mathrm{mt} 49$ & & $m^{1}$ \\
\hline 206 & 0 & $\mathrm{mt} 13$ & & $?$ & 164 & 0 & $\mathrm{mt} 50$ & & $\mathrm{~m}$ \\
\hline 208 & 0 & $\mathrm{mt} 14$ & & $\mathrm{~m}$ & 179 & 1 & $\mathrm{mt50}$ & & w \\
\hline 303 & 0 & $\mathrm{mt} 14$ & Y2?Y15? & $\mathrm{m}$ & 344 & 1 & $\mathrm{mt} 50$ & & w \\
\hline 214 & 1 & $\mathrm{mt} 15$ & & $w ?$ & 374 & 0 & n.d. & Y1?Y4?Y8?Y12 & $\mathrm{m}$ \\
\hline \multirow[t]{2}{*}{227} & 1 & $\mathrm{mt} 16$ & Y11 & $m$ & 480 & 0 & n.d. & Y5 & $\mathrm{m}$ \\
\hline & & & & & 655 & 0 & n.d. & Y15 & $\mathrm{m}$ \\
\hline
\end{tabular}

$w^{1}$ bzw. $m^{1}=$ Daten beruhen nur auf archäologischen und/oder anthropologischen Bestimmung, da für diese Individuen keine Ergebnisse zur molekularen Geschlechtsbestimmung vorliegen. n.d. = nicht determiniert 


\subsubsection{1 mt-Variabilität im Geschlechtervergleich}

Folgende Punkte sind beim Vergleich der mitochondrialen Variabilitäten zwischen den Geschlechtern zu beachten, die einer eingehenderen Betrachtung bedürfen. So ist die Anzahl der männlichen Individuen deutlich höher, 57 männlichen stehen 32 weibliche Individuen gegenüber, die Anzahl der in den Geschlechtergruppen vertretenen unterschiedlichen mt-Typen ist jedoch nahezu gleich: es lassen sich unter den Männern 33 mt-Linien ausmachen, innerhalb der Frauen sind 27 verschiedene Matrilinien festzustellen. Dies gründet sich darauf, daß für die weiblichen Individuen insgesamt 24 singuläre mt-Typen detektiert wurden und nur drei bzw. 2 Individuen identische mt-Typen zeigen (vgl. Tabelle 5.21). Es ist also im Geschlechtervergleich eine insgesamt geringere Variabilität innerhalb des männlichen mitochondrialen DNA-Pools festzustellen.

\subsubsection{Y-STR-Variabilität vs. männliche mt-Variabilität}

Eine besondere Betrachtung soll den 30 männlichen Individuen zukommen, für die eine Y-STR-Typisierung gelungen ist. Erschwert wird die Interpretation dieser Daten dadurch, daß zwar für 17 Individuen Typisierungsergebnisse zu erhalten waren, die für die eindeutige Definierung eines Y-Haplotypen hinreichend waren, für die übrigen Individuen war aber nur eine vorsichtige Zuordnung zu diesen Patrilinien vorzunehmen. Werden lediglich die 17 sicher eingeordneten Individuen betrachtet, ergibt sich, daß diese auf $16 \mathrm{Y}$-Haplotypen und $12 \mathrm{mt}$-Linien aufgeteilt sind. Der mt-Typus von zwei Individuen war nicht determinierbar. Mit relativ großer Wahrscheinlichkeit sind fünf weitere Individuen zwei der definierten Y-Linien zuzuordnen (vgl. Tabelle 5.6, Haplotypen Y1 und Y6). Dadurch würde sich ergeben, daß die insgesamt 22 männlichen Individuen 16 verschiedene Y-Haplotypen aufweisen und auf der anderen Seite $15 \mathrm{mt}$-Linien zuzuordnen sind. Werden weiterhin die sechs Individuen hinzugenommen, für die eine Zuordnung zu zwei unterschiedlichen Y-Haplotypen in Frage steht, was aufgrund fehlender Typisierungsergebnisse aber nicht endgültig abzuklären ist, lassen sich diese 28 männlichen Individuen auf 16 Patrilinien und 21 Matrilinien aufteilen. Da zwei der Y-typisierten Individuen ohne mt-Ergebnis waren, könnte sich diese Zahl auf 23 erhöhen. Damit bestünde für diese Individuen ein nicht unwesentlicher 
Unterschied hinsichtlich der Variabilität der Y-Haplotypen und der mitochondrialen Linien. Insgesamt 18 der Y-typisierten Individuen sind Matrilinien zuzuordnen, die innerhalb der Population mindestens durch ein weiteres Individuum vertreten sind. Acht der männlichen Individuen weisen mt-Typen auf, deren einziger Vertreter sie sind. Wie auch das vorher genannte Ergebnis, könnte auch dies ein Hinweis auf Patrilokalität sein.

\subsection{Genealogische Verwandtschaftsbeziehungen}

Das Weingartener Skelettkollektiv wurde auf das Vorhandensein direkter genealogischer Verwandtschaftsbeziehungen untersucht. Hierdurch soll überprüft werden, ob die Individuen, die anhand der genetischen Typisierungen als putative Mitglieder einer Kernfamilie angesehen werden können, dieselben Sozialgruppenzugehörigkeiten aufweisen.

Die Determination von putativen Familien gelingt über die Gruppierung von Individuen mit einheitlichen mt-Typen bzw. Y-Haplotypen, womit die potentielle Zugehörigkeit zu derselben maternalen bzw. paternalen Abstammungslinie dokumentiert ist. Durch den daran anschließenden Vergleich autosomaler Marker, findet schließlich eine Überprüfung auf direkte Verwandtschaftsverhältnisse im Sinne von Elternschaft statt (Schultes 2000).

Im folgenden ist eine Bewertung der Ergebnisse zum Teil bereits enthalten. Die sich für die Sozialstruktur der Weingartener Population ergebenden Interpretationen der Daten schließen sich in der Diskussion an. 


\subsubsection{Patrilineare Verwandtschaft}

In Tabelle 5.22 sind die Individuen aufgeführt, die aufgrund ihres Y-Haplotyps und aufgrund der autosomalen STR-Profile als putative Vater-Sohn-Paare in Frage kommen. Angegeben ist auch die für die jeweiligen Konstellationen berechnete Vaterschaftswahrscheinlichkeit (vgl. 4.5). Vorangestellt sei, daß auch weitere Verwandtschaftsverhältnisse nicht auszuschließen sind.

Tabelle 5.22. Zusammenstellung der Individuen, für die aufgrund der Y-chromosomalen und autosomalen STR-Profile ein direktes Verwandtschaftsverhältnis möglich ist.

\begin{tabular}{|c|c|c|c|c|c|c|}
\hline Ind. & Alter & Rang & Y-STRs & $\begin{array}{l}\text { Übereinstimmung } \\
\text { autosomaler STRs }\end{array}$ & $\begin{array}{c}\text { Vaterschafts- } \\
\text { wahrscheinlichkeit }\end{array}$ & mt-Linie \\
\hline 134 & adult & 0 & $00 / 13 / 29 / 23$ & mind. $50 \%$ & $97.01 \%$ & $\mathrm{mt5}$ \\
\hline 326 & matur & 0 & $15 / 13 / 00 / 23$ & & & $\mathrm{mt} 25$ \\
\hline 275 & adult & 1 & $14 / 12 / 00 / 23$ & mind. $50 \%$ & vgl. Tabelle 5,23 & $\mathrm{mt} 22$ \\
\hline 409 & adult & 1 & $14 / 12 / 28 / 23$ & & & $\mathrm{mt10}$ \\
\hline 704 & adult & 0 & $14 / 12 / 00 / 23$ & & & mt3 \\
\hline 257 & adult & 1 & $16 / 12 /(30) / 00$ & mind. $50 \%$ & Berechnung nicht & $\mathrm{mt} 4$ \\
\hline 282 & adult & 0 & $16 / 12 / 30 / 00$ & & möglich* & $\mathrm{mt} 4$ \\
\hline 282 & adult & 0 & $16 / 12 / 30 / 00$ & mind. $50 \%$ & $98,76 \%$ & $\mathrm{mt} 4$ \\
\hline 644 & adult & 0 & $16 / 12 / 00 / 22$ & & & $\mathrm{mt} 17$ \\
\hline 374 & adult & 0 & $00 / 13 / 00 / 00$ & mind. $50 \%$ & $78,59 \%$ ** & -- \\
\hline 748 & matur & 1 & $00 / 13 / 00 / 25$ & & & $\mathrm{mt} 42$ \\
\hline 478 & adult & 1 & $14 / 12 / 00 / 00$ & mind. $50 \%$ & Berechnung nicht & $\mathrm{mt} 36$ \\
\hline 655 & matur & 0 & $14 / 12 / 30 / 00$ & & möglich* & -- \\
\hline
\end{tabular}


Tabelle 5.23: Angabe der Vaterschaftswahrscheinlichkeiten für die Individuen 275, 409 und 704.

\begin{tabular}{c|cc}
\hline Mögliche & 275 (R1) & 704 (R0) \\
Vater-Sohn Beziehung & & \\
\hline 409 (R1) & $77,11 \% *$ & \\
704 (R0) & $88,79 \%$ & $88,99 \%$ \\
\hline
\end{tabular}

*Wert ergibt sich lediglich aus der Berechung von vier autosomalen Systemen.

Für die in Tabelle 5.22 aufgeführten Vater-Sohn-Paare ist allein anhand der vorliegenden genetischen Informationen ohne Kenntnis des Genotyps der Mutter nicht zu entscheiden, bei welchen der Individuen es sich um den Putativvater handelt und welche die Söhne darstellen könnten. Da alle betrachteten Individuen im reproduktionsfähigen Alter sind, lassen sich auch über die Alterangaben keine Aussagen über die Generationsabfolge erhalten.

Auch für die drei in Tabelle 5.23 gegenübergestellten Individuen ist eine Klärung der Generationsabfolge nicht möglich. Zu beachten ist außerdem, daß der Wert, der sich in der Berechnung der Vaterschaftswahrscheinlichkeit für die Konstellation der Individuen 409/275 ergibt, vor allen Dingen deswegen niedriger ist, weil hier aufgrund der zum Teil unvollständigen Typisierung beider Individuen insgesamt fünf der neun Systeme aus der Berechnung ausgenommen werden müssen (vgl. Tabelle 5.24).

Tabelle 5.24: Ergebnisse der autosomalen Typisierungsergebnisse für die Individuen 275, 409 und 704, die vermutlich in einen konkreten Familienzusammenhang gestellt werden können.

\begin{tabular}{|l|l|c|c|c|c|c|c|c|c|c|}
\hline Ind. & Sex & D3S1358 & D8S1179 & D5S818 & VWA & D21S11 & D13S317 & FGA & D18S51 & D7S820 \\
\hline $\mathbf{2 7 5}$ & $\mathrm{XY}$ & $15 / 16$ & $13 / 15$ & $11 / 12$ & $16 / 17$ & $30.2 / 0$ & $11 / 0$ & $22 / 0$ & $0 / 0$ & $11 / 0$ \\
\hline $\mathbf{4 0 9}$ & $\mathrm{XY}$ & $15 / 15$ & $13 /(13)$ & $11 / 12$ & $16 / 18$ & $30.2 / 31.2$ & $10 / 11$ & $21 / 22$ & $0 / 0$ & $10 / 12$ \\
\hline $\mathbf{7 0 4}$ & $\mathrm{XY}$ & $15 / 16$ & $13 / 15$ & $12 / 13$ & $14 / 16$ & $31 / 31.2$ & $0 / 0$ & $20 / 22$ & $14 / 14$ & $12 / 0$ \\
\hline
\end{tabular}

Durch die Prüfung der autosomalen STRs ist unter Umständen auch die Frage nach der patrilinearen Zugehörigkeit der Individuen 275 (Y-Typ: 14/12/00/00) und 704 (Y-Typ: 14/12/00/23) zu klären. Für beide war aufgrund fehlender Typisierungsergebnisse der Y-Marker (vgl. Tabelle 5.6) die Zuordnung zu zwei feststehenden Y-Haplotypen in Betracht zu ziehen. Es war nicht zu entscheiden, ob 
die Individuen möglicherweise der Patrilinie Y3 zuzuordnen sind, die durch das Individuum 409 (Y-Typ: 14/12/28/23) repräsentiert wird oder der Patrilinie Y15, vertreten durch das Individuum 655 (Y-Typ: 14/12/30/00). Dadurch, daß die Individuen 409, 275 und 704 wahrscheinlich in einen engen familiären Zusammenhang im Sinne einer Kernfamilie zu stellen sind, erscheint es auch plausibel die Individuen 275 und 704 der Patrilinie Y3 zuzuordnen.

Nicht ausgeschlossen werden können für fast alle angeführten Individuen-Paare und das dargestellte Terzett auch weitere Verwandtschaftsverhältnisse. So ist z.B. denkbar, daß es sich bei einem Individuen-Paar, das denselben Y-Haplotypen aufweist, um Halbgeschwister handelt, die denselben Vater haben oder aber um Cousins, die in väterliche Linie miteinander verwandt sind. Auszuschließen ist dies allerdings für das Individuenpaar 257 / 282, die dieselbe Matrilinie aufweisen (vgl. hierzu auch Tabelle 5.27). Ebenfalls nicht auszuschließen ist für die meisten Individuen-Paare auch eine Verwandtschaftsbeziehung im Sinne von in väterlicher Linie verbundenen Onkel und Neffen, wovon wiederum die Individuen 257 / 282 wahrscheinlich ausgenommen sind. Nicht entkräftet, aber unwahrscheinlicher werden diese vom Vater-Sohn-Verwandtschaftskonzept abweichenden Theorien allerdings dadurch, daß alle Individuen-Paare, für die eine Berechung möglich ist, eine mindestens 50\% Übereinstimmung der autosomalen STRs aufweisen, wie es für Elter-Kind-Beziehungen zu erwarten ist. Zwei Individuen, die nicht in diesem direkten Verwandtschaftsbezug zueinander stehen, können selbstverständlich eine genauso hohe Anzahl übereinstimmender Allele zeigen, es bleibt jedoch zu bedenken, daß sogar Vollgeschwister kein identisches Allel miteinander teilen müssen. Als abschließende Aussage kann so vielleicht dennoch gelten, daß verwandtschaftliche Verbindungen zwischen den Individuen im Sinne von VaterSohn am plausibelsten erscheinen.

\subsubsection{Matrilineare Verwandtschaft}

In der Tabelle 5.25 sind die Individuen verzeichnet, die einheitliche mt-Haplotypen aufweisen, also potentiell derselben maternalen Linie angehören und die darüber hinaus eine mindestens 50\% Übereinstimmung der autosomalen STR-Profile zeigen. Der Abgleich der autosomalen STRs ist nur angezeigt, wenn es sich bei den 
fraglichen Individuen um männliche $u n d$ weibliche handelt, so daß eine Überprüfung auf Mutter-Sohn-Paare stattfinden kann. Aufgrund geringer Typisierungserfolge der autosomalen STR-Systeme, ist dieser Vergleich nur für eine relativ geringe Anzahl von Individuen durchführbar. In Tabelle 5.25 sind nur die beiden Mutter-Sohn-Paare dargestellt, für die sich durch Überprüfung der autosomalen STRs kein Verwandtschaftsausschluß ergibt. Dies bedeutet nicht, daß nicht weitere MutterSohn/(Söhne)-Paare in der Weingartener Bevölkerungsstichprobe vorliegen. So läßt sich Tabelle 5.21 entnehmen, daß mehrere Matrilinien bestehen, der männliche und weibliche Individuen angehören (unter anderen $\mathrm{mt} 1, \mathrm{mt} 3, \mathrm{mt} 4$ etc.). Für diese Individuen ist ein konkretes Verwandtschaftsverhältnis im Sinne einer Mutter-Sohn Beziehung nicht auszuschließen, eine Überprüfung durch autosomale STR-Profile kann aber aufgrund fehlender Typisierungsergebnisse nicht durchgeführt werden.

Tabelle 5.25: Aufführung von Individuen, für die ein Verwandtschaftsverhältnis Mutter-Sohn möglich ist

\begin{tabular}{cccccc}
\hline Ind. & Sex & Rang & mt-Linie & $\begin{array}{c}\text { Übereinstimmung } \\
\text { autosomaler STRs }\end{array}$ & $\begin{array}{c}\text { Mutterschaftswahr- } \\
\text { scheinlichkeit }\end{array}$ \\
\hline 464 & $\mathrm{w}$ & 1 & $\mathrm{mt} 4$ & mind. 50\% & $\begin{array}{c}\text { Berechnung nicht } \\
\text { möglich* }\end{array}$ \\
785 & $\mathrm{~m}$ & 0 & $\mathrm{mt} 4$ & & $89,48 \%$ \\
196 & $\mathrm{w}$ & 0 & $\mathrm{mt} 12$ & mind. 50\% & \\
757 & $\mathrm{~m}$ & 1 & $\mathrm{mt} 12$ & & \\
\hline
\end{tabular}

${ }^{*}$ Aufgrund unvollständiger Typisierungsergebnisse der autosomalen STRs ist eine Berechnung der Mutterschaftswahrscheinlichkeit nicht möglich.

Das weibliche Individuum 697, das der Matrilinie mt4 (vgl. Tabelle 5.21) zugeordnet ist, konnte in sechs STR-Systemen genotypisiert werden. Abgleich mit Individuen, die derselben Matrilinie zugeordnet sind und für die ausreichende Typisierungsergebnisse vorliegen, zeigen, daß das Individuum 697 als putative Mutter dieser Individuen auszuschließen ist.

In Tabelle 5.26 sind die männlichen Individuen aufgeführt, die derselben Matrilinie zuzuordnen sind und für die gleichzeitig Y-STR-Daten vorliegen. Zeigen zwei männliche Individuen identische mt-Haplotypen, ist das Verwandtschaftsverhältnis nicht unmittelbar zu erschließen, abgesehen davon, daß sie über die mütterliche 
Verwandtschaftslinie verbunden sind. Liegen als zusätzliche Information jedoch Y-STR Daten vor, die auf einen ebenfalls identischen Y-Haplotypen hinweisen, wie im Falle der Individuen 257 und 282, erscheint es plausibel diese Individuen als Brüder einzuordnen, obwohl auch andere Verwandtschaftsbeziehungen nicht auszuschließen sind. Umgekehrt gilt aber, daß bei Nichtübereinstimmen der Ychromosomalen Marker eine solche Verbindung auszuschließen ist, wie z.B. für die Individuen 221 und 270 demonstriert werden kann. Männliche Individuen, für die zwar ein einheitlicher mt-Typus nachgewiesen ist, für die jedoch keine Y-STR Informationen vorliegen, sind in der Tabelle 5.26 nicht angeführt.

Tabelle 5.26: Darstellung von möglichen und auszuschließenden Verwandtschaftsverhältnissen durch Gruppierung von männlichen Individuen, die Übereinstimmung der mütterlichen Linien zeigen.

\begin{tabular}{|c|c|c|c|c|c|}
\hline Ind. & Sex & Rang & mt-Linie & $\begin{array}{c}\text { Übereinstimmung Y- } \\
\text { STRs }\end{array}$ & $\begin{array}{l}\text { Mögliches } \\
\text { Verwandtschafts- } \\
\text { verhältnis }\end{array}$ \\
\hline 221 & $\mathrm{~m}$ & 0 & mt1 & $14 / 13 / 29 / 24$ & Keine \\
\hline 270 & $\mathrm{~m}$ & 0 & mt1 & $14 / 12 / 28 / 23$ & $\begin{array}{c}\text { paternale } \\
\text { Verwandtschaft }\end{array}$ \\
\hline 257 & $\mathrm{~m}$ & 1 & $\mathrm{mt} 4$ & 16/12/(30)/00 & Brüder? \\
\hline 282 & $\mathrm{~m}$ & 0 & $\mathrm{mt} 4$ & $16 / 12 / 30 / 00$ & \\
\hline 257 & $\mathrm{~m}$ & 1 & $\mathrm{mt} 4$ & $16 / 12 /(30) / 00$ & Keine \\
\hline 282 & $\mathrm{~m}$ & 0 & $\mathrm{mt} 4$ & $16 / 12 / 30 / 00$ & paternale \\
\hline 631 & $\mathrm{~m}$ & 0 & $\mathrm{mt} 4$ & $13 / 13 / 30 / 25$ & Verwandtschaft \\
\hline 202 & $\mathrm{~m}$ & 1 & $\mathrm{mt} 10$ & $15 / 12 / 00 / 23$ & Keine \\
\hline 204 & $\mathrm{~m}$ & 0 & $\mathrm{mt} 10$ & $13 / 14 / 00 / 00$ & paternale \\
\hline 409 & $\mathrm{~m}$ & 1 & $\mathrm{mt} 10$ & $14 / 12 / 28 / 23$ & Verwandtschaft \\
\hline
\end{tabular}

Die Individuen 257 und 282 können aufgrund ihrer Übereinstimmung der patri- und matriliniaren Marker als putatives Brüderpaar angenommen werden. Allerdings ist auch eine Verwandtschaftsbeziehung im Sinne eines Vater-Sohn-Verhältnisses, wie in Tabelle 5.22 angezeigt, vorstellbar. In diesem Fall würde der Putativvater denselben mt-Haplotypen aufweisen, wie die zum Familienterzett gehörende Mutter. Als Vater für 282 kommt jedoch mit einer relativ hohen Vaterschaftswahrscheinlichkeit auch Individuum 644 in Frage (vgl. Tabelle 5.22 und Tabelle 5.27). 
Tabelle 5.27: Typisierungsergebnisse der Individuen 644 und 282, die als putatives Vater-Sohn-Paar in Frage stehen und Individuum 257, der als Putativbruder von 282 in Frage kommt.

\begin{tabular}{|c|c|c|c|c|c|c|c|c|c|c|c|}
\hline Ind. & SeX & D3S1358 & D8S1179 & D5S818 & VWA & D21S11 & D13S317 & FGA & D18S51 & D7S820 & mt-Typ \\
\hline $\mathbf{6 4 4}$ & XY & $15 / 18$ & $12 / 0$ & $9 / 12$ & $16 / 20$ & $29 / 31.2$ & $9 / 11$ & $19 / 20$ & $0 / 0$ & $10 / 11$ & $\mathrm{mt} 17$ \\
$\mathbf{2 8 2}$ & $\mathrm{XY}$ & $16 / 18$ & $13 / 14 / 15$ & $11 /(12)$ & $14 / 20$ & $29 / 32.2$ & $11 / 13$ & $20 / 23$ & $0 / 0$ & $8 / 11$ & $\mathrm{mt}$ \\
\hline \multicolumn{10}{|c|}{257 möglicherweise Putativ-Bruder von 282, Vaterschaft von 644 zu 257 aber eher auszuschließen } \\
(vgl. System VWA) \\
\hline $\mathbf{2 5 7}$ & $\mathrm{XY}$ & $18 / 0$ & $11 / 12 / 13$ & $0 / 0$ & $14 /(14)$ & $29 / 0$ & $0 / 0$ & $21 / 0$ & $14 / 0$ & $0 / 0$ & $\mathrm{mt}$ \\
\hline
\end{tabular}

Als Vater von 257 scheint Individuum 644 aufgrund einer Unstimmigkeit im System VWA nicht in Frage zu kommen, allerdings ist für das Individuum 257 das zweite Allel bei VWA nur als unsicher determiniertes Allel verzeichnet, so daß ein endgültiger Ausschluß nicht vorgenommen werden kann.

Für die übrigen in Tabelle 5.26 aufgeführten Individuen, die denselben Matrilinien zugeordnet sind, kann ein Verwandtschaftsverhältnis über die paternale Linie ausgeschlossen werden.

\subsection{Kontrollproben}

\subsubsection{Autosomale und Y-chromosomale STRs}

Zur Überprüfung der Daten auf etwaige Kontaminationen, wurde das SoftwareProgramm ,aDNA-Typing“ verwendet, das für die speziellen Anforderungen dieser Arbeit konzipiert wurde. Das von der Firma MoReData erstellte Programm ist in der Lage, durch Abgleich mit einer Datenbank, in der die Fingerprints sämtlicher untersuchter historischer und rezenter Proben gespeichert sind, Ähnlichkeiten zwischen Allelprofilen festzustellen. Dies ist auch möglich, wenn nur fragmentarische Allelprofile zur Untersuchung anstehen.

Alle für die Weingartener Individuen erhaltenen Ergebnisse wurden mit Hilfe dieses Programms überprüft. So konnten Kontaminationen erkannt und unter Umständen auch deren Verursacher festgestellt werden. Letztendlich konnten so Ergebnisse, deren Generierung auf Kontaminationen unterschiedlicher Provenienz beruhten, von weiteren Analyse ausgenommen werden, so daß eine Aufnahme falsch-positiver Resultate verhindert wurde. 
So wurde z.B. für die Probe 194 in der Reaktion Z1 8.25a ein Einzelergebnis erhalten, das bei Überprüfung durch das ,aDNA-Typing“-Programm Ähnlichkeit mit dem DNA-Profil eines Mitarbeiters anzeigte. Anzumerken ist dabei, das in diesem Fall kein vollständiger Fingerprint detektiert wurde, sondern sich die rezente DNA offenbar schon in einem degradierten Zustand befand oder aber nur in geringsten Mengen die PCR-Reaktion kontaminiert hat.

Tabelle 5.29: Einzelergebnisse der für das Individuum 194 durchgeführten Amplifikationen, wobei sich Reaktion 8.25a als Ergebnis einer Kontamination darstellt.

\begin{tabular}{|c|c|c|c|c|c|c|c|c|c|c|}
\hline Ex/PCR & Amelo & D3S1358 & VWA & $F G A$ & D8S1179 & D21S11 & D18S51 & D5S818 & D13S317 & D7S820 \\
\hline Z1 1.1a & $x$ & 1 & 19 & 23 & $10 / 12$ & I & 1 & I & I & 1 \\
\hline Z1 1.1b & $x$ & $14 / 15$ & 1 & 22 & 1 & I & I & I & I & I \\
\hline Z1 3.2a & I & 15 & I & 22 & 12 & 26 & 19 & 1 & 1 & 1 \\
\hline $\mathrm{Z1} 3.2 \mathrm{~b}$ & $x$ & 15 & $16 / 18$ & I & I & I & 19 & I & I & 1 \\
\hline Z1 3.3a & I & 15 & I & I & $10 / 14$ & 30 & I & $(11) / 12$ & 8 & I \\
\hline Z1 3.3b & $x$ & I & 19 & I & 12 & I & 15 & I & I & 10 \\
\hline Z1 3.5a & $x$ & 15 & $14 / 16$ & I & 12 & I & I & 1 & I & I \\
\hline Z1 3.5b & I & 15 & I & 21 & I & I & I & I & I & I \\
\hline Z1 8.19 & $x$ & $12 / 15$ & 14 & I & 10 & 30 & I & 11 & 11 & 10 \\
\hline Z1 8.23a & I & I & I & I & I & I & I & I & I & I \\
\hline Z1 8.23b & I & I & 18 & 20 & 10 & I & I & I & I & I \\
\hline Z1 8.25a & $X Y$ & 17 & 17 & $21 / 22$ & $12 / 13$ & $30 / 31.2$ & $14 / 19$ & 13 & $10 / 11$ & 9 \\
\hline Z1 8.25b & $x$ & 1 & 1 & 24 & 1 & 1 & 1 & 1 & 13 & 1 \\
\hline Z1 86.97 & $x$ & I & 15 & I & I & I & I & 13 & I & I \\
\hline Z2 99.105 & I & I & I & I & I & I & I & I & I & I \\
\hline Z2 101.111 & $x$ & $(14) / 15$ & 18 & 22 & 13 & 33.2 & I & I & I & I \\
\hline Genotyp & $x X$ & $15 /(15)$ & I & 22 & $10 / 12$ & 30 & (19) & I & I & 10 \\
\hline
\end{tabular}

Tabelle 5.30: Allelprofil des Verursachers der Kontamination von Reaktion Z1 8.25a der Probe 194

\begin{tabular}{|c|c|c|c|c|c|c|c|c|c|c|}
\hline Ex/PCR & Amelo & D3S1358 & VWA & FGA & D8S1179 & D21S11 & D18S51 & D5S818 & D13S317 & D7S820 \\
\hline Genotyp & XY & $15 / 17$ & $16 / 17$ & $21 / 22$ & $12 / 13$ & $30 / 31.2$ & $14 / 19$ & $13 / 13$ & $10 / 11$ & $8 / 9$ \\
\hline
\end{tabular}

In sieben weiteren Fällen war die Kontamination einzelner PCR-Reaktionen durch Mitarbeiter wahrscheinlich. Auch hier traten fragmentarische Allelprofile auf, die vermutlich den Fingerprints von Mitarbeitern des Labors zuzuordnen sind. In jedem Fall flossen die Ergebnisse dieser Einzelamplifikationen nicht in die Endgenotypisierung ein. In zwei weiteren Fällen waren Kreuzkontamination zwischen Proben feststellbar, hierbei handelte es sich um Proben, die in derselben 
Extraktions-Reaktionen mitgeführt wurden. Auch diese Kontaminationen wurden durch Überprüfung mit Hilfe des „DNA-Typing“-Programms erkannt, die Ergebnisse folglich von den Endtypisierungen ausgenommen.

In einigen Fällen ergaben sich in den Einzelamplifikationen Ergebnisse, die von den restlichen für eine Probe erhaltenen Ergebnissen eklatant abwichen. Ein Beispiel dafür ist in Tabelle 5.31 dargestellt. Hier zeigt die Reaktion Z1 19.S1 einen fast vollständigen Fingerprint, der in allen Systemen Abweichungen zu denen im weiteren ermittelten Amplifikations-Ergebnissen zeigt. Dieses Phänomen deutet auf eine Kontamination mit moderner DNA während der PCR hin, die Überprüfung des Allelprofils ergab jedoch keine Übereinstimmung mit den gespeicherten Fingerprints. So ist eine sporadische Kontamination des PCR-Cups, wie von Schmidt et al. (1995) beschrieben, nicht auszuschließen. In diesem, wie auch in ähnlich gelagerten Fällen, wurden die Ergebnisse von der Endtypisierung ausgenommen.

Tabelle 5.31: Einzelergebnisse der für das Individuum 359 durchgeführten Amplifikationen, wobei sich im Vergleich mit den weiteren Typisierungsergebnissen, das Resultat von Reaktion Z1 19.S1 als Amplifikationsergebnis einer Kontamination darstellt.

\begin{tabular}{|c|c|c|c|c|c|c|c|c|c|c|}
\hline Ex/PCR & Amelo & D3S1358 & VWA & $F G A$ & D8S1179 & D21S11 & D18S51 & D5S818 & D13S317 & D7S820 \\
\hline Z1 6.13a & $x$ & 15 & 18 & 21 & 11 & 1 & 1 & 1 & 12 & 10 \\
\hline Z1 6.13b & $X Y$ & 15 & 1 & 21 & 14 & 30 & 1 & $(11) 12(13)$ & 1 & 1 \\
\hline Z1 6.14 & $X Y$ & 16 & 1 & $21 / 23$ & 1 & 30 & 15 & 1 & 1 & 1 \\
\hline Z1 18.35a & $X Y$ & $16 / 18$ & 18 & 1 & $11 / 14$ & 1 & 1 & 1 & 1 & 1 \\
\hline Z1 18.35b & $X Y$ & 15 & 1 & 21 & 14 & 1 & 1 & $11 / 13$ & 1 & 1 \\
\hline Z1 19.S1 & $X Y$ & 15 & $15 / 17$ & 20 & $13 / 15$ & $28 / 32.2$ & 12 & 12 & $11 / 12$ & $11 / 12$ \\
\hline Z2 36.54 & $X Y$ & $(15) / 16$ & 18 & 21 & 1 & 1 & 1 & 13 & $10 / 12$ & 1 \\
\hline Z2 40.59 & $X Y$ & $15 / 16$ & 18 & $21 / 23$ & $11 / 14$ & 30 & 1 & 11 & 1 & 1 \\
\hline Z2 57.58 & $X Y$ & $15 / 16$ & 18 & $21 / 23$ & 11 & 28 & 1 & $11 / 13$ & 10 & 11 \\
\hline Z2 82.94 & $X Y$ & $15 / 16$ & 18 & 21 & $11 / 14$ & $28 / 29 / 30$ & 1 & $8^{* 11 / 12}$ & 8 & 1 \\
\hline Z2 63.129 & 1 & 16 & 18 & 1 & $11 / 14$ & 29 & 1 & $11 / 13$ & 1 & 1 \\
\hline Genotyp & $\mathbf{X Y}$ & $15 / 16$ & $18 / 18$ & $21 / 23$ & $11 / 14$ & $28 / 29 / 30$ & I & $11 / 13$ & $10 / 12$ & I \\
\hline
\end{tabular}

Dadurch, daß stets mehrere Extraktionen und Amplifikationen durchgeführt wurden und sich der Genotyp eines Individuums schließlich erst durch die Zusammenfassung der Ergebnisse der Einzelamplifikationen ergibt, können Kontaminationen erkannt werden und aus der Endtypisierung ausgeschlossen werden, wie in Tabelle 5.29 und 5.31 dargestellt. 


\subsubsection{Blind- und Leerkontrollen}

Insgesamt wurden 18 Blindkontrollen, d.h. parallel $\mathrm{zu}$ den Knochenproben bearbeitete Extraktionskontrollen, mitgeführt, wobei in sechs dieser Proben DNA-Produkt nachzuweisen war. Drei davon waren aber zur Kontrolle eines vorherigen Bedienungsfehlers in einem Extraktionslauf gemeinsam bearbeitet worden. Die für diese Proben typisierten Allele sind in Tabelle $10.2 \mathrm{im}$ Tabellenanhang dargestellt. Für keine dieser Proben ist ein vollständiger Fingerprint nachweisbar. Von 31 mitgeführten PCR-Leerkontrollen in autosomalen und Y-PCRs zeigten 27 kein nachweisbares Ergebnis. Bei drei der Kontrollen war nur jeweils ein System detektierbar, in einer Kontrolle zeigten sich Ergebnisse in drei STR-Systemen und dem Amelogenin-System, wobei diese Ergebnisse auf Kontaminationen der PCR-Gefäße zurückzuführen sind (Schmidt et al. 1995).

\subsection{2 mt-DNA-Kontrollen}

Die Feststellung von möglichen Kontaminationen in Amplifikationen mitochondrialer Abschnitte stellt eine größere Anforderung dar, als dies bei der Amplifikation von autosomalen STRs der Fall ist, da hier eine Individualisierbarkeit der Ergebnisse nur im eingeschränkterem Maße möglich ist. Aus diesem Grund wurde für die Vermehrung der mt-Sequenzen ebenfalls eine Multiplex-Strategie gewählt (vgl. Kapitel 3.9). Sehr wichtig wird dieser Aspekt der Abgrenzung gegen kontaminierende Sequenzen deswegen, da aufgrund einer extrem hohen Anzahl werkseitig kontaminierter PCR-Reaktionsgefäße, in einem großen Anteil der mitgeführten Kontrollansätze (90\%) sichtbare Banden im Agarose-Gel zu detektieren waren. Wie Schmidt et al. (1995) in einer Studie umfassend nachweisen, zeigen PCR-Gefäße verschiedener Hersteller bei der Amplifikation mitochondrialer Marker zum Teil Kontaminationsraten, die regelhaft bei $80-90 \%$ liegen. Selbst zwischen verschiedenen Chargen desselben Herstellers können durchaus unterschiedlich hohe Kontaminationsraten festzustellen sein. Auf die Kontaminationsquelle der PCRGefäße weisen auch andere Autoren hin (Kolman \& Tuross 2000; Hauswirth et al. 1994). Offensichtlich besteht Diskrepanz zwischen Kontrollproben, die bei der Amplifikation chromosomaler Marker mitgeführt werden und die zu einem großen Prozentsatz ohne Signal sind (vgl. 5.7.1.1) und den Leerkontroll-Ansätzen, die bei 
der Amplifikation mitochondrialer Sequenzen mitgeführt werden, die im Gegensatz dazu eine sehr hohe Kontaminationsrate aufweisen. Zurückzuführen ist dieser Unterschied auf die höhere Kopienzahl des mitochondrialen Genoms pro Zelle, die etwa 100-1000 mal höher ist, als die Anzahl des chromosomalen Genoms, das in jeder Zelle nur in zweifacher Ausführung vorliegt (Bogenhagen \& Clayton 1974).

Allerdings zeigt sich, wie in Abbildung 5.5 feststellbar, daß in vielen Fällen die amplifizierten kontaminierenden Fragmente eine sichtbar geringere Intensität als die eigentlichen Proben zeigen, woraus sich schließen lässt, daß es durch die kontaminierende DNA nur zu geringer Produktbildung während der Amplifikation kommt. Nur in wenigen Fällen war aufgrund der geringen Produktmenge eine Sequenzierung der kontaminierenden Banden möglich. Da es sich hier meist um Mischspuren handelte, die sich aus den Sequenzen mehrerer Personen zusammensetzten, erkenntlich an der hohen Anzahl unsicherer Basenbestimmungen, konnte keine eindeutige Sequenzbestimmung erreicht werden.

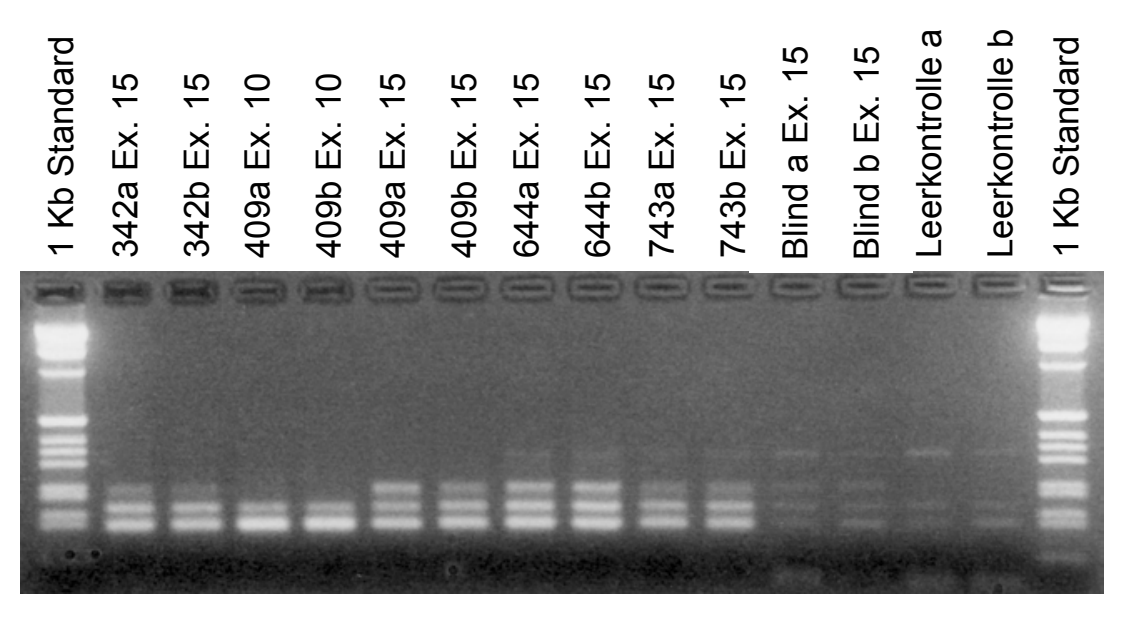

\begin{abstract}
Abbildung 5.5: Amplifikationsprodukte der mt-DNA-Multiplex-PCR an Zahnproben von fünf Weingartener Individuen und der mitgeführten Extraktions- bzw. PCR-Kontrollproben. Die im Doppelansatz amplifizierten Proben der Individuen zeigen die Bildung von drei Fragmenten, in Fällen geringerer DNA-Erhaltung sind zwei Banden gebildet worden. Die generell hohe Kontaminationsanfälligkeit bei Amplifikation mitochondrialer Abschnitte, die ausführlich in der Studie von Schmidt et al. (1995) dargelegt wird und die offenbar auf die nicht zu verhindernde Anwesenheit kontaminierender Sequenzen in PCR-Gefäßen zurückzuführen ist, zeigt sich bei der Amplifikation von Kontroll-Proben ohne DNA-Zugabe. In diesem Fall weisen die verwendeten Eppendorf „Safe-Lock“ Reaktionsgefäße $(0,5 \mathrm{ml})$ eine extrem hohe Kontaminationsrate auf. $\mathrm{Zu}$ erkennen ist allerdings, daß die Banden der vier mitgeführten Kontrollproben deutlich geringere Signal-Intensitäten aufweisen.
\end{abstract}




\section{$6 \quad$ DISKUSSION}

Die vorliegende Arbeit stellt eine der wenigen Studien dar, in der genetische Typisierungen an einer größeren historischen Bevölkerungsstichprobe vorgenommen werden, und die die Analyse sowohl mitochondrialer Genom-Abschnitte als auch nuklearer DNA-Loci einschließt, wobei autosomale und Y-chromosomale STRs untersucht werden. Zwar liegen Arbeiten an historischen Populationen vor, in denen eine ähnlich hohe Anzahl an Individuen untersucht wurden, meist steht hier aber die Analyse mitochondrialer-DNA im Vordergrund, während auf die Information, die sich durch die Untersuchung chromosomaler DNA-Abschnitte erhalten lassen, nicht zugegriffen wird. Dazu ist außerdem anzumerken, daß in vielen Arbeiten auf die direkte Sequenzierung der mitochondrialen DNA verzichtet wird und mt-Haplogruppen durch die Untersuchung spezifischer RestriktionsfragmentLängenpolymorphismen definiert werden.

\subsection{Amplifikationserfolge}

In der Weingartener Studie wurden an 161 historischen Skelettindividuen molekulare Analysen vorgenommen. Vergleichbar ist dem die Arbeit von Stone \& Stoneking (1998), die 700 Jahre alte Überreste von 152 amerikanischen Ureinwohnern untersuchen. Wang et al. (2000) führen für ein aus 63 Individuen bestehendes, 2500 Jahre altes chinesisches Skelettkollektiv aDNA-Analysen durch, während die von Oota et al. (1999) untersuchte Stichprobe, deren Alter bei 2000 Jahren liegt, 58 Individuen umfaßt. In einer Studie von Shinoda et al. (1994) werden 55 Skelettindividuen, die einem 2000 Jahre alten japanischen Gräberfeld entstammen, genetisch typisiert. Kaestle \& Smith (2001) analysieren mt-Haplotypen von insgesamt 48 amerikanischen Ureinwohnern, wobei das Alter der Proben zwischen 350 und 9200 Jahren liegt. Gonzáles-Oliver et al. (2001) beziehen 28 Maya-Individuen in ihre Untersuchungen ein. Weitere Studien weisen deutlich geringere Individuenanzahlen auf (Horai et al. 1991; Shinoda \& Kanai 1999; Hauswirth et al. 1994). Alle angeführten Studien widmen sich ausschließlich der Analyse mitochondrialer DNA, lediglich Stone \& Stoneking (1998) führen für 
20 Individuen zusätzlich Amplifikationen des auf den Geschlechtschromosomen lokalisierten Amelogenin-Gens durch. Anzugeben ist aber die Studie von Schultes (2000), der an 36 bronzezeitlichen Individuen mitochondriale und STR-Typisierungen durchführt und die Untersuchung von Bramanti et al. (2000a), in der der Versuch unternommen wird, für 93 frühneuzeitliche Individuen STR-Fingerprints zu erstellen.

\subsubsection{Mitochondriale Sequenzanalysen}

Nicht unerwartet zeigen sich in der Weingartener Stichprobe für die Amplifikation der mitochondrialen Regionen die höchsten Typisierungserfolge (vgl. Tabelle 5.1). Für 83 von 121 untersuchten Individuen ließ sich die aus drei Fragmenten zusammengesetzte mitochondriale Sequenz vollständig nachweisen, so daß ein Amplifikationserfolg von $68 \%$ zu verzeichnen ist. Dieser Erfolg dürfte auf der hohen Kopienanzahl des mitochondrialen Genoms innerhalb der Zellen gründen (Bogenhagen \& Clayton 1974), womit sich die Wahrscheinlichkeit erhöht, daß trotz zahlreicher, zum Abbau der Nukleinsäuren führender Prozesse (Burger et al. 1999), intakte mt-DNA-Abschnitte aus Knochen- und Zahnzellen zu extrahieren sind. In anderen Studien liegt die Rate erfolgreicher mitochondrialer Amplifikationen bei 71\% (Stone \& Stoneking 1998) bzw. 81\% (Kaestle \& Smith 2001) wobei hier aber Restriktionsfragment-Längenpolymorphismen analysiert werden. Wang et al. (2000), die direkte Sequenzierungen durchführen, geben eine Erfolgsquote von $63 \%$ an, während diese Rate bei Oota et al. (1999) bei 38\% liegt, wohingegen Shinoda et al. (1994) für zwei Skelettserien, die unterschiedlichen Bereichen desselben Gräberfelds entstammen, Amplifikationsraten von 61\%, respektive 39\% angeben.

\subsubsection{Kontaminationen}

Bei der Betrachtung der Ergebnisse der mitochondrialen Amplifikationen ist die hohe Kontaminationsanfälligkeit, die bei Vermehrung dieser Sequenzen generell zu beobachten ist, nicht außer Acht $\mathrm{zu}$ lassen. Trotz strikter Einhaltung aller Vorkehrungen, die der Vermeidung des Eintrages von Kontaminationen dienen (vgl. Kapitel 3.2.1.1), ist zumindest innerhalb der Leerproben eine Kontaminationsrate zu 
beobachten (vgl. Kapitel 5.7.2), die mit dem Satz: „Despite these precautions, contamination occasionally occurs" (Carlyle et al. 2000; S. 91) nicht abgetan werden kann. Aufschlussreich ist in diesem Zusammenhang vielleicht die Feststellung, daß in vielen Studien, die sich der Untersuchung mitochondrialer Sequenzen historischer Individuen widmen, zwar stets auf die Mitführung von Blind- und Leerkontrollen verwiesen wird, die Anzahl der im Endeffekt Produkt-zeigenden Kontrollproben aber nicht angegeben wird (Stone \& Stoneking 1998; Kaestle \& Smith 2001; Hauswirth et al. 1994; Gonzalez-Oliver et al. 2001; Oota et al. 1999; Wang et al. 2000; Oota et al. 1995; Shinoda \& Kunisada 1994).

Im Prinzip kommt der Anzahl der kontaminierten vermeintlichen Leerkontrollen (vgl. Abbildung 5.5) nur geringe Aussagekraft zu, da hierdurch nur die Rate der durch Fremd-DNA verunreinigten PCR-Cups angezeigt wird (Schmidt et al. 1995). Von Bedeutung ist vielmehr die Authentifizierung der Proben-Ergebnisse durch Reproduktion, wobei der in dieser Arbeit gewählten Vorgehensweise der Amplifikation der mitochondrialen Abschnitte in einem Multiplex-Ansatz große Bedeutung zukommt und dabei der von Schultes (2000) erarbeiteten Methode gefolgt wird. Durch die Amplifikation von drei verschiedenen Fragmente in einem Ansatz erhöht sich die Aussagekraft der Resultate. So konnten Ergebnisse, denen die Amplifikation kontaminierender Sequenzen zugrunde liegt, aufgrund fehlender probenspezifischer Reproduzierbarkeit erkannt und somit von der Typisierung ausgeschlossen werden. Hiermit ist gewährleistet, daß in die Auswertung nur probenendogene Sequenzen eingeflossen sind.

\subsubsection{Amplifikation autosomaler STRs}

Die Anzahl der Weingartener Individuen, die reproduzierbare Ergebnisse bei Amplifikation der autosomalen STRs ergaben, ist deutlich geringer als die bei der Amplifikation der mitochondrialen Sequenzen beobachtete Anzahl (vgl. Tabelle 5.1). Reproduzierbare Amplifikationsergebnisse in mindestens vier der neun untersuchten autosomalen STR-Systeme zeigen 39\% der Proben. Für diese Daten gibt es kaum Vergleichsangaben. Schultes (2000) konnte für 58\% der von ihm untersuchten Individuen Genotypen erstellen, die sich aus mindestens sechs Systemen zusammensetzen. Hier lag jedoch ein Skelettkollektiv vor, das, obwohl eindeutig 
älter als die Weingartener Serie, vom DNA-Erhaltungszustand als exzeptionell zu bezeichnen ist. Damit wird deutlich, daß der Erhaltungszustand von DNA eher unabhängig von der Liegezeit ist, jedoch im stärksten Maße vom Liegemilieu beeinflusst wird. Dies zeigt sich unter anderem auch an den von Shinoda et al. (1994) angegebenen unterschiedlichen mt-Amplifikationsraten für Individuen, deren Grabstätten zeitgleich angelegt worden sind, jedoch in einer Entfernung von ca. $100 \mathrm{~m}$ zueinander liegen. Wahrscheinlich können schon geringste Abweichungen des Bodenmilieus $\mathrm{zu}$ einer unterschiedlichen Erhaltung der DNA innerhalb eines einzigen Knochenelements führen (Hanson \& Buikstra 1987). So mag der stark geröllhaltige Geschiebeboden des in einem Flußtal gelegenen Gräberfeldes nicht unbedingt zur Erhaltung der Skelette und der in ihnen enthaltenen DNA beigetragen haben. Da ein vollständiger Lageplan der Gräberfeldanlage nicht existiert, ist eine Untersuchung hinsichtlich einer möglichen Korrelation zwischen erfolgreich zu typisierenden Proben und der Lage dieser Individuen im Bestattungsareal nicht durchzuführen.

\subsubsection{Amplifikation Y-chromosomaler STRs}

Der Amplifikationserfolg der Y-chromosomalen Marker liegt in der Weingartener Stichprobe bei 28\% (vgl. Tabelle 5.1). Im Vergleich dazu konnte Schultes (2000) neun von zwölf Individuen unter Verwendung derselben Primer typisieren. Dies ist mit großer Wahrscheinlichkeit durch den besseren DNA-Erhaltungszustand der in jener Studie untersuchten Skelettindividuen erklärlich. Auch Corach et al. (1997) erhielten bei der Untersuchung von menschlichen Überresten aus einem ca. 30 Jahre alten Massengrab bei der Amplifikation Y-chromosomaler Systeme geringere Erfolge, während sich die Amplifikation autosomaler STRs erfolgreicher gestaltet. Der geringere Amplifikationserfolg der Y-chromosomalen Single-Copy-Abschnitte im Vergleich mit den autosomalen STRs basiert unter Umständen auf der vom Profiler Plus Kit abweichenden Zusammensetzung des Amplifikationspuffers. Im Gegensatz zu dem im kommerziell erhältlichen AmpFlSTR Profiler Plus PCR Amplification Kit enthaltenen Reaktionsansatz, enthält der bei Vermehrung der Y-STR-Systeme verwendete Puffer keine Zusatz-Agenzien wie z.B. BSA, denen PCR-optimierende Eigenschaften zugeschrieben werden (Kolman \& Tuross 2000). 
Schmerer (1999) konnte allerdings zeigen, daß PCR-Zusätze, die durchaus positive Auswirkungen auf die Amplifikation eines Genortes haben, zur Abnahme des Amplifikationserfolges eines anderen Locus führen können, was insbesondere bei der Durchführung von Multiplex-Amplifikationen problematisch ist.

\subsubsection{Geschlechtsdetermination}

Die molekulare Geschlechtsbestimmung wurde für 77 der historischen Skelettindividuen des Weingartener Gräberfeldes erfolgreich durchgeführt (vgl. Kapitel 5.2.4). Damit war das biologische Geschlecht etwa der Hälfte der untersuchten Individuen durch Nachweis geschlechtschromosomaler Fragmente feststellbar. Die Amplifikation des auf dem X- und Y-Chromosom lokalisierten Amelogenin-Gens wird in mehreren Studien verwendet, die sich der Untersuchung von Individuen aus archäologischen Fundkomplexen widmen, wobei sich die molekulare Geschlechtsdetermination vor allem zur Untersuchung von Kinderskeletten und bei fragmentiert vorliegendem Material eignet (Lassen et al. 1996; Stone et al. 1996; Faerman et al. 1998; Matheson \& Loy 2001).

Interessant ist eine nähere Betrachtung der Individuen, deren Analyse Abweichungen zwischen den Ergebnissen der molekularen Geschlechtsbestimmung und den unabhängig von dieser Arbeit durchgeführten Untersuchungen zur Feststellung des Geschlechts auf morphologischer und archäologischer Basis ergaben (vgl. Tabelle 5.10). In zwei Fällen lassen sowohl die morphologischen Daten als auch die Einschätzung der Grabbeigaben auf ein weibliches Individuum schließen, während durch die molekulare Analyse das Y-chromosomale Fragment nachgewiesen werden kann. So sind für das Individuum 374 durch die Amplifikation der Amelogeninsequenz nicht nur Y-spezifische, 112 bp lange Produkte nachzuweisen, sondern darüber hinaus auch Y-chromosomale STRs (vgl. Tabelle $10.3 \mathrm{im}$ Tabellenanhang). Die Ergebnisse der Amelogenin-Ampflikation, generiert aus zwei unabhängigen Extraktionen und vier PCRs, gehen einher mit reproduzierbaren STRDaten, die die Erstellung eines individualspezifischen Allelprofils erlauben, was die Authentizität der Amelogenin-Ergebnisse unterstreicht. In einer dritten Extraktion läßt sich nur das X-Fragment nachweisen, was durch einen stochastisch bedingten Amplifikations-Ausfall des Y-chromosomalen Fragments bedingt sein kann. Für das 
Individuum 141 läßt sich die Amplifikation des Y-Fragments in zwei Extraktionen nachweisen, in den übrigen durchgeführten Extraktionen ist nur das X-chromosomale Fragment nachweisbar. Da für die autosomalen STRs kein vollständiger Fingerprint zu erhalten ist, und auch hier Allelausfälle zu beobachten sind, ist nicht sicher zu entscheiden, ob hier abweichend von der morphologischen und archäologischen Einordnung tatsächlich ein männliches Individuum vorliegt. Definitiv als männlich typisiert ist das Individuum 221, sowohl durch reproduzierbare Amelogenin-Amplifikation, als auch durch Nachweis eines YHaplotypen. Hier hat aufgrund fehlender Grabbeigaben keine Bestimmung auf archäologischer Basis stattgefunden, die morphologische Bestimmung deutet jedoch auf weibliches Geschlecht des Individuums hin. Ähnlich sicher ist aufgrund der molekularen Ergebnisse die Annahme des männlichen Geschlechts auch für das Individuum 658, wobei hier die archäologische Angabe mit der molekularen übereinstimmt. Allerdings wird anhand der morphologischen Untersuchung auf ein weibliches Individuum geschlossen, hierbei dürfte es sich um eine Fehldiagnose handeln. Unter den untersuchten Individuen des frühmittelalterlichen Gräberfeldes von Weingarten ergibt sich so nur in einem Fall (Individuum 374) eine Diskordanz zwischen dem durch molekulare Typisierungen festgelegten Geschlecht und dem, das aufgrund des ,geschlechtstypischen“ Grabinventares (Perlenkette, Nadel, Schnalle, Kamm) anzunehmen ist. Eine molekulare Fehltypisierung ist hier aufgrund der hinreichenden Reproduktion der Daten auszuschließen. Hier sind die Bemerkungen von Brown (1998) in Betracht zu ziehen, die zu bedenken gibt, daß biologisches Geschlecht (biological sex) und sozial determiniertes Geschlecht (social gender) in der Mehrzahl der archäologischen Fälle zwar korrelieren, Ausnahmen jedoch nicht gänzlich auszuschließen sind. So wäre bei Feststellung des weiblichen Geschlechts auf molekularer Grundlage für ein Individuum aus einem waffentragenden Grab nicht umgehend auf einen Typisierungsfehler oder gar eine Kontamination zu schließen, sondern die sich daraus ergebenden Implikationen für die Geschlechtsdefinition in der jeweiligen Gesellschaft zu diskutieren oder auch die archäologischen Kriterienkataloge zur Geschlechtsbestimmung kritischer zu betrachten. 


\subsection{Populationsdifferenzierung}

Bei der Analyse menschlicher Überreste aus archäologischen Fundkontexten kommt der Ergründung biologisch determinierter, gesellschaftlich relevanter Beziehungen eine elementare Bedeutung $\mathrm{zu}$, da sich dadurch Rückschlüsse auf die soziale Binnenstruktur der untersuchten (prä)historischen Bevölkerung ziehen lassen. Dabei stützten sich die Untersuchungen zur Feststellung von Verwandtschaft bislang weitestgehend auf die Aufnahme morphologischer Merkmale (Ishida \& Dodo 1997; Alt et al. 1996; Alt \& Vach 1995; Ullrich 1969). Interessant sind generell vor allem Untersuchungen an Skelettserien, die sich aufgrund der Bestattungs- oder Beigabensituation in Subgruppen differenzieren lassen und damit Hinweise auf kulturelle Unterschiede zwischen den Individuen geben. Auswertungen derartiger Serien durch morphologische Analysen des Skelettmaterials wurden vorgenommen (Hemphill 1999; Prowse \& Lovell 1996; Rösing 1986), erbrachten jedoch nur unbefriedigende Ergebnisse, da Verwandtschaftsbeziehungen zwischen den Individuen kaum festzustellen waren. Die Ausbildung der betrachteten Merkmale ist durch nicht-genetische Faktoren stark beeinflusst, im weiteren ist auch der ihnen zu Grunde liegende Vererbungsweg nicht bekannt, so daß die Aussagekraft der morphologischen Methoden schnell an Grenzen stößt.

Deswegen ist die direkte Einbeziehung genetischer Markersysteme durch die Analyse von aDNA bei der Untersuchung historischer Populationen die Methode der Wahl, da so die Unwägsamkeiten der Untersuchung phänotypischer Merkmale umgangen werden. Im besonderen bietet sich diese Analyse-Strategie an, wenn Unterscheidungen zwischen Subgruppen innerhalb einer Bevölkerung herausgestellt werden sollen, da hier die Unterschiede nur gering und so nur durch sehr feine Analysemethoden erfaßbar sind. Den Beleg, daß diese Differenzierung zwischen Subgruppen unter Verwendung von STR-Daten und mitochondrialen Sequenzdaten $\mathrm{zu}$ leisten ist, erbringen Studien an rezenten Populationen (Reddy et al. 2001; Zhivotovsky et al. 2001; Williams et al. 2002). Letztere zeigen durch die Untersuchung von Yanomamö-Dorfgemeinschaften, daß die genetische Differenzierung zwischen getrennten Gruppen innerhalb kürzester Zeit, und zwar nach wenigen Generationen, vollzogen und nachweisbar ist. 
Damit Abhängigkeiten zwischen genetischen Markern und Statusgruppen innerhalb einer historischen Population nachzuweisen sind, müssen bestimmte Voraussetzungen erfüllt sein: Die Population muß in gegeneinander abgrenzbare Subgruppen unterteilt sein, z.B. aufgrund differenter materieller Hinterlassenschaften. Damit es zu einer Herausbildung genetischer Unterschiede zwischen den Gruppen kommt (bzw. diese bestehen bleiben, wenn die Gruppen aus zugewanderten und alteingesessenen Individuen mit abweichender genetischer Ausprägung bestehen), darf zwischen ihnen kein bedeutender genetischer Austausch stattfinden.

Eine Einteilung in Statusgruppen liegt für die untersuchte Stichprobe durch archäologische Evaluierung der Grabinventare vor. Abzuklären, ob und inwieweit unterschiedliche Beigabenensembles überhaupt einen rechtlichen sozialen Rang dokumentieren können, und ob im weiteren die für Weingarten angenommenen Rangzuordnungen den tatsächlichen historischen Gegebenheiten entsprechen, und wie die Individuen auf die in den merowingerzeitlichen Quellen erwähnten rechtlichen Statusgruppen der servi, liberi und nobiles aufzuteilen sind, ist nicht Aufgabe dieser Untersuchung. Stattdessen wurde die Einteilung der Individuen in verschiedene Ranggruppen als eine externe Setzung verstanden, die somit als „Null-Hypothese“ für die genetischen Untersuchungen galt. Die Abklärung der Frage, ob eine genetische Differenzierung zwischen den Statusgruppen vorliegt, erfolgte durch die statistische Überprüfung der genetischen Daten.

\subsubsection{Ergebnisse der statistischen Tests}

Die statistischen Tests, durchgeführt um nachzuweisen, ob die archäologisch gegeneinander abgrenzbaren Sozialgruppen auch genetische Merkmale aufweisen, nach denen sie sich unterscheiden lassen, zeigen ein einheitliches Ergebnis: Die durch die Zusammensetzung der materiellen Hinterlassenschaften definierten Gruppen lassen sich aufgrund der untersuchten genetischen Marker nicht in gleicher Weise voneinander differenzieren. Unterschiede zwischen den Gruppen zeigen sich weder bei Untersuchung der Häufigkeitsverteilungen der Allele (vgl. Tabelle 5.13), noch in der Verteilung der Genotypen (vgl. Tabelle 5.14). Ein dementsprechendes Ergebnis zeigt auch der Test zur Überprüfung auf Abweichungen vom Hardy- 
Weinberg-Gleichgewicht (vgl. Tabelle 5.15), hier zeigt die untersuchte historische Stichprobe eine Übereinstimmung der unter HW-Gleichgewicht erwarteten Genotypfrequenzen. Auch die ermittelten $\mathrm{F}_{\mathrm{ST}}$-Werte, die direkter Hinweis auf vorhandene Substrukturierungen innerhalb einer Population sind, weisen die beiden Subgruppen als eine genetisch nicht zu differenzierende Gesamtgemeinschaft aus (vgl. Tabelle 5.17). Dafür sprechen auch die Ergebnisse des Assignment-Tests, durch den sich keine konkrete Zuordnung der Individuen zu den Sozialgruppen nachweisen läßt, sondern der eine Vermischung der Individuen entlang der Gleichheitslinie anzeigt. Zusammenfassend sprechen diese Ergebnisse dafür, daß aufgrund der Genotypen der Individuen keine Unterscheidung zwischen den sozialen Subgruppen besteht (vgl. Abbildung 5.4). Dieses Ergebnis läßt sich auch bei Untersuchung der mitochondrialen Variabilitäten erhalten, wobei sich zeigt, daß zwischen den Gruppen keine Unterschiede in der mt-Haplotypverteilung zu beobachten sind (vgl. Tabellen 5.18 und 5.19). Da eine Differenzierung der Weingartener Subgruppen aufgrund der untersuchten genetischen Marker demnach nicht nachzuweisen ist, ergibt sich folgende Interpretationsmöglichkeit.

Die naheliegendste Auslegung der Daten besteht darin, die Weingartener Bevölkerungsstichprobe als eine genetisch homogene Gruppe anzusehen, in der keine genetischen Differenzierungen zwischen den definierten Gruppen vorliegen, so daß anzunehmen ist, daß zwischen den Gruppenmitgliedern im weitesten Ausmaß Zufallspaarungen stattgefunden haben. Dieses Ergebnis könnte als Hinweis darauf gelten, daß in der frühmittelalterlichen Gesellschaft von Weingarten keine präskriptiven Heiratsordnungen befolgt wurden, zumindest nicht in der Hinsicht, daß Heiratsverbindungen zwischen Individuen verschiedenen Sozialstatus unterbunden wurden, bzw. keine Regeln existierten, die überzufällig häufige Paarungen zwischen Individuen desselben Sozialranges förderten. Möchte man der Huberschen Theorie (1967) Beachtung schenken, die das Vorhandensein verschiedener Ethnien innerhalb der Weingartener Gesellschaft propagiert, nämlich die der zugewanderten Germanenstämme und die der romanisierten, alteingesessenen Bevölkerungsteile, so wäre aufgrund der vorliegenden Ergebnisse der Beweis erbracht, daß zwischen diesen Gruppen im weitesten Ausmaß Heiratsbeziehungen bestanden. 
$\mathrm{Zu}$ der im vorangegangenen Kapitel dargelegten Interpretation der Daten müssen folgende Anmerkungen bedacht werden: In der vorliegenden Arbeit werden die genetischen Eigenschaften eines Individuums ermittelt, zweifellos ein durch jegliche Einflüsse unveränderbares Charakteristikum eines jeden Individuums. Dagegen wird bei Feststellung des sozialen Rang nur die Sozialgruppen-Zugehörigkeit eines Individuums zum Zeitpunkt des Todes erfasst. Beim obigen Erklärungsansatz wird nach den in Kapitel 1.6 aufgeführten Prämissen davon ausgegangen, daß der Rang eines Individuums durch Geburt festgelegt und nicht veränderbar ist. Allerdings ist genau dies bis heute Gegenstand angeregter Diskussionen innerhalb der archäologischen Forschungsgemeinschaft, wobei Siegmund (1998b) anmerkt, daß eine Lösung dieses Fragenkomplexes nicht unmittelbar in Aussicht steht.

Für die Sozialgruppeneinteilung, die als Setzung für die genetischen Überprüfungen gilt, ergäbe sich eine andere Ausgangslage, wenn wahrscheinlich ist, daß ein ursprünglich niederrangiges Individuum aufgrund von im Leben erbrachten Leistungen schließlich mit den Status-Insignien bestattet wird, die zu seiner Einordnung als höherrangiges Individuen führen. Diesem Individuum würde durch die archäologische Kategorisierung ein hoher Rang zugeordnet, dem seine genetische Herkunft jedoch nicht entspricht. Aufstiegsmöglichkeit durch Statusveränderung wird aber der merowingerzeitlichen Gesellschaft zumindest von Steuer (1997) zugeschrieben, auf den die Bezeichnung der „offenen Ranggesellschaft“ zurückgeht. Danach kann eine Statusposition im Leben erworben, aber auch wieder verloren werden. Auch der umgekehrte Fall ist denkbar, daß Individuen aufgrund ihrer genetischen Herkunft an sich der höherrangigen Gruppe zuzurechnen wären: durch sozialen Statusverlust im Laufe des Lebens jedoch mit einem Beigabenensemble bestattet und aufgefunden werden, das zu ihrer Einordnung als niederrangige Individuen führt. Darüber hinaus kann unzutreffende Zuordnung von Individuen in die Sozialgruppen auch durch die allgegenwärtige Sitte des Grabraubs verursacht sein. So ist vorstellbar, daß Individuen aufgrund von Beraubung nur ein unvollständiges Beigaben-Inventar aufweisen. Siegmund (2000) geht davon aus, daß die Rate beraubter Gräber bei über 30\% liegen könnte. Dies ist begleitet vom Umstand, daß aufgrund der schlechten Bodenverhältnisse innerhalb des Weingartener Gräberfeldes nur wenige Details zum Grabbau aufzunehmen waren 
und so auch Anzeichen der Beraubung nicht in jedem Fall nachgewiesen werden konnten (Roth 1977). Ob Gräber also intentional beigabenlos sind, oder Beigaben aufgrund von Beraubungen fehlen, kann nicht immer festgestellt werden. Dem Aspekt des Grabraubs ist allerdings entgegenzusetzen, daß dadurch nur inkorrekte Zuordnungen von Individuen des höheren Ranges zur Gruppe der Individuen des niederen Ranges vorgenommen werden können und nicht umgekehrt.

So stellt sich die Frage, wie die nachgewiesene genetische Homogenität der Bevölkerung $\mathrm{zu}$ interpretieren ist. Denn ein weiteres, im folgenden dargestelltes Ergebnis, zeigt, daß die Annahme eines durch Geburt prädisponierten und damit lebenslang festgelegten Status vermutlich nicht berechtigt ist. Dies wird durch die Betrachtung der für das Weingartener Skelettkollektiv festgestellten unmittelbaren Familienverwandtschaften deutlich.

\subsubsection{Familienzugehörigkeit und Sozialstatus}

Für die Darstellung von Familie und Status ist der Vergleich von Individuen relevant, die aufgrund der für sie ermittelten genetischen Profile wahrscheinlich in einem unmittelbaren Verwandtschaftsverhältnis zueinander stehen. Möglicherweise läßt sich hierüber ein Beitrag zur Klärung der Frage leisten, ob ein Individuum über die Lebenszeit hinweg in seinem Geburts-Sozialstatus verbleibt. Würde diese Annahme zutreffen, müssten die vermuteten Vater-Sohn und Mutter-Sohn Paare identische Rangzugehörigkeiten aufweisen. Die in Kapitel 5.6 gezeigten Ergebnisse unterstützen dies jedoch nicht: die mit Hilfe der genetischen Typisierungen als putative Mitglieder einer Kernfamilie angesehenen Individuen weisen in den meisten Fällen nicht dieselben Gruppenzugehörigkeiten auf, sondern sind unterschiedlichen sozialen Gruppen zugeordnet. So sind zwei von drei Individuen (275, 409 und 704), die möglicherweise ein Familienterzett bilden, dem Rang 1 zugeordnet, während 704 als niederrangiges Individuum gilt (vgl. Tabelle 5.23). Ein weiteres Beispiel sind die Individuen 257 und 282, die aufgrund ihrer identischen Y- und mt Haplotypen als putative Brüder in Frage kommen (vgl. Tabelle 5.27). Individuum 257 ist aber aufgrund des Grabinventars als Mitglied der höherrangigen Gruppe definiert, während Individuum 282 als im Sozialstatus niedriger stehend eingestuft wird. Hier scheiden im übrigen auch auf unterschiedlichem Alter beruhende Unterschiede in der 
Grabausstattung aus (Härke 1990), da beide Individuen der Alterskategorie ,adult“ angehören. Die genannten Beispiele könnten Hinweis darauf sein, daß es sich bei der merowingerzeitlichen Gesellschaft tatsächlich um eine durchlässige Gesellschaft im Sinne Steuers handelt, in der Söhne nicht zwingend denselben Status wie ihre Väter besitzen müssen, wie es für eine ständisch gegliederte Gesellschaft angenommen wird.

\subsubsection{Genetische Homogenität der Weingartner Bevölkerung}

Mit dieser Beobachtung muß der Gruppenvergleich nach Rängen differenzierter betrachtet werden. Durch die in Kapitel 6.2.2 erläuterten Ergebnisse läßt sich die Prämisse der prädisponierten Rangzugehörigkeit, die sich im Leben nicht ändert, nicht aufrecht erhalten. So ist nicht abschätzbar, ob die genetische Homogenität der Sozialränge auf Heiratsbeziehungen zwischen Individuen der Gruppen zurückzuführen ist oder ob lediglich Ranggruppenveränderung der Individuen durch Sozialstatusverlust oder -gewinn während des Lebens zu einer „Vermischung“ der Individuen beigetragen hat, die sich dann als genetische Homogenität darstellt. Folgende Aspekte sprechen jedoch dafür, daß die erste Annahme - genetische Homogenität durch Heiratsbeziehungen - zutreffend ist. Dies wird aus den Überprüfungen zum Hardy-Weinberg-Gleichgewicht ersichtlich, für das sich bei der Betrachtung der Gesamtstichprobe keine Abweichung beobachten läßt (vgl. Tabelle 5.15). Deutet eine Abweichung auf Substrukturierung der Gemeinschaft hin, läßt die gezeigte Einhaltung des HW-Gleichgewichts darauf schließen, daß vom Vorhandensein wie auch immer gearteter Subgruppen in der Weingartener Population nicht auszugehen ist. Ein weiteres Indiz ist der F-Wert von Wright, der wiederum unter Einbeziehung der Gesamtstichprobe (unter Ausnahme des Wertes für D8S1179) bei 0,001 liegt (vgl. Tabelle 5.16). Dieser Wert nahe Null spricht für eine panmiktische Gemeinschaft. Für eine nicht-substrukturierte Gesellschaft könnte auch die hohe Rate an singulären mt-Linien ein Hinweis sein (vgl. Tabelle 5.21): auch bei zufällig vorgenommener Gruppierung der Individuen, unter Nichtbeachtung der archäologischen Vorgaben, ergibt sich in keinem Fall eine Aufteilung ergeben, die dazu führt, daß zwischen Gruppen von Individuen eine genetische Differenzierung nachweisbar wäre. 


\subsubsection{Mitochondriale Sequenzdiversität}

Es ist festzustellen, daß sich durch Analyse der mitochondrialen Bereiche eine hohe Sequenzdiversität ergibt. Zusammen genommen läßt sich für die Weingartener Stichprobe eine Gene Diversity von 0,95 feststellen. Dies erscheint als ein relativ hoher Wert für eine Stichprobe, die einem Kollektiv von Individuen entstammt, das zumindest in einem gewissen Ausmaß über die maternale Linie verwandtschaftlich miteinander verbunden sein dürfte. Hier sind aber Vergleichsdaten zu nennen (Stone \& Stoneking 1998), die am 700 Jahre alten Gräberfeld der Norris-Farm erhoben wurden, ein Friedhof amerikanischer Ureinwohner, der nur über ein bis zwei Generationen hinweg belegt wurde. Obwohl von einer nahen Verwandtschaft zwischen den bestatteten Individuen auszugehen ist, ergibt sich auch in diesem Fall eine Diversität der mitochondrialen Sequenzen von 0,9. Auch Ward et al. (1991), die Individuen einer rezenten amerindischen Stammesgemeinschaft untersuchen, erhalten mit dem Wert von 0,95 eine beträchtliche mt-Diversität. Zu diskutieren ist, woraus sich die hohe Anzahl an singulären mt-Linien begründet, die in der Weingartener Bevölkerung bei 64\% liegt (vgl. Tabelle 5.20) und die auch in der von Stone \& Stoneking (1998) bearbeiteten historischen Bevölkerung einen Wert von $73 \%$ aufweist. Unter Umständen liegt hier ein Hinweis darauf, daß es sich bei der Weingartener Bevölkerung nicht um eine Population handelt, in der sich aufgrund eines Bottlenecks und Gründereffekts eine Abnahme der Diversität vollzogen hat. Dies würde auf eine nicht-isolierte Population schließen lassen, in die von außen ständig Individuen hinzukommen, die zum Neueintrag mitochondrialer Sequenzen beitragen.

\subsection{Verwandtenehen in Weingarten?}

Die Betrachtung des F-Wertes von Wright, der sich für die Weingartener Bevölkerung als sehr aufschlussreich darstellen könnte, ist durch die komplexe Datenlage erschwert (vgl. Tabelle 5.17). Der F-Wert ist ein Maß dafür, ob und in welchem Ausmaß in einer Population vom Prinzip der Zufallspaarung abgewichen wird und inwiefern stattdessen non-random mating-Strategien verfolgt werden. $\mathrm{Zu}$ unterscheiden wäre dabei zwischen sogenannten ,positive assortative mating“, was bedeutet, daß bei der Partnerwahl bevorzugt ähnliche Individuen ausgewählt werden, 
was in der extremsten Form heißt, daß es zu Fortpflanzungen zwischen naheverwandten Individuen kommt, die genetische Ähnlichkeiten aufweisen. „Negative assortative mating“ bedeutet in der Umkehrung, daß zur Fortpflanzung Individuen ausgewählt werden, die sich nicht ähnlich sind. Dies könnte heißen, daß bei Auswahl der Ehepartner die Wahl bevorzugt auf nicht-verwandte Individuen fällt. Der F-Wert für die Weingartener Population kann aber nicht eindeutig angegeben werden. Die Frage ist, ob das System D8S1179 aus der Analyse herausfallen muß, da bei der Überprüfung auf Heterozygotenüberschuß für diesen Locus eine signifikante Abweichung vom HW-Gleichgewicht nachzuweisen ist, die auf eine überzufällig hohe Rate an heterozygoten Genotypen für dieses System hinweist. Wird das System mitbewertet, ergibt sich für die Weingartener Stichprobe ein Wert nahe Null $(-0,009)$, bei Einbeziehung von D8S1179 ist der Wert positiv und liegt bei 0,016. Letzteres würde auf Inzuchtprozesse innerhalb der Weingartener Population schließen lassen. Dies würde im Gegensatz zu den für die merowingerzeitliche Gesellschaft angenommenen Inzuchttabus (de Jong 1989) stehen, die einen sehr weiten Personenkreis auch von nur entfernt verwandten Individuen als Heiratspartner ausschließen (vgl. Kapitel 1.5). Hier könnte ein Hinweis auf Bedas „Ecclesiastical History of the English People“ nützlich sein (Beda zitiert nach McClure 1994). Beda, ein Mönch des 7. Jahrhunderts, beschreibt die Schwierigkeiten, die sich bei der Bekehrung der heidnischen Angelsachsen ergaben, wozu die Problematik gehört, wie bestehende eheliche Verbindungen zwischen nahe-verwandten Individuen $\mathrm{zu}$ behandeln seien, die nach dem neuen christlichen Recht unzulässig waren. Hierbei werden auch Ehen zwischen Cousin und Cousine ersten Grades genannt, woraus Goody (1983) folgert, daß solche Verbindungen nicht nur in England, sondern vermutlich auch in der, von der Rechtsauffassung ähnlichen germanischen Gesellschaft durchaus vorkam.

\subsection{Residenzverhalten der Weingartener Bevölkerung}

Aufgrund des geringen Erfolgs der Y-chromosomalen STR-Amplifikationen (vgl. Kapitel 5.2.2) wird eine Determination des Wohnfolgeverhaltens in der frühmittelalterlichen Bevölkerung von Weingarten erschwert. Der Nachweis eines bestimmten Residenzverhaltens kann unmittelbar nur durch den Vergleich der 
Diversitäten für die maternal vererbten Sequenzen und der paternalen Marker gelingen (vgl. Kapitel 4.4). Im vorliegenden Fall ist zwar die Diversität der mitochondrialen Marker ermittelt worden (vgl. Tabelle 5.20), für die Y-chromosomalen Systeme schließt sich aber die Nennung eines statistisch ermittelten Diversität-Wertes aus, so daß ein rein deskriptiver Vergleich vorgenommen wurde (vgl. Kapitel 5.5).

\subsection{1 mt-Variabilitäten im Geschlechtervergleich}

Bei Betrachtung der mitochondrialen Variabilitäten zwischen den Geschlechtern innerhalb der Weingartener Stichprobe ist eine insgesamt geringere Variabilität des männlichen mitochondrialen DNA-Pools festzustellen (vgl. Kapitel 5.5.1.1).

Dazu muß angemerkt werden, daß ein Vergleich mitochondrialer Variabilitäten zwischen und innerhalb von Gruppen prinzipiell zur Feststellung von Matrilokalität führen kann (vgl. Tabelle 4.3). Die weiblichen Individuen sollten sich in diesem Fall beim Vergleich zwischen Gruppen genetisch heterogener darstellen als die männlichen Individuen. Innerhalb der Gruppen, und nur dies ist für das Weingartener Skelettkollektiv durchführbar, sollte sich hingegen die mitochondriale Variabilität der weiblichen Individuen als geringer erweisen, als die der männlichen. Wird jedoch Patrilokalität praktiziert, werden sich die Variabilitäten hinsichtlich der mitochondrialen Daten zwischen Männern und Frauen im Intrapopulationsvergleich nicht unterscheiden. Die männlichen Individuen zeigen aufgrund der mt-Haplotyp-Variabilitäten, die im Endeffekt die Variabilitäten der in den vorherigen Generationen zugezogenen Frauen darstellen (die der Mütter der Männer), die gleichen Variabilitätsmuster auf, wie die mit ihnen verglichenen weiblichen Individuen.

Aufgrund des Befunds der geringeren mitochondrialen Variabilität für die untersuchten männlichen Weingartener Individuen ist unter Umständen auszuschließen, daß in dieser merowingerzeitlichen Bevölkerung matrilokales Wohnfolgeverhalten praktiziert wurde, da sich, wie beschrieben (vgl. Kapitel 4.4, Tabelle 4.3), in einem solchen Fall eine höhere Diversität im männlichen Genpool zeigen sollte. Gerade der Umstand, daß die Variabilität im männlichen mt-Pool 
geringer ist, obwohl nahezu doppelt so viele Männer wie Frauen typisiert wurden (vgl. 5.5.1.1), unterstützt diesen Gedankengang. Allerdings ist als Umkehrschluß eine Festlegung auf Patrilokalität nicht zulässig. Die mt-Diversität der Männer ist, bedingt durch den maternalen Vererbungsweg der mitochondrialen DNA, auch immer Abbild der mt-Diversität der Müttergeneration. Insofern ist mit dem Befund einer niedrigeren männlichen mitochondrialen Diversität eine Interpretationsgrenze erreicht, die weitere Aussagen nicht zuläßt.

\subsubsection{Anzeichen für Patrilokalität}

Ein weiterer Umstand läßt jedoch - mit aller gebotenen Vorsicht - die Annahme zu, daß in der Weingartener Bevölkerung patrilokales Residenzverhalten zugrunde gelegt werden kann.

Ein Vergleich der genetischen Diversitäten nur der männlichen Y-typisierten Individuen zeigt, daß diese Individuen einer geringeren Anzahl Patrilinien als Matrilinien zugeordnet werden können (vgl. Kapitel 5.5.1.2). Die Beobachtung, daß die 28 Individuen auf 16 Patrilinien und 21 Matrilinien aufzuteilen sind, demnach also eine höhere Variabilität der mt-Linien aufweisen, könnte auf Patrilokalität als Residenzordnung schließen lassen. Die Betrachtung der Y-typisierten Männer zeigt außerdem an, daß ein größerer Anteil von ihnen (18 von insgesamt 28) Matrilinien zuzuordnen sind, die in der Bevölkerung für mehrere Individuen nachgewiesen werden können. Eine Beantwortung der Frage, ob es sich vor allem bei den mt-Linien, die lediglich von zwei Individuen geteilt werden, um Mutter-Sohn-Paare handelt, ist nicht zu beantworten, da in diesen Fällen häufig keine auswertbaren Typisierungen autosomaler STRs vorliegen (vgl. Kapitel 5.6.2). Daß die Y-typisierten Männer in der Bevölkerung mehr oder weniger geläufigen Matrilinien zuzuordnen sind (vgl. Tabelle 5.21), scheint dafür zu sprechen, daß sie in der Gesamtpopulation verwurzelt sind. Handelte es sich um Männer, die tatsächlich im Rahmen von Heiratsmigration in die Gemeinschaft des Siedlungsplatzes aufgenommen wurden, wäre eher davon auszugehen, daß solche Individuen vorwiegend singuläre mt-Typen aufweisen. Interessant wäre damit die Untersuchung der acht männlichen Individuen, die als Träger singulärer mitochondrialer und Y-chromosomaler Haplotypen ausgewiesen sind (vgl. Tabelle 5.21). Unter 
Umständen ließen sich durch Analysen spezifischer Isotopen-Signaturen von Knochen und Zähnen dieser Männer Hinweise darauf erhalten, ob es sich bei ihnen um Heiratsmigranten aus umliegenden Siedlungen handelt (Ezzo et al. 1997; Grupe et al. 1997; Price et al. 1994).

Ein weiterer Grund für eine geringere Variabilität der Y-chromosomalen Sequenzen könnte auch in den unterschiedlichen effektiven Populationsgrößen von männlichen und weiblichen Individuen liegen. Die effektive Populationsgröße bestimmt sich aus der Anzahl der Individuen, die einen genetischen Beitrag zur Formierung des Genbestandes der nächsten Generation leisten. Dieser Wert kann vom Heiratsverhalten einer Population bestimmt sein. So führt Polygynie zu einer geringeren effektiven Populationsgröße bei Männern, da nur einige wenige männliche Individuen an der Fortpflanzung teilnehmen, während für eine größere Anzahl Männer nicht die Gelegenheit besteht, ihre Gene in den Genpool der nächsten Generation zu überführen. Daß Polygynie in der frühmittelalterlichen Gesellschaft praktiziert wurde, ist allerdings ohne Anhalt. Eine denkbare Erklärung für eine geringere effektive Populationsgröße des männlichen Geschlechts wäre z.B. mit einer höheren männlichen Sterblichkeit vor der reproduktiven Phase gegeben (juvenis und jünger), z.B. bedingt durch Jagd oder Krieg, vermutlich aber vor allem auch begründet durch eine höhere prä- und postnatale Sterblichkeit von männlichen Individuen (Lassen 1998). Innerhalb des Weingartener Gräberfelds sind jedoch die jüngeren Individuen, wie bei der Untersuchung vieler Reihengräberfriedhöfe zu beobachten, deutlich unterrepräsentiert. Die vorliegenden Individuen dieser Alterstufen sind darüber hinaus auch nur zum Teil geschlechtsbestimmt, so daß eine Aussage zu dieser Erklärungsweise nicht vorgenommen werden kann.

Unter Zusammenfassung aller dargestellten Aspekte wird deutlich, daß anhand molekulargenetischer Untersuchungen ein Beitrag zur Beantwortung kultur- bzw. sozialwissenschaftlicher Fragestellungen geleistet werden kann. So kann durch die Rekonstruktion von unmittelbaren und weiter gefassten Verwandtschaftsstrukturen innerhalb der historischen Bevölkerung Weingartens wahrscheinlich davon ausgegangen werden, daß in dieser Bevölkerung Patrilokalität praktiziert wurde. Dies 
würde mit Angaben historischer Schriftquellen und archäologischen Erkenntnissen übereinstimmen, die die Situation innerhalb einer frühmittelalterlichen Siedlung so beschreiben, daß die verheirateten Söhne mit ihren Familien, nahe beim, wenn nicht sogar im Hause des Vaters wohnen (Steuer 1982; Njeussychin 1961. Die Archäologen gehen davon aus, daß die Ehefrau nach der Heirat zur Familie des Mannes zog. Dies wird unter anderem dadurch belegt, daß die Muntgewalt über die Frau an den Ehemann überging (Siegmund 1998a), zum anderen hatte bei Neuverheiratung einer Witwe der neue Bräutigam eine Zahlungsverpflichtung (den sogenannten „reipus“) gegenüber den Verwandten des verstorbenen Ehemanns, sozusagen als Entschädigung für den Arbeitskraftverlust, den dessen Familie durch den Fortgang der Frau erfuhr (Njeussychin 1961).

Die Beobachtung, daß Individuen innerhalb der durch genetische Typisierungen determinierten Familien unterschiedliche Ränge aufweisen, kann vielleicht doch zur Lösung der Frage nach festgelegter Rangzugehörigkeit beitragen, deren Aufklärung Siegmund (1998b) durch archäologische Forschungsergebnisse skeptisch beurteilt. Die auf molekularer Untersuchungsgrundlage getroffene Feststellung, daß auch innerhalb von Familien Rangunterschiede bestehen, weisen Steuers (1997) Standpunkt als plausibel aus, nach dessen Ansicht zum Beispiel das Familienoberhaupt eine gehobenere Position einnehmen kann als die Söhne. Der erbrachte Nachweis einer genetisch homogenen Bevölkerung kann jene Auffassung stützen, die die alamannische Gesellschaft als „offene Ranggesellschaft“ ohne festgefügte Schichten betrachtet, die geprägt scheint durch eine hohe soziale Mobilität. 


\section{$7 \quad$ ZUSAMMENFASSUNG}

Der Erfassung sozialer Strukturen kommt entscheidende Bedeutung bei der Rekonstruktion der Lebensverhältnisse historischer Bevölkerungen zu. Durch Typisierung alter DNA ist der Nachweis biologisch determinierter Verwandtschaftsbeziehungen zwischen Individuen eines Skelettkollektivs zu erbringen. Die Ergebnisse der Verwandtschaftsrekonstruktionen können, auch im Verbund mit archäologischen Forschungsbefunden, aufschlußreiche Einblicke in den Aufbau historischer Lokalpopulationen gewähren.

Die genetische Charakterisierung einer 161 Individuen umfassenden Stichprobe, die dem frühmittelalterlichen (6.-7. Jh.) Gräberfeld von Weingarten (BadenWürttemberg) entstammt, sollte zur Aufklärung der Sozialstruktur dieser historischen Bevölkerungsgruppe beitragen. Im Vordergrund stand dabei die Aufklärung von Heiratssystemen, da Heiratsbeziehungen einen nicht unerheblichen Teil des soziokulturellen Systems einer Gesellschaft ausmachen.

Kennzeichnend für die Reihengräberfeldkultur, zu der die Weingartener Nekropole zählt, ist die umfangreiche Beigaben-Ausstattung der Gräber. Archäologische Kategorisierungen dieser Begleitfunde lassen eine soziale Strukturierung der zugehörigen Bevölkerungen in verschiedene Ranggruppen erkennen. Ein zentraler Punkt der vorliegenden Arbeit bestand darin, zu überprüfen, ob die kulturelle Differenzierbarkeit, die eine Aufteilung der Weingartener Population in zwei Gruppen der höher- und niederrangigen Individuen zur Folge hatte, auch auf eine genetische Unterscheidung dieser beiden Sozialgruppen auszuweiten ist. Dabei stand die Darstellung der genetischen Variabilität innerhalb und zwischen den Statusgruppen im Vordergrund, da so das Ausmaß der (Heirats)-Beziehungen zwischen den Gruppen beurteilt werden kann. Des weiteren sind durch Untersuchung der genetischen Variabilität auch Rückschlüsse auf das nach Eheschließung gezeigte Wohnfolgeverhalten zu ziehen. 
Es wurden sowohl autosomale und Y-chromosomale Short Tandem Repeats (STRs) als auch mitochondriale Sequenzabschnitte analysiert. Durch die Einbeziehung dieser polymorphen Marker lassen sich genetische Diversität sowie genetisch bedingte Substrukturierungen innerhalb einer Bevölkerung erfassen. Darüber hinaus sind mit Hilfe der autosomalen STRs Eltern-Kind-Beziehungen zu rekonstruieren, während durch Untersuchung mitochondrialer Sequenzen und der Y-STRs Individuen identifizierbar sind, die derselben Matri- bzw. Patrilinie zugeordnet werden können.

Anhand der durchgeführten genetischen Analysen durch autosomale und mitochondriale Marker ließ sich nachweisen, daß es sich bei der Weingartener Gesamtstichprobe um eine genetisch homogene Bevölkerungsgruppe handelt. Die archäologische Einteilung der Individuen in verschiedene Sozialränge ist somit nicht auf eine genetische Differenzierung der Individuen auszudehnen. Es mögen in der untersuchten frühmittelalterlichen Bevölkerung unterschiedliche Sozialgruppen bestanden haben, eine Trennung der Individuen auf molekularer Ebene liegt aber nicht vor, so daß anzunehmen ist, daß im weitesten Ausmaß Heiratsbeziehungen zwischen Angehörigen verschiedener Sozialränge bestanden haben. Darüber hinaus wurde aufgrund der ermittelten höheren mitochondrialen Variabilität im Vergleich zur Variabilität der Y-Marker auf ein Heiratssystem geschlossen, in dem ein Paar nach seiner Heirat nahe oder in der Familie des Ehemanns lebte. Da innerhalb der durch STR-Typisierungen nachgewiesenen Familiengruppen die putativen Familienmitglieder unterschiedliche Rangzugehörigkeiten aufweisen, wird außerdem angenommen, daß sozialer Rang in der merowingerzeitlichen Gesellschaft Weingartens nicht durch Geburt determiniert, sondern im Leben veränderlich war.

Die vorliegende Arbeit ist Beispiel dafür, daß durch die Kombination der Ergebnisse molekularer Analysen an historischen Populationen und Erkenntnissen, die unter anderem durch die Archäologie und Geschichtsforschung erbracht werden, ein vollständigeres Bild der Sozialstruktur historischer Gesellschaften zu erhalten ist. 
Alt KW, Pichler S, Vach W, Huckenbeck W, Stloukal M (1996) Early bronze age family burial from Velké Pavlovice. Verification of kinship hypothesis by odontologic and other nonmetric traits. Homo 46: 256-266

Alt KW, Vach W (1995) Odontologic kinship analysis in skeletal remains - Concepts, methods, and results. Forensic Sci Int 74: 99-113

Anderson S, Bankier AT, Barrell BG, de Bruijn MH, Coulson AR, Drouin J, Eperon IC, Nierlich DP, Roe BA, Sanger F, Schreier PH, Smith AJ, Staden R, Young IG (1981) Sequence and organization of the human mitochondrial genome. Nature 290: 457465

Anslinger K, Keil W, Weichhold G, Eisenmenger W (2000) Y-chromosomal STR haplotypes in a population sample from Bavaria. Int J Legal Med 113: 189-192

Anslinger K, Rolf B, Keil W (2001a) Evaluation and application of the AmpFlSTR Profiler Plus PCR amplification kit in a Bavarian population sample. Int J Legal Med 114: $278-280$

Anslinger K, Weichhold G, Keil W, Bayer B, Eisenmenger W (2001b) Identification of the skeletal remains of Martin Bormann by mtDNA analysis. Int J Legal Med 114: 194196

Bamshad MJ, Watkins WS, Dixon ME, Jorde LB, Rao BB, Naidu JM, Prasad BVR, Rasanayagam A, Hammer MF (1998) Female gene flow stratifies Hindu castes. Nature 395: 651-652

Banks MA, Eichert W (2000) WHICHRUN (version 3.2): A computer program for population assignment of individuals based on multilocus genotype data. J Hered 91: $87-89$

Barnard A, Good A (1984) Research practices in the study of kinship. Academic Press, London

Beck H (1986) Ehe. In: Beck H, Jankuhn H, Ranke K, Wenskus R (eds) Reallexikon Germanischer Altertumskunde. De Gruyter, Berlin New York, pp 478-479

Bogenhagen D, Clayton DA (1974) The number of mitochondrial deoxyribonucleic acid genomes in mouse L and human HeLa cells. Quantitative isolation of mitochondrial deoxyribonucleic acid. J Biol Chem 249: 7991-7995

Bramanti B, Hummel S, Schultes T, Herrmann B (2000a) Genetic characterization of an historical human society by means of aDNA analysis of autosomal STRs. Biennal Books of EAA: 147-163

Bramanti B, Hummel S, Schultes T, Herrmann B (2000b) STR allelic frequencies in a German skeleton collection. Anthropol Anz 58: 45-49

Brenner CH (1993) A note on paternity computation in cases lacking a mother. Transfusion 33: $51-54$

Brown K (1998) Gender and Sex - What can ancient DNA tell us? Ancient Biomolecules 2: 3-15

Brown K, Pluciennik M (2001) Archaeology and human genetics: lessons for both. Antiquity 75: $101-106$ 
Burger J (1997) Erhaltungszustand von DNA aus prähistorischen Zähnen unterschiedlichen Liegemilieus und verschiedener Art der Lagerung. Magisterarbeit. Mainz

Burger J, Hummel S, Herrmann B, Henke W (1999) DNA preservation: A microsatelliteDNA study on ancient skeletal remains. Electrophoresis 20: 1722-1728

Caglia A, Dobosz M, Boschi I, d'Aloja E, Pascali VL (1998) Increased forensic efficiency of a STR-based Y-specific haplotype by addition of the highly polymorphic DYS385 locus. Int J Legal Med 111: 142-146

Carlyle SW, Parr RL, Hayes MG, O'Rourke DH (2000) Context of maternal lineages in the Greater Southwest. Am J Phys Anthropol 113: 85-101

Christlein R (1991) Die Alamannen. Archäologie eines lebendigen Volkes. Theiss, Stuttgart

Clayton TM, Whitaker JP, Sparkes R, Gill P (1998) Analysis and interpretation of mixed forensic stains using DNA STR profiling. Forensic Sci Int 91: 55-70

Cockerham CC (1973) Analysis of gene frequencies. Genetics 74: 679-700

Comas D, Calafell F, Mateu E, Perez-Lezaun A, Bosch E, Martinez-Arias R, Clarimon J, Facchini F, Fiori G, Luiselli D, Pettener D, Bertranpetit J (1998) Trading genes along the silk road: mtDNA sequences and the origin of central Asian populations. Am J Hum Genet 63: 1824-1838

Cone RW, Fairfax MR (1993) Protocol for ultraviolet irradiation of surfaces to reduce PCR contamination. PCR Meth Appl 3: 15-17

Cooper A, Poinar HN (2000) Ancient DNA: Do it right or not at all. Science 289: 1139

Cooper A, Wayne R (1998) New uses for old DNA. Curr Opin Biotechnol 9: 49-53

Corach D, Sala A, Penacino G, Iannucci N, Bernardi P, Doretti M, Fondebrider L, Ginarte A, Inchaurregui A, Somigliana C, Turner S, Hagelberg E (1997) Additional approaches to DNA typing of skeletal remains: The search for "missing" persons killed during the last dictatorship in Argentina. Electrophoresis 18: 1608-1612

Davies N, Villablanca FX, Roderick GK (1999) Determining the source of individuals: multilocus genotyping in nonequilibrium population genetics. Trends Ecol Evol 14: $17-21$

de Jong M (1989) To the limits of kinship: Anti-incest legislation in the early medieval west (500 - 900). In: Bremmer J (ed) From Sappho to de Sade. Moments in the history of sexuality. Routledge, London New York, pp 36-59

de Knijff P, Kayser M, Caglia A, Corach D, Fretwell N, Gehrig C, Graziosi G, Heidorn F, Herrmann S, Herzog B, Hidding M, Honda K, Jobling MA, Krawczak M, Leim K, Meuser S, Meyer E, Oesterreich W, Pandya A, Parson W (1997) Chromosome Y microsatellites: population genetic and evolutionary aspects. Int J Legal Med 110: 134-149

Dommasnes LH (1982) Late iron age in Western Norway. Female roles and ranks as deduced from an analysis of burial customs. Norw Arch Rev 15: 70-84

Donat P, Ullrich H (1971) Einwohnerzahlen und Siedlungsgröße der Merowingerzeit. Ein methodischer Beitrag zur demographischen Rekonstruktion frühgeschichtlicher Bevölkerungen. Z Archäol 5: 234-265

Edwards A, Civitello A, Hammond HA, Caskey CT (1991) DNA typing and geneticmapping with trimeric and tetrameric tandem repeats. Am J Hum Genet 49: 746-756

Eglinton G, Logan GA (1991) Molecular preservation. Philos Trans R Soc Lond B Biol Sci: 315-328 
Excoffier L, Smouse PE, Quattro JM (1992) Analysis of molecular variance inferred from metric distances among DNA haplotypes - application to human mitochondrial-DNA restriction data. Genetics 131: 479-491

Ezzo JA, Johnson CM, Price TA (1997) Analytical perspectives on prehistoric migration: A case study from East-Central Arizona. J Archaeol Sci 24: 447-466

Faerman M, Bar-Gal GK, Filon D, Greenblatt CL, Stager L, Oppenheim A, Smith P (1998) Determining the sex of infanticide victims from the late Roman era through ancient DNA analysis. J Archaeol Sci 25: 861-865

Findlay I, Taylor A, Quirke P, Frazier R, Urquhart AJ (1997) DNA fingerprinting from single cells. Nature 389: 555-556

Finis C (2001) Megaplex STR analysis from a single amplification: Validation of the PowerPlex16 System. Profiles in DNA 4: 3-6

Foster EA, Jobling MA, Taylor PG, Donnelly P, de Knijff P, Mieremet R, Zerjal T, TylerSmith C (1998) Jefferson fathered slave's last child. Nature 396: 27-28

Francalacci P (1995) DNA recovery from ancient tissues: problems and perspectives. Hum Evol 10: 81-91

Fregeau CJ, Fourney RM (1993) DNA typing with fluorescently tagged short tandem repeats: a sensitive and accurate approach to human identification. Biotechniques 15: $100-119$

Gagneux P, Boesch C, Woodruff DS (1997) Microsatellite scoring errors associated with noninvasive genotyping based on nuclear DNA amplified from shed hair. Mol Ecol 6: $861-868$

Gerstenberger J, Hummel S, Schultes T, Hack B, Herrmann B (1999) Reconstruction of a historical genealogy by means of STR analysis and Y-haplotyping of ancient DNA. Eur J Human Genet 7: 469-477

Geuenich D (1997) Ein junges Volk macht Geschichte. In: Archäologisches Landesmuseum Baden-Württemberg (ed) Die Alamannen. Theis, Stuttgart, pp 73-78

Gill P, Ivanov PL, Kimpton CP, Piercy R, Benson N, Tully G, Evett I, Hagelberg E, Sullivan KM (1994) Identification of the remains of the Romanov family by DNA analysis. Nature Genet 6: 130-135

Gill P, Urquhart AJ, Millican ES, Oldroyd N, Watson SK, Sparkes R, Kimpton CP (1996) A new method of STR interpretation using inferential logic - development of a criminal intelligence database. Int J Legal Med 109: 14-22

Gonzalez-Oliver A, Marquez-Morfin L, Jimenez JC, Torre-Blanco A (2001) Founding Amerindian mitochondrial DNA lineages in ancient Maya from Xcaret, Quintana Roo. Am J Phys Anthropol 116: 230-235

Goody J (1983) The development of the family and marriage in Europe. University Press, Cambridge

Goudet J, Raymond M, de Meeus T, Rousset F (1996) Testing differentiation in diploid populations. Genetics 144: 1933-1940

Grupe P, Price TD, Schröter P, Sollner F, Johnson CM, Beard BL (1997) Mobility of Bell Beaker people revealed by strontium isotope ratios of tooth and bone; a study of southern Bavarian skeletal remains. Appl Geochem 12: 517-525

Guo SW, Thompson EA (1992) Performing the exact test for Hardy-Weinberg proportion for multiple Alleles. Biometrics 48: 361-372 
Gusmao L, Sanchez-Diz P, Alves C, Lareu MV, Carracedo A, Amorim A (2000) Genetic diversity of nine STRs in two northwest Iberian populations: Galicia and northern Portugal. Int J Legal Med 114: 109-113

Haack K, Hummel S, Herrmann B (2000) Ancient DNA fragments longer than $300 \mathrm{bp}$. Anthropol Anz 58: 51-56

Hammer MF, Spurdle AB, Karafet T, Bonner MR, Wood ET, Novelletto A, Malaspina P, Mitchell RJ, Horai S, Jenkins T, Zegura SL (1997) The geographic distribution of human Y chromosome variation. Genetics 145: 787-805

Han GR, Lee YW, Lee HL, Kim SM, Ku TW, Kang IH, Lee HS, Hwang JJ (2000) A Korean population study of the nine STR loci FGA, VWA, D3S1358, D18S51, D21S11, D8S1179, D7S820, D13S317 and D5S818. Int J Legal Med 114: 41-44

Handt O, Höss M, Krings M, Pääbo S (1994) Ancient DNA - Methodological challenges. Experientia 50: 524-529

Hanson DB, Buikstra JE (1987) Histomorphological alteration in buried human bone from the lower Illinois Valley: implications for paleodietary research. J Archaeol Sci 14: $549-563$

Hartl DL, Clark AG (eds) (1997) Principles of population genetics. Third Edition Sinauer Associates, Sunderland, MA

Hauge XY, Litt M (1993) A study of the origin of "shadow bands" seen when typing dinucleotide repeat polymorphisms by the PCR. Hum Mol Gen 2: 411-415

Hauswirth WW, Dickel CD, Rowold DJ, Hauswirth MA (1994) Inter- and intrapopulation studies of ancient humans. Experientia 50: 585-591

Härke H (1990) "Warrior Graves"? The backround of the Anglo-Saxon weapon burial rite. Past and Present 126: 22-43

Härke H (1992) Angelsächische Waffengräber des 5. bis 7. Jahrhunderts. Rheinland-Verlag, Köln

Hemphill BE (1999) Foreign elites from the Oxus civilization? A craniometric study of anomalous burials from Bronze Age Tepe Hissar. Am J Phys Anthropol 110: 421434

Herrmann B (2001) Zwischen Molekularbiologie und Mikrohistorie. Vom Ort der Historischen Anthropologie. Jahrbuch 2000 der Deutschen Akademie der Naturforscher Leopoldina (Halle/Saale). LEOPOLDINA (R3). vol. 46 Akademie der Naturforscher Leopoldina, Halle/Saale, pp 391-408

Herrmann B, Hummel S (1993) Introduction. In: Herrmann B, Hummel S (eds) Ancient DNA. Recovery and analysis of genetic material from palaeontological, archaeological, museum, medical, and forensic specimens. Springer, New York Berlin Heidelberg, pp 1-12

Herrmann B, Hummel S, Bramanti B, Gerstenberger J, Schultes T (2001) Genealogische Rekonstruktionen durch DNA-Analysen an historischen Skelettserien. Nova Acta Leopoldina 84: 21-33

Hite JM, Eckert KA, Cheng KC (1996) Factors affecting fidelity of DNA synthesis during PCR amplification of d(C-A)n d(G-T)n microsatellite repeats. Nucleic Acids Res 24: 2429-2434

Hofreiter M, Serre D, Poinar HN, Kuch M, Pääbo S (2001) Ancient DNA. Nature Reviews Genetics 2: 353-359 
Holland MM, Fisher DL, Mitchell LG, Rodriquez WC, Canik JJ, Merril CR, Weedn VW (1998) Mitochondrial DNA sequence analysis of human skeletal remains: Identification of remains from the Vietnam War. J Forensic Sci 38: 542-553

Horai S, Kondo R, Murayama K, Hayashi S, Koike H, Nakai N (1991) Phylogenetic affiliation of ancient and contemporary humans inferred from mitochondrial-DNA. Phil Trans R Soc Lond B Biol Sci: 409-416

Huber NM (1967) Anthropologische Untersuchungen an den Skeletten aus dem alamannischen Reihengräberfeld von Weingarten, $\mathrm{Kr}$. Ravensburg. Naturwissenschaftliche Untersuchungen zur Vor- und Frühgeschichte in Württemberg und Hohenzollern 3.

Hummel S, Bramanti B, Schultes T, Kahle M, Haffner S, Herrmann B (2000) Megaplex DNA typing can provide a strong indication of the authenticity of ancient DNA amplifications by clearly recognizing any possible type of modern contamination. Anthropol Anz 58: 15-21

Hummel S, Herrmann B (1997) Verwandtschaftsfeststellung durch aDNA-Analyse. Anthropol Anz 55: 217-223

Ishida H, Dodo Y (1997) Cranial variation in prehistoric human skeletal remains from the Marianas. Am J Phys Anthropol 104: 399-410

Jeffreys AJ, Pena SD (1993) Brief introduction to human fingerprinting. In: Pena SD, Chakraborty R, Epplen JT, Jeffreys AJ (eds) DNA fingerprinting: State of the science. Birkhäuser, Basel, pp 1-20

Jehaes E, Decorte R, Peneau A, Petrie JH, Boiry PA, Gilissen A, Moisan JP, Van den Berghe H, Pascal O, Cassiman JJ (1998) Mitochondrial DNA analysis on remains of a putative son of Louis XVI, King of France and Marie-Antoinette. Eur J Human Genet 6: 383-395

Jobling MA, Tyler-Smith C (1995) Fathers and sons - the Y-chromosome and human evolution. Trends Genet 11: 449-456

Jones DA (1972) Blood samples: probability of discrimination. J Forensic Sci Soc 12: 355359

Jorde LB, Bamshad MJ, Watkins WS, Zenger R, Fraley AE, Krakowiak PA, Carpenter KD, Soodyall H, Jenkins T, Rogers AR (1995) Origins and affinities of modern humans A comparison of mitochondrial and nuclear genetic data. Am J Hum Genet 57: 523538

Jorde LB, Watkins WS, Bamshad MJ, Dixon ME, Ricker CE, Seielstad MT, Batzer MA (2000) The distribution of human genetic diversity: A comparison of mitochondrial, autosomal, and Y-chromosome data. Am J Hum Genet 66: 979-988

Kaestle FA, Smith DG (2001) Ancient mitochondrial DNA evidence for prehistoric population movement: the Numic expansion. Am J Phys Anthropol 115: 1-12

Kayser M, Caglia A, Corach D, Fretwell N, Gehrig C, Graziosi G, Heidorn F, Herrmann S, Herzog B, Hidding M, Honda K, Jobling MA, Krawczak M, Leim K, Meuser S, Meyer E, Oesterreich W, Pandya A, Parson W, Penacino G (1997) Evaluation of Ychromosomal STRs: A multicenter study. Int J Legal Med 110: 125-133

Kimpton CP, Gill P, Walton A, Urquhart AJ, Millican ES, Adams M (1993) Automated DNA profiling employing multiplex amplification of short tandem repeat loci. PCR Meth Appl 3: 13-22 
Kitchin PA, Szotyori Z, Fromholc C, Almond N (1990) Avoidance of false positives. Nature: 201

Kolman CJ, Tuross N (2000) Ancient DNA analysis of human populations. Am J Phys Anthropol 111: 5-23

Krings M, Stone AC, Schmitz RW, Krainitzki H, Stoneking M, Pääbo S (1997) Neandertal DNA sequences and the origin of modern humans. Cell 90: 19-30

Kwok S (1990) Procedures to minimize PCR-product carry-over. In: Innis MA, Gelfand D, Sninsky JJ, White TJ (eds) PCR protocols: A guide to methods and applications. Academic Press, San Diego, pp 142-145

Lambert JB (1998) Traces of the past. Unraveling the secrets of archaeology through chemistry. Perseus Books, Reading, Massachusetts

Lassen C (1998) Molekulare Geschlechtsdetermination der Traufkinder des Gräberfeldes Aegerten (Schweiz). Dissertation, Universität Göttingen

Lassen C, Hummel S, Herrmann B (1996) PCR based sex identification in ancient human bones by amplification of $\mathrm{X}$ - and $\mathrm{Y}$ chromosomal sequences. A comparison. Ancient Biomolecules 1: 25-33

Lederer T, Betz P, Seidl S (2001) DNA analysis of fingernail debris using different multiplex systems: a case report. Int J Legal Med 114: 263-266

Lehmkühler S (1991) Heiratskreise in der Vorgeschichte. Archäologische Informationen 14: $155-159$

Levi-Strauss C (ed) (1981) Die elementaren Strukturen der Verwandtschaft. Suhrkamp, Frankfurt a.M.

Lindahl T (1993) Instability and decay of the primary structure of DNA. Nature 362: 709715

Litt M, Luty JA (1989) A hypervariable microsatellite revealed by in vitro amplification of a dinucleotide repeat within the cardiac muscle actin gene. Am J Hum Genet 44: 397401

Lygo JE, Johnson PE, Holdaway DJ, Woodroffe S, Whitaker JP, Clayton TM, Kimpton CP, Gill P (1994) The validation of short tandem repeat (STR) loci for use in forensic casework. Int J Legal Med 107: 77-89

Martin M (1997) Kleider machen Leute. Trachten und Bewaffnung in fränkischer Zeit. In: Archäologisches Landesmuseum Baden-Württemberg (ed) Die Alamannen. Theiss, Stuttgart, pp 349-358

Matheson CD, Loy TH (2001) Genetic Sex Identification of 9400-year-old Human Skull Samples from Cayönü Tepesi, Turkey. J Archaeol Sci 28: 569-575

McClure J (1994) Bede. Ed. with an introduction by Judith McClure. The ecclesiastical history of the English people : the greater chronicle and Bede's letter to Egbert. Oxford University Press, Oxford

Merriwether DA, Clark AG, Ballinger SW, Schurr TG, Soodyall H, Jenkins T, Sherry ST, Wallace DC (1991) The structure of human mitochondrial DNA variation. J Mol Evol 33: 543-555

Merriwether DA, Rothhammer F, Ferrell R (1994) Genetic variation in the New World: ancient teeth, bone, and tissue as sources of DNA. Experientia 50: 592-601 
Meyer S, Weiss G, von Haeseler A (1999) Pattern of nucleotide substitution and rate heterogeneity in the hypervariable regions I and II of human mtDNA. Genetics 152: $1103-1110$

Mullis KB, Faloona FA (1987) Specific synthesis of DNA in vitro via a polymerasecatalysed chain reaction. Meth Enzymol: 335-350

Müller A (2000) DNA-Extraktion aus Knochen - ein Methodenvergleich. Diplom-Arbeit, Universität Göttingen

Nei M (1987) Molecular Evolutionary Genetics. Columbia University Press, New York

Neuffer EM (1975) Das Alamannische Gräberfeld von Weingarten, Kr. Ravensburg. In: Ausgrabungen in Deutschland, gefördert von der Deutschen Forschungsgemeinschaft 1950-1975. Verlag des Römisch-Germanischen Zentralmuseums, Mainz

Neuhuber F, Radacher M, Meisner N, Tutsch-Bauer E (1999) Nine STR markers plus amelogenin (AmpFlSTR Profiler Plus): a forensic study in an Austrian population. Int J Legal Med 113: 60-62

Njeussychin AI (1961) Die Entstehung der abhängigen Bauernschaft als Klasse der frühfeudalen Gesellschaft in Westeuropa vom 6.-8. Jahrhundert. Akademie-Verlag, Berlin

Odelberg SJ, White R (1993) A method of accurate amplification of polymorphic CA-repeat sequences. PCR Meth Appl 3: 7-12

Oota H, Saitou N, Matsushita T, Ueda S (1995) A genetic study of 2,000-year-old human remains from Japan using mitochondrial DNA sequences. Am J Phys Anthropol 98: $133-145$

Oota H, Saitou N, Matsushita T, Ueda S (1999) Molecular genetic analysis of remains of a 2,000-year-old human population in China - and its relevance for the origin of the modern Japanese population. Am J Hum Genet 64: 250-258

Oota H, Settheetham-Ishida W, Tiwawech D, Ishida T, Stoneking M (2001) Human mtDNA and Y-chromosome variation is correlated with matrilocal versus patrilocal residence. Nature Genet 29: 20-21

Owens K, King MC (1999) Genomic views of human history. Science 286: 451-453

Pader EJ (1982) Symbolism, social relations and the interpretation of mortuary remains. British Archaeological Reports International Series. BAR, Oxford

Parr RL, Carlyle SW, O'Rourke DH (1996) Ancient DNA analysis of Fremont Amerindians of the Great Salt Lake Wetlands. Am J Phys Anthropol 99: 507-518

Parsons TJ, Coble MD (2001) Increasing the forensic discrimination of mitochondrial DNA testing through analysis of the entire mitochondrial DNA genome. Croat Med J 42: 304-309

Pena SDJ, Chakraborty R (1994) Paternity testing in the DNA era. Trends Genet 10: 204209

Perez-Lezaun A, Calafell F, Comas D, Mateu E, Bosch E, Martinez-Arias R, Clarimon J, Fiori G, Luiselli D, Facchini F, Pettener D, Bertranpetit J (1999) Sex-specific migration patterns in Central Asian populations, revealed by analysis of Ychromosome short tandem repeats and mtDNA. Am J Hum Genet 65: 208-219 
Perez-Lezaun A, Calafell F, Seielstad M, Mateu E, Comas D, Bosch E, Bertranpetit J (1997) Population genetics of Y-chromosome short tandem repeats in humans. J Mol Evol 45: $265-270$

Poloni ES, Semino O, Passarino G, Santachiara-Benerecetti AS, Dupanloup I, Langaney A, Excoffier L (1997) Human genetic affinities for Y-chromosome P49a,f/TaqI haplotypes show strong correspondence with linguistics. Am J Hum Genet 61: 10151035

Price TA, Johnson TM, Ezzo JA, Burton JH, Ericson J (1994) Residential mobility in the Prehistoric Southwest: a preliminary study using strontium isotope analysis. J Archaeol Sci 21: 315-330

Pritchard JK, Rosenberg NA (1999) Use of unlinked genetic markers to detect population stratification in association studies. Am J Hum Genet 65: 220-228

Prowse TL, Lovell NC (1996) Concordance of cranial and dental morphological traits and evidence for endogamy in ancient Egypt. Am J Phys Anthropol 101: 237-246

Raymond M, Rousset F (1995a) An exact test for population differentiation. Evolution 49: $1280-1283$

Raymond M, Rousset F (1995b) GENEPOP (version 1.2): population genetics software for exact tests and ecumenicism. J Hered 86: 248-249

Reddy BH, Sun G, Luis JR, Crawford MH, Hemam NS, Deka R (2001) Genomic diversity at thirteen short tandem repeat loci in a substructured caste population, Golla, of southern Andhra Pradesh, India. Hum Biol 73: 175-190

Renfrew C (2001) From molecular genetics to archaeogenetics. Proc Natl Acad Sci USA 98: $4830-4832$

Ritte U, Neufeld E, Broit M, Shavit D, Motro U (1993) The differences among Jewish communities - Maternal and paternal contributions. J Mol Evol 37: 435-440

Robb J, Bigazzi R, Lazzarini L, Scarsini C, Sonego F (2001) Social "status" and biological "status": A comparison of grave goods and skeletal indicators from Pontecagnano. Am J Phys Anthropol 115: 213-222

Roewer L, Kayser M, Dieltjes P, Nagy M, Bakker E, Krawczak M, de Knijff P (1996) Analysis of molecular variance (AMOVA) of Y-chromosome-specific microsatellites in two closely related human populations. Hum Mol Gen 5: 10291033

Roth H (1977) Bemerkungen zur Totenberaubung während der Merowingerzeit. Archä Korrespondenzbl 7: 287-290

Roth H (1984) Frühmittelalter-Archäologie. In: Roth H, Warmers E (eds) Hessen im Frühmittelalter. Archäologie und Kunst. Jan Thorbecke, Sigmaringen, pp 24-33

Roth H, Theune C (1995) Das frühmittelalterliche Gräberfeld bei Weingarten ( $\mathrm{Kr}$. Ravensburg). 1. Katalog der Grabinventare. Theiss, Stuttgart

Rösing F (1986) Kith or kin? On the feasibility of kinship reconstructions in skeletons. In: David AR (ed) Science in Egyptology. Manchester University Press, Manchester, pp 223-237

Saiki RK, Scharf SJ, Faloona FA, Mullis KB, Horn GT, Ehrlich HA, Arnheim N (1985) Enzymatic amplification of beta-globin genomic sequences and restriction analysis for diagnosis of sickle-cell anemia. Science 230: 1350-1354 
Sajantila A, Salem AH, Savolainen P, Bauer K, Gierig C, Pääbo S (1996) Paternal and maternal DNA lineages reveal a bottleneck in the founding of the Finnish population. Proc Natl Acad Sci USA 93: 12035-12039

Salem AH, Badr FM, Gaballah MF, Pääbo S (1996) The genetics of traditional living: Ychromosomal and mitochondrial lineages in the Sinai Peninsula. Am J Hum Genet 59: 741-743

Sanger F, Nicklen S, Coulson AR (1977) DNA sequencing with chain-terminating inhibitors. Proc Natl Acad Sci USA 74: 5463

Schach-Dörges H (1997) "Zusammengespülte und vermengte Menschen". In: Archäologisches Landesmuseum Baden-Württemberg (ed) Die Alamannen. Theiss, Stuttgart,

Schmerer WM (1999) Optimierung der STR-Genotypenanalyse an Extrakten alter DNA aus bodengelagertem menschlichen Skelettmaterial. Dissertation, Universität Göttingen

Schmerer WM, Hummel S, Herrmann B (1997) Reproduzierbarkeit von aDNA-typing. Anthropol Anz 55: 199-206

Schmidt HD (1989) Migration aus historisch-demographischer Sicht und ihre Bedeutung für die Bevölkerungsbiologie. Anthropol Anz 47: 97-108

Schmidt T, Hummel S, Herrmann B (1995) Evidence of contamination in PCR laboratory disposables. Naturwissenschaften 82: 431

Schmitz CA (1964) Grundformen der Verwandtschaft. Pharos-Verlag Schwabe, Basel

Schneider, S., Rosseli, D., and Excoffier, L.(2000) Arlequin Ver. 2.000: A software for population genetics analysis. Genetics and Biometry Laboratory: University of Geneva, Switzerland

Scholz M, Hengst S, Broghammer M, Pusch CM (2001) Intrapopulational relationships in ancient societies: a multidisciplinary study. Z Morphol Anthropol 83: 5-21

Schultes T (2000) Typisierung alter DNA zur Rekonstruktion von Verwandtschaft in einem bronzezeitlichen Skelettkollektiv. Dissertation, Universität Göttingen

Schultes T, Hummel S, Herrmann B (1999) Amplification of Y-chromosomal STRs from ancient skeletal material. Hum Genet 104: 164-166

Schulze R (1986) Eherecht. In: Beck H, Jankuhn H, Ranke K, Wenskus R (eds) Reallexikon der Germanischen Altertumskunde. vol. 6 de Gruyter, Berlin, New York, pp 480500

Schutkowski H, Herrmann B, Wiedemann F, Bocherens H, Grupe G (1999) Diet, status and decomposition at Weingarten: Trace element and isotope analysis on early mediaeval skeletal material. J Archaeol Sci 26: 675-685

Shinoda K, Kanai S (1999) Intracemetery genetic analysis at the Nakazuma Jomon site in Japan by mitochondrial DNA sequencing. Anthropol Sci 107: 129-140

Shinoda K, Kunisada T (1994) Analysis of ancient Japanese society through mitochondrial DNA sequencing. Intern J Osteoarch 4: 291-297

Siegmund F (1998a) Pactus Legis Salicae § 13: Über den Frauenraub in der Merowingerzeit. In: Keller H, Meier C (eds) Frühmittelalterliche Studien. Jahrbuch des Instituts für Frühmittelalterforschung der Universität Münster. De Gruyter, Berlin, pp 101-123

Siegmund F (1998b) Social structure and relations. In: Ausenda G, Wood I (eds) Franks and Alamanni in the Merovingian period. An ethnographic perspective. Boydell Press, Woodbridge, pp 177-199 
Siegmund F (2000) Alemannen und Franken. Ergänzungsbände zum Reallexikon der Germanischen Altertumskunde. de Gruyter, Berlin New York

Smith RN (1995) Accurate size comparison of short tandem repeat alleles amplified by PCR. Biotechniques 18: 122-128

Solberg B (1985) Social Status in the Merovingian and Viking periods in Norway from archaeological and historical sources. Norw Arch Rev 18: 61-76

Stenico M, Nigro L, Bertorelle G, Calafell F, Capitanio M, Corrain C, Barbujani G (1996) High mitochondrial sequence diversity in linguistic isolates of the Alps. Am J Hum Genet 59: 1363-1375

Steuer H (1982) Frühgeschichtliche Sozialstrukturen in Mitteleuropa: Eine Analyse der Auswertung des archäologischen Quellenmaterials. Vandenhoeck und Ruprecht, Göttingen

Steuer H (1997) Krieger und Bauern - Bauernkrieger. In: Archäologisches Landesmuseum Baden-Württemberg (ed) Die Alamannen. Theiss, Stuttgart, pp 275-287

Stone AC, Milner GR, Pääbo S, Stoneking M (1996) Sex determination of ancient human skeletons using DNA. Am J Phys Anthropol 99: 231-238

Stone AC, Starrs JE, Stoneking M (2001) Mitochondrial DNA analysis of the presumptive remains of Jesse James. J Forensic Sci 46: 173-176

Stone AC, Stoneking M (1998) mtDNA analysis of a prehistoric Oneota population: implications for the peopling of the New World. Am J Hum Genet 62: 1153-1170

Stoneking M (2000) Hypervariable sites in the mtDNA control region are mutational hotspots. Am J Hum Genet 67: 1029-1032

Stork I (1997) Als Persönlichkeit ins Jenseits. Bestattungssitte und Grabraub als Kontrast? In: Archäologisches Landesmuseum Baden-Württemberg (ed) Die Alamannen. Theiss, Stuttgart, pp 418-432

Sullivan KM, Mannucci A, Kimpton CP, Gill P (1993) A rapid and quantitative DNA sex test: fluorescence-based PCR analysis of X-Y homologous gene amelogenin. Biotechniques 15: 636-1

Ullrich H (1969) Interpretation morphologisch-metrischer Ähnlichkeiten an ur- und frühgeschichtlichen Skeletten in verwandtschaftlicher Hinsicht. Z Archäol 3: 48-88

Urquhart AJ, Oldroyd NJ, Kimpton CP, Gill P (1995) Highly discriminating heptaplex short tandem repeat PCR system for forensic Identification. Biotechniques 18: 116-121

Vivelo FR (ed) (1981) Handbuch der Kulturanthropologie: Eine grundlegende Einführung. Klett-Cotta, Stuttgart

Walsh PS, Fildes NJ, Reynolds R (1996) Sequence analysis and characterization of stutter products at the tetranucleotide repeat locus vWA. Nucleic Acids Res 24: 2807-2812

Wang L, Oota H, Saitou N, Jin F, Matsushita T, Ueda S (2000) Genetic structure of a 2,500year-old human population in China and its spatiotemporal changes. Mol Biol Evol 17: $1396-1400$

Ward RH, Frazier BL, Dew-Jager K, Pääbo S (1991) Extensive mitochondrial diversity within a single Amerindian tribe. Proc Natl Acad Sci U S A 88: 8720-8724

Weber JL, May PE (1989) Abundant class of human DNA polymorphisms which can be typed using the polymerase chain reaction. Am J Hum Genet 44: 388-396 
Weichhold G, Bark JE, Korte W, Eisenmenger W, Sullivan KM (1998) DNA analysis in the case of Kaspar Hauser. Int J Legal Med 111: 287-291

Werner J (1970) Zur Verbreitung frühgeschichtlicher Metallarbeiten (WerkstattWanderhandwerk-Handel-Familienverbindungen). Early Medieval Studies 1 Antikvariskt Arkiv 38: 65-81

Williams SR, Chagnon NA, Spielman RS (2002) Nuclear and mitochondrial genetic variation in the Yanomamö: A test case for ancient DNA studies of prehistoric populations. Am J Phys Anthropol 117: 246-259

Wilson JF, Goldstein DB (2000) Consistent long-range linkage disequilibrium generated by admixture in a Bantu-Semitic hybrid population. Am J Hum Genet 67: 926-935

Wright S (1951) The genetical structure of populations. Ann Eugen 15: 323-354

Wright S (1965) Evolution and the genetics of populations. The theory of gene frequencies. The University of Chicago Press, Chicago

Zamir A, Springer E, Glattstein B (2000) Fingerprints and DNA: STR typing of DNA extracted from adhesive tape after processing for fingerprints. J Forensic Sci Soc 45: $687-688$

Zerjal T, Dashnyam B, Pandya A, Kayser M, Roewer L, Santos FR, Schiefenhövel W, Fretwell N, Jobling MA, Harihara S, Shimizu K, Semjidmaa D, Sajantila A, Salo P, Crawford MH, Ginter EK, Evgrafov OV, Tyler-Smith C (1997) Genetic relationships of Asians and Northern Europeans, revealed by Y- chromosomal DNA analysis. Am J Hum Genet 60: 1174-1183

Zhivotovsky LA, Ahmed S, Wang W, Bittles AH (2001) The forensic DNA implications of genetic differentiation between endogamous communities. Forensic Sci Int 119: 269-272

Ziegle JS, Su Y, Corcoran KP, Nie L, Mayrand PE, Hoff LB, McBride LJ, Kronick MN, Diehl SR (1992) Application of automated DNA sizing technology for genotyping microsatellite loci. Genomics 14: 1026-1031

Zischler H, Höss M, Handt O, von Haeseler A, van der Kuyl AC, Goudsmith J, Pääbo S (1995) Detecting dinosaur DNA. Science 268: 1192-1193 


\section{$9 \quad$ ANHANG}

\subsection{Einheiten und Abkürzungen}

\begin{tabular}{|c|c|}
\hline aDNA & ancient DNA \\
\hline ahd & althochdeutsch \\
\hline APS & Ammoniumpersulfat \\
\hline bp & Basenpaare \\
\hline bidest & bidestillata, zweifach destilliert \\
\hline BSA & Bovine Serum Albumin \\
\hline CDTA & 1,2-Cyclohexamindiamintetra-acetic acid \\
\hline DNA & Desoxiribonucleic Acid \\
\hline dATP & Desoxiadenintriphosphat \\
\hline $\mathrm{dCTP}$ & Desoxicytidintriphosphat \\
\hline ddNTP & Didesoxynukleosidtriphosphat \\
\hline dGTP & Desoxiguasonintriphosphat \\
\hline dNTP & Desoxinukleotidtriphosphat \\
\hline dTTP & Desoxithymidintriphosphat \\
\hline ed(s) & Editor(s) \\
\hline EDTA & Ethylendiamintetraacetat \\
\hline engl. & englisch \\
\hline et al. & und Weitere \\
\hline 6-FAM & 6-Carboxylfluorescein \\
\hline $\mathrm{HCl}$ & Salzsäure \\
\hline HEX & 6-Carboxyl-2',4',7',4,7-Hexachlorofluorescein \\
\hline IUB & International Union of Biochemistry \\
\hline Jh. & Jahrhundert \\
\hline $\mathrm{Kb}$ & Kilobasenpaare \\
\hline M & molar \\
\hline $\mathrm{MgCl}$ & Magnesiumchlorid \\
\hline $\mathrm{mM}$ & millimolar \\
\hline $\mathrm{mt}$ & mitochondrial \\
\hline$\mu l$ & Mikroliter \\
\hline$n g$ & Nanogramm \\
\hline
\end{tabular}




$\begin{array}{ll}\text { nm } & \text { Nanometer } \\ \text { PAGE } & \text { Polyacrylamid-Gelelektrophorese } \\ \text { PCR } & \text { Polymerase Chain Reaction } \\ \text { pg } & \text { Picogramm } \\ \text { pH } & \text { pondus Hydrogeni, Protonenaktivitätsexponent } \\ \text { pM } & \text { picomolar } \\ \text { pmol } & \text { Picomol } \\ \text { B } & \text { rechtlich geschützt } \\ \text { RT } & \text { Raumtemperatur } \\ \text { ROX } & \text { 6-Carboxylrhodamin } \\ \text { sec } & \text { Sekunde(n) } \\ \text { STR } & \text { Short Tandem Repeat } \\ \text { s/w } & \text { schwarz/weiß } \\ \text { Taq-Polymerase } & \text { Thermus aquaticus-DNA Polymerase } \\ \text { TBE } & \text { Tris-Borat-EDTA-Puffer } \\ \text { TEMED } & \text { N,N,N',N' Tetramethylethylendiamin } \\ \text { TM } & \text { Trademark } \\ \text { Tris } & \text { Tri[hydroxymethyl]aminomethan } \\ \text { U } & \text { unit, Einheit für Enzymaktivität } \\ \text { UV } & \text { Ultraviolett } \\ \text { U/min } & \text { Wmdrehung pro Minute } \\ \text { w/v } & \end{array}$

\subsection{Geräte, Chemikalien, Kits und Computersoftware}

\subsubsection{Geräte}

Bidestillationsanlage Typ 1071, Köttermann

Dentalbohrmaschine Typ K10, 1000-40000 U/min, EWL

Digital-pH-Meter Typ 646 mit Standard Glaselektrode, Knick

DNA-Extraktor GenePure Typ 341A, Applied Biosystems

DNA-Sequencer Modell 310 und 373A stretch mit 672 GENESCAN-ANALYSIS Software und 672 GENESCAN-COLLECTION software zur Fragmentlängenanalyse, Applied Biosystems

DNA Thermal Cycler Typ TC1, Perkin Elmer Cetus

Dremel Multi 395 mit 3,2 mm Hochgeschwindigkeitsfräser-Aufsatz 
Elektrophoresekammern Horizon ${ }^{\text {тм }}$ 1060BD 5.8 (5x8 cm), Gibco BRL

Elektrophoresekammern Horizon ${ }^{\text {тм }}$ 1060BD 11.14 (11x14 cm), Gibco BRL

Kugelschwingmühle Typ MM2, mit Zirkonium-Mahlbechern, Retsch

Magnetrührer Ikamag ${ }^{\circledR}$ RET, Ikamag ${ }^{\circledR}$ MTC, Ikamag ${ }^{\circledR}$ RH, Janke \& Kunkel Ika-Werk

Polaroid $^{\mathrm{TM}}$-Film, ISO $3000^{\circ}$, Typ 667, Polaroid ${ }^{\mathrm{TM}}$

Polaroid $^{\mathrm{TM}}$-Kamera, MP4 Land Camera, Polaroid ${ }^{\mathrm{TM}}$ mit Orangefilter Typ 15 für Ethidiumbromidfärbung, Polaroid

Präzisionswaage excellence Typ E 1200S, Sartorius

Rotator (Eigenbau), $15 \mathrm{U} / \mathrm{min}$

Schüttelapparat, Typ 3011, GFL

Stromversorgung Typ P25, 400V/1000 mA, Biometra

Stromversorgung Typ ST504 Electrophoresis Power Supply, Gibco BRL

Stromversorgung Typ ST606 Electrophoresis Power Supply, Gibco BRL

Thermomixer Typ 5437, Eppendorf

Thermostat Typ 5320, Eppendorf

Transilluminator Typ IL-350K, 254 nm, Bachofer

UV-Handlampen Typ UVK-12, $254 \mathrm{~nm}$, Neolab

Variable Mikroliterpipetten Reference ${ }^{\circledR}$, Typ 4810, Satz: 0,5-10 $\mu 1,10-100 \mu 1,100 \mu 1-1000 \mu 1$ 500-2500 $\mu 1$, Eppendorf

Zentrifuge Typ 5402, Eppendorf

Zentrifuge Typ 5415C, Eppendorf

\subsubsection{Chemikalien}

1 Kb DNA-Leiter (Molekulargewichtslängenstandard), Life Technologies

$2 \times$ Lyse-Puffer, DNA purification grade, Applied Biosystems

Acrylamid/Bisacrylamid 29:1, 40\% (w/v), Amresco $^{\circledR}$

Agarose UltraPure ${ }^{\mathrm{TM}}$, electrophoresis grade, Gibco BRL

Agarose, analytical grade for DNA electrophoresis, Serva

Alconox (Detergenz), Aldrich

Ammoniumpersulfat, ACS grade, Amresco ${ }^{\circledR}$

AmpliTaq Gold ${ }^{\mathrm{TM}}$ DNA-Polymerase (5 U/ $\mu$ 1), Perkin Elmer Cetus

Ampuwa $^{\circledR}$ (steriles Wasser), Fresenius

Aqua bidestilata, eigene Herstellung

Borsäure, p.a., Merck

Bromphenolblau Natriumsalz, p.a., Serva 
Chelex ${ }^{\circledR} 100$ Resin, BioRad

Chloroform, DNA purification grade, Applied Biosystems

dATP, dCTP, dGTP, dTTP, Sigma

Dextran-Blau, Fluka

EDTA (Ethylendinitrotetraacetat Dinatriumsalz-Dihydrat): Titriplex ${ }^{\circledR}$ III, Merck

Ethanol absolut, p.a., Abgabestellen der Bundesmonopolverwaltung: Zander-Göttingen, Nordbrand-Nordhausen (Abfüllung Universitätsklinikumsapotheke Göttingen)

Ethidiumbromid, wässrige Lösung 1\% (w/v), 10 mg/ml, Serva

$\operatorname{Extran}^{\circledR}$ Typ AP13 alkalisch mit Detergenzien, Merck

Formamid, Fluka

GeneAmp $^{\circledR} 10$ x PCR Buffer II \& $\mathrm{MgCl}_{2}$ Solution 25 mM, Perkin Elmer Cetus

GeneAmp ${ }^{\circledR} 10$ x PCR Buffer, Perkin Elmer Cetus

Glasmilk $^{\circledR}$ Typ UltraClean ${ }^{\circledR}, 15$ Ultra Bind, Bio 101, QBioGene

Genescan-500 ROX Kit, (spurinterner Standard, Loading Buffer) Applied Biosystems

Harnstoff, Gibco BRL

Hexadecylmethylammoniumbromid (CTAB), Merck-Suchardt

Isopropanol, p.a., Merck

Mineralöl NUJOL, Perkin Elmer Cetus

Natriumacetatpuffer, 2 M, pH 4,5, DNA purification grade, Applied Biosystems

Natriumhydroxyd, p.a., Merck

Phenol:Chloroform:Wasser (70:16:14), DNA purification grade, Applied Biosystems

Proteinase K, DNA purification grade, Applied Biosystems

Salpetersäure, $\mathrm{HNO}_{3}, 65 \%$, p.a., Merck

Salzsäure rauchend, $\mathrm{HCl}, 37 \%$, Merck

TEMED (Tetramethylethylendiamin) Amresco ${ }^{\circledR}$

Tris (Tri[hydroxymethyl]aminoethan), Trizma ${ }^{\text {тм }}$ Base, p.a., Sigma

\subsubsection{Einwegmaterialien und Hilfsmittel}

Dental-Diamantsägeblätter Typ Diaflex-TH350 220, Horico

Einmaluntersuchungshandschuhe Peha ${ }^{\circledR}$-safe, Peha ${ }^{\circledR}$-soft, Hartmann

Eppendorf Reaktionsgefäße (0,5 ml) safe-lock, Eppendorf

Eppendorf Reaktionsgefäße (2,0 ml) safe-lock, Eppendorf

Gesichtsmasken: Surgine face mask, Johnson \& Johnson

Kimwipes ${ }^{\circledR}$ Lite 200, Kimberley-Clark ${ }^{\circledR}$

Parafilm $\mathrm{M}^{\circledR}$, American National Can ${ }^{\mathrm{TM}}$ 
PE-Zentrifugationsgefäße, BlueMax ${ }^{\text {TM }} 15 \mathrm{ml}$ Conical Tubes 2070, Falcon ${ }^{\circledR}$

PE-Zentrifugationsgefäße, BlueMax ${ }^{\text {TM }} 50 \mathrm{ml}$ Conical Tubes 2070, Falcon ${ }^{\circledR}$

Pipettenspitzen: blaue Spitzen $1 \mathrm{ml}$, Sarstedt

Pipettenspitzen: gelbe Spitzen $100 \mu 1$, Sarstedt

Pipettenspitzen: Standardtips $10 \mu 1$, Eppendorf

Pipettenspitzen: Standardtips 2,5 ml, Eppendorf

Präzipitetten: $13 \mathrm{~mm}$ Precipitette ${ }^{\text {тм }}$-II Cardridge, Applied Biosystems

Sterilfiltrationseinheiten, $0,2 \mu \mathrm{m}$ Membran, Nalgene

\subsubsection{Kits}

AmpFlSTR Profiler Plus PCR Amplification Kit, PE Applied Biosystems

BigDye $^{\mathrm{TM}}$ Ready Reaction Mix, Applied Biosystems

Wizzard PCR Prep ${ }^{\mathrm{T} M}$ DNA Purification System, Promega

QIAquick PCR Purification Kit, Qiagen

\subsubsection{Computerprogramme}

aDNA-Typing. MoReData, Kassel.

ARLEQUIN. A software for population genetics data analysis. Version 2.000 (Schneider et al. 2000); (URL: http://lgb.unige.ch/arlequin/)

DNAStar. Softwarepaket Lasergene Biocomputing Software for Windows. DNASTAR, Inc.

GENEPOP, Version 3.3 (Raymond \& Rousset 1995b); (URL: http//wbiomed.curtin.edu.au/genepop/)

Whichrun, Version 3.2 (Banks \& Eichert 2000); (URL: http://wwwbml.ucdavis.edu/whichrun.htm) 
10 TABELLENANHANG

Tabelle 10.1: $p$-Werte und für die Überpüfung des Linkage Disequilibriums für alle Locuspaare der Weingartener Gesamtpopulation

\begin{tabular}{|c|c|c|c|}
\hline Locus 1 & Locus 2 & $p$-Wert & S.E. ${ }^{*}$ \\
\hline D3S1358 & VWA & 0,35685 & 0,03482 \\
\hline D3S1358 & FGA & 0,67751 & 0,03608 \\
\hline VWA & FGA & 0,42611 & 0,04390 \\
\hline D3S1358 & D8S1179 & 0,81344 & 0,02446 \\
\hline VWA & D8S1179 & 0,53488 & 0,03996 \\
\hline FGA & D8S1179 & 1,00000 & 0,00000 \\
\hline D3S1358 & D21S11 & 0,60429 & 0,03230 \\
\hline VWA & D21S11 & 0,84590 & 0,03790 \\
\hline FGA & D21S11 & 1,00000 & 0,00000 \\
\hline D8S1179 & D21S11 & 0,65228 & 0,03084 \\
\hline D3S1358 & D18S51 & 1,00000 & 0,00000 \\
\hline VWA & D18S51 & 1,00000 & 0,00000 \\
\hline FGA & D18S51 & 1,00000 & 0,00000 \\
\hline D8S1179 & D18S51 & No info & \\
\hline D21S11 & D18S51 & No info & \\
\hline D3S1358 & D5S818 & 0,61346 & 0,02951 \\
\hline VWA & D5S818 & 0,13323 & 0,02732 \\
\hline FGA & D5S818 & 0,81486 & 0,01606 \\
\hline D8S1179 & D5S818 & 0,07559 & 0,00595 \\
\hline D21S11 & D5S818 & 0,55665 & 0,02873 \\
\hline D18S51 & D5S818 & 0,17539 & \\
\hline D3S1358 & D13S317 & 1,00000 & 0,00000 \\
\hline VWA & D13S317 & 1,00000 & 0,00000 \\
\hline FGA & D13S317 & 1,00000 & 0,00000 \\
\hline D8S1179 & D13S317 & 1,00000 & 0,00000 \\
\hline D21S11 & D13S317 & 1,00000 & 0,00000 \\
\hline D18S51 & D13S317 & No Info & \\
\hline D5S818 & D13S317 & 0,12694 & 0,00000 \\
\hline D3S1358 & D7S820 & 1,00000 & 0,00000 \\
\hline VWA & D7S820 & 1,00000 & 0,00000 \\
\hline FGA & D7S820 & 1,00000 & 0,00000 \\
\hline D8S1179 & D7S820 & 1,00000 & \\
\hline D21S11 & D7S820 & 0,37891 & 0,00871 \\
\hline D18S51 & D7S820 & No info & \\
\hline D5S818 & D7S820 & 0,05223 & 0,00000 \\
\hline D13S317 & D7S820 & 1,00000 & 0,00000 \\
\hline
\end{tabular}

*Standard Error 
Tabelle 10.2: Determinierte Allele der Produkt-zeigenden PCR- und Extraktions-Kontrollproben.

\begin{tabular}{|c|c|c|c|c|c|c|c|c|c|c|}
\hline \multicolumn{11}{|c|}{ PCR-Kontrollen } \\
\hline Ex/PCR & Amelo & D3S1358 & VWA & $F G A$ & D8S1179 & D21S11 & D18S51 & D5S818 & D13S317 & D7S820 \\
\hline $4.6 a$ & 1 & 16 & 1 & 1 & 1 & 1 & 1 & 1 & 1 & 1 \\
\hline $5.9 a$ & l & 1 & I & I & I & 30.1 & I & I & I & I \\
\hline 13.32 & $x$ & l & l & 25 & 12 & 28 & l & I & l & \\
\hline 14.30 & l & 15 & l & 1 & l & l & l & I & l & I \\
\hline \multicolumn{11}{|c|}{ Extraktions-Kontrollen } \\
\hline Ex/PCR & Amelo & D3S1358 & VWA & FGA & D8S1179 & D21S11 & D18S51 & D5S818 & $D 13 S 317$ & D7S820 \\
\hline 2.1 & 1 & 1 & 1 & 1 & 1 & 1 & 1 & 1 & 11 & 1 \\
\hline $17 . S 1$ & I & 19 & 1 & I & 1 & I & I & I & 1 & I \\
\hline 26.44 & $x$ & I & 18 & I & 12 & I & I & I & I & I \\
\hline $28.46 a^{*}$ & $x$ & 1 & I & I & 1 & I & I & 1 & I & I \\
\hline $28.46 b^{*}$ & $Y$ & 15 & 19 & 20 & $13 / 15$ & I & I & $8 / 10$ & I & I \\
\hline $28.46 c^{*}$ & $x$ & I & I & 24 & I & I & I & I & 1 & I \\
\hline $41.59 a^{*}$ & 1 & I & 1 & I & I & I & I & I & 10 & I \\
\hline $41.59 b^{*}$ & $X Y$ & I & 14 & 25 & 12 & I & I & 11 & 1 & I \\
\hline $41.59 c^{*}$ & 1 & I & 19 & 21 & I & I & I & I & I & I \\
\hline
\end{tabular}

*Diese Proben wurden zur Überprüfung auf Kreuzkontaminationen zwischen Vesseln eines der automatischen Extraktoren bearbeitet. Das fragmentarische Allelprofil in Probe 28.46b war keinem Proben- oder Mitarbeiterprofil zuzuordnen. Nach Silanisierung des Vesselplates waren in den erneut mitgeführten Blindkontrollen keine Kontaminationen feststellbar. 
Tabelle 10.3: Ergebnisse der Typisierungen der autosomalen und Y-chromosomalen STRs, die für die Weingartener Individuen durchgeführt wurden. Unsichere Alleldeterminierungen sind in Klammern angegeben. Die Bezeichnung ü.a. steht für "über-amplifiziert" und zeigt an, daß, verursacht durch einen Überschuß an Produkt, die generierten Fluoreszenz-Signale zu stark sind, um eine Auswertung zuzulassen. Bei kursiv gedruckten Typisierungsergebnisse besteht die Vermutung, daß es zu einem Kontaminationseintrag gekommen ist.

\begin{tabular}{|c|c|c|c|c|c|c|c|c|c|c|c|c|c|c|c|}
\hline \multicolumn{16}{|c|}{ WG 51 (Zahn 26) } \\
\hline Ex/PCR & Amelo. & 10.1 .1 & VWA & FGA & D8S1179 & 10.2 & D18S51 & 10.2 .1 & D13S317 & D7S820 & Ex/PCR & DYS19 & DYS389I & DYS389II & DYS390 \\
\hline Z1 70.91 & 1 & 1 & 1 & 1 & 1 & 1 & 1 & 1 & 1 & 1 & & & & & \\
\hline Genotyp & 1 & 1 & 1 & 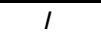 & 1 & 1 & 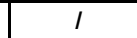 & 1 & 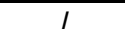 & 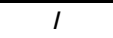 & Haplotyp & & & & \\
\hline \multicolumn{16}{|c|}{ WG 52 (Zahn 37, Zahn 47) } \\
\hline Ex/PCR & Amelo. & 10.2 .2 & VWA & FGA & D8S1179 & $10.3 \quad \mathrm{D}$ & D18S51 & \begin{tabular}{|l|}
10.3 .1 \\
\end{tabular} & D13S317 & D7S820 & Ex/PCR & DYS19 & DYS3891 & DYS389II & DYS390 \\
\hline Z1 6.13a & $\mathrm{XY}$ & 16 & 1 & 1 & $9 / 11 / 15$ & $29 / 30$ & 1 & 12 & 9 & $10 / 11$ & Z1 6.15a & 15 & 1 & 1 & 25 \\
\hline Z1 6.13b & $\mathrm{x}$ & 1 & 17 & 22 & 1 & 30 & 14 & $11 / 12$ & 12 & 9 & $\mathrm{Z1} 6.15 \mathrm{~b}$ & 1 & 1 & 1 & 1 \\
\hline Z1 6.14 & $X Y$ & 15 & 16 & $22 / 23$ & 1 & $29 / 30$ & 1 & 1 & 9 & 1 & Z1 21.41 & 15 & 14 & 1 & 1 \\
\hline Z1 21.39 & $\mathrm{XY}$ & $15 / 16$ & 17 & $19 / 23$ & $13 / 14$ & 30 & $14 / 17$ & $11 / 12$ & $8 / 12$ & 1 & Z1 21.43 & 1 & $12 / 14$ & 1 & 1 \\
\hline Z1 24.40 & $\mathrm{XY}$ & 15 & $16 / 17$ & 1 & $13 / 14$ & $29 / 30$ & 17 & $9 / 11$ & $9 / 12$ & 1 & Z1 24.41 & 1 & 1 & 1 & 1 \\
\hline Z1 24.42 & $x$ & 16 & 17 & 22 & 13 & 28 & 17 & 9/12 & 1 & 1 & Z2 26.47a & 15 & 1 & 1 & 1 \\
\hline Z2 26.44 & $x$ & 1 & 17 & 23 & $13 / 14$ & 1 & 1 & $11 / 12$ & 1 & 10 & Z2 26.47b & 1 & 1 & 1 & 1 \\
\hline Z2 53.72 & $X Y$ & 16 & $\begin{array}{ll}16 / 18 \\
\end{array}$ & $(21) / 22$ & 13 & $31 / 32$ & 17 & $10 / 11 / 12$ & $10 /(11)$ & 1 & & & & & \\
\hline Z2 54.74 & $\mathrm{XY}$ & 15 & $16 / 17 / 18$ & $21 / 22$ & 13 & 1 & 1 & 1 & 1 & 1 & & & & & \\
\hline Genotyp & $\mathrm{XY}$ & $15 / 16$ & 16/17 & $22 / 23$ & $13 / 14$ & $29 / 30$ & $17 / 17$ & $11 / 12$ & 9/12 & 10 & Haplotyp & I & I & I & I \\
\hline \multicolumn{16}{|c|}{ WG 65 (Zahn 23) } \\
\hline Ex/PCR & Amelo. & 10.3 .2 & VWA & FGA & D8S1179 & 10.4 & D18S51 & \begin{tabular}{|l|}
10.4 .1 \\
\end{tabular} & D13S317 & D7S820 & Ex/PCR & DYS19 & DYS3891 & DYS389II & DYS390 \\
\hline Z1 44.61 & 1 & 1 & 1 & 1 & 1 & 1 & 1 & 1 & 1 & 1 & & & & & \\
\hline Genotyp & I & 1 & 1 & I & 1 & I & I & 1 & 1 & I & Haplotyp & & & & \\
\hline \multicolumn{16}{|c|}{ WG 66 (Femur) } \\
\hline Ex/PCR & Amelo. & 10.4 .2 & VWA & FGA & D8S1179 & 10.5 & D18S51 & 10.5 .1 & D13S317 & D7S820 & Ex/PCR & DYS19 & DYS389I & DYS389II & DYS390 \\
\hline K 110.119 & 1 & 15 & 1 & 1 & 1 & 1 & 1 & 1 & 1 & 1 & & & & & \\
\hline Genotyp & 1 & 1 & 1 & 1 & 1 & 1 & 1 & 1 & 1 & 1 & Haplotyp & & & & \\
\hline \multicolumn{16}{|c|}{ WG 79 (Zahn 36) } \\
\hline Ex/PCR & Amelo. & 10.5 .2 & VWA & FGA & D8S1179 & 10.6 & D18S51 & 10.6 .1 & D13S317 & D7S820 & Ex/PCR & DYS19 & DYS3891 & DYS389II & DYS390 \\
\hline Z1 73.88 & 1 & 1 & 1 & 1 & 1 & 1 & 1 & 1 & 1 & 1 & & & & & \\
\hline Genotyp & 1 & 1 & 1 & 1 & 1 & 1 & 1 & 1 & 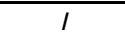 & 1 & Haplotyp & & & & \\
\hline \multicolumn{16}{|c|}{ WG 99 (Radius) } \\
\hline
\end{tabular}




\begin{tabular}{|c|c|c|c|c|c|c|c|c|c|c|c|c|c|c|c|}
\hline Ex/PCR & Amelo. & 10.6 .2 & VWA & FGA & D8S1179 & $10.7 \quad D$ & D18S51 & 10.7 .1 & D13S317 & D7S820 & Ex/PCR & DYS19 & DYS389I & DYS389II & DYS390 \\
\hline $\mathrm{K} 20.37 \mathrm{a}$ & 1 & 1 & 1 & 1 & 1 & 1 & 1 & 1 & 1 & 1 & & & & & \\
\hline K 20.37b & 1 & 1 & 1 & 1 & 1 & 1 & 1 & 1 & 1 & 1 & & & & & \\
\hline $\mathrm{K} 20.38$ & 1 & $15 / 18$ & 1 & 1 & 15 & 1 & 15 & $8 / 12$ & 1 & 1 & & & & & \\
\hline K 39.59 & 1 & 1 & 1 & 1 & 1 & 1 & 1 & 1 & 1 & 1 & & & & & \\
\hline Genotyp & 1 & 1 & 1 & 1 & 1 & 1 & 1 & 1 & 1 & 1 & Haplotyp & & & & \\
\hline \multicolumn{16}{|c|}{ WG 111 (Zahn 48, Zahn 47) } \\
\hline Ex/PCR & Amelo. & 10.7 .2 & VWA & FGA & D8S1179 & 10.8 & D18S51 & 10.8 .1 & D13S317 & D7S820 & Ex/PCR & DYS19 & DYS3891 & DYS389II & DYS390 \\
\hline Z1 10.26a & $\mathrm{x}$ & $15 / 18$ & 14 & $21 / 22$ & $(13) / 14$ & 1 & 1 & 1 & 1 & 10 & & & & & \\
\hline $\mathrm{Z1} 10.26 \mathrm{~b}$ & $\mathrm{x}$ & 18 & 17 & 1 & 1 & 26 & 19 & 1 & 1 & 8 & & & & & \\
\hline Z1 10.32a & Ü.a. & 1 & 1 & 20 & 1 & 1 & 1 & 1 & 1 & 1 & & & & & \\
\hline Z1 10.32b & Ü.a. & 1 & 17 & 1 & $13 / 14$ & 31.2 & 1 & $10 / 11$ & $10 / 13$ & 10 & & & & & \\
\hline Z1 89.100 & 1 & 1 & 1 & 1 & 1 & 1 & 1 & 1 & 1 & 1 & & & & & \\
\hline Z2 96.103 & $x$ & 18 & 1 & 1 & 13 & 1 & 1 & 11 & 8 & 1 & & & & & \\
\hline Z2 101.111 & $x$ & 1 & 1 & 1 & 13 & 1 & 1 & 1 & 1 & 1 & & & & & \\
\hline Genotyp & $x x$ & 18 & $(17)$ & 1 & $13 /(14)$ & 1 & 1 & 11 & 1 & (10) & & & & & \\
\hline \multicolumn{16}{|c|}{ WG 113 (Zahn 43) } \\
\hline Ex/PCR & Amelo. & 10.8 .2 & VWA & FGA & D8S1179 & 10.9 & D18S51 & \begin{tabular}{|l|}
10.9 .1 \\
\end{tabular} & D13S317 & D7S820 & Ex/PCR & DYS19 & DYS3891 & DYS389II & DYS390 \\
\hline Z1 14.30a & 1 & 1 & 1 & 23 & 1 & 1 & 1 & 1 & 11 & 1 & & & & & \\
\hline Z1 14.30b & $\overline{X Y}$ & 15 & 1 & 1 & 1 & 33.2 & 1 & 1 & 1 & 1 & & & & & \\
\hline Z1 14.32a & $X Y$ & 15 & 1 & 21 & 13 & 29 & 1 & 13 & 11 & 1 & & & & & \\
\hline Z1 14.32b & $x$ & 1 & 1 & 1 & 13 & 1 & 1 & 1 & 1 & 1 & & & & & \\
\hline Genotyp & (XY) & (15) & 1 & 1 & (13) & I & & & (11) & 1 & Haplotyp & & & & \\
\hline \multicolumn{16}{|c|}{ WG 115 (Zahn 47) } \\
\hline Ex/PCR & Amelo. & 10.9 .2 & VWA & FGA & D8S1179 & \begin{tabular}{ll|}
10.10 & $D$
\end{tabular} & D18S51 & 10.10 .1 & D13S317 & D7S820 & Ex/PCR & DYS19 & DYS3891 & DYS389II & DYS390 \\
\hline Z1 44.61 & $\mathrm{Y}$ & 16 & 17 & 1 & 14 & 1 & $15 / 16$ & 1 & 1 & 1 & 73.110 & 1 & 1 & 1 & 1 \\
\hline Z1 73.88 & $X Y$ & 1 & $17 / 18$ & 1 & $13 / 14 / 15$ & 1 & 15 & 1 & 1 & 1 & & & & & \\
\hline Genotyp & $\mathrm{XY}$ & 1 & 17 & 1 & 14 & 1 & 15 & 1 & $I$ & 1 & Haplotyp & 1 & 1 & 1 & 1 \\
\hline \multicolumn{16}{|c|}{ WG 119 (Zahn 28, Zahn 25) } \\
\hline Ex/PCR & Amelo. & 10.10 .2 & VWA & FGA & D8S1179 & $10.11 \quad \mathrm{D}$ & D18S51 & 10.11 .1 & D13S317 & D7S820 & Ex/PCR & DYS19 & DYS3891 & DYS389II & DYS390 \\
\hline Z1 29.48 & $X Y$ & $14 / 18$ & $16 / 18$ & 19 & $10 / 13$ & $29 / 30$ & 1 & 12 & 11 & 1 & Z1 29.55 & 1 & 13 & 29 & 23 \\
\hline Z1 29.51 & $\mathrm{x}$ & $14 / 17 / 18$ & $16 / 18$ & $19 / 25$ & $10 / 13$ & 30 & $16 / 17$ & 1 & 11 & $9 / 10$ & $Z 134.55$ & 1 & 1 & 1 & 1 \\
\hline Z1 34.53 & $x$ & $14 / 17$ & $16 / 18$ & $19 / 25$ & $10 / 13$ & $29 / 30$ & 1 & 12 & 1 & 1 & & & & & \\
\hline $\mathrm{Z1} 48.67$ & $\bar{x}$ & $14 / 18$ & $16 / 18$ & $19 / 25$ & $10 / 13$ & $30 / 31$ & 17 & 12 & 11 & 9 & & & & & \\
\hline Z2 85.97 & 1 & 1 & 1 & 1 & 1 & 1 & 1 & 1 & 1 & 1 & & & & & \\
\hline Genotyp & $x x$ & 14/18 & 16/18 & $19 / 25$ & $10 / 13$ & $29 / 30$ & 17 & $12 / 12$ & $11 / 11$ & 9 & Haplotyp & 1 & 1 & 1 & 1 \\
\hline
\end{tabular}


WG 125 (Zahn 36, Zahn 65)

\begin{tabular}{|c|c|c|c|c|c|c|c|c|c|c|c|c|c|c|c|}
\hline \multicolumn{16}{|c|}{ WG 125 (Zahn 36, Zahn 65) } \\
\hline Ex/PCR & Amelo. & 10.11.2 & VWA & FGA & D8S1179 & $10.12 \mathrm{D}$ & D18S51 & 10.12 .1 & D13S317 & D7S820 & Ex/PCR & DYS19 & DYS389I & DYS389II & DYS390 \\
\hline Z1 73.88 & $\mathrm{x}$ & 18 & 1 & 24 & 1 & 1 & 1 & 8 & 1 & 1 & & & & & \\
\hline Z1 85.97 & $x$ & 15/16/17 & 16 & I & 13 & $29 / 31$ & I & (10)11/12 & I & 10 & & & & & \\
\hline Z1 89.100 & 1 & I & 19 & 1 & 1 & 1 & 16 & 12 & 1 & 1 & & & & & \\
\hline Z2 99.105 & $\mathrm{x}$ & 15 & $15 / 20$ & 26 & 13 & 29 & 1 & 12 & 1 & 1 & & & & & \\
\hline Genotyp & $\mathbf{X X}$ & $\frac{1}{1}$ & 1 & $\frac{1}{1}$ & 1 & 1 & $I$ & 1 & I & $I$ & & & & & \\
\hline \multicolumn{16}{|c|}{ WG 130 (Zahn 17, Zahn 18, Femur) } \\
\hline Ex/PCR & Amelo. & 10.12 .2 & VWA & FGA & D8S1179 & $10.13 \quad D$ & D18S51 & 10.13 .1 & D13S317 & D7S820 & Ex/PCR & DYS19 & DYS389I & DYS389II & DYS390 \\
\hline Z1 14.30a & $\mathrm{x}$ & 15 & 16 & $21 / 23$ & $(16) / 17$ & $30 / 33.2$ & 17 & $10 / 12$ & $8 / 10$ & 10 & & & & & \\
\hline Z1 14.30b & $\mathrm{Y}$ & 15 & 1 & 1 & 14 & 1 & 1 & 12 & 1 & 12 & & & & & \\
\hline Z1 14.32a & $\mathrm{Y}$ & 1 & 14 & 1 & 11 & 1 & 15 & 1 & 1 & 1 & & & & & \\
\hline Z1 14.32b & 1 & 15 & 14 & 1 & 14 & 26 & 1 & 11 & 1 & 10 & & & & & \\
\hline Z1 73.88 & 1 & 1 & 1 & 1 & 1 & 1 & 1 & 1 & 1 & 1 & & & & & \\
\hline Z2 85.97 & $x$ & $15 / 17$ & 18 & 19 & 13 & 31 & 1 & 11 & $12 / 13$ & 10 & & & & & \\
\hline Z2 89.100 & $X Y$ & 15 & 18 & $22 / 24$ & $13 / 14$ & $28 / 29.2$ & 13 & $10 / 11$ & 11 & $8 / 12$ & & & & & \\
\hline K 112.123 & 1 & 1 & 1 & 1 & 1 & 1 & 1 & 1 & 1 & 1 & & & & & \\
\hline Genotyp & $X Y$ & 15 & (14) & 1 & (14) & 1 & 1 & 10 & I & $I$ & & & & & \\
\hline \multicolumn{16}{|c|}{ WG 134 (Zahn 27, Zahn 16, Femur) } \\
\hline Ex/PCR & Amelo. & 10.13 .2 & VWA & FGA & D8S1179 & $10.14 \quad D$ & D18S51 & 10.14.1 & D13S317 & D7S820 & Ex/PCR & DYS19 & DYS389I & DYS389II & DYS390 \\
\hline Z1 12.27a & $X Y$ & $15 / 16$ & 15 & 21 & 1 & 1 & 1 & 1 & $13 / 14$ & 1 & Z1 12.28a & 1 & 1 & 1 & 1 \\
\hline Z1 12.27b & $\mathrm{XY}$ & 1 & 1 & 22 & 1 & $29 / 30$ & 1 & 1 & 13 & 10 & Z1 12.28b & 1 & 1 & 1 & 1 \\
\hline Z1 12.31a & $X Y$ & $15 / 16$ & 15/17/19 & 22 & $11 / 13 /(14)$ & 1 & I & 11 & 1 & 1 & Z1 21.41 & 1 & 13 & 29 & 23 \\
\hline Z1 12.31b & $X Y$ & 16 & 16 & 22 & $11 / 14$ & 30 & 1 & $11 /(12)$ & 1 & 10 & $Z 121.43$ & 1 & 1 & 1 & 22 \\
\hline Z1 21.39 & $X Y$ & $15 / 17$ & $15 / 18$ & $22 / 23$ & $11 / 14$ & 1 & 15 & 11 & 1 & 1 & Z1 24.41 & 1 & 1 & 1 & 23 \\
\hline Z1 24.40 & $X Y$ & $15 / 17$ & 17 & 22 & $11 / 15$ & 28 & 1 & $8 /(10) / 11$ & $10 / 12$ & I & Z2 85.98 & 1 & 13 & 29 & 23 \\
\hline Z1 24.42 & $X Y$ & $15 / 16$ & $14 / 16$ & 1 & $11 / 14$ & 1 & 1 & 1 & 1 & 1 & K 112.126 & 1 & 1 & 1 & 1 \\
\hline Z1 28.46 & $\mathrm{x}$ & 1 & 18 & 1 & 1 & 1 & 1 & 1 & 1 & 1 & & & & & \\
\hline Z2 33.52 & $X Y$ & $15 / 16$ & 15/16/18 & 1 & 11 & 30 & 1 & 12 & 13 & 1 & & & & & \\
\hline Z2 34.53 & $X Y$ & $15 / 16$ & 18 & 1 & 1 & 29 & 1 & 12 & 13 & 1 & & & & & \\
\hline Z2 41.59 & $X Y$ & $15 / 16$ & 1 & 1 & $11 / 14$ & 30 & 1 & 1 & 1 & 1 & & & & & \\
\hline Z2 73.88 & $X Y$ & 1 & (17)/18 & 1 & 1 & 1 & 1 & 1 & 1 & 1 & & & & & \\
\hline Z2 85.97 & $X Y$ & 15 & $17 / 18$ & 22 & 13 & $(29) / 30$ & 1 & 10/(11)/12 & 10 & 1 & & & & & \\
\hline K 116.128 & $X Y$ & 1 & $15 / 18$ & 22 & $11 / 14$ & 1 & 1 & 11 & 1 & 12 & & & & & \\
\hline Genotyp & $X Y$ & $15 / 16$ & 15/17/18 & $22 / 22$ & $11 / 14$ & $29 / 30$ & 1 & $11 / 12$ & $10 / 13$ & (10) & Haplotyp & 1 & 13 & 29 & 23 \\
\hline
\end{tabular}




\begin{tabular}{|c|c|c|c|c|c|c|c|c|c|c|c|c|c|c|c|}
\hline Ex/PCR & Amelo. & 10.14 .2 & VWA & FGA & D8S1179 & $10.15 \quad D$ & D18S51 & 10.15 .1 & D13S317 & D7S820 & Ex/PCR & DYS19 & DYS389I & DYS389II & DYS390 \\
\hline Z1 4.6a & $X Y$ & $14 / 15$ & 17 & 19/27 & $13 / 14$ & 30 & 14 & $(11) / 12$ & 12 & 9 & Z1 4.8 & 15 & 15 & 1 & 1 \\
\hline Z1 4.6b & $X Y$ & $(14) / 15 /(16)$ & 17 & $19(21) 22 / 27$ & $13 / 14$ & 1 & 17 & (11)/12 & $9 / 12$ & 10 & Z1 7.18a & 15 & 15 & 1 & 1 \\
\hline Z1 4.7a & $X Y$ & $14 / 15$ & 17 & $19 / 27$ & $13 / 14$ & $29 / 30$ & $12 / 14 / 17$ & $(11) / 12$ & 12 & 9 & Z1 7.18b & 15 & 15 & 1 & 1 \\
\hline $\mathrm{Z1} \mathrm{4.7b}$ & $\mathrm{XY}$ & 15 & 17 & 1 & $(12) / 13$ & 30 & 14 & $(11) / 12$ & 12 & 9 & Z1 7.18c & 1 & 1 & 1 & 1 \\
\hline Z1 7.16a & 1 & 15 & 1 & $26 / 27$ & 14 & 1 & 1 & 1 & 1 & 1 & Z1 8.21 a & 1 & 1 & 1 & 1 \\
\hline Z1 7.16b & 1 & 17 & 16 & 1 & 1 & 1 & 1 & 1 & 1 & 1 & $\mathrm{Z} 18.21 \mathrm{~b}$ & 1 & 1 & 1 & 1 \\
\hline Z1 8.19 & 1 & 1 & 1 & 1 & $8 / 10 / 11$ & 31.2 & 1 & 1 & 1 & 1 & Z1 8.22 & 1 & 1 & 1 & 1 \\
\hline Z1 8.23a & $X Y$ & 1 & $(16) / 17$ & $(18) / 19$ & $13 / 14 / 15$ & 1 & 1 & $10 / 11 / 12$ & 8 & 10 & Z1 8.24 & 16 & 1 & 7 & 1 \\
\hline $\mathrm{Z1} 8.23 \mathrm{~b}$ & $\mathrm{x}$ & $15 / 17$ & 1 & 1 & 1 & 29 & 1 & 1 & 11 & 1 & Z1 21.41 & 1 & 1 & 1 & 1 \\
\hline Z1 21.39 & $X Y$ & 15 & 17 & 22 & 13 & 1 & 1 & 11 & 1 & 1 & Z1 21.43 & 1 & 1 & 1 & 1 \\
\hline Z2 24.40 & $\mathrm{x}$ & 1 & 17 & 19 & $13 / 14 / 15$ & 1 & 1 & $11 / 12$ & 1 & I & Z2 24.41 & 1 & 1 & 1 & 1 \\
\hline Z2 39.59 & $X Y$ & 15/17 & 17 & 19 & $13 / 14$ & 29 & 1 & $11 / 12$ & $12 / 13$ & 1 & Z2 89.110 & 1 & 1 & 1 & 1 \\
\hline Z2 37.57 & $X Y$ & 15 & $(16) / 17$ & 1 & 14 & 29 & 1 & 11 & 1 & 1 & & & & & \\
\hline Z2 73.88 & $\mathrm{x}$ & 1 & 1 & 1 & 1 & 1 & 1 & 1 & 1 & 1 & & & & & \\
\hline Z2 85.97 & $x$ & $15 / 16$ & $15 / 17 / 18$ & 22 & 13 & $(29) / 31$ & 1 & $10(11) 12$ & 10 & 1 & & & & & \\
\hline Genotyp & $\mathrm{XY}$ & 15/17 & $17 / 17$ & 19/27 & $13 / 14$ & $29 / 30$ & $\begin{array}{l}(14) /(17) \\
\end{array}$ & $11 / 12$ & 12 & (9)/10 & Haplotyp & 15 & 15 & I & 1 \\
\hline \multicolumn{16}{|c|}{ WG 141 (Zahn 37, Zahn 47) } \\
\hline Ex/PCR & Amelo. & 10.15 .2 & VWA & FGA & D8S1179 & $10.16 \quad \mathrm{D}$ & D18S51 & 10.16 .1 & D13S317 & D7S820 & Ex/PCR & DYS19 & DYS3891 & DYS389II & DYS390 \\
\hline Z1 10.26a & 1 & 1 & 18 & 1 & 1 & 1 & 1 & 1 & 1 & 1 & Z2 107.120 & 1 & 1 & 1 & 1 \\
\hline $\mathrm{Z1} 10.26 \mathrm{~b}$ & $\mathrm{XY}$ & 1 & 18 & 1 & 13 & 1 & 1 & 10 & 1 & 1 & & & & & \\
\hline Z1 10.32a & $X Y$ & 1 & 1 & 1 & 1 & 1 & 1 & 12 & 1 & 1 & & & & & \\
\hline Z1 10.32b & $\mathrm{x}$ & 17 & 16 & $21 / 22$ & 14 & 1 & 19 & 1 & 1 & 1 & & & & & \\
\hline Z1 89.100 & $\mathrm{x}$ & 1 & 15 & 21 & 13 & 1 & 1 & $(10)(11) / 12$ & 12 & 1 & & & & & \\
\hline Z296.103 & $X Y$ & 15 & 15 & $21 / 26$ & 13 & 1 & 1 & $11 / 12$ & 12 & 1 & & & & & \\
\hline Z2 99.105 & $\mathrm{x}$ & 15 & 1 & 1 & 13 & 1 & 1 & 11 & 1 & 1 & & & & & \\
\hline Z2 101.111 & $x$ & $(14) / 15 / 16$ & 15 & 1 & 13 & 1 & 1 & 1 & 1 & 1 & & & & & \\
\hline Genotyp & $\mathrm{XY}$ & $15 / 15$ & $15 /(18)$ & 21 & $13 / 13$ & $I$ & 1 & $11 / 12$ & 12 & 1 & Haplotyp & 1 & 1 & 1 & $I$ \\
\hline \multicolumn{16}{|c|}{ WG 144 (Zahn 16, Zahn 17) } \\
\hline Ex/PCR & Amelo. & 10.16 .2 & VWA & FGA & D8S1179 & $10.17 \quad \mathrm{D}$ & D18S51 & 10.17.1 & D13S317 & D7S820 & Ex/PCR & DYS19 & DYS3891 & DYS389II & DYS390 \\
\hline Z1 1.1a & $X Y$ & 15 & 1 & 1 & 10 & I & 1 & 11 & 13 & 1 & Z1 3.4a & 1 & 13 & 1 & 22 \\
\hline Z11.1b & $\overline{X Y}$ & 1 & 17 & 1 & 1 & 1 & 1 & 1 & 1 & 1 & Z1 3.4b & 13 & 13 & 1 & 22 \\
\hline$Z 13.2 a$ & $X Y$ & $14 / 17$ & 1 & 1 & $10 /(13) 14$ & 1 & 13 & 11 & 1 & 1 & Z1 7.18a & 13 & 13 & 1 & 22 \\
\hline $\mathrm{Z1} \mathrm{3.2b}$ & $X Y$ & $14 / 17$ & 17 & 1 & $10 / 14$ & 29 & 1 & 11 & 1 & 1 & $Z 17.18 \mathrm{~b}$ & 13 & 13 & 1 & 22 \\
\hline Z1 3.3a & $X Y$ & 14 & 17 & 1 & $10 / 14$ & 1 & 1 & $11 /(12)$ & 1 & 1 & $\mathrm{Z1} 7.18 \mathrm{c}$ & 13 & 13 & 1 & 22 \\
\hline Z1 3.3b & $\mathrm{x}$ & $(14) / 15$ & 17 & 1 & $10 / 14$ & $26 / 29 / 30$ & 1 & 11 & I & I & & & & & \\
\hline
\end{tabular}




\begin{tabular}{|c|c|c|c|c|c|c|c|c|c|c|c|c|c|c|c|}
\hline Z1 7.16a & Ü.a & Ü.a & 14/17 & 1 & Ü.a & 30 & 14 & Ü.a & 1 & 1 & & & & & \\
\hline Z1 7.16b & Ü.a & $14 / 17$ & $14 / 17$ & 1 & 14 & 1 & 1 & 1 & 13 & 10 & & & & & \\
\hline Z1 15.34 & $X Y$ & $14 / 17$ & 17 & 24 & 14 & 30 & 14 & 12 & 13 & 1 & & & & & \\
\hline Z1 28.46 & 1 & 1 & 1 & 1 & 1 & 1 & 1 & 1 & 1 & 1 & & & & & \\
\hline Z2 35.54 & $\mathrm{XY}$ & $14 / 17$ & 17 & 24 & $10 / 14$ & $29 / 30$ & 1 & 11 & 1 & 1 & & & & & \\
\hline Z2 37.57 & $\mathrm{XY}$ & $14 / 17$ & 17 & 1 & $10 / 14$ & $29 / 30$ & 1 & 1 & 1 & 1 & & & & & \\
\hline Z2 56.76 & $\overline{X Y}$ & $14 / 17$ & $17 / 19$ & 24 & $10 / 13$ & 29 & 13 & $11 / 12$ & 13 & 1 & & & & & \\
\hline Z2 73.88 & 1 & 1 & 1 & 1 & 1 & 1 & 1 & 1 & 1 & 1 & & & & & \\
\hline Z2 74.89 & 1 & 1 & 1 & 1 & 1 & 1 & 1 & 1 & 1 & 1 & & & & & \\
\hline Genotyp & $\mathbf{X Y}$ & $14 / 17$ & $17 /(17)$ & $24 / 24$ & $10 / 14$ & $29 / 30$ & $13 / 14$ & $11 / 12$ & $13 / 13$ & $I$ & Haplotyp & 13 & 13 & 1 & 22 \\
\hline \multicolumn{16}{|c|}{ WG 153 (Zahn 21) } \\
\hline Ex/PCR & Amelo. & 10.17 .2 & VWA & FGA & D8S1179 & $10.18 \quad \mathrm{D}$ & D18S51 & 10.18 .1 & D13S317 & D7S820 & Ex/PCR & DYS19 & DYS3891 & DYS389II & DYS390 \\
\hline Z1 29.48 & $x$ & 17 & 10 & 21 & 10 & 1 & 15 & 1 & 1 & 1 & Z1 29.55 & 1 & 1 & 1 & 25 \\
\hline Z1 29.51 & 1 & 1 & 1 & 1 & 1 & 1 & 1 & 1 & 1 & 1 & & & & & \\
\hline Z134.53 & 1 & 1 & 1 & 1 & 1 & 1 & 1 & 1 & 1 & 1 & & & & & \\
\hline Genotyp & 1 & 1 & 1 & 1 & 1 & 1 & 1 & 1 & 1 & 1 & Haplotyp & 1 & 1 & 1 & 1 \\
\hline \multicolumn{16}{|c|}{ WG 157 (Zahn 44) } \\
\hline Ex/PCR & Amelo. & 10.18 .2 & VWA & FGA & D8S1179 & $10.19 \quad \mathrm{D}$ & D18S51 & 10.19 .1 & D13S317 & D7S820 & & & & & \\
\hline Z174.88 & 1 & 1 & 1 & 1 & 1 & 1 & 1 & 1 & 1 & 1 & & & & & \\
\hline Z1 85.97 & $x$ & 1 & 1 & 1 & 1 & 1 & 1 & 11 & 1 & 1 & & & & & \\
\hline Z1 96.103 & $x$ & 1 & 1 & 22.2 & $14 / 15$ & $29 / 30$ & 1 & $(11) / 12$ & 8 & 1 & & & & & \\
\hline Genotyp & $x x$ & $I$ & $I$ & 1 & 1 & 1 & $I$ & (11) & $I$ & $I$ & & & & & \\
\hline \multicolumn{16}{|c|}{ WG 161 (Femur) } \\
\hline Ex/PCR & Amelo. & 10.19 .2 & VWA & FGA & D8S1179 & $10.20 \quad \mathrm{D}$ & D18S51 & 10.20 .1 & D13S317 & D7S820 & Ex/PCR & DYS19 & DYS3891 & DYS38911 & DYS390 \\
\hline K 40.59 & $\mathrm{X}$ & 15 & 1 & 1 & 10 & 1 & 1 & 1 & 11 & 1 & & & & & \\
\hline Genotyp & 1 & 1 & 1 & 1 & 1 & $I$ & 1 & 1 & 1 & 1 & & & & & \\
\hline \multicolumn{16}{|c|}{ WG 163 (Zahn 37) } \\
\hline Ex/PCR & Amelo. & 10.20 .2 & VWA & FGA & D8S1179 & $10.21 \quad \mathrm{D}$ & D18S51 & 10.21 .1 & D13S317 & D7S820 & Ex/PCR & DYS19 & DYS3891 & DYS389II & DYS390 \\
\hline Z1 18.35a & $\mathrm{x}$ & 1 & 10 & 1 & $11 /$ & 1 & 1 & 1 & 1 & 1 & Z1 18.36 & 1 & 1 & 1 & 1 \\
\hline Z1 18.35b & 1 & 1 & 16 & 1 & 14 & 1 & 1 & 1 & 1 & 1 & & & & & \\
\hline Z1 37.57b & $X Y$ & 16 & 1 & 1 & $10 / 14$ & 1 & 1 & $11 / 12$ & 1 & 1 & & & & & \\
\hline Z1 39.59 & $\overline{X Y}$ & 16 & 1 & 1 & $10 / 14$ & 1 & 1 & 1 & 1 & 1 & & & & & \\
\hline Z1 74.88 & $X Y$ & 1 & 1 & 1 & 10 & 1 & 1 & 12 & 1 & 1 & & & & & \\
\hline Genotyp & $\overline{X Y}$ & 16 & 1 & 1 & $10 / 14$ & 1 & 1 & 12 & $I$ & 1 & Haplotyp & $T$ & 1 & 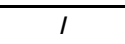 & $\frac{1}{1}$ \\
\hline \multicolumn{16}{|c|}{ WG 164 (Zahn 47) } \\
\hline Ex/PCR & Amelo. & 10.21 .2 & VWA & FGA & D8S1179 & 10.22 & D18S51 & 10.22 .1 & D13S317 & D7S820 & Ex/PCR & DYS19 & DYS3891 & DYS389II & DYS390 \\
\hline
\end{tabular}




\begin{tabular}{|c|c|c|c|c|c|c|c|c|c|c|c|c|c|c|c|}
\hline Z1 39.59 & $X Y$ & 15 & $16 / 18$ & 1 & $13 / 15$ & 1 & 1 & 1 & 1 & 1 & & & & & \\
\hline Z1 74.88 & 1 & 1 & 1 & 1 & 1 & 1 & 1 & 1 & 1 & 1 & & & & & \\
\hline Z1 86.97 & $x$ & 15 & 1 & 1 & $13 / 15$ & 32.2 & 14 & 12 & 13 & 10 & & & & & \\
\hline Z1 101.111 & $X Y$ & 15 & 18 & 25 & $(14) / 15$ & 30 & 1 & 12 & 1 & 1 & & & & & \\
\hline Genotyp & $\mathrm{XY}$ & $15 / 15$ & 18 & 1 & $13 / 15$ & 1 & 1 & 12 & 1 & 1 & & & & & \\
\hline \multicolumn{16}{|c|}{ WG 165 (Femur) } \\
\hline Ex/PCR & Amelo. & 10.22 .2 & VWA & FGA & D8S1179 & $10.23 \quad \mathrm{D}$ & D18S51 & 10.23 .1 & D13S317 & D7S820 & Ex/PCR & DYS19 & DYS389I & DYS389II & DYS390 \\
\hline K 5.9a & 1 & 15 & 1 & 22.2 & 1 & 1 & 1 & 1 & 1 & 1 & K 5.10a & 1 & 1 & 1 & 1 \\
\hline K 5.9b & 1 & 1 & 1 & 1 & 1 & 1 & 1 & 9 & 1 & 1 & K 5.10b & 1 & 1 & 1 & 23 \\
\hline K 5.11a & $x$ & 15 & 1 & 22 & $13 / 14$ & $29 / 30$ & 1 & 12 & 1 & 10 & K 5.12 & 15 & 1 & 1 & 1 \\
\hline K 5.11b & 1 & 1 & 1 & 1 & 1 & 1 & 1 & 1 & 10 & 1 & & & & & \\
\hline K 113.124 & 1 & 1 & 1 & 1 & 1 & 1 & 1 & 1 & 1 & I & & & & & \\
\hline Genotyp & 1 & (15) & 1 & 1 & 1 & 1 & 1 & I & I & I & Haplotyp & 1 & 1 & I & I \\
\hline \multicolumn{16}{|c|}{ WG 167 (Zahn 33, Zahn 34) } \\
\hline Ex/PCR & Amelo. & 10.23 .2 & VWA & FGA & D8S1179 & $10.24 \quad D$ & D18S51 & 10.24.1 & D13S317 & D7S820 & & & & & \\
\hline Z1 55.75 & 1 & 1 & 1 & 1 & 1 & 1 & 1 & 1 & 1 & 1 & & & & & \\
\hline Z174.88 & $x$ & $(15) / 16$ & 19 & 1 & 1 & 1 & 1 & 1 & 1 & 1 & & & & & \\
\hline Z2 86.97 & $\mathrm{x}$ & 1 & 1 & I & 1 & 1 & 1 & 1 & 1 & I & & & & & \\
\hline Genotyp & $(\mathrm{XX})$ & 1 & 1 & 1 & 1 & 1 & 1 & 1 & I & 1 & & & & & \\
\hline \multicolumn{16}{|c|}{ WG 173 (Zahn 17) } \\
\hline Ex/PCR & Amelo. & 10.24 .2 & VWA & FGA & D8S1179 & $10.25 \mathrm{D}$ & D18S51 & 10.25 .1 & D13S317 & D7S820 & Ex/PCR & DYS19 & DYS389I & DYS389II & DYS390 \\
\hline Z1 8.19 & $\mathrm{x}$ & 1 & $14 / 15$ & 1 & 14 & 1 & 1 & 1 & 1 & 1 & & & & & \\
\hline$Z 18.23 a$ & 1 & 15 & 1 & 1 & 8 & 27 & 1 & 1 & 1 & 8 & & & & & \\
\hline $\mathrm{Z1} \mathrm{8.23b}$ & 1 & 17 & 1 & 1 & 1 & 29 & 1 & 7 & 9 & 1 & & & & & \\
\hline Z1 8.25a & 1 & 1 & 1 & 1 & 1 & 1 & 1 & 1 & $10 / 11$ & 1 & & & & & \\
\hline $\mathrm{Z1} \mathrm{8.25b}$ & 1 & 17 & 1 & 1 & 1 & 1 & 1 & 1 & 11 & 1 & & & & & \\
\hline Z1 10.26a & $X Y$ & 18 & 1 & 1 & 1 & 26 & 1 & 1 & 1 & 1 & & & & & \\
\hline Z1 10.26b & 1 & 18 & 1 & 21 & 8 & 1 & 1 & 8 & 1 & 1 & & & & & \\
\hline Z1 10.32a & $\bar{x}$ & 1 & 16 & 1 & $11 / 13 / 14$ & $26 / 30$ & 1 & 12 & 1 & 1 & & & & & \\
\hline Z1 10.32b & $\mathrm{XY}$ & 1 & 14 & 1 & 13 & 1 & 15 & 1 & 1 & 1 & & & & & \\
\hline Genotyp & $X(Y)$ & $(17) /(18)$ & 14 & 1 & 1 & 1 & 1 & I & I & I & Haplotyp & & & & \\
\hline \multicolumn{16}{|c|}{ WG 175 (Zahn 18, Zahn 28) } \\
\hline Ex/PCR & Amelo. & 10.25 .2 & VWA & FGA & D8S1179 & \begin{tabular}{ll|}
10.26 & $\mathrm{D}$ \\
\end{tabular} & D18S51 & 10.26 .1 & D13S317 & D7S820 & Ex/PCR & DYS19 & DYS3891 & DYS389II & DYS390 \\
\hline Z1 14.30a & $\mathrm{x}$ & $13 / 15$ & 1 & 1 & 13 & 31 & 14 & 1 & 1 & 1 & & & & & \\
\hline Z1 14.30b & $X Y$ & 15 & 1 & 25 & 13 & 1 & 1 & 13 & 1 & 1 & & & & & \\
\hline Z1 14.32a & $X Y$ & I & $(15) / 16$ & $19 / 25$ & 13 & 29 & 1 & 1 & 1 & 1 & & & & & \\
\hline
\end{tabular}




\begin{tabular}{|c|c|c|c|c|c|c|c|c|c|c|c|c|c|c|c|}
\hline Z1 14.32b & $X Y$ & 17 & 16 & 21 & $12 / 13$ & 1 & 19 & 1 & 1 & 1 & & & & & \\
\hline Z1 55.75 & $\mathrm{x}$ & $15 / 17$ & 1 & 1 & 1 & 1 & 1 & 12 & 1 & 1 & & & & & \\
\hline Z174.88 & 1 & 1 & 1 & 1 & 1 & 1 & 1 & 1 & 1 & 1 & & & & & \\
\hline Z2 86.97 & $x$ & $(16) / 17 / 18$ & 1 & 1 & 13 & 1 & 14 & 13 & 1 & 1 & & & & & \\
\hline Z2 94.102 & $x$ & $15 / 17$ & 1 & 25 & 13 & 1 & 1 & 13 & 1 & 1 & & & & & \\
\hline Genotyp & $X(Y)$ & $15 / 17$ & $I$ & 25 & $13 / 13$ & 1 & 14 & 13 & 1 & 1 & Haplotyp & & & & \\
\hline \multicolumn{16}{|c|}{ WG 178 (Zahn 45) } \\
\hline Ex/PCR & Amelo. & 10.26 .2 & VWA & FGA & D8S1179 & $10.27 \quad \mathrm{D}$ & D18S51 & \begin{tabular}{|l|}
10.27 .1 \\
\end{tabular} & D13S317 & D7S820 & & & & & \\
\hline Z1 10.32a & $x$ & 15 & 17 & 1 & $(14) / 15$ & 30 & 1 & 12 & 12 & 8 & & & & & \\
\hline Z1 10.32.b & $x$ & 1 & 1 & 21 & 1 & 1 & 1 & 1 & 1 & 10 & & & & & \\
\hline Z1 13.29a & 1 & 1 & 1 & 1 & 1 & 1 & 1 & 1 & 1 & 1 & & & & & \\
\hline Z1 13.29b & 1 & 1 & 1 & 1 & 1 & 1 & 1 & 1 & 1 & 1 & & & & & \\
\hline Genotyp & $x x$ & 1 & 1 & 1 & 1 & 1 & 1 & 1 & 1 & 1 & & & & & \\
\hline \multicolumn{16}{|c|}{ WG 179 (Zahn 18) } \\
\hline Ex/PCR & Amelo. & 10.27 .2 & VWA & FGA & D8S1179 & $10.28 \quad D$ & D18S51 & 10.28 .1 & D13S317 & D7S820 & Ex/PCR & DYS19 & DYS3891 & DYS389II & DYS390 \\
\hline Z174.88 & 1 & 1 & 1 & 1 & 1 & 1 & 1 & 1 & 1 & 1 & & & & & \\
\hline Z1 86.97 & $\mathrm{X}$ & 1 & 15 & 1 & 13 & 1 & 1 & 1 & 1 & 1 & & & & & \\
\hline Genotyp & $I$ & $I$ & $I$ & $I$ & 1 & $I$ & $I$ & 1 & 1 & $I$ & Haplotyp & & & & \\
\hline \multicolumn{16}{|c|}{ WG 182 (Zahn 33, Zahn 45) } \\
\hline Ex/PCR & Amelo. & 10.28 .2 & VWA & FGA & D8S1179 & $10.29 \quad D$ & D18S51 & 10.29 .1 & D13S317 & D7S820 & Ex/PCR & DYS19 & DYS3891 & DYS389II & DYS390 \\
\hline Z1 18.35a & 1 & $15 / 17$ & 1 & 23 & $11 / 14$ & 1 & 15 & 12 & 1 & 1 & Z1 18.36 & 1 & 1 & 1 & 1 \\
\hline Z1 18.35b & $X Y$ & $(15) / 16 / 17$ & 14 & 19 & 13 & 1 & 1 & 1 & 1 & 10 & & & & & \\
\hline Z1 38.58 & $X Y$ & $18 / 19$ & 15 & 22 & $12 / 13$ & 1 & 1 & 9/12 & 13 & 1 & & & & & \\
\hline Z2 44.61 & $\mathrm{x}$ & 17 & 1 & 1 & 1 & 1 & 15 & 12 & 1 & 1 & & & & & \\
\hline Genotyp & $\overline{X Y}$ & 17 & 1 & 1 & 13 & I & 15 & 12 & $I$ & $I$ & Haplotyp & & & & \\
\hline \multicolumn{16}{|c|}{ WG 184 (Femur) } \\
\hline Ex/PCR & Amelo. & 10.29 .2 & VWA & FGA & D8S1179 & $10.30 \quad \mathrm{D}$ & D18S51 & 10.30 .1 & D13S317 & D7S820 & Ex/PCR & DYS19 & DYS3891 & DYS389II & DYS390 \\
\hline $\mathrm{K} 2.1 \mathrm{a}$ & 1 & 1 & 1 & 1 & 1 & 1 & 1 & 1 & 1 & 1 & & & & & \\
\hline $\mathrm{K} 2.1 \mathrm{~b}$ & 1 & 1 & 1 & 1 & 1 & 1 & 1 & 1 & 1 & 1 & & & & & \\
\hline Genotyp & 1 & 1 & 1 & 1 & 1 & 1 & 1 & 1 & $I$ & 1 & Haplotyp & & & & \\
\hline \multicolumn{16}{|c|}{ WG 186 (Zahn 18) } \\
\hline Ex/PCR & Amelo. & 10.30 .2 & VWA & FGA & D8S1179 & $10.31 \quad \mathrm{D}$ & D18S51 & 10.31 .1 & D13S317 & D7S820 & Ex/PCR & DYS19 & DYS3891 & DYS389II & DYS390 \\
\hline Z1 5.9a & $X Y$ & 17 & 16 & $19 / 22$ & $11 / 13$ & 1 & 15 & $12 / 13$ & 1 & 1 & Z1 5.10a & 1 & 1 & 1 & 1 \\
\hline $\mathrm{Z1} \mathrm{5.9b}$ & $x$ & 15 & 1 & 22 & $11 / 14$ & 1 & 1 & $11 / 13$ & 1 & 1 & Z15.10b & 1 & 1 & 1 & 1 \\
\hline Z1 5.11a & 1 & 15 & 15 & 22 & 14 & 28 & 1 & 1 & 1 & 10 & Z1 5.12 & 1 & 12 & 1 & 1 \\
\hline Z1 5.11b & $x$ & 1 & 1 & 22 & 13 & 1 & 1 & 1 & 1 & 1 & & & & & \\
\hline
\end{tabular}




\begin{tabular}{|c|c|c|c|c|c|c|c|c|c|c|c|c|c|c|c|}
\hline Z1 28.46 & $\mathrm{x}$ & 1 & 1 & 1 & 1 & 1 & 1 & 1 & 1 & 1 & & & & & \\
\hline Genotyp & $\mathbf{X}(\mathbf{X})$ & (15) & 1 & (22) & (11)(13)(14) & $I$ & 1 & (13) & 1 & 1 & Haplotyp & I & I & 1 & 1 \\
\hline \multicolumn{16}{|c|}{ WG 194 (Zahn 37, Zahn 36) } \\
\hline Ex/PCR & Amelo. & 10.31 .2 & VWA & FGA & D8S1179 & $10.32 \quad D$ & D18S51 & 10.32 .1 & D13S317 & D7S820 & & & & & \\
\hline Z1 1.1a & $x$ & 1 & 19 & 23 & $10 / 12$ & 1 & 1 & 1 & 1 & 1 & & & & & \\
\hline Z1 1.1b & $x$ & $14 / 15$ & 1 & 22 & 1 & 1 & 1 & 1 & 1 & 1 & & & & & \\
\hline$Z 13.2 a$ & 1 & 15 & 1 & 22 & 12 & 26 & 19 & 1 & $\frac{1}{1}$ & 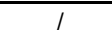 & & & & & \\
\hline$Z 13.2 b$ & $\mathrm{x}$ & 15 & $16 / 18$ & 1 & 1 & 1 & 19 & 1 & 1 & 1 & & & & & \\
\hline Z1 3.3a & 1 & 15 & 1 & 1 & $10 / 14$ & 30 & 1 & $(11) / 12$ & 8 & 1 & & & & & \\
\hline Z1 3.3b & $x$ & 1 & 19 & 1 & 12 & 1 & 15 & 1 & 1 & 10 & & & & & \\
\hline Z13.5a & $x$ & 15 & $14 / 16$ & 1 & 12 & 1 & 1 & 1 & 1 & 1 & & & & & \\
\hline$Z 13.5 b$ & 1 & 15 & 1 & 21 & 1 & 1 & 1 & 1 & 1 & 1 & & & & & \\
\hline Z1 8.19 & $x$ & $12 / 15$ & 14 & 1 & 10 & 30 & 1 & 11 & 11 & 10 & & & & & \\
\hline $\mathrm{Z1} 8.23 a$ & 1 & 1 & 1 & 1 & 1 & 1 & 1 & 1 & 1 & 1 & & & & & \\
\hline$Z 18.23 b$ & 1 & 1 & 18 & 20 & 10 & 1 & 1 & 1 & 1 & 1 & & & & & \\
\hline Z1 8.25a & $X Y$ & 17 & 17 & $21 / 22$ & $12 / 13$ & $30 / 31.2$ & $14 / 19$ & 13 & $10 / 11$ & 9 & & & & & \\
\hline $\mathrm{Z1} \mathrm{8.25b}$ & $\mathrm{x}$ & 1 & 1 & 24 & 1 & 1 & 1 & 1 & 13 & 1 & & & & & \\
\hline Z1 86.97 & $x$ & 1 & 15 & 1 & 1 & 1 & 1 & 13 & 1 & 1 & & & & & \\
\hline Z2 99.105 & 1 & 1 & 1 & 1 & 1 & 1 & 1 & $\frac{1}{1}$ & 1 & 1 & & & & & \\
\hline Z2 101.111 & $\mathrm{x}$ & $(14) / 15$ & 18 & 22 & 13 & 33.2 & 1 & 1 & 1 & 1 & & & & & \\
\hline Genotyp & $x x$ & $15 / 15$ & 18 & 22 & $10 / 12$ & 30 & (19) & 1 & $I$ & 10 & & & & & \\
\hline \multicolumn{16}{|c|}{ WG 196 (Zahn 47, Zahn 44) } \\
\hline Ex/PCR & Amelo. & 10.32 .2 & VWA & FGA & D8S1179 & $10.33 \quad \mathrm{D}$ & D18S51 & 10.33 .1 & D13S317 & D7S820 & & & & & \\
\hline Z1 25.44a & $\mathrm{x}$ & $15 / 17$ & $14 / 16$ & $21 / 22$ & $14 / 15$ & 1 & 17 & $(11) / 12$ & 11 & 10 & & & & & \\
\hline Z1 25.44b & $x$ & $15 / 18$ & 14 & 21 & $(14) / 15$ & $27 / 31.2$ & 1 & 11 & 13 & 1 & & & & & \\
\hline Z1 26.44 & $x$ & $15 / 18$ & 16 & 21 & $11 / 14$ & 1 & 17 & 1 & 1 & 1 & & & & & \\
\hline Z1 28.46 & $x$ & 15 & 16 & 24 & 1 & 1 & 1 & 11 & 1 & 1 & & & & & \\
\hline Z1 35.54 & $\bar{x}$ & 15 & 14 & $21 / 22$ & 14 & $27 / 28$ & 17 & 11 & 7 & 8 & & & & & \\
\hline Z2 55.75 & 1 & 17 & 1 & 24 & 1 & 1 & 1 & 1 & 1 & 1 & & & & & \\
\hline Z2 86.97 & $x$ & $15 / 16 /(17)$ & 14 & 22 & $13 / 14$ & 30.2 & 1 & $11 / 12$ & 1 & 1 & & & & & \\
\hline Genotyp & $x x$ & $15 / 18$ & $14 / 16$ & $21 / 22$ & $14 /(15)$ & 27 & $17 / 17$ & $11 / 12$ & $I$ & 1 & & & & & \\
\hline \multicolumn{16}{|c|}{ WG 199 (Zahn 36) } \\
\hline Ex/PCR & Amelo. & 10.33 .2 & VWA & FGA & D8S1179 & \begin{tabular}{|l|}
10.34 \\
$D$
\end{tabular} & D18S51 & 10.34 .1 & D13S317 & D7S820 & & & & & \\
\hline Z1 69.91 & 1 & 1 & 1 & 1 & 1 & 1 & 1 & 10 & 8 & 1 & & & & & \\
\hline Z1 71.87 & 1 & 1 & 1 & 1 & 1 & 1 & 1 & $8 / 10$ & 1 & 1 & & & & & \\
\hline
\end{tabular}




\begin{tabular}{|c|c|c|c|c|c|c|c|c|c|c|c|c|c|c|c|}
\hline Z1 86.97 & $\mathrm{x}$ & 15 & $16 / 18$ & 1 & $13 / 14$ & 29 & 1 & $10 / 11$ & 1 & $(9) / 10$ & & & & & \\
\hline Z194.102 & $x$ & 1 & 17 & 1 & 1 & 1 & 1 & 1 & $8 / 11$ & 1 & & & & & \\
\hline Genotyp & $\mathrm{XX}$ & 1 & 1 & 1 & I & I & 1 & 1 & 1 & 1 & & & & & \\
\hline \multicolumn{16}{|c|}{ WG 201 (Femur) } \\
\hline Ex/PCR & Amelo. & 10.34 .2 & VWA & FGA & D8S1179 & \begin{tabular}{ll|}
10.35 & $\mathrm{D}$ \\
\end{tabular} & D18S51 & 10.35 .1 & D13S317 & D7S820 & Ex/PCR & DYS19 & DYS3891 & DYS389II & DYS390 \\
\hline $\mathrm{K} 2.1 \mathrm{a}$ & $\mathrm{x}$ & 16 & 1 & 22 & 1 & 1 & 1 & 14 & 10 & 1 & & & & & \\
\hline $\mathrm{K} 2.1 \mathrm{~b}$ & 1 & $15 /(16)$ & 1 & 1 & $11 / 13$ & 1 & 17 & 14 & 1 & 1 & & & & & \\
\hline K 41.59 & $\mathrm{XY}$ & $15 / 16$ & 14 & 1 & $11 / 13$ & 1 & 1 & 14 & 1 & 1 & & & & & \\
\hline Genotyp & 1 & $15 / 16$ & 1 & 1 & $11 / 13$ & 1 & $I$ & $14 / 14$ & I & I & Haplotyp & & & & \\
\hline \multicolumn{16}{|c|}{ WG 202 (Zahn 38, Zahn 16) } \\
\hline Ex/PCR & Amelo. & 10.35 .2 & VWA & FGA & D8S1179 & $10.36 \quad \mathrm{D}$ & D18S51 & 10.36 .1 & D13S317 & D7S820 & Ex/PCR & DYS19 & DYS389I & DYS389II & DYS390 \\
\hline Z1 4.6a & $X Y$ & 15 & $16 / 19$ & 1 & $12 / 14$ & 30 & 19 & 9 & $(12) / 13$ & 1 & Z1 4.8 & 15 & 12 & 1 & 23 \\
\hline Z1 4.6b & $X Y$ & 15 & $13 / 19$ & 23 & $12 / 14$ & 1 & 1 & 12 & 1 & 10 & Z1 18.36 & 1 & 1 & 1 & 1 \\
\hline Z1 4.7a & $X Y$ & 15 & 14 & 1 & $11 / 13$ & 1 & 1 & 9/14 & 8 & 10 & Z2 71.98 & 15 & 12 & 1 & 23 \\
\hline $\mathrm{Z1} 4.7 \mathrm{~b}$ & Ü.a. & 15 & 16 & 1 & Ü.a. & $29 / 30$ & 1 & $(11 / 12)$ & 1 & 1 & Z2 84.110 & 1 & 1 & 1 & 1 \\
\hline Z1 18.37a & $\mathrm{X}$ & 15 & 17 & 1 & 1 & 1 & 1 & 12 & 1 & 1 & & & & & \\
\hline Z1 18.37b & $X Y$ & 17 & 16 & 1 & 14 & 30 & 1 & 12 & 1 & 1 & & & & & \\
\hline Z1 39.59 & 1 & 1 & 1 & 1 & 1 & 1 & 1 & 1 & 1 & I & & & & & \\
\hline Z1 55.75 & $X Y$ & 1 & 1 & 1 & 12 & 1 & 1 & 1 & 1 & 1 & & & & & \\
\hline Z2 70.86 & $\overline{X Y}$ & 15 & 1 & 1 & $12 / 14$ & 31.2 & 1 & 12 & 1 & 10 & & & & & \\
\hline Z2 69.71 & $\mathrm{XY}$ & $15 / 16$ & 19 & 1 & $12 / 14$ & 31 & 18 & $10 / 11$ & 10 & 1 & & & & & \\
\hline Z2 71.87 & $X Y$ & 15 & $15 / 19$ & 19 & $12 / 13 / 14$ & 29 & $14 / 18$ & \begin{tabular}{|l|}
$(10)(11) 12$ \\
\end{tabular} & 1 & 10 & & & & & \\
\hline Genotyp & $X Y$ & $15 /(15)$ & $16 / 19$ & 1 & $12 / 14$ & $29 / 30$ & 18 & \begin{tabular}{|l|}
12 \\
\end{tabular} & $I$ & $10 / 10$ & Haplotyp & 15 & 12 & 1 & 23 \\
\hline \multicolumn{16}{|c|}{ WG 204 (Zahn 46, Zahn 47, Femur) } \\
\hline Ex/PCR & Amelo. & 10.36 .2 & VWA & FGA & D8S1179 & $10.37 \quad \mathrm{D}$ & D18S51 & \begin{tabular}{|l|}
10.37 .1 \\
\end{tabular} & D13S317 & D7S820 & Ex/PCR & DYS19 & DYS3891 & DYS389II & DYS390 \\
\hline Z1 5.9a & $X Y$ & $16 / 17$ & 15/16/18 & 1 & 13 & 1 & 1 & 13 & 1 & 1 & Z1 5.10a & 13 & 14 & 1 & 1 \\
\hline $\mathrm{Z15.9b}$ & $\mathrm{x}$ & $16 / 17$ & 14 & 1 & $(13) / 14$ & 1 & 13 & 13 & 1 & 1 & Z15.10b & 15 & 14 & 1 & 1 \\
\hline Z15.11a & $\mathrm{XY}$ & 15 & $14 / 16$ & 22 & 13 & 30 & 15 & $10 / 11$ & 1 & 10 & Z15.12 & 13 & 1 & 1 & 1 \\
\hline Z1 5.11b & $\mathrm{XY}$ & $16 / 18$ & 1 & 24 & $13 / 14$ & 1 & 13 & $11 / 13$ & 1 & 1 & $\mathrm{Z17.18a}$ & 1 & 14 & 1 & 1 \\
\hline Z1 7.16a & $X Y$ & $16 / 17$ & $14 / 17$ & 22 & $(12) / 13$ & $29 / 30$ & 1 & 11 & 1 & 10 & $\mathrm{Z1} \mathrm{7.18b}$ & 1 & 1 & 1 & 22 \\
\hline Z17.16b & $\mathrm{XY}$ & $15 / 17$ & $16 / 18$ & 21 & $13 / 14$ & $26 / 29 / 30$ & 1 & $(12) / 13$ & 13 & 1 & $\mathrm{Z1} \mathrm{7.18c}$ & 13 & 14 & 1 & 1 \\
\hline $\mathrm{Z17.17a}$ & $\overline{X Y}$ & $(14) / 15$ & 19 & 1 & $(12) / 13 / 16$ & $29 / 30$ & 17 & $11 / 13$ & 12 & 1 & Z1 12.28a & 1 & 1 & 1 & 24 \\
\hline $\mathrm{Z1} 7.17 \mathrm{~b}$ & $X Y$ & $15 / 16$ & 16 & 22 & 1 & $29 / 30$ & 17 & $11 / 13$ & 1 & 1 & $\mathrm{Z1} 12.28 \mathrm{~b}$ & 1 & 1 & 1 & 1 \\
\hline Z1 12.27a & $X Y$ & 1 & 1 & 1 & 13 & 1 & 1 & 1 & 12 & 1 & Z2 84.110 & 1 & 1 & 1 & 1 \\
\hline Z1 12.27b & 1 & 17 & 1 & 1 & $11 / 13 / 14$ & 1 & 1 & 11 & 1 & 1 & & & & & \\
\hline Z1 12.31a & $\mathrm{X}$ & Ü.a. & 1 & 22 & 13 & 1 & 1 & 1 & 1 & I & & & & & \\
\hline
\end{tabular}




\begin{tabular}{|c|c|c|c|c|c|c|c|c|c|c|c|c|c|c|c|}
\hline Z1 12.31b & $X Y$ & $16(\mathrm{kl})$ & 1 & 1 & 1 & 1 & 1 & $11 / 13$ & 1 & 10 & & & & & \\
\hline Z135.59 & 1 & 1 & 1 & 1 & 1 & 1 & 1 & 1 & 1 & 1 & & & & & \\
\hline Z2 37.75 & 1 & 1 & 1 & 1 & 1 & 1 & 1 & 1 & 1 & 1 & & & & & \\
\hline Z2 70.86 & 1 & 15 & 1 & 1 & 1 & 1 & 1 & 1 & 1 & 1 & & & & & \\
\hline Z2 84.86 & $\mathrm{XY}$ & 15 & 16 & 1 & 1 & 1 & 1 & 1 & 1 & 1 & & & & & \\
\hline K 116.128 & 1 & 1 & 1 & 1 & 1 & 1 & 1 & 1 & 1 & 1 & & & & & \\
\hline Genotyp & $\mathrm{XY}$ & 15/16/17 & 14/16/18 & 22 & $13 / 14$ & $29 / 30$ & $(13) /(17)$ & $11 / 13$ & 12 & $10 / 10$ & Haplotyp & 13 & 14 & 1 & 1 \\
\hline \multicolumn{16}{|c|}{ WG 206 (Zahn 47, Zahn 18) } \\
\hline Ex/PCR & Amelo. & 10.37 .2 & VWA & FGA & D8S1179 & $10.38 \quad \mathrm{D}$ & D18S51 & 10.38 .1 & D13S317 & D7S820 & Ex/PCR & DYS19 & DYS3891 & DYS389II & DYS390 \\
\hline Z1 13.29a & $\mathrm{x}$ & 1 & 14 & 21 & 1 & 1 & 1 & 1 & 1 & 1 & & & & & \\
\hline$Z 113.29 b$ & $X Y$ & 1 & 17 & 1 & 1 & 1 & 1 & 12 & 1 & 1 & & & & & \\
\hline Z1 13.32a & 1 & 1 & 1 & 22 & 1 & 1 & 1 & 11 & 1 & 1 & & & & & \\
\hline Z1 13.32b & $X Y$ & 14/16/18 & 16 & 21 & 15 & 31 & 1 & 12 & 10 & 12 & & & & & \\
\hline Z194.102 & $\mathrm{x}$ & 1 & 1 & 1 & 1 & 1 & 12 & 1 & 1 & 1 & & & & & \\
\hline Z2 99.105 & 1 & 1 & 1 & 1 & 1 & 1 & 1 & 1 & 1 & 1 & & & & & \\
\hline Z2 102.112 & $x$ & 14 & 14 & 22 & 18 & 28 & 17 & 15 & I & $8 / 12$ & & & & & \\
\hline Genotyp & $(\mathrm{XY})$ & 1 & 1 & $I$ & 1 & 1 & 1 & $I$ & 1 & 1 & & & & & \\
\hline \multicolumn{16}{|c|}{ WG 208 (Zahn 45, Zahn 27) } \\
\hline Ex/PCR & Amelo. & 10.38 .2 & VWA & FGA & D8S1179 & $10.39 \quad \mathrm{D}$ & D18S51 & 10.39 .1 & D13S317 & D7S820 & Ex/PCR & DYS19 & DYS3891 & DYS389II & DYS390 \\
\hline Z1 4.6a & 1 & $\begin{array}{l}(14) / 15 \\
\end{array}$ & 1 & 1 & 1 & 29 & 1 & 1 & 9 & 1 & Z14.8 & 1 & 1 & 29 & 25 \\
\hline Z1 4.6b & 1 & (18)/19 & 1 & 1 & $9 /(11) / 12$ & 1 & 1 & 9 & 1 & 1 & Z1 84.110 & 1 & I & 1 & 1 \\
\hline Z1 4.7a & 1 & 1 & $14 / 18$ & 1 & 1 & 1 & 1 & 1 & 1 & 1 & Z1 112.126 & 1 & 1 & 1 & 1 \\
\hline $\mathrm{Z} 14.7 \mathrm{~b}$ & 1 & 1 & 1 & 1 & 1 & 1 & 1 & 1 & 1 & 1 & & & & & \\
\hline Z1 39.59 & 1 & 1 & 1 & 1 & 1 & 1 & 1 & 1 & 1 & 1 & & & & & \\
\hline Z1 84.96 & $\mathrm{Y}$ & 14 & 1 & 19 & 1 & 1 & 1 & $(11) / 12$ & 9/13 & $8 / 10$ & & & & & \\
\hline Z1 95.103 & $X Y$ & 15 & 1 & 1 & $11 / 13$ & 1 & 1 & 11 & 1 & 1 & & & & & \\
\hline Z2 101.111 & $X Y$ & 14 & 1 & 20 & $11 / 13$ & 1 & 1 & 1 & 1 & 1 & & & & & \\
\hline Z2 112.123 & $X Y$ & 14 & 14/17 & 24 & 13 & 1 & 15 & 1 & 12 & 1 & & & & & \\
\hline Z2 115.127 & $\mathrm{x}$ & 15 & 1 & 1 & 1 & 28 & 1 & $11 / 14$ & 12 & 1 & & & & & \\
\hline Genotyp & $X Y$ & $14 / 15$ & 1 & 1 & $11 / 13$ & 1 & 1 & 11 & $9 / 12$ & 1 & Haplotyp & 1 & 1 & 1 & $I$ \\
\hline \multicolumn{16}{|c|}{ WG 211 (Zahn 16) } \\
\hline Ex/PCR & Amelo. & 10.39 .2 & VWA & FGA & D8S1179 & 10.40 & D18S51 & 10.40 .1 & D13S317 & D7S820 & Ex/PCR & DYS19 & DYS3891 & DYS389II & DYS390 \\
\hline Z1 5.9a & $X Y$ & 1 & 14 & 22 & 11 & I & 1 & 8 & 1 & 1 & Z1 $5.10 \mathrm{a}$ & 1 & 1 & 1 & 1 \\
\hline Z1 5.9b & 1 & 15 & 14 & 1 & 8 & 30 & 1 & 1 & 1 & 1 & Z1 5.10 b & 1 & 1 & 1 & 1 \\
\hline Z15.11a & $X Y$ & $(14) / 15$ & 16 & 1 & 15 & 1 & 1 & 12 & 1 & 1 & Z1 5.12 & 1 & 1 & 1 & 1 \\
\hline Z1 5.11b & $x$ & 15 & 1 & 21 & 1 & 1 & 1 & 1 & 1 & 1 & & & & & \\
\hline
\end{tabular}




\begin{tabular}{|c|c|c|c|c|c|c|c|c|c|c|c|c|c|c|c|}
\hline Z1 44.61 & $\mathrm{x}$ & 1 & 1 & 1 & 1 & 1 & 1 & 10 & 1 & 1 & & & & & \\
\hline Z1 101.111 & $\mathrm{XY}$ & 15 & 15 & 22 & 10 & 30 & 1 & $11 / 12$ & 8 & 1 & & & & & \\
\hline Genotyp & $\mathbf{X Y}$ & $15 / 15$ & (14) & 22 & 1 & 30 & 1 & 12 & $I$ & I & Haplotyp & 1 & 1 & I & 1 \\
\hline \multicolumn{16}{|c|}{ WG 214 (Zahn 16) } \\
\hline Ex/PCR & Amelo. & 10.40 .2 & VWA & FGA & D8S1179 & $10.41 \quad D$ & D18S51 & 10.41 .1 & D13S317 & D7S820 & Ex/PCR & DYS19 & DYS3891 & DYS389II & DYS390 \\
\hline Z1 31.49 & $X Y$ & (15) 16 & 17 & 23 & $12 / 14$ & 30 & 1 & I & $8 /(12) / 13$ & I & Z1 31.55 & 1 & 1 & 1 & 1 \\
\hline Z1 31.51 & $x$ & $15 / 16$ & 17 & 23 & 13 & 1 & 1 & 10/11 & 8 & 1 & & & & & \\
\hline Z1 69.61 & 1 & 1 & 1 & 1 & 1 & 1 & 1 & 1 & 1 & 1 & & & & & \\
\hline Z1 71.87 & 1 & 1 & 1 & 23 & 1 & 32.2 & 1 & $10 / 11$ & 1 & 1 & & & & & \\
\hline Z1 84.96 & $x$ & 1 & 1 & 1 & 13 & $28 / 29$ & 1 & 13 & 1 & 10 & & & & & \\
\hline Z1 91.101 & $x$ & 1 & 1 & 1 & 1 & 1 & 1 & 1 & 1 & 1 & & & & & \\
\hline Genotyp & $X(X)$ & 1 & 1 & 1 & 1 & 1 & 1 & 1 & 1 & I & Haplotyp & 1 & 1 & I & 1 \\
\hline \multicolumn{16}{|c|}{ WG 221 (Zahn 37) } \\
\hline Ex/PCR & Amelo. & 10.41 .2 & VWA & FGA & D8S1179 & $10.42 \quad D$ & D18S51 & 10.42 .1 & D13S317 & D7S820 & Ex/PCR & DYS19 & DYS3891 & DYS389II & DYS390 \\
\hline Z1 25.44 & $X Y$ & $16 / 17$ & $14 / 16$ & 1 & $(13) / 14$ & 30 & 1 & $11 / 12$ & $8 / 11$ & 1 & Z1 25.50a & 14 & 1 & 29 & 24 \\
\hline Z1 71.87 & $X Y$ & 1 & $14 / 16$ & $19 / 21$ & $13 / 14$ & 30 & 1 & $10 / 11$ & 1 & 1 & Z1 25.50b & 1 & 13 & 1 & 1 \\
\hline Z1 84.86 & $X Y$ & $16 / 18$ & $14 / 16$ & $19 / 21$ & $13 / 14$ & 30 & 1 & $11 / 12$ & $8 /(9) / 11$ & $8 / 9$ & Z1 84.98 & 14 & 13 & 29 & 24 \\
\hline Z1 112.124 & 1 & 18 & 1 & 1 & 1 & 1 & 1 & 1 & 1 & 1 & & & & & \\
\hline Genotyp & $X Y$ & 16/18 & $14 / 16$ & $19 / 21$ & $13 / 14$ & $30 / 30$ & 1 & $11 / 12$ & $8 / 11$ & 1 & Haplotyp & 14 & 13 & 29 & 24 \\
\hline \multicolumn{16}{|c|}{ WG 226 (Zahn 35) } \\
\hline Ex/PCR & Amelo. & 10.42 .2 & VWA & FGA & D8S1179 & $10.43 \quad \mathrm{D}$ & D18S51 & 10.43 .1 & D13S317 & D7S820 & Ex/PCR & DYS19 & DYS3891 & DYS389II & DYS390 \\
\hline Z1 13.29a & 1 & 1 & 1 & 1 & 1 & 1 & 1 & 1 & 1 & 1 & Z1 13.28a & 1 & 1 & 1 & 1 \\
\hline Z1 13.29b & 1 & 1 & 1 & 1 & 1 & 1 & 1 & 1 & 1 & 1 & Z1 13.28b & 1 & 1 & 1 & 1 \\
\hline Z1 84.96 & 1 & 1 & 1 & 1 & 1 & 1 & 1 & 1 & 1 & 1 & & & & & \\
\hline Genotyp & $I$ & $I$ & 1 & 1 & $I$ & 1 & 1 & 1 & $I$ & 1 & Haplotyp & & & & \\
\hline \multicolumn{16}{|c|}{ WG 227 (Zahn 28, Zahn 17) } \\
\hline Ex/PCR & Amelo. & 10.43 .2 & VWA & FGA & D8S1179 & \begin{tabular}{ll|}
10.44 & $D$
\end{tabular} & D18S51 & 10.44 .1 & D13S317 & D7S820 & Ex/PCR & DYS19 & DYS389| & DYS389II & DYS390 \\
\hline Z1 13.29a & $X Y$ & 1 & 1 & 1 & 14 & 1 & 19 & 1 & 1 & 9 & Z1 $13.28 \mathrm{a}$ & 1 & 12 & 28 & 23 \\
\hline$Z 113.29 b$ & 1 & 15 & 1 & 21 & 14 & 1 & 1 & 1 & 1 & 1 & $\mathrm{Z1} 13.28 \mathrm{~b}$ & 1 & 1 & 1 & 22 \\
\hline Z2 33.52 & $X Y$ & $15 / 17$ & (18)/19 & 1 & 13 & 28 & 1 & 12 & 1 & 1 & Z1 11.28 a & 1 & 12 & 1 & 1 \\
\hline \multirow[t]{5}{*}{ Z2 35.54} & $X Y$ & 15/17 & 19 & $22 / 23$ & $13 / 14$ & 1 & 1 & $11 / 12$ & $8 / 12$ & 1 & Z1 11.28b & 1 & 12 & 1 & 1 \\
\hline & & & & & & & & & & & Z1 11.33a & 15 & 1 & 1 & 1 \\
\hline & & & & & & & & & & & Z1 11.33b & 15 & 1 & 1 & 22 \\
\hline & & & & & & & & & & & Z1 11.36 & 1 & 1 & 1 & 1 \\
\hline & & & & & & & & & & & $\mathrm{Z2} 35.62$ & 1 & 12 & 1 & 1 \\
\hline Genotyp & $X Y$ & $15 / 17$ & 19 & $I$ & $13 / 14$ & 1 & 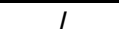 & 12 & I & I & Haplotyp & 15 & 12 & 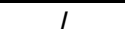 & 22 \\
\hline
\end{tabular}




\begin{tabular}{|c|c|c|c|c|c|c|c|c|c|c|c|c|c|c|c|}
\hline \multicolumn{16}{|c|}{ WG 228 (Zahn 45) } \\
\hline Ex/PCR & Amelo. & 10.44 .2 & VWA & FGA & D8S1179 & 10.45 & D18S51 & 10.45 .1 & D13S317 & D7S820 & Ex/PCR & DYS19 & DYS3891 & DYS389II & DYS390 \\
\hline Z199.105 & $x$ & 18 & 17 & 1 & 1 & 1 & 1 & 13 & 10 & 1 & & & & & \\
\hline Genotyp & 1 & 1 & 1 & 1 & 1 & 1 & 1 & 1 & 1 & 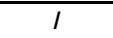 & Haplotyp & & & & \\
\hline \multicolumn{16}{|c|}{ WG 231 (Zahn 48) } \\
\hline Ex/PCR & Amelo. & 10.45 .2 & VWA & FGA & D8S1179 & $10.46 \quad \mathrm{D}$ & D18S51 & 10.46 .1 & D13S317 & D7S820 & Ex/PCR & DYS19 & DYS3891 & DYS389II & DYS390 \\
\hline Z1 12.27a & 1 & 15 & 1 & 21 & 1 & 1 & 22 & 12 & 1 & 7 & Z1 12.28 a & 1 & 1 & 1 & 1 \\
\hline$Z 112.27 b$ & 1 & 1 & 1 & 1 & 1 & 1 & 1 & 1 & 1 & 1 & Z1 12.28 b & 1 & 1 & 1 & 1 \\
\hline$\overline{Z 112.31 a}$ & $X Y$ & $15 / 18$ & 16 & 1 & 1 & 30 & 7 & 12 & 1 & $\frac{1}{1}$ & & & & & \\
\hline Z1 12.31b & $\overline{X Y}$ & $15 / 16$ & 17 & 23 & 1 & 1 & 1 & 1 & 1 & 10 & & & & & \\
\hline Z1 94.102 & 1 & 1 & 1 & 1 & 1 & 1 & 1 & 1 & 1 & 1 & & & & & \\
\hline Genotyp & $(\mathrm{XY})$ & (15) & 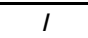 & 1 & 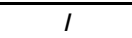 & 1 & 1 & (12) & $T$ & $\frac{1}{1}$ & Haplotyp & 1 & 1 & 1 & 1 \\
\hline \multicolumn{16}{|c|}{ WG 232 (Zahn 48) } \\
\hline Ex/PCR & Amelo. & 10.46 .2 & VWA & FGA & D8S1179 & 10.47 & D18S51 & 10.47 .1 & D13S317 & D7S820 & Ex/PCR & DYS19 & DYS389I & DYS389II & DYS390 \\
\hline Z1 25.44 & $x$ & 1 & 14 & 1 & $9 / 12$ & 30 & 14 & 12 & 1 & 1 & Z1 25.47a & 1 & 1 & 1 & 1 \\
\hline Z1 57.78 & $X Y$ & 18 & 1 & 1 & 1 & 1 & 1 & 13 & 1 & 1 & Z1 25.47b & 1 & 1 & 1 & 1 \\
\hline Z1 84.96 & $\mathrm{Y}$ & 1 & 1 & 1 & 1 & 1 & 1 & 1 & 1 & 1 & & & & & \\
\hline Genotyp & $X Y$ & 1 & 1 & 1 & 1 & 1 & 1 & 1 & 1 & 1 & Haplotyp & 1 & 1 & 1 & 1 \\
\hline \multicolumn{16}{|c|}{ WG 233 (Zahn 55) } \\
\hline Ex/PCR & Amelo. & 10.47 .2 & VWA & FGA & D8S1179 & 10.48 & D18S51 & 10.48 .1 & D13S317 & D7S820 & Ex/PCR & DYS19 & DYS3891 & DYS389II & DYS390 \\
\hline Z1 70.86 & $x$ & $15 / 16$ & 1 & 1 & 1 & 1 & 1 & 1 & 1 & 1 & & & & & \\
\hline Z1 72.87 & 1 & 1 & 1 & 1 & 1 & 1 & 1 & 1 & 1 & 1 & & & & & \\
\hline Genotyp & $I$ & 1 & 1 & 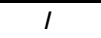 & 1 & 1 & 1 & 1 & 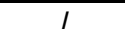 & 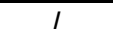 & Haplotyp & & & & \\
\hline \multicolumn{16}{|c|}{ WG 234 (Femur) } \\
\hline Ex/PCR & Amelo. & 10.48 .2 & VWA & FGA & D8S1179 & $10.49 \quad \mathrm{D}$ & D18S51 & 10.49 .1 & D13S317 & D7S820 & Ex/PCR & DYS19 & DYS3891 & DYS389II & DYS390 \\
\hline $\mathrm{K} 2.1 \mathrm{a}$ & 1 & 1 & 1 & 1 & 1 & 1 & 1 & 1 & 1 & 1 & & & & & \\
\hline $\mathrm{K} 2.1 \mathrm{~b}$ & 1 & 1 & 1 & 1 & $(13) / 14$ & 29 & 1 & 1 & 1 & 1 & & & & & \\
\hline Genotyp & 1 & 1 & 1 & 1 & 1 & 1 & 1 & 1 & 1 & 1 & Haplotyp & & & & \\
\hline \multicolumn{16}{|c|}{ WG 238 (Zahn 17) } \\
\hline Ex/PCR & Amelo. & 10.49 .2 & VWA & FGA & D8S1179 & $10.50 \quad \mathrm{D}$ & D18S51 & 10.50 .1 & D13S317 & D7S820 & Ex/PCR & DYS19 & DYS3891 & DYS389II & DYS390 \\
\hline Z1 27.46 & $X Y$ & 15 & $17 / 19$ & 23 & 12 & $30 / 31$ & 1 & 12 & $12 /(13)$ & 1 & Z1 27.47a & 14 & 12 & 28 & 22 \\
\hline Z1 32.49 & $\mathrm{XY}$ & 15 & $17 / 19$ & 1 & $12 / 13$ & $30 / 31$ & 15 & 12 & $12 / 13$ & $8 / 9$ & Z1 27.47b & 14 & 12 & 28 & 22 \\
\hline Z1 32.51 & $X Y$ & 15 & 17 & $22 / 22.2$ & $12 / 13$ & $30 / 31$ & 15 & 12 & $12 / 13$ & 9 & Z1 32.50a & 14 & 12 & 28 & 22 \\
\hline Z1 72.87 & 1 & 1 & 1 & 1 & 1 & 1 & 1 & 1 & 1 & 1 & Z1 32.50b & 14 & 12 & 28 & 22 \\
\hline Z1 75.91 & 1 & 1 & 1 & 1 & 1 & 1 & 1 & 1 & 1 & 1 & & & & & \\
\hline Genotyp & $X Y$ & $15 / 15$ & $17 / 19$ & 1 & $12 /(13)$ & $30 / 31$ & $15 / 15$ & $12 /(12)$ & $12 /(13)$ & (9) & Haplotyp & 14 & 12 & 28 & 22 \\
\hline
\end{tabular}


WG 241 (Zahn 47)

\begin{tabular}{|c|c|c|c|c|c|c|c|c|c|c|c|c|c|c|c|}
\hline \multicolumn{16}{|c|}{ WG 241 (Zahn 47) } \\
\hline Ex/PCR & Amelo. & 10.50 .2 & VWA & FGA & D8S1179 & 10.51 & D18S51 & 10.51 .1 & D13S317 & D7S820 & & & & & \\
\hline Z 3.52 & 1 & 15 & 18 & 1 & $(12) / 13$ & 1 & 1 & 1 & 1 & 1 & & & & & \\
\hline Z 5.54 & $x$ & 15 & 1 & 22 & 1 & 1 & 1 & 10 & 12 & 11 & & & & & \\
\hline Z 83.95 & $\bar{x}$ & 1 & 7 & 1 & 7 & 7 & 7 & 1 & $\frac{1}{1}$ & 1 & & & & & \\
\hline Z 94.102 & 1 & 1 & 1 & 1 & 1 & 1 & 1 & 1 & 1 & 1 & & & & & \\
\hline Genotyp & $x X$ & 15 & $I$ & 1 & $I$ & $I$ & 1 & 1 & $I$ & 1 & & & & & \\
\hline \multicolumn{16}{|c|}{ WG 243 (3 Zähne) } \\
\hline Ex/PCR & Amelo. & 10.51 .2 & VWA & FGA & D8S1179 & $10.52 \quad \mathrm{D}$ & D18S51 & 10.52 .1 & D13S317 & D7S820 & Ex/PCR & DYS19 & DYS3891 & DYS389II & DYS390 \\
\hline Z1 67.84 & 1 & 1 & 1 & 1 & 1 & 1 & 1 & 1 & 1 & 1 & & & & & \\
\hline Z2 83.95 & 1 & 1 & 1 & 1 & 1 & 1 & 1 & 1 & 1 & 1 & & & & & \\
\hline Z3 94.102 & I & 1 & 1 & 1 & 1 & 1 & 1 & I & 1 & 1 & & & & & \\
\hline Genotyp & $I$ & $I$ & $I$ & I & $I$ & $I$ & I & 1 & $I$ & $I$ & Haplotyp & & & & \\
\hline \multicolumn{16}{|c|}{ WG 244 (Femur) } \\
\hline Ex/PCR & Amelo. & 10.52 .2 & VWA & FGA & D8S1179 & \begin{tabular}{ll|}
$10.53 \quad \mathrm{D}$ \\
\end{tabular} & D18S51 & 10.53 .1 & D13S317 & D7S820 & Ex/PCR & DYS19 & DYS3891 & DYS389II & DYS390 \\
\hline K 20.37a & 1 & 1 & 1 & 1 & 1 & 1 & 1 & 1 & 1 & 1 & K 113.126 & 1 & 1 & 1 & 1 \\
\hline K 20.37b & 1 & 1 & 1 & 1 & 1 & 1 & 1 & 1 & 1 & 1 & & & & & \\
\hline K 20.38 & 1 & 1 & 14 & 1 & 14 & 1 & 1 & 1 & 1 & 1 & & & & & \\
\hline K 113.124 & 1 & 15 & 16 & 22 & 15 & $29.2 / 30.2$ & 1 & 1 & 1 & 1 & & & & & \\
\hline Genotyp & $I$ & 1 & 1 & 1 & $I$ & 1 & I & 1 & 1 & 1 & Haplotyp & & & & \\
\hline \multicolumn{16}{|c|}{ WG 253 (Zahn 47, Zahn 48; Femur) } \\
\hline Ex/PCR & Amelo. & 10.53 .2 & VWA & FGA & D8S1179 & $10.54 \quad \mathrm{D}$ & D18S51 & 10.54 .1 & D13S317 & D7S820 & Ex/PCR & DYS19 & DYS3891 & DYS389II & DYS390 \\
\hline Z1 38.58 & $\mathrm{XY}$ & $15 / 16 / 17$ & 1 & 22 & 1 & 30 & 1 & 12 & 8 & $11 / 13$ & \begin{tabular}{|l|} 
Z2 94.122 \\
\end{tabular} & 1 & 1 & 1 & 1 \\
\hline Z1 44.61 & $x$ & 15 & 16 & 1 & 1 & 28 & 1 & 1 & 1 & 9 & Z2 94.110 & 1 & 1 & 1 & 1 \\
\hline Z1 57.78 & $\overline{X Y}$ & $(16) / 17$ & 1 & 15 & $13 / 16$ & $29 / 30$ & 17 & 12 & 11 & $8 / 11$ & Z2 102.121 & 1 & 12 & 1 & 1 \\
\hline Z1 67.84 & 1 & 1 & 1 & 1 & 1 & 1 & 1 & 1 & 1 & 1 & Z2 102.120 & 1 & 1 & 1 & 1 \\
\hline Z2 79.93 & $\overline{X Y}$ & 1 & 1 & 1 & $13 / 15$ & 29 & 1 & $10 / 12$ & $8 / 13$ & 1 & K 113.126 & 1 & 1 & 1 & 1 \\
\hline Z2 83.95 & 1 & 1 & 1 & 1 & 1 & 1 & 1 & 1 & 1 & 1 & & & & & \\
\hline Z2 94.102 & $\overline{X Y}$ & 15 & 16 & 1 & $13 / 15$ & 1 & 16 & 12 & 1 & 1 & & & & & \\
\hline Z2 102.111 & $X Y$ & 15 & $15 / 16$ & 1 & 13 & 30 & $14 / 17$ & 12 & 12 & 1 & & & & & \\
\hline K 113.123 & 1 & 1 & 1 & 1 & 1 & 1 & 1 & 1 & 1 & 1 & & & & & \\
\hline K 117.131 & $\bar{Y}$ & $15 / 17$ & 1 & 22 & $14 / 15$ & $29 / 33.2$ & 15 & $12 /(13)$ & 12 & 1 & & & & & \\
\hline Genotyp & $X Y$ & $15 / 17$ & $16 / 16$ & 22 & $13 / 15$ & $29 / 30$ & 17 & $12 / 12$ & $8 / 12$ & 11 & Haplotyp & 1 & 1 & I & I \\
\hline \multicolumn{16}{|c|}{ WG 256 (3 Zähne) } \\
\hline Ex/PCR & Amelo. & 10.54 .2 & VWA & FGA & D8S1179 & $10.55 \quad \mathrm{D}$ & D18S51 & 10.55 .1 & D13S317 & D7S820 & Ex/PCR & DYS19 & DYS3891 & DYS389II & DYS390 \\
\hline Z2 44.61 & $X Y$ & $16 / 18$ & $14 / 16$ & $19 / 23$ & $9 / 11 / 12$ & 30 & 15 & 11 & 1 & 8 & Z1 11.28a & 16 & 1 & 1 & 1 \\
\hline
\end{tabular}




\begin{tabular}{|c|c|c|c|c|c|c|c|c|c|c|c|c|c|c|c|}
\hline Z2 57.78 & $\mathrm{XY}$ & $15 / 16 / 18$ & $14 / 17$ & 23 & $11 / 13 / 15$ & 29 & $14 / 18$ & 12 & $11 / 12$ & 9 & Z1 11.28b & 1 & 1 & 1 & 1 \\
\hline Z3 112.123 & $x$ & 15 & 1 & 22 & 10 & 30 & 1 & 12 & 12 & 1 & Z3 112.126 & 1 & 1 & 1 & 1 \\
\hline Genotyp & $\mathbf{X Y}$ & $16 / 18$ & 14 & 23 & 1 & 30 & 1 & 12 & 12 & I & Haplotyp & 1 & 1 & I & I \\
\hline \multicolumn{16}{|c|}{ WG 257 (Zahn 47, Femur) } \\
\hline Ex/PCR & Amelo. & 10.55 .2 & VWA & FGA & D8S1179 & $10.56 \quad \mathrm{D}$ & D18S51 & 10.56 .1 & D13S317 & D7S820 & Ex/PCR & DYS19 & DYS3891 & DYS389II & DYS390 \\
\hline Z1 21.39 & $X Y$ & 18 & 1 & $20 / 21 / 22$ & $(11) / 12$ & 29 & 1 & 1 & 1 & 1 & Z1 21.41 & 16 & 12 & 1 & 1 \\
\hline Z124.40 & $\mathrm{XY}$ & 15 & 14 & 1 & $11 / 12 / 13$ & 30 & 1 & $12 /(13) / 14$ & 11 & 12 & Z121.43 & 1 & 12 & 1 & 1 \\
\hline Z1 24.42 & $X Y$ & $14 / 16 / 18$ & 14 & 21 & $11 / 13$ & $28 / 29$ & 14 & 10 & 1 & 1 & Z1 24.41 & 1 & 13 & 30 & 25 \\
\hline Z127.46 & $\mathrm{Y}$ & 18 & 1 & 1 & 1 & 1 & 1 & 1 & $\frac{1}{1}$ & $\frac{1}{1}$ & Z193.109 & 16 & 12 & 1 & 1 \\
\hline Z1 67.84 & 1 & $17 / 18$ & 1 & 1 & $13 / 14$ & $29 / 33$ & 14 & 1 & $8 / 12$ & 9 & K 114.126 & 1 & 1 & 1 & 1 \\
\hline Z193.102 & $x$ & 1 & 14 & 24 & $12 / 13$ & 1 & 1 & $11 / 12$ & 10 & 1 & & & & & \\
\hline K 114.125 & $\mathrm{x}$ & 1 & 1 & 1 & 1 & 1 & 1 & 11 & 1 & I & & & & & \\
\hline Genotyp & $\mathrm{XY}$ & 18 & $14 /(14)$ & 21 & $11 / 12 / 13$ & 29 & 14 & 1 & 1 & 1 & Haplotyp & 16 & 12 & I & 1 \\
\hline \multicolumn{16}{|c|}{ WG 258 (Zahn) } \\
\hline Ex/PCR & Amelo. & 10.56 .2 & VWA & FGA & D8S1179 & 10.57 & D18S51 & 10.57 .1 & D13S317 & D7S820 & Ex/PCR & DYS19 & DYS3891 & DYS389II & DYS390 \\
\hline Z1 99.105 & $\mathrm{x}$ & $15 / 18$ & 1 & 1 & 1 & 1 & 1 & 1 & 12 & 1 & & & & & \\
\hline Z1 103.112 & 1 & 1 & 1 & 1 & 1 & 1 & 1 & 1 & 1 & 1 & & & & & \\
\hline Genotyp & 1 & I & 1 & 1 & I & I & 1 & 1 & 1 & I & Haplotyp & & & & \\
\hline \multicolumn{16}{|c|}{ WG 259 (Zahn 37) } \\
\hline Ex/PCR & Amelo. & 10.57 .2 & VWA & FGA & D8S1179 & 10.58 & D18S51 & 10.58 .1 & D13S317 & D7S820 & Ex/PCR & DYS19 & DYS3891 & DYS389II & DYS390 \\
\hline Z1 67.84 & 1 & 1 & 1 & 1 & 1 & 1 & 1 & 1 & 1 & 1 & & & & & \\
\hline$Z 183.95$ & 1 & 1 & 1 & 1 & 1 & 1 & 1 & 1 & 1 & 1 & & & & & \\
\hline Genotyp & 1 & 1 & 1 & 1 & 1 & 1 & 1 & 1 & I & I & Haplotyp & & & & \\
\hline \multicolumn{16}{|c|}{ WG 260 (Zahn 55) } \\
\hline Ex/PCR & Amelo. & 10.58 .2 & VWA & FGA & D8S1179 & \begin{tabular}{ll|}
10.59 & $\mathrm{D}$ \\
\end{tabular} & D18S51 & 10.59 .1 & D13S317 & D7S820 & Ex/PCR & DYS19 & DYS3891 & DYS389II & DYS390 \\
\hline Z1 67.84 & 1 & 1 & 1 & 1 & 1 & 1 & 1 & 1 & 1 & 1 & & & & & \\
\hline Z1 83.95 & 1 & 17 & $(20) / 21 / 22$ & 1 & 1 & 1 & 1 & 1 & 1 & 1 & & & & & \\
\hline Genotyp & $I$ & 1 & 1 & $I$ & $I$ & $I$ & 1 & 1 & 1 & 1 & Haplotyp & & & & \\
\hline \multicolumn{16}{|c|}{ WG 270 (Zahn 37, Zahn 18) } \\
\hline Ex/PCR & Amelo. & 10.59 .2 & VWA & FGA & D8S1179 & $10.60 \quad \mathrm{D}$ & D18S51 & 10.60 .1 & D13S317 & D7S820 & Ex/PCR & DYS19 & DYS3891 & DYS389II & DYS390 \\
\hline Z1 21.39 & $X Y$ & 17 & $15 / 17$ & $20 / 21$ & $10 / 12$ & $28 / 29 / 31.2$ & 16 & $12 / 13$ & 12 & $9 / 14$ & Z1 21.41 & 14 & 12 & 1 & 23 \\
\hline Z1 24.40 & $\overline{X Y}$ & $15 /(16) / 17$ & 1 & 21 & 12 & 29 & 16 & 13 & 1 & 1 & $Z 121.43$ & 14 & $12 / 14$ & 1 & 23 \\
\hline Z1 24.42 & $X Y$ & 17 & $15 / 17$ & 1 & $10 / 12$ & 31.2 & 1 & 13 & 13 & 1 & Z1 24.41 & 14 & 12 & 28 & \\
\hline Z1 27.46a & $X Y$ & 17 & $15 / 17$ & $21 / 24$ & $10 / 12$ & 31.2 & 1 & 1 & 10 & 1 & Z1 38.85 & 1 & 12 & 28 & 1 \\
\hline Z1 27.46b & $X Y$ & 17 & $15 / 18$ & 20 & $10 / 12$ & 1 & 1 & 13 & 12 & 1 & & & & & \\
\hline Z1 27.46a & $\mathrm{x}$ & 17 & 1 & $20 / 21$ & $10 / 12$ & 1 & 1 & 1 & 1 & I & & & & & \\
\hline
\end{tabular}




\begin{tabular}{|c|c|c|c|c|c|c|c|c|c|c|c|c|c|c|c|}
\hline Z1 27.46b & $\mathrm{XY}$ & 17 & 16 & 1 & 10 & 1 & 13 & 12 & 1 & 1 & & & & & \\
\hline Z138.58 & $\mathrm{XY}$ & $15 / 17$ & $14 / 17$ & 20/21/21.2 & 12 & 1 & $15 / 18$ & 12 & $10 / 11 / 12$ & 10 & & & & & \\
\hline Z1 40.59 & $\mathrm{XY}$ & 17 & 1 & 21 & $12 / 13$ & 1 & 1 & $11 / 13$ & 1 & 1 & & & & & \\
\hline Z2 44.61 & 1 & 1 & 1 & 1 & 1 & 1 & 1 & 1 & 1 & 1 & & & & & \\
\hline Z2 67.84 & 1 & 1 & 1 & 1 & 1 & 1 & 1 & 1 & 1 & 1 & & & & & \\
\hline Genotyp & $\mathrm{XY}$ & $17 /(17)$ & $15 / 17$ & $20 / 21$ & 10/12 & 29/31.2 & 16 & $12 / 13$ & $10 / 12$ & 1 & Haplotyp & 14 & 12 & 28 & 23 \\
\hline \multicolumn{16}{|c|}{ WG 271 (Zahn 17) } \\
\hline Ex/PCR & Amelo. & 10.60 .2 & VWA & FGA & D8S1179 & $10.61 \mathrm{D}$ & D18S51 & 10.61 .1 & D13S317 & D7S820 & Ex/PCR & DYS19 & DYS3891 & DYS389II & DYS390 \\
\hline Z1 99.105 & 1 & 1 & 1 & 1 & 1 & 1 & 1 & 1 & 1 & 1 & & & & & \\
\hline Genotyp & $I$ & 1 & $I$ & 1 & 1 & $I$ & $I$ & 1 & 1 & 1 & Haplotyp & & & & \\
\hline \multicolumn{16}{|c|}{ WG 272 (Zahn 48, Zahn 45) } \\
\hline Ex/PCR & Amelo. & 10.61 .2 & VWA & FGA & D8S1179 & $10.62 \mathrm{D}$ & D18S51 & 10.62 .1 & D13S317 & D7S820 & Ex/PCR & DYS19 & DYS3891 & DYS389II & DYS390 \\
\hline Z1 57.78 & 1 & 15 & 1 & 22 & 1 & 1 & 1 & 1 & 1 & 1 & & & & & \\
\hline Z2 100.105 & $X Y$ & 17 & 1 & 23 & $10 / 15 / 16$ & 29 & 17 & 13 & 8 & 11 & & & & & \\
\hline Z2 110.119 & $\mathrm{x}$ & 15 & 14 & 1 & 1 & 1 & 1 & 12 & 1 & 1 & & & & & \\
\hline Genotyp & 1 & 15 & 1 & 1 & 1 & $I$ & 1 & 1 & 1 & 1 & Haplotyp & & & & \\
\hline \multicolumn{16}{|c|}{ WG 275 (Zahn 47, Zahn 46, Femur) } \\
\hline Ex/PCR & Amelo. & 10.62 .2 & VWA & FGA & D8S1179 & $10.63 \mathrm{D}$ & D18S51 & 10.63 .1 & D13S317 & D7S820 & Ex/PCR & DYS19 & DYS3891 & DYS389II & DYS390 \\
\hline Z1 40.39 & $X Y$ & 15 & 16 & 22 & $(12) 13 / 15$ & 30.2 & 15 & 11 & 11 & 8 & Z1 40.65 & 1 & 12 & 1 & 23 \\
\hline Z1 57.78 & $\overline{X Y}$ & 15 & 16 & 22 & $13 / 15$ & 30.2 & 13 & 11 & 11 & 1 & Z1 79.98 & 14 & 12 & 1 & 23 \\
\hline Z1 68.84 & 1 & I & 1 & 1 & 1 & 1 & 1 & 1 & 1 & 1 & Z1 79.110 & 14 & 12 & 1 & 1 \\
\hline Z1 79.93 & $X Y$ & $15 / 16$ & $15 / 16 / 18$ & 26 & $13 / 14 / 15$ & $29 / 30.2$ & 14 & $11 / 12$ & 12 & 11 & K 113.126 & 1 & 1 & 1 & 1 \\
\hline Z2 79.93 & 1 & 1 & 1 & 1 & 1 & 1 & 1 & 1 & 1 & 1 & & & & & \\
\hline Z2 83.95 & $\mathrm{XY}$ & 1 & 17 & 1 & 13 & 30.2 & 16 & 1 & 1 & 1 & & & & & \\
\hline K 113.124 & $x$ & 15 & 16 & 1 & 1 & 31 & 1 & 12 & 8 & 1 & & & & & \\
\hline K 115.127 & $x$ & 16 & $16 / 17$ & $22 / 25$ & 15 & 29 & 1 & 12 & 11 & 1 & & & & & \\
\hline $\mathrm{K} 117.131$ & $X Y$ & $15 / 19$ & $16 / 17$ & $19 / 24 / 25 / 26$ & 13 & $27 / 31$ & 19 & 11 & 10(11)(12)13 & $9 / 11$ & & & & & \\
\hline Genotyp & $\mathrm{XY}$ & $15 / 16$ & $16 / 17$ & 22 & $13 / 15$ & 30.2 & $I$ & $11 / 12$ & 11 & 11 & Haplotyp & 14 & 12 & 1 & 23 \\
\hline \multicolumn{16}{|c|}{ WG 278 (Zahn 38) } \\
\hline Ex/PCR & Amelo. & 10.63 .2 & VWA & FGA & D8S1179 & $10.64 \quad \mathrm{D}$ & D18S51 & 10.64 .1 & D13S317 & D7S820 & Ex/PCR & DYS19 & DYS3891 & DYS389II & DYS390 \\
\hline Z1 29.48 & $x$ & 15 & $16 / 18$ & 22 & $12 / 14$ & 30 & 1 & 12 & $8 /(11) 12$ & 10 & Z1 29.55 & 1 & 14 & 1 & 25 \\
\hline Z1 29.51 & $\overline{X Y}$ & 15 & $(16) 17 / 18$ & 22 & $12 /(13) / 14$ & 1 & 17 & $11 / 12$ & $8 / 12 / 13$ & $9 / 10$ & Z1 34.55 & 1 & 1 & 1 & 1 \\
\hline Z1 34.53 & $x$ & 15 & 18 & 1 & 12 & 30 & 1 & 1 & 10 & 9 & & & & & \\
\hline Z1 68.84 & $X Y$ & 1 & 1 & 22 & 1 & 1 & 1 & 1 & 1 & 1 & & & & & \\
\hline Genotyp & $\mathrm{XY}$ & $15 / 15$ & $(16) / 18$ & $22 / 22$ & $12 /(14)$ & 30 & $I$ & (12) & $(8 / 12)$ & $9 /(10)$ & Haplotyp & 1 & 1 & 1 & 1 \\
\hline
\end{tabular}




\begin{tabular}{|c|c|c|c|c|c|c|c|c|c|c|c|c|c|c|c|}
\hline Ex/PCR & Amelo. & 10.64 .2 & VWA & FGA & D8S1179 & $10.65 \mathrm{D}$ & D18S51 & 10.65 .1 & D13S317 & D7S820 & Ex/PCR & DYS19 & DYS389I & DYS389II & DYS390 \\
\hline Z15.9a & $X Y$ & $14(15) / 16 / 18$ & 14 & 23 & 13 & $25 / 32.2$ & 1 & 11 & 1 & 1 & Z1 5.10a & 16 & (12) & 1 & 1 \\
\hline Z1 5.9b & $x$ & 18 & 14 & 1 & 1 & 32.2 & 1 & 1 & 11 & 1 & $\mathrm{Z1} \mathrm{5.10b}$ & 1 & 1 & 1 & 1 \\
\hline Z1 5.11a & $X Y$ & $15 / 16$ & $14 / 20$ & $20 / 23$ & $14 / 15$ & 29 & 1 & $11 / 12$ & 1 & 11 & Z1 5.12a & / & 15 & I & 22 \\
\hline Z1 5.11b & $\mathrm{Y}$ & $16 / 18$ & 17 & 1 & $14 / 15$ & $25 / 29$ & 1 & 11 & 1 & 1 & Z1 7.18a & 1 & 1 & 1 & 1 \\
\hline Z1 7.16a & $X Y$ & $15 / 18$ & 14 & 1 & 13 & 29 & 1 & 11 & 1 & 8 & $\mathrm{Z1} \mathrm{7.18b}$ & 1 & 12 & 30 & 1 \\
\hline Z1 7.16b & Ü.a. & $13 / 16 / 18$ & $14 / 17$ & 1 & $13 / 15$ & 29 & 1 & 11 & 11 & 1 & $\mathrm{Z1} 7.18 \mathrm{c}$ & 16 & 1 & 1 & 1 \\
\hline Z17.17a & $X Y$ & $16 / 18$ & 1 & $23 / 26$ & $13 / 15$ & 1 & 1 & 1 & 1 & 8 & Z1 15.33a & 15 & 12 & 1 & 1 \\
\hline $\mathrm{Z17.17b}$ & $X Y$ & $16 / 18$ & 14 & $20 / 23$ & $13 / 15$ & 32.2 & 1 & 11 & 1 & 11 & Z1 15.33b & 1 & 12 & 1 & 1 \\
\hline Z1 15.34 & $X Y$ & $16 / 18$ & 20 & 1 & 14 & $29 / 30$ & 13 & 11 & $11 / 13$ & 10 & Z1 30.50a & 16 & 1 & 30 & 1 \\
\hline Z1 30.48 & $\mathrm{XY}$ & $16 / 18$ & $14 / 20$ & 1 & $13 / 14$ & $29 / 30$ & 1 & 11 & 11 & $8 / 11$ & Z1 30.50b & 16 & 1 & 1 & 1 \\
\hline Z1 34.53 & $\mathrm{Y}$ & $16 / 18$ & 1 & 20 & 13 & 1 & 1 & $10 / 13$ & 11 & I & Z2 45.65 & 16 & 12 & 1 & 25 \\
\hline Z2 45.61 & $X Y$ & 18 & $14 / 20$ & $20 / 23$ & $13 / 15$ & 32.2 & 14 & 11 & 13 & 1 & & & & & \\
\hline Z2 68.84 & $X Y$ & 1 & 1 & 1 & $14 / 15$ & 1 & 16 & $11 /(12)$ & 1 & 1 & & & & & \\
\hline Z2 81.94 & $\mathrm{XY}$ & $(15) / 16$ & 1 & 23 & 15 & 29 & 15 & 1 & 11 & 1 & & & & & \\
\hline Z2 102.111 & $X Y$ & 1 & 1 & 1 & 13 & 1 & 1 & 1 & 1 & 1 & & & & & \\
\hline Genotyp & $\overline{X Y}$ & $16 / 18$ & $14 / 20$ & $20 / 23$ & $13 / 14 / 15$ & $29 / 32.2$ & 1 & $11 /(12)$ & $11 / 13$ & $8 / 11$ & Haplotyp & 16 & 12 & 30 & 1 \\
\hline \multicolumn{16}{|c|}{ WG 283 (Zahn 34, Zahn 43) } \\
\hline Ex/PCR & Amelo. & 10.65 .2 & VWA & FGA & D8S1179 & $10.66 \quad \mathrm{D}$ & $\mathrm{D} 18 \mathrm{~S} 51$ & \begin{tabular}{|l|}
10.66 .1 \\
\end{tabular} & D13S317 & D7S820 & Ex/PCR & DYS19 & DYS3891 & DYS389II & DYS390 \\
\hline Z15.9a & $\mathrm{Y}$ & 1 & 17 & 1 & 1 & 29 & 1 & 11 & 1 & 1 & Z1 5.10a & 1 & 1 & 1 & 1 \\
\hline $\mathrm{Z1} \mathrm{5.9b}$ & $\mathrm{x}$ & $(14) / 15$ & (11) & 1 & 1 & 26 & 1 & 1 & 1 & 9 & Z1 5.10b & 1 & 1 & 1 & 1 \\
\hline Z15.11a & 1 & 15 & 1 & 1 & 1 & 1 & 1 & 1 & 1 & 1 & $\mathrm{Z} 15.12$ & 17 & 12 & 1 & 1 \\
\hline Z1 5.11b & $\mathrm{x}$ & $15 / 17$ & 1 & 1 & $(13) / 14$ & 1 & 1 & 11 & 1 & 1 & Z2 68.110 & 1 & 1 & 1 & 1 \\
\hline Z1 21.39 & $X Y$ & $16 / 17$ & 1 & 1 & $11 / 13 / 14$ & 1 & 1 & $10 /(11) / 12$ & 8 & 1 & & & & & \\
\hline Z1 24.40 & 1 & 1 & 1 & 1 & 14 & $29 / 30$ & 1 & 1 & 1 & 1 & & & & & \\
\hline Z2 35.54 & $x$ & $15 / 17$ & 19 & 1 & 14 & 1 & 1 & 1 & 1 & 1 & & & & & \\
\hline Z2 68.84 & $\mathrm{Y}$ & 1 & 1 & 21 & 14 & 1 & 18 & $11 / 12$ & 1 & 1 & & & & & \\
\hline Genotyp & $\mathrm{XY}$ & $15 / 17$ & 1 & 1 & $14 / 14$ & 29 & 1 & $11 / 12$ & $I$ & 1 & Haplotyp & 1 & 1 & 1 & $I$ \\
\hline \multicolumn{16}{|c|}{ WG 293 (Zahn 48) } \\
\hline Ex/PCR & Amelo. & 10.66 .2 & VWA & FGA & D8S1179 & $10.67 \quad \mathrm{D}$ & D18S51 & \begin{tabular}{|l|}
10.67 .1 \\
\end{tabular} & D13S317 & D7S820 & Ex/PCR & DYS19 & DYS3891 & DYS389II & DYS390 \\
\hline Z1 100.105 & $x$ & 1 & 1 & 1 & $11 / 13$ & 1 & 1 & 1 & 1 & 1 & & & & & \\
\hline Genotyp & 1 & $I$ & $I$ & 1 & 1 & $I$ & I & 1 & $I$ & 1 & Haplotyp & & & & \\
\hline \multicolumn{16}{|c|}{ WG 298 (Zähne) } \\
\hline Ex/PCR & Amelo. & 10.67 .2 & VWA & FGA & D8S1179 & 10.68 & D18S51 & 10.68 .1 & D13S317 & D7S820 & Ex/PCR & DYS19 & DYS3891 & DYS389II & DYS390 \\
\hline Z1 68.84 & 1 & 1 & 1 & 1 & 1 & 1 & 1 & 1 & 1 & 1 & & & & & \\
\hline Z2 81.94 & 1 & 1 & 1 & 1 & 1 & 1 & 1 & 1 & 1 & I & & & & & \\
\hline
\end{tabular}




\begin{tabular}{|c|c|c|c|c|c|c|c|c|c|c|c|c|c|c|c|}
\hline Genotyp & I & I & 1 & 1 & I & I & I & 1 & I & 1 & Haplotyp & & & & \\
\hline \multicolumn{16}{|c|}{ WG 303 (Zahn 23, Zahn 18, Femur) } \\
\hline Ex/PCR & Amelo. & 10.68 .2 & VWA & FGA & D8S1179 & \begin{tabular}{ll|}
10.69 & $\mathrm{D}$ \\
\end{tabular} & D18S51 & 10.69 .1 & D13S317 & D7S820 & Ex/PCR & DYS19 & DYS3891 & DYS389II & DYS390 \\
\hline Z1 25.44 & $X Y$ & $14 / 18$ & 17 & 23 & $13 /(14)$ & 31.2 & 1 & $11 /(12)$ & 12 & & \begin{tabular}{|l|} 
Z1 32.50a \\
\end{tabular} & 1 & 1 & 1 & 1 \\
\hline Z1 32.49 & $\mathrm{XY}$ & 14 & 17 & 23 & $13 / 14$ & $29 / 31.2$ & 1 & $11 / 12$ & 1 & 1 & Z1 32.50b & 1 & 1 & 1 & 1 \\
\hline Z1 32.51 & $\mathrm{XY}$ & $14 / 18$ & 17 & 23 & $13 / 14$ & $29 / 31.2$ & 1 & $11 / 12$ & $\frac{1}{1}$ & $\frac{1}{1}$ & Z1 38.35 & 14 & 12 & 28 & 22 \\
\hline Z1 38.58 & $\overline{X Y}$ & $(14) / 15$ & 17 & 23 & 13 & 1 & 12 & 1 & 1 & 1 & Z1 79.98 & 14 & 12 & 1 & 22 \\
\hline Z1 68.84 & $\mathrm{x}$ & 14 & $17 / 18$ & 23 & $13 / 14$ & 32 & 1 & $(10) / 11$ & 11 & 10 & & & & & \\
\hline Z1 79.93 & $\mathrm{XY}$ & 14 & 17 & 23 & $8 / 13$ & 29 & 14 & $11 / 12$ & 12 & 11 & & & & & \\
\hline Z2 79.93 & $\mathrm{XY}$ & $14 / 18$ & 1 & 1 & 1 & 1 & 1 & 12 & 1 & 10 & & & & & \\
\hline Z2 100.93 & $X Y$ & $14 / 18$ & 1 & 1 & 13 & 1 & 1 & 1 & 1 & 1 & & & & & \\
\hline Z2 102.111 & $X Y$ & 1 & 1 & 1 & 14 & 1 & 1 & 1 & 1 & 1 & & & & & \\
\hline K 108.128 & $\mathrm{Y}$ & 1 & 1 & 1 & 14 & 31.2 & 15 & 11 & 1 & 1 & & & & & \\
\hline K 117.131 & $x$ & $15 / 18$ & 16 & 1 & $11 / 13 / 14$ & 30 & 1 & 12 & 1 & $8 / 11$ & & & & & \\
\hline Genotyp & $\mathrm{XY}$ & 14/18 & $17 / 17$ & $23 / 23$ & $13 / 14$ & $29 / 31.2$ & 1 & $11 / 12$ & 12 & 10 & Haplotyp & 14 & 12 & 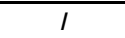 & 22 \\
\hline \multicolumn{16}{|c|}{ WG 313 (Zahn 37, Zahn 38) } \\
\hline Ex/PCR & Amelo. & 10.69 .2 & VWA & FGA & D8S1179 & \begin{tabular}{ll|}
10.70 & $\mathrm{D}$ \\
\end{tabular} & D18S51 & 10.70 .1 & D13S317 & D7S820 & & & & & \\
\hline Z1 31.49 & $\mathrm{x}$ & 1 & 17 & 1 & 1 & 1 & 1 & 1 & 1 & 1 & & & & & \\
\hline Z1 68.84 & 1 & 1 & 1 & 1 & 1 & 28 & 1 & 1 & 1 & 1 & & & & & \\
\hline Z1 81.94 & $x$ & 15 & $16 / 17$ & 1 & 14 & 1 & 1 & 11 & 1 & 1 & & & & & \\
\hline Z2 100.105 & 1 & 1 & 1 & 1 & 1 & 1 & 1 & 1 & 1 & 1 & & & & & \\
\hline Z2 103.112 & 1 & 1 & 1 & 1 & 1 & 1 & 1 & 1 & 1 & 1 & & & & & \\
\hline Z2 110.119 & $x$ & 18 & 1 & 1 & 1 & 1 & 1 & 1 & 1 & 1 & & & & & \\
\hline Genotyp & $x x$ & 1 & 1 & 1 & 1 & 1 & 1 & $I$ & 1 & 1 & & & & & \\
\hline \multicolumn{16}{|c|}{ WG 322 (Zahn) } \\
\hline Ex/PCR & Amelo. & 10.70 .2 & VWA & FGA & D8S1179 & $10.71 \quad D$ & D18S51 & 10.71 .1 & D13S317 & D7S820 & & & & & \\
\hline Z1 81.94 & $x$ & 15 & 17 & $19 / 21$ & 13 & 33 & 1 & 10 & 12 & 1 & & & & & \\
\hline Z1 90.100 & $\mathrm{x}$ & $17 / 18$ & 1 & 22 & 15 & 28 & 1 & 12 & 1 & 1 & & & & & \\
\hline Genotyp & $x x$ & 1 & 1 & 1 & 1 & 1 & 1 & 1 & 1 & 1 & & & & & \\
\hline \multicolumn{16}{|c|}{ WG 323 (Zahn 21) } \\
\hline Ex/PCR & Amelo. & 10.71 .2 & VWA & FGA & D8S1179 & $10.72 \quad D$ & D18S51 & 10.72 .1 & D13S317 & D7S820 & Ex/PCR & DYS19 & DYS389I & DYS389II & DYS390 \\
\hline Z1 20.37a & 1 & 1 & 1 & 1 & 1 & 1 & 1 & 1 & 1 & 1 & & & & & \\
\hline Z1 20.37 & 1 & 1 & 1 & 1 & 1 & 1 & 1 & 1 & 1 & 1 & & & & & \\
\hline Z1 20.38 & $\mathrm{Y}$ & 1 & 1 & 1 & 11 & 30 & 1 & 1 & 1 & 1 & & & & & \\
\hline
\end{tabular}




\begin{tabular}{|c|c|c|c|c|c|c|c|c|c|c|c|c|c|c|c|}
\hline Z1 42.60 & 1 & 1 & 1 & 1 & 1 & 1 & 1 & I & I & l & & & & & \\
\hline Genotyp & 1 & 1 & 1 & 1 & I & 1 & 1 & 1 & 1 & I & Haplotyp & & & & \\
\hline \multicolumn{16}{|c|}{ WG 326 (Zahn 46, Zahn 45) } \\
\hline Ex/PCR & Amelo. & 10.72 .2 & VWA & FGA & D8S1179 & $10.73 \mathrm{D}$ & D18S51 & 10.73 .1 & D13S317 & D7S820 & Ex/PCR & DYS19 & DYS3891 & DYS389II & DYS390 \\
\hline Z1 6.13a & $\mathrm{XY}$ & $15 /(17) /(18)$ & 19 & $19 / 22$ & $11 / 15$ & 1 & 1 & 11/12/13 & $10 / 12$ & 10 & Z16.15a & 15 & $13 / 14$ & $29 / 30 / 31$ & 1 \\
\hline Z1 6.13b & $X Y$ & $(15) / 16$ & 17 & 19 & $11 / 15$ & 1 & 15 & $11 / 13$ & 1 & 1 & Z1 6.15b & 1 & $13 / 14$ & 1 & 23 \\
\hline Z1 6.14a & Ü.a & $16 / 19$ & $(17) / 18$ & $19 / 22$ & $11 / 15$ & 1 & 1 & $11 / 13$ & $10 / 12$ & I & Z1 22.41 & 15 & 13 & 1 & 1 \\
\hline Z1 22.39 & $X Y$ & 16 & $17 / 18$ & $19 / 22$ & $11 / 15$ & 1 & 1 & $11 / 13$ & $10 / 12$ & 1 & Z1 22.43 & 15 & 13 & 1 & 1 \\
\hline Z1 23.40 & $X Y$ & $16 / 19$ & 17 & 22 & $11 / 15$ & 28 & 1 & $8 /(10) / 11$ & $10 / 12$ & 1 & Z1 23.41 & 1 & 1 & 1 & 1 \\
\hline Z2 20.37a & 1 & 1 & 16 & 21 & 1 & 26 & 14 & 1 & 1 & 10 & Z2 38.85 & 15 & 13 & 1 & 23 \\
\hline Z2 20.37b & $\mathrm{Y}$ & $(14) / 15$ & 1 & 1 & 1 & 1 & 1 & 1 & $11 / 13$ & 9 & & & & & \\
\hline Z2 20.38 & 1 & 1 & 1 & 1 & 1 & 1 & 1 & 1 & 1 & 1 & & & & & \\
\hline Z2 38.58 & $X Y$ & $16 /(18) / 19$ & $15 / 17 /(18)$ & $19 / 22$ & $11 / 15$ & 31.2 & 1 & $8 / 11 / 13$ & 12 & 9 & & & & & \\
\hline Z2 81.94 & $X Y$ & $16 / 19$ & 18 & 23 & 15 & 28 & 18 & 1 & 1 & 1 & & & & & \\
\hline Genotyp & $X Y$ & $16 / 19$ & $17 / 18$ & $19 / 22$ & $11 / 15$ & 28 & 1 & $11 / 13$ & $10 / 12$ & 10 & Haplotyp & 15 & 13 & 1 & 23 \\
\hline \multicolumn{16}{|c|}{ WG 330 (4 Zähne) } \\
\hline Ex/PCR & Amelo. & 10.73 .2 & VWA & FGA & D8S1179 & $10.74 \quad \mathrm{D}$ & D18S51 & \begin{tabular}{|l|l|}
10.74 .1 \\
\end{tabular} & D13S317 & D7S820 & Ex/PCR & DYS19 & DYS389I & DYS389II & DYS390 \\
\hline Z1 6.13a & $X Y$ & $16 / 17$ & $15 / 18$ & 23 & 14 & 28 & $12 / 15$ & $11 / 12$ & 11 & 1 & Z16.15 a & 13 & 1 & 1 & 1 \\
\hline Z1 6.13b & $X Y$ & $15 / 16$ & $14 / 17$ & 21 & $13 / 14$ & 1 & 19 & $11 / 12$ & 1 & 1 & $\mathrm{Z} 16.15 \mathrm{~b}$ & 13 & 13 & 1 & 1 \\
\hline Z1 6.14 & Ü.a & $(15) / 16 / 17$ & 16/17 & 20 & (13)/14 & 1 & 19 & 11 & 1 & 1 & Z1 18.36 & 1 & 1 & 1 & 1 \\
\hline Z1 23.41 & 1 & 1 & 1 & 1 & $13 / 14$ & 29 & $12 / 19$ & $11 / 12 / 13$ & 13 & 1 & Z1 22.41 & 13 & 13 & 1 & 24 \\
\hline Z1 23.40 & $X Y$ & 16 & 14 & 1 & 14 & 29 & 1 & 11 & 11 & 1 & Z1 23.41 & 14 & $12 / 14$ & 28 & $22 / 24$ \\
\hline Z1 18.35a & $\mathrm{XY}$ & 16 & 16/17 & 1 & $11 / 14$ & $29 / 30$ & 1 & $11 / 12$ & 13 & 1 & Z1 22.43 & 13 & 13 & 30 & 24 \\
\hline Z1 18.35b & $\mathrm{Y}$ & 15/16/17 & 17 & 23 & (13)/14 & 1 & 1 & 1 & 1 & 1 & Z2 36.62 & 1 & 1 & 1 & 1 \\
\hline Z2 24.42 & $X Y$ & (15)(16)17 & 17 & 1 & $13 / 14$ & 1 & 1 & $(11) / 12$ & 10 & 1 & Z4 94.121 & 13 & 1 & 1 & 1 \\
\hline Z2 33.52 & $\mathrm{Y}$ & $15 / 17$ & 15 & 1 & 1 & 1 & 1 & 1 & 1 & 1 & Z4 102.121 & 1 & 1 & 1 & 1 \\
\hline Z3 36.54 & $X Y$ & $16 / 17$ & $17 / 18$ & 24 & 1 & 1 & 1 & 1 & 11 & 1 & & & & & \\
\hline Z4 65.82 & 1 & 14 & $14 /(15)$ & 1 & 13 & 28 & 16 & 12 & 1 & 1 & & & & & \\
\hline Z1/Z2 81.84 & $x$ & 16 & $17 / 18$ & 23 & 14 & $(27) / 28$ & 1 & 1 & 1 & 1 & & & & & \\
\hline Z4 102.111 & $X Y$ & 16 & 17 & 1 & 1 & 1 & 1 & 1 & 1 & 1 & & & & & \\
\hline Genotyp & $X Y$ & $16 / 17$ & 14/17 & 23 & $13 / 14$ & $28 / 29$ & $12 / 19$ & $11 / 12$ & $11 / 13$ & 1 & Haplotyp & 13 & 13 & 1 & 24 \\
\hline \multicolumn{16}{|c|}{ WG 332 (Femur) } \\
\hline Ex/PCR & Amelo. & 10.74 .2 & VWA & FGA & D8S1179 & $10.75 \mathrm{D}$ & D18S51 & 10.75 .1 & D13S317 & D7S820 & Ex/PCR & DYS19 & DYS389| & DYS389II & DYS390 \\
\hline $\mathrm{K} 20.37 \mathrm{a}$ & 1 & 1 & 1 & 1 & 1 & 1 & 1 & 1 & 1 & 1 & & & & & \\
\hline K 20.37b & 1 & 1 & 1 & 1 & 1 & 1 & 1 & 1 & 1 & 1 & & & & & \\
\hline
\end{tabular}




\begin{tabular}{|c|c|c|c|c|c|c|c|c|c|c|c|c|c|c|c|}
\hline K 20.38 & 1 & 1 & 1 & 1 & 1 & 1 & 1 & 1 & 1 & 1 & & & & & \\
\hline Genotyp & 1 & 1 & 1 & 1 & 1 & 1 & 1 & 1 & 1 & 1 & Haplotyp & & & & \\
\hline \multicolumn{16}{|c|}{ WG 335 (Humerus) } \\
\hline Ex/PCR & Amelo. & 10.75 .2 & VWA & FGA & D8S1179 & $10.76 \quad D$ & D18S51 & 10.76.1 & D13S317 & D7S820 & Ex/PCR & DYS19 & DYS3891 & DYS389II & DYS390 \\
\hline K 2.1a & $\mathrm{x}$ & 15 & 1 & 23 & 1 & 1 & 1 & 11 & 1 & 1 & & & & & \\
\hline $\mathrm{K} 2.1 \mathrm{~b}$ & $x$ & $15 /(16)$ & 1 & 1 & 13 & 30 & 1 & 1 & 1 & 1 & & & & & \\
\hline Genotyp & 1 & 1 & $t$ & 1 & $\frac{1}{1}$ & 1 & 1 & 1 & 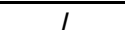 & $\frac{T}{1}$ & Haplotyp & & & & \\
\hline \multicolumn{16}{|c|}{ WG 342 (Zahn 36, Zahn 28) } \\
\hline Ex/PCR & Amelo. & 10.76 .2 & VWA & FGA & D8S1179 & \begin{tabular}{ll|}
10.77 & $\mathrm{D}$
\end{tabular} & D18S51 & 10.77 .1 & D13S317 & D7S820 & Ex/PCR & DYS19 & DYS3891 & DYS389II & DYS390 \\
\hline Z1 4.6a & $X Y$ & 15 & 16/17 & $(21) / 22$ & 15 & 1 & 14 & 12 & 15 & 10 & Z1 4.8 & 1 & 13 & 29 & 1 \\
\hline $\mathrm{Z1} \mathrm{4.6b}$ & $\mathrm{XY}$ & 1 & 16 & $22 / 25$ & 15 & 1 & 1 & $9 / 12$ & 13 & 1 & Z1 7.18a & 1 & 1 & 1 & $22 / 25$ \\
\hline $\mathrm{Z1} \mathrm{4.7a}$ & 1 & $(14) / 15$ & Ü.a. & $22 / 25$ & Ü.a. & 1 & 1 & 1 & 13 & 1 & $\mathrm{Z1} 7.18 \mathrm{~b}$ & 1 & 12 & 1 & 1 \\
\hline Z1 4.7b & Ü.a. & $15 / 17$ & 16 & $22 / 25$ & 15 & 1 & 1 & 12 & 10 & 10 & Z1 7.18c & 1 & 1 & 1 & 1 \\
\hline Z1 7.16a & $X Y$ & $15 / 16$ & 17 & $22 / 25$ & 14 & $26 / 30$ & 19 & 11 & $8 / 12$ & 1 & Z1 15.33a & 14 & 1 & 1 & 1 \\
\hline$Z 17.16 b$ & Ü.a. & 1 & 16 & 22 & 1 & 1 & 1 & 1 & 1 & 1 & Z1 15.33b & 14 & 13 & 1 & 1 \\
\hline $\mathrm{Z1} \mathrm{7.17a}$ & $\mathrm{Y}$ & $12 / 15$ & 1 & 1 & 1 & 1 & 1 & $8 / 12$ & 1 & 10 & \begin{tabular}{|l|} 
Z1 30.50a \\
\end{tabular} & 14 & 13 & 1 & 23 \\
\hline $\mathrm{Z1} \mathrm{7.17b}$ & $x$ & 1 & 17 & 24 & 10 & 30 & 1 & 1 & 1 & 1 & $\mathrm{Z1} 30.50 \mathrm{~b}$ & 16 & 13 & 1 & 1 \\
\hline Z1 15.34a & $\mathrm{XY}$ & $15 / 18$ & 16 & $22 / 23 / 25$ & 1 & 1 & 1 & 1 & 1 & 1 & Z2 47.68 & 14 & 13 & 1 & 23 \\
\hline Z1 30.48 & $\mathrm{XY}$ & 15 & $\begin{array}{l}(16) / 17 \\
\end{array}$ & $22 / 25$ & $10 / 15$ & $31.2 / 32.2$ & 1 & 12 & 13 & 10 & & & & & \\
\hline Z2 47.66 & $X Y$ & $15 / 17$ & $16 / 17$ & $22 / 25$ & $10 / 15$ & $31.2 / 32.2$ & 10 & 1 & 14 & 1 & & & & & \\
\hline Z2 63.81 & $X Y$ & 15 & 1 & & $10 / 15$ & 1 & $12 / 14$ & 1 & 14 & 10 & & & & & \\
\hline Z2 65.82 & $X Y$ & 15 & $16 / 17$ & $22 / 25$ & $10 / 15$ & 31.2 & 1 & 12 & 13 & 10 & & & & & \\
\hline Z2 82.84 & $\mathrm{X}$ & 15 & 1 & 1 & 1 & 32.2 & 1 & 1 & 1 & 1 & & & & & \\
\hline Z2 115.127 & $X Y$ & 15 & $16 / 17$ & $22 / 25$ & $10 / 15$ & $31.2 / 32.2$ & 1 & 12 & 13 & 1 & & & & & \\
\hline Genotyp & $X Y$ & $15 /(17)$ & $16 / 17$ & $22 / 25$ & $10 / 15$ & $31.2 / 32.2$ & 14 & $12 / 12$ & $13 / 14$ & $10 / 10$ & Haplotyp & 14 & 13 & 1 & 23 \\
\hline \multicolumn{16}{|c|}{ WG 344 (Zahn 47) } \\
\hline Ex/PCR & Amelo. & 10.77 .2 & VWA & FGA & D8S1179 & \begin{tabular}{|l|}
10.78 \\
$D$
\end{tabular} & D18S51 & 10.78.1 & D13S317 & D7S820 & & & & & \\
\hline Z1 57.58 & $x$ & 1 & 1 & 22 & 10 & 1 & 1 & 10 & 1 & 1 & & & & & \\
\hline Z1 90.100 & $x$ & 1 & 1 & 1 & 1 & 1 & 1 & 1 & 1 & 1 & & & & & \\
\hline Z1 103.112 & 1 & 1 & 1 & 1 & 1 & 1 & 1 & 1 & 1 & 1 & & & & & \\
\hline Genotyp & $x \mathrm{XX}$ & I & 1 & 1 & $I$ & $I$ & 1 & $I$ & $I$ & 1 & & & & & \\
\hline \multicolumn{16}{|c|}{ WG 348 (Zahn 37, Zahn 38) } \\
\hline Ex/PCR & Amelo. & 10.78 .2 & VWA & FGA & D8S1179 & \begin{tabular}{|l|}
10.79 \\
\end{tabular} & D18S51 & 10.79 .1 & D13S317 & D7S820 & & & & & \\
\hline Z1 27.46 & $\mathrm{x}$ & 17 & 1 & 1 & 15 & 1 & 1 & 13 & 1 & 1 & & & & & \\
\hline Z1 97.104 & $x$ & 14 & 1 & 1 & 1 & 1 & 1 & 1 & 1 & 1 & & & & & \\
\hline
\end{tabular}




\begin{tabular}{|c|c|c|c|c|c|c|c|c|c|c|c|c|c|c|c|}
\hline Z2 98.104 & $\mathrm{x}$ & 17 & 1 & 23 & 15 & 1 & 16 & 12 & 1 & 1 & & & & & \\
\hline Genotyp & $x \mathrm{XX}$ & 17 & 1 & 1 & 15 & 1 & 1 & 1 & I & I & & & & & \\
\hline \multicolumn{16}{|c|}{ WG 359 (Zahn 37, Zahn 38) } \\
\hline Ex/PCR & Amelo. & 10.79 .2 & VWA & FGA & D8S1179 & $10.80 \mathrm{D}$ & D18S51 & 10.80 .1 & D13S317 & D7S820 & Ex/PCR & DYS19 & DYS3891 & DYS389II & DYS390 \\
\hline Z1 6.13a & $\mathrm{x}$ & 15 & 18 & 21 & 11 & 1 & 1 & 1 & 12 & 10 & Z1 $6.15 \mathrm{a}$ & 1 & 1 & 1 & 1 \\
\hline Z1 6.13b & $X Y$ & 15 & 1 & 21 & 14 & 30 & 1 & $(11) 12(13)$ & 1 & 1 & $\mathrm{Z1} 6.15 \mathrm{~b}$ & 1 & 1 & 1 & 23 \\
\hline $\mathrm{Z} 16.14$ & $\mathrm{XY}$ & 16 & 1 & $21 / 23$ & 1 & 30 & 15 & 1 & 1 & 1 & Z1 18.36 & 1 & 1 & 1 & 1 \\
\hline Z1 18.35a & $X Y$ & $16 / 18$ & 18 & 1 & $11 / 14$ & 1 & 1 & 1 & 1 & 7 & Z2 36.62 & 1 & 13 & $\frac{1}{1}$ & $\frac{1}{1}$ \\
\hline Z1 18.35b & $X Y$ & 15 & 1 & 21 & 14 & 1 & 1 & $11 / 13$ & 1 & 1 & Z2 40.85 & 1 & 13 & 1 & 23 \\
\hline Z1 19.S1 & $X Y$ & 15 & 15/17 & 20 & 13/15 & $28 / 32.2$ & 12 & 12 & 11/12 & $11 / 12$ & & & & & \\
\hline Z2 36.54 & $X Y$ & (15)/16 & 18 & 21 & 1 & 1 & 1 & 13 & $10 / 12$ & 1 & & & & & \\
\hline Z2 40.59 & $X Y$ & $15 / 16$ & 18 & $21 / 23$ & $11 / 14$ & 30 & 1 & 11 & 1 & 1 & & & & & \\
\hline Z2 57.58 & $\mathrm{XY}$ & $15 / 16$ & 18 & $21 / 23$ & 11 & 28 & 1 & $11 / 13$ & 10 & 11 & & & & & \\
\hline Z2 82.94 & $X Y$ & $15 / 16$ & 18 & 21 & $11 / 14$ & $28 / 29 / 30$ & 1 & $811 / 12$ & 8 & 1 & & & & & \\
\hline Z2 63.129 & 1 & 16 & 18 & 1 & $11 / 14$ & 29 & 1 & $11 / 13$ & 1 & 1 & & & & & \\
\hline Genotyp & $\mathrm{XY}$ & $15 / 16$ & $18 / 18$ & $21 / 23$ & $11 / 14$ & $28 / 29 / 30$ & 1 & $11 / 13$ & $10 / 12$ & 1 & Haplotyp & 1 & 13 & 1 & 23 \\
\hline \multicolumn{16}{|c|}{ WG 363 (Zahn 37) } \\
\hline Ex/PCR & Amelo. & 10.80 .2 & VWA & FGA & D8S1179 & $10.81 \quad \mathrm{D}$ & D18S51 & 10.81 .1 & D13S317 & D7S820 & Ex/PCR & DYS19 & DYS3891 & DYS389II & DYS390 \\
\hline Z1 82.94 & $X Y$ & 16 & $14 / 17$ & $22 / 24$ & $14 / 18$ & 31.2 & 1 & 11 & 1 & 1 & & & & & \\
\hline Z190.100 & $\mathrm{x}$ & 16 & $17 / 19$ & 1 & 14 & 1 & 12 & 11 & 11 & 1 & & & & & \\
\hline Z1 100.105 & 1 & 1 & 1 & 1 & 1 & 1 & 1 & 1 & 1 & 1 & & & & & \\
\hline Genotyp & $X(Y)$ & 16 & 17 & 1 & 14 & 1 & 1 & \begin{tabular}{|l|}
11 \\
\end{tabular} & 1 & 1 & Haplotyp & & & & \\
\hline \multicolumn{16}{|c|}{ WG 374 (Zahn 38, Ulna) } \\
\hline Ex/PCR & Amelo. & 10.81 .2 & VWA & FGA & D8S1179 & $10.82 \quad \mathrm{D}$ & D18S51 & \begin{tabular}{|l|}
10.82 .1 \\
\end{tabular} & D13S317 & D7S820 & Ex/PCR & DYS19 & DYS3891 & DYS389II & DYS390 \\
\hline Z1 29.48 & $X Y$ & $(15) / 16 / 18$ & $15 / 17$ & $(20) / 21 / 24$ & $12 / 15$ & 29 & 1 & $9 / 11$ & $11 / 12 / 13$ & $9 / 12$ & Z1 29.55 & 1 & 1 & 1 & 1 \\
\hline Z1 29.51 & $X Y$ & $(16) / 17$ & 17 & 24 & $12 / 13$ & $28 / 29$ & $13 / 14 / 16$ & $9 / 12$ & $11 / 13$ & 12 & Z1 31.55a & 1 & 13 & 29 & 25 \\
\hline Z1 31.49 & $X Y$ & $(15) / 16 / 17$ & 15 & 20 & $12 / 13$ & $28 / 30 / 31$ & $13 / 16$ & 11 & $9 / 11$ & 1 & Z1 31.55b & 1 & 13 & 29 & 1 \\
\hline Z1 31.51 & $X Y$ & $14 / 16 /(17)$ & $17 / 19$ & $20 /(21) / 26$ & $13 / 15$ & $28 / 30 / 31$ & 16 & 11 & $12 / 13$ & 1 & & & & & \\
\hline Z1 34.53 & $\mathrm{x}$ & $15 / 17$ & $16 / 17 / 19$ & 20 & $12 / 15$ & 30 & 1 & 11 & $11 / 13$ & 1 & & & & & \\
\hline K 114.125 & 1 & 1 & 1 & 1 & 1 & 1 & 1 & 1 & 1 & 1 & & & & & \\
\hline Genotyp & $X Y$ & $15 / 16 / 17$ & $15 / 17 / 19$ & $20 / 24$ & $12 / 13 / 15$ & $28 / 30$ & $13 / 16$ & $9 / 11$ & $11 / 13$ & 12 & Haplotyp & $I$ & 13 & 29 & 1 \\
\hline \multicolumn{16}{|c|}{ WG 376 (Zahn 35, Zahn 36) } \\
\hline Ex/PCR & Amelo. & 10.82 .2 & VWA & FGA & D8S1179 & 10.83 & D18S51 & 10.83 .1 & D13S317 & D7S820 & Ex/PCR & DYS19 & DYS3891 & DYS389II & DYS390 \\
\hline Z1 82.94 & 1 & 1 & 1 & 1 & 1 & 1 & 1 & 1 & 1 & 1 & & & & & \\
\hline Z2 90.100 & 1 & 1 & 1 & 1 & 1 & 1 & 1 & 1 & I & I & & & & & \\
\hline
\end{tabular}




\begin{tabular}{|c|c|c|c|c|c|c|c|c|c|c|c|c|c|c|c|}
\hline Genotyp & 1 & 1 & 1 & 1 & I & I & 1 & 1 & 1 & 1 & Haplotyp & & & & \\
\hline \multicolumn{16}{|c|}{ WG 377 (Zahn 37) } \\
\hline Ex/PCR & Amelo. & 10.83 .2 & VWA & FGA & D8S1179 & $10.84 \quad D$ & D18S51 & 10.84 .1 & D13S317 & D7S820 & Ex/PCR & DYS19 & DYS3891 & DYS389II & DYS390 \\
\hline Z1 12.27a & 1 & 1 & 1 & 1 & 15 & 1 & 1 & 1 & 1 & 1 & $12.28 \mathrm{a}$ & 1 & 1 & 1 & 1 \\
\hline Z1 12.27b & 1 & 1 & 1 & 1 & 1 & 1 & 1 & 1 & 1 & 1 & $12.28 \mathrm{~b}$ & 1 & 1 & 1 & 1 \\
\hline Z1 12.31a & $x$ & 1 & 1 & 22 & 1 & 1 & 1 & 1 & 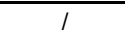 & 10 & & & & & \\
\hline Z1 12.31b & $\bar{Y}$ & 1 & 1 & 1 & 15 & 1 & 19 & 12 & 1 & 1 & & & & & \\
\hline Z1 42.60 & 1 & 1 & 1 & 1 & 1 & 1 & 1 & 1 & 1 & 1 & & & & & \\
\hline Genotyp & 1 & 1 & 1 & 1 & 1 & I & 1 & 1 & 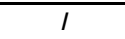 & 1 & Haplotyp & I & I & I & I \\
\hline \multicolumn{16}{|c|}{ WG 379 (Zahn 25) } \\
\hline Ex/PCR & Amelo. & 10.84 .2 & VWA & FGA & D8S1179 & $10.85 \quad \mathrm{D}$ & D18S51 & 10.85 .1 & D13S317 & D7S820 & Ex/PCR & DYS19 & DYS3891 & DYS389II & DYS390 \\
\hline Z1 20.37 & 1 & 1 & 1 & 1 & 1 & 1 & 1 & 1 & 1 & 1 & & & & & \\
\hline Z1 20.37 & 1 & 1 & 1 & 1 & 1 & 1 & 1 & 1 & 1 & 1 & & & & & \\
\hline Z1 20.38 & $\mathrm{Y}$ & 15 & 1 & 1 & 1 & 1 & 1 & 1 & 1 & 1 & & & & & \\
\hline Genotyp & 1 & $\frac{1}{1}$ & 1 & 1 & 1 & 1 & 1 & 1 & 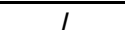 & 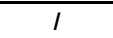 & Haplotyp & & & & \\
\hline \multicolumn{16}{|c|}{ WG 385 (Zahn 38, Zahn 25) } \\
\hline Ex/PCR & Amelo. & 10.85 .2 & VWA & FGA & D8S1179 & $10.86 \quad \mathrm{D}$ & D18S51 & 10.86 .1 & D13S317 & D7S820 & Ex/PCR & DYS19 & DYS3891 & DYS389II & DYS390 \\
\hline $\mathrm{Z1} 46.64$ & $\mathrm{XY}$ & $15 / 17(\mathrm{kl})$ & $18 / 19$ & $22 / 23$ & $12 / 14$ & 30 & 1 & 12 & 11 & 10 & Z1 46.85 & 1 & 1 & 1 & 1 \\
\hline Z1 42.60 & $\mathrm{XY}$ & 15 & $18 / 19$ & 22 & $12 / 14$ & 30 & 1 & 12 & 11 & 1 & Z1 52.77 & 1 & 1 & 1 & 1 \\
\hline Z1 52.70 & $\mathrm{Y}$ & 15 & 1 & 1 & 14 & 1 & 1 & 12 & 1 & 1 & & & & & \\
\hline Z1 52.76 & 1 & 1 & 18 & 1 & 1 & 1 & 1 & 1 & 1 & 1 & & & & & \\
\hline Z2 66.82 & $\mathrm{XY}$ & 16 & 17 & 23 & $14 / 18$ & $28 / 30$ & 1 & 12 & 11 & 1 & & & & & \\
\hline Genotyp & $\mathrm{XY}$ & $15 /(15)$ & $18 / 19$ & $22 / 23$ & $12 / 14$ & $30 /(30)$ & $I$ & $12 / 12$ & $11 / 11$ & $I$ & Haplotyp & 1 & 1 & 1 & $I$ \\
\hline \multicolumn{16}{|c|}{ WG 395 (Zahn) } \\
\hline Ex/PCR & Amelo. & 10.86 .2 & VWA & FGA & D8S1179 & $10.87 \quad D$ & D18S51 & 10.87 .1 & D13S317 & D7S820 & Ex/PCR & DYS19 & DYS3891 & DYS389II & DYS390 \\
\hline Z1 13.29a & $\mathrm{Y}$ & $15 / 17 / 18$ & 1 & 1 & 1 & 31.2 & 1 & 1 & 1 & 10 & & & & & \\
\hline Z1 13.29b & $\mathrm{x}$ & 1 & 15 & 24 & 1 & 1 & 19 & 1 & 1 & 1 & & & & & \\
\hline Z1 13.32a & $x$ & 15 & 1 & 1 & 13 & 29 & 1 & 10 & 1 & 1 & & & & & \\
\hline Z1 13.32b & $\mathrm{Y}$ & 16 & 17 & 26 & 1 & 1 & 1 & 13 & 1 & 1 & & & & & \\
\hline Z1 82.94 & 1 & 1 & 1 & 1 & 1 & 1 & 1 & 1 & 1 & 1 & & & & & \\
\hline Genotyp & $X Y$ & (15) & 1 & 1 & 1 & 1 & 1 & 1 & I & 1 & & & & & \\
\hline \multicolumn{16}{|c|}{ WG 397 (Zahn 37, Zahn 15) } \\
\hline Ex/PCR & Amelo. & 10.87 .2 & VWA & FGA & D8S1179 & 10.88 & D18S51 & \begin{tabular}{|l|l|}
10.88 .1 \\
\end{tabular} & D13S317 & D7S820 & Ex/PCR & DYS19 & DYS389I & DYS389II & DYS390 \\
\hline Z1 8.19 & $x$ & 16 & 1 & 1 & 1 & 1 & 1 & 1 & 1 & 1 & Z1 8.21a & 1 & 1 & 1 & 1 \\
\hline
\end{tabular}




\begin{tabular}{|c|c|c|c|c|c|c|c|c|c|c|c|c|c|c|c|}
\hline Z1 8.23a & $\mathrm{x}$ & 1 & 1 & 1 & 1 & 1 & 1 & 1 & 1 & 1 & Z1 8.21b & 1 & 1 & 1 & 1 \\
\hline Z1 8.23b & $\mathrm{Y}$ & 15 & 1 & 1 & 1 & 1 & 1 & 1 & 1 & 1 & Z1 8.22a & 1 & 1 & 1 & 26 \\
\hline Z2 82.94 & 1 & 1 & 1 & 1 & 1 & 1 & 1 & 1 & 1 & 1 & $Z 18.22 b$ & 1 & 1 & 1 & 1 \\
\hline Genotyp & 1 & 1 & 1 & 1 & 1 & $I$ & $I$ & 1 & 1 & 1 & Haplotyp & 1 & 1 & 1 & 1 \\
\hline \multicolumn{16}{|c|}{ WG 399 (Zahn 38, Femur) } \\
\hline Ex/PCR & Amelo. & 10.88 .2 & VWA & FGA & D8S1179 & $10.89 \quad \mathrm{D}$ & D18S51 & 10.89 .1 & D13S317 & D7S820 & Ex/PCR & DYS19 & DYS3891 & DYS389II & DYS390 \\
\hline Z1 13.29a & 1 & 1 & 1 & 24 & $9 / 13$ & 31.2 & 1 & 12 & 11 & 1 & \begin{tabular}{|l|} 
Z1 13.28a \\
\end{tabular} & 1 & 1 & 1 & $21 / 24$ \\
\hline Z1 13.29b & $\mathrm{Y}$ & 15 & 1 & 1 & 13 & 1 & 1 & 1 & 1 & 1 & Z1 13.28b & 1 & 1 & 1 & 1 \\
\hline Z1 35.54 & $X Y$ & 15 & 15 & 22 & 9 & 31 & 1 & $12 / 13$ & 12 & 1 & & & & & \\
\hline Z1 42.00 & 1 & 1 & 1 & 1 & 1 & 1 & 1 & 1 & 1 & 1 & & & & & \\
\hline K 117.131 & 1 & 1 & 1 & 1 & 1 & 1 & 1 & 1 & 1 & 1 & & & & & \\
\hline Genotyp & $\mathrm{XY}$ & 15 & 1 & 1 & $9 /(13)$ & 1 & 1 & 12 & $I$ & 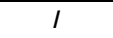 & Haplotyp & 1 & 1 & I & I \\
\hline \multicolumn{16}{|c|}{ WG 405 (Zahn 17) } \\
\hline Ex/PCR & Amelo. & 10.89 .2 & VWA & FGA & D8S1179 & $10.90 \quad \mathrm{D}$ & D18S51 & 10.90 .1 & D13S317 & D7S820 & Ex/PCR & DYS19 & DYS389I & DYS389II & DYS390 \\
\hline Z1 10.26a & 1 & 1 & 16 & 1 & 14 & 1 & 1 & 1 & 1 & 1 & Z1 10.28b & 15 & 1 & 1 & 1 \\
\hline$Z 110.26 b$ & $X Y$ & 1 & 17 & 21 & $12 / 14$ & 1 & 1 & 1 & 1 & 1 & Z1 10.28b & 15 & 1 & 1 & 1 \\
\hline Genotyp & 1 & 1 & 1 & 1 & (14) & 1 & 1 & 1 & 1 & 1 & Haplotyp & 1 & 1 & 1 & 1 \\
\hline \multicolumn{16}{|c|}{ WG 406 (Zahn 27, Zahn 26) } \\
\hline Ex/PCR & Amelo. & 10.90 .2 & VWA & FGA & D8S1179 & $10.91 \quad \mathrm{D}$ & D18S51 & 10.91 .1 & D13S317 & D7S820 & Ex/PCR & DYS19 & DYS389I & DYS389II & DYS390 \\
\hline Z1 58.78 & $X Y$ & $15 / 16$ & $17 / 20$ & 21 & 14 & $29 / 30$ & 12 & 12 & $11 / 14$ & $10 / 12$ & & & & & \\
\hline Z1 59.79 & $\mathrm{x}$ & 1 & 1 & 1 & 1 & 1 & 1 & 1 & 1 & 1 & & & & & \\
\hline Z2 82.94 & 1 & 1 & 1 & 1 & 1 & 1 & 1 & 1 & 1 & 1 & & & & & \\
\hline Genotyp & I & I & 1 & 1 & I & I & I & 1 & I & I & Haplotyp & & & & \\
\hline \multicolumn{16}{|c|}{ WG 408 (Zahn 47) } \\
\hline Ex/PCR & Amelo. & 10.91 .2 & VWA & FGA & D8S1179 & $10.92 \mathrm{D}$ & D18S51 & 10.92 .1 & D13S317 & D7S820 & Ex/PCR & DYS19 & DYS3891 & DYS389II & DYS390 \\
\hline Z1 31.49 & $\mathrm{x}$ & 1 & 1 & 1 & $14 / 16$ & 30 & 1 & 1 & 1 & 1 & & & & & \\
\hline Genotyp & 1 & 1 & 1 & 1 & 1 & 1 & 1 & 1 & 1 & $\frac{1}{1}$ & Haplotyp & & & & \\
\hline \multicolumn{16}{|c|}{ WG 409 (Zahn 36, Zahn 47) } \\
\hline Ex/PCR & Amelo. & 10.92 .2 & VWA & FGA & D8S1179 & $10.93 \quad \mathrm{D}$ & D18S51 & \begin{tabular}{|l|}
10.93 .1 \\
\end{tabular} & D13S317 & D7S820 & Ex/PCR & DYS19 & DYS389I & DYS389II & DYS390 \\
\hline Z1 6.13a & $X Y$ & 15 & 16 & 22 & 13 & 30.2 & 1 & $(10) /(11) / 12$ & 10 & $(9) / 10$ & Z1 6.15a & 1 & 12 & 1 & 23 \\
\hline Z1 6.13b & $X Y$ & 1 & 16 & $(21) / 22$ & $11 / 13$ & 31.2 & 1 & $(11) / 12$ & 10/11 & 1 & Z1 6.15b & 1 & 1 & 1 & 23 \\
\hline Z1 6.14 & $X Y$ & 15 & 18 & 22 & 13 & 31.2 & 1 & $10 / 11 / 12$ & 11 & 12 & Z1 10.28a & 1 & 1 & 1 & 1 \\
\hline Z1 10.26a & $X Y$ & 15 & 16/18 & 21 & 13/14 & $31 / 32$ & 1 & $\begin{array}{l}(11) / 12 \\
\end{array}$ & 11 & 10 & Z1 10.28b & 1 & 12 & 1 & 1 \\
\hline Z1 10.26b & $X Y$ & 15 & $16 / 18$ & 22 & 13 & 31.2 & 1 & $10 / 11 / 12$ & 1 & 10 & Z1 15.33a & 1 & 1 & 1 & 1 \\
\hline Z1 15.34 & 1 & 14 & 18 & $21 / 25$ & 1 & 1 & 1 & 12 & 1 & 1 & Z1 15.33b & 1 & 1 & 1 & 1 \\
\hline Z1 26.44 & $X Y$ & 15 & 16/18 & $21 / 22$ & 13 & $30.2 / 31.2$ & 1 & $11 / 12$ & $10 / 11$ & 12 & Z1 26.47a & 14 & 12 & 28 & 1 \\
\hline
\end{tabular}




\begin{tabular}{|c|c|c|c|c|c|c|c|c|c|c|c|c|c|c|c|}
\hline Z1 32.49 & $X Y$ & 15 & $16 / 18$ & 22 & 13 & 30.2 & $12 / 17$ & 12 & 10/11 & 12 & Z1 26.47b & 14 & 12 & 28 & 23 \\
\hline \multirow[t]{2}{*}{ Z2 52.70} & $\mathrm{x}$ & 16 & 15 & 21 & 16 & 30 & 1 & 15 & 1 & 1 & Z1 32.50a & 1 & 12 & 1 & 1 \\
\hline & & & & & & & & & & & $\mathrm{Z132.50 \textrm {b }}$ & 1 & 12 & 1 & 1 \\
\hline Genotyp & $\mathbf{X Y}$ & $15 / 15$ & $16 / 18$ & $21 / 22$ & $13 /(13)$ & $30.2 / 31.2$ & 1 & $11 / 12$ & $10 / 11$ & $10 / 12$ & Haplotyp & 14 & 12 & 28 & 23 \\
\hline \multicolumn{16}{|c|}{ WG 411 (Zahn 45, Zahn 34) } \\
\hline Ex/PCR & Amelo. & 10.93 .2 & VWA & FGA & D8S1179 & $10.94 \quad \mathrm{D}$ & D18S51 & 10.94.1 & D13S317 & D7S820 & Ex/PCR & DYS19 & DYS3891 & DYS389II & DYS390 \\
\hline Z1 14.30a & 1 & 1 & $16 / 17$ & 1 & 1 & 1 & 1 & 1 & 1 & 1 & Z1 56.110 & 1 & 1 & 1 & 1 \\
\hline Z1 14.30b & 1 & 15 & $16 /(17)$ & 22 & 1 & 1 & 1 & 12 & 11 & 9 & & & & & \\
\hline Z1 14.32a & $X Y$ & $15 / 17$ & 19 & 23 & $11 / 14 / 16$ & 29 & 1 & 11 & 10 & 1 & & & & & \\
\hline $\mathrm{Z1} 14.32 \mathrm{~b}$ & $X Y$ & $15 / 17$ & $16 / 19$ & $(21) / 22$ & 14 & 1 & 1 & $11 / 13$ & $10 / 11$ & 10 & & & & & \\
\hline Z1 56.76 & $X Y$ & 1 & 1 & 26 & 13 & 1 & 14 & 1 & 1 & 8 & & & & & \\
\hline Z2 90.100 & 1 & 1 & 1 & 1 & 1 & 1 & 1 & 1 & 1 & I & & & & & \\
\hline Z2 94.102 & 1 & 1 & 1 & 1 & 1 & 1 & 1 & 1 & 1 & 1 & & & & & \\
\hline Genotyp & $\mathrm{XY}$ & $(15) /(17)$ & (16)(19) & (22) & (14) & 1 & 1 & 1 & $(10) /(11)$ & 1 & Haplotyp & 1 & 1 & 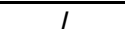 & I \\
\hline \multicolumn{16}{|c|}{ WG 414 (Zahn 38) } \\
\hline Ex/PCR & Amelo. & 10.94 .2 & VWA & FGA & D8S1179 & 10.95 & D18S51 & 10.95 .1 & D13S317 & D7S820 & & & & & \\
\hline Z1 97.104 & $x$ & 17 & 1 & 1 & 1 & 1 & 1 & \begin{tabular}{|l} 
\\
\end{tabular} & 1 & 1 & & & & & \\
\hline Z1 98.104 & $\mathrm{X}$ & 17 & $16 / 18$ & 21 & 13 & 31.2 & 16 & $10 / 11$ & 11 & I & & & & & \\
\hline Z1 111.119 & $x$ & 17 & 16 & 23 & 13 & 31.2 & 1 & $10 / 11$ & 1 & 1 & & & & & \\
\hline Genotyp & $x x$ & $17 / 17$ & 16 & 1 & 13 & 31.2 & 1 & $10 / 11$ & 1 & 1 & & & & & \\
\hline \multicolumn{16}{|c|}{ WG 417 (Zahn 47, Zahn 36) } \\
\hline Ex/PCR & Amelo. & 10.95 .2 & VWA & FGA & D8S1179 & $10.96 \quad \mathrm{D}$ & D18S51 & 10.96 .1 & D13S317 & D7S820 & Ex/PCR & DYS19 & DYS3891 & DYS389II & DYS390 \\
\hline Z1 59.79 & $\mathrm{x}$ & $14 / 15$ & 15 & 23 & 1 & 1 & 1 & 1 & 1 & 9 & & & & & \\
\hline Z1 94.102 & 1 & 1 & 1 & 1 & 1 & 1 & 1 & 1 & 1 & 1 & & & & & \\
\hline Z2 103.112 & 1 & 1 & 1 & 1 & 1 & 1 & 1 & 1 & 1 & 1 & & & & & \\
\hline Genotyp & 1 & $I$ & $I$ & 1 & $I$ & $I$ & $I$ & 1 & $I$ & 1 & Haplotyp & & & & \\
\hline \multicolumn{16}{|c|}{ WG 426 (Femur) } \\
\hline Ex/PCR & Amelo. & 10.96 .2 & VWA & FGA & D8S1179 & 10.97 & D18S51 & 10.97 .1 & D13S317 & D7S820 & Ex/PCR & DYS19 & DYS3891 & DYS389II & DYS390 \\
\hline K 41.59 & $\mathrm{x}$ & 1 & 1 & 1 & 1 & 1 & 1 & 1 & 1 & 1 & & & & & \\
\hline Genotyp & 1 & 1 & 1 & 1 & 1 & 1 & 1 & 1 & 1 & 1 & Haplotyp & & & & \\
\hline \multicolumn{16}{|c|}{ WG 441 (Zahn 47, Zahn 45) } \\
\hline Ex/PCR & Amelo. & 10.97 .2 & VWA & FGA & D8S1179 & $10.98 \quad \mathrm{D}$ & D18S51 & 10.98 .1 & D13S317 & D7S820 & Ex/PCR & DYS19 & DYS3891 & DYS389II & DYS390 \\
\hline Z1 59.79 & $x$ & 13 & 19 & 24 & $12 / 13 / 14$ & $27 / 28$ & 12 & I & 10 & 1 & & & & & \\
\hline Z1 100.105 & 1 & 1 & 1 & 1 & 1 & 1 & 1 & 1 & 1 & 1 & & & & & \\
\hline Z2 103.112 & 1 & 1 & 1 & 1 & 1 & 1 & 1 & 1 & 1 & 1 & & & & & \\
\hline Genotyp & 1 & 1 & I & 1 & 1 & 1 & 1 & 1 & I & 1 & Haplotyp & & & & \\
\hline
\end{tabular}


WG 442 (Zahn 38, Zahn 36)

\begin{tabular}{|c|c|c|c|c|c|c|c|c|c|c|c|c|c|c|c|}
\hline \multicolumn{16}{|c|}{ WG 442 (Zahn 38, Zahn 36) } \\
\hline Ex/PCR & Amelo. & 10.98 .2 & VWA & FGA & D8S1179 & 10.99 & D18S51 & 10.99 .1 & D13S317 & D7S820 & Ex/PCR & DYS19 & DYS389I & DYS389II & DYS390 \\
\hline Z1 4.6a & $X Y$ & 15 & 1 & $(21) / 22 / 23$ & $11 / 13$ & 1 & 1 & 12 & 1 & 10 & Z1 4.8 & 15 & 1 & 1 & 1 \\
\hline Z1 4.6b & $\mathrm{x}$ & 1 & 1 & 1 & 1 & 26 & 1 & 1 & 1 & 1 & Z194.121 & 1 & 14 & 1 & 1 \\
\hline $\mathrm{Z14.7a}$ & Ü.a & $15 / 17$ & 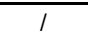 & 25 & Ü.a & 30 & 1 & Ü.a & 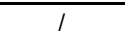 & 1 & Z194.110 & 1 & $\frac{1}{1}$ & 7 & $\frac{T}{1}$ \\
\hline $\mathrm{Z1} \mathrm{4.7b}$ & Ü.a & 15 & 16 & 1 & 13 & 1 & 13 & 11 & $11 / 13$ & 13 & & & & & \\
\hline Z1 20.37a & 1 & 1 & 1 & 1 & 1 & 1 & 1 & 1 & 1 & 1 & & & & & \\
\hline Z1 20.37b & $\overline{X Y}$ & $\frac{1}{1}$ & 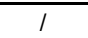 & $\frac{T}{1}$ & 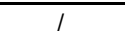 & 7 & 1 & 7 & 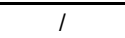 & $\frac{T}{1}$ & & & & & \\
\hline Z1 20.38a & $X Y$ & 15 & 1 & 22 & $11 / 14$ & 1 & 1 & 1 & 1 & 1 & & & & & \\
\hline Z1 58.78 & $\overline{X Y}$ & $15 / 18$ & 14 & 1 & 11 & 30.2 & 11 & 12 & 9 & 10 & & & & & \\
\hline Z194.102 & $X Y$ & 15 & 15 & 22 & $11 / 13$ & $28 / 30$ & 1 & 12 & 13 & 10 & & & & & \\
\hline Z2 102.111 & $\overline{X Y}$ & 1 & 1 & 1 & 1 & 1 & 1 & 1 & 1 & 1 & & & & & \\
\hline Genotyp & $\overline{X Y}$ & $15 /(15)$ & $I$ & 22 & $11 / 13$ & 30 & $I$ & $12 /(12)$ & 13 & $10 /(10)$ & Haplotyp & 1 & 1 & $I$ & 1 \\
\hline \multicolumn{16}{|c|}{ WG 443 (Zahn 43) } \\
\hline Ex/PCR & Amelo. & 10.99 .2 & VWA & FGA & D8S1179 & $10.100 \mathrm{D}$ & D18S51 & 10.100 .1 & D13S317 & D7S820 & Ex/PCR & DYS19 & DYS3891 & DYS389II & DYS390 \\
\hline Z1 97.104 & $x$ & 1 & 19 & 1 & 13 & 1 & 1 & 1 & 1 & 1 & & & & & \\
\hline Z198.104 & 1 & 7 & $17 / 18$ & 1 & 1 & 7 & 7 & 1 & 7 & $\frac{1}{1}$ & & & & & \\
\hline Genotyp & $I$ & I & 1 & $I$ & $I$ & I & I & 1 & 1 & $I$ & Haplotyp & & & & \\
\hline \multicolumn{16}{|c|}{ WG 456 (Zahn 16) } \\
\hline Ex/PCR & Amelo. & 10.100 .2 & VWA & $\overline{\mathrm{FGA}}$ & D8S1179 & $10.101 \mathrm{D}$ & D18S51 & 10.101 .1 & D13S317 & D7S820 & Ex/PCR & DYS19 & DYS389I & DYS389II & DYS390 \\
\hline Z1 8.19 & $\mathrm{Y}$ & $16 / 18$ & 1 & 1 & 1 & 1 & 1 & 1 & 1 & 1 & & & & & \\
\hline Z1 8.23a & $x$ & 15 & 1 & 21 & 12 & 1 & 1 & 11 & 1 & 1 & & & & & \\
\hline Z1 8.23b & $x$ & $(17) / 18$ & 18 & $22 / 23$ & 11 & 1 & 15 & $8 / 11$ & 11 & 11 & & & & & \\
\hline Z1 8.25a & 1 & 1 & 1 & 1 & 1 & 1 & 1 & 1 & 1 & 1 & & & & & \\
\hline Z1 8.25b & 1 & 1 & 1 & 22 & 1 & 1 & 1 & 1 & 1 & I & & & & & \\
\hline Z1 111.119 & $X Y$ & 1 & 1 & 1 & 1 & 1 & 1 & 1 & 1 & 1 & & & & & \\
\hline Genotyp & $I$ & $I$ & $I$ & (22) & $I$ & $I$ & 1 & (11) & $I$ & $I$ & Haplotyp & & & & \\
\hline \multicolumn{16}{|c|}{ WG 461 (Femur) } \\
\hline Ex/PCR & Amelo. & 10.101 .2 & VWA & $\overline{F G A}$ & D8S1179 & $10.102 \mathrm{D}$ & D18S51 & 10.102 .1 & D13S317 & D7S820 & Ex/PCR & DYS19 & DYS389I & DYS389II & DYS390 \\
\hline $\mathrm{K} 2.1 \mathrm{a}$ & 1 & 1 & 1 & 1 & 1 & 1 & 1 & 1 & 1 & 1 & & & & & \\
\hline $\mathrm{K} 2.1 \mathrm{~b}$ & 1 & 17 & 1 & 1 & $13 / 14$ & 1 & 1 & 1 & 1 & 1 & & & & & \\
\hline Genotyp & 1 & 1 & 1 & 1 & 1 & 1 & 1 & 1 & 1 & 1 & Haplotyp & & & & \\
\hline \multicolumn{16}{|c|}{ WG 464 (Zahn 36, Zahn 37) } \\
\hline Ex/PCR & Amelo. & 10.102 .2 & VWA & $\overline{\mathrm{FGA}}$ & D8S1179 & $10.103 \mathrm{D}$ & D18S51 & 10.103 .1 & D13S317 & D7S820 & & & & & \\
\hline Z1 8.19 & $\mathrm{X}$ & $15 / 17$ & 14 & 21 & $9 / 10$ & 30 & 1 & $(11) / 12$ & 11 & 1 & & & & & \\
\hline Z1 8.23a & $x$ & 14 & 1 & 1 & 1 & 1 & 15 & 1 & 1 & I & & & & & \\
\hline
\end{tabular}




\begin{tabular}{|c|c|c|c|c|c|c|c|c|c|c|c|c|c|c|c|}
\hline Z1 8.23b & 1 & 1 & 14 & 1 & 13 & 1 & 1 & 1 & 1 & 1 & & & & & \\
\hline Z1 8.25a & $x$ & 14/16/17 & 15 & 1 & 9/11 & 1 & 16 & $11(12) / 13$ & 1 & 1 & & & & & \\
\hline Z1 8.25b & $x$ & $15 / 18$ & $(14) / 15 / 19$ & 21 & 11 & 1 & 1 & 1 & 1 & 1 & & & & & \\
\hline Z1 58.78 & $x$ & 17 & 1 & 1 & 15 & 1 & 1 & 1 & 1 & 1 & & & & & \\
\hline Z1 80.93 & 1 & 1 & 1 & 1 & 1 & 1 & 1 & 1 & 1 & 1 & & & & & \\
\hline Z2 80.93 & $x$ & 1 & $14 / 15$ & 1 & 9/11 & 1 & 14 & 12 & 11 & 1 & & & & & \\
\hline Z2 94.102 & $x$ & 17 & $14 / 15$ & 21 & 9/11 & 1 & 1 & 11 & 11 & 1 & & & & & \\
\hline Genotyp & $x x$ & $(14) /(15) / 1$ & $14 / 15$ & $21 / 21$ & 9/11 & 1 & 1 & $11 / 12$ & $11 / 11$ & I & & & & & \\
\hline \multicolumn{16}{|c|}{ WG 469 (Femur) } \\
\hline Ex/PCR & Amelo. & 10.103 .2 & VWA & FGA & D8S1179 & $10.104 \quad \mathrm{D}$ & D18S51 & 10.104 .1 & D13S317 & D7S820 & Ex/PCR & DYS19 & DYS3891 & DYS389II & DYS390 \\
\hline K2.1a & 1 & 18 & 16 & 1 & 1 & 1 & 1 & 1 & 1 & 1 & & & & & \\
\hline $\mathrm{K} 2.1 \mathrm{~b}$ & 1 & 1 & 1 & 1 & 1 & 1 & 1 & 1 & 1 & 9 & & & & & \\
\hline Genotyp & 1 & I & $I$ & 1 & I & 1 & $I$ & 1 & I & 1 & Haplotyp & & & & \\
\hline \multicolumn{16}{|c|}{ WG 477 (Zahn) } \\
\hline Ex/PCR & Amelo. & 10.104 .2 & VWA & FGA & D8S1179 & $10.105 \mathrm{D}$ & D18S51 & 10.105 .1 & D13S317 & D7S820 & Ex/PCR & DYS19 & DYS389I & DYS389II & DYS390 \\
\hline Z1 31.49 & $\mathrm{x}$ & 1 & 1 & 1 & 1 & 1 & 1 & 1 & 1 & 1 & & & & & \\
\hline Genotyp & 1 & 1 & 1 & 1 & I & I & 1 & 1 & 1 & 1 & Haplotyp & & & & \\
\hline \multicolumn{16}{|c|}{ WG 478 (Zahn 28, Zahn 27, Femur) } \\
\hline Ex/PCR & Amelo. & 10.105 .2 & VWA & FGA & D8S1179 & $10.106 \mathrm{D}$ & D18S51 & 10.106 .1 & D13S317 & D7S820 & Ex/PCR & DYS19 & DYS3891 & DYS389II & DYS390 \\
\hline Z1 1.1a & 1 & I & 1 & 1 & 1 & 1 & 1 & 13 & 1 & I & Z1 $3.4 \mathrm{a}$ & 1 & 12 & 1 & 1 \\
\hline Z1 1.1b & 1 & 1 & 1 & 1 & 1 & 1 & 1 & 1 & 1 & 10 & Z1 $3.4 \mathrm{~b}$ & 1 & 1 & 1 & 1 \\
\hline $\mathrm{Z1} 3.2 \mathrm{a}$ & $\mathrm{x}$ & I & 1 & 25 & 11 & 1 & 1 & 12 & 1 & 1 & Z1 9.21 a & 14 & 12 & 1 & 1 \\
\hline $\mathrm{Z1} \mathrm{3.2b}$ & $X Y$ & 17 & 16 & 1 & 11 & 1 & 1 & $10 / 12$ & 12 & 1 & Z1 9.21 b & 14 & 12 & 1 & 1 \\
\hline Z1 3.3a & $\mathrm{XY}$ & 15 & 1 & 22 & 11 & 1 & 1 & $10 / 12$ & 13 & 1 & Z1 9.22 & 1 & 12 & 1 & 1 \\
\hline Z1 3.3b & $X Y$ & 1 & 1 & $21 / 22$ & 11 & 1 & 19 & $11 / 12$ & 1 & 1 & Z1 22.41 & 1 & 12 & 1 & 1 \\
\hline Z1 9.19 & $X Y$ & 17 & 16 & $23 / 25$ & 10/11/14 & 28 & 1 & 1 & 12 & 10 & Z1 22.43 & 1 & 12 & 1 & 1 \\
\hline Z1 9.23a & $X Y$ & 1 & $14 / 16$ & 1 & $11 / 14 / 15$ & $30(\mathrm{kl})$ & 1 & 12 & 1 & 1 & Z1 23.41 & 1 & 1 & 1 & 1 \\
\hline Z1 9.23b & $X Y$ & 16 & 14 & 1 & $10 / 14$ & 1 & 1 & $10 / 12$ & 8 & 8 & K 114.126 & 1 & 1 & 1 & 1 \\
\hline Z1 22.39 & 1 & $15 / 19$ & $16 / 17$ & $20 / 24$ & 13 & $27 / 30 / 31$ & $12 / 14$ & $(9) / 10 / 12$ & $11 / 13$ & $11 / 13$ & & & & & \\
\hline Z2 23.40 & $x$ & 16 & 16 & 21 & $13 / 14$ & 1 & $12 / 14$ & $\begin{array}{l}(11) / 12 \\
\end{array}$ & 1 & 11 & & & & & \\
\hline Z2 33.52 & 1 & 17 & 16 & 24 & $13 / 15$ & 30 & 12 & 1 & 1 & 1 & & & & & \\
\hline Z2 35.54 & $X Y$ & 17 & 1 & 22 & 1 & 29 & 1 & 1 & 1 & 1 & & & & & \\
\hline K 114.125 & $X Y$ & 17 & 1 & 22 & 1 & 1 & 1 & 1 & 1 & 1 & & & & & \\
\hline Genotyp & $\mathrm{XY}$ & $16 / 17$ & $(14) / 16$ & $(21) 22(25)$ & $11 / 13 / 14$ & 30 & $12 / 14$ & $10 / 12$ & $12 / 13$ & $10 / 11$ & Haplotyp & 14 & 12 & 1 & 1 \\
\hline \multicolumn{16}{|c|}{ WG 480 (Zahn 47, Zahn 46) } \\
\hline Ex/PCR & Amelo. & 10.106 .2 & VWA & FGA & D8S1179 & $10.107 \quad D$ & D18S51 & 10.107 .1 & D13S317 & D7S820 & Ex/PCR & DYS19 & DYS3891 & DYS389II & DYS390 \\
\hline
\end{tabular}




\begin{tabular}{|c|c|c|c|c|c|c|c|c|c|c|c|c|c|c|c|}
\hline Z1 14.30a & $X Y$ & $15 / 17$ & 19 & 22 & 14 & 29 & 15 & $11 / 13$ & $11 / 13$ & 1 & Z1 22.41 & 13 & 13 & 31 & 22 \\
\hline Z1 14.30b & $\mathrm{XY}$ & $15 / 17$ & 19 & 22 & $14 / 16$ & 1 & 1 & $11 / 13$ & 10 & 1 & Z1 22.43 & 13 & 1 & 1 & 1 \\
\hline Z1 22.39 & $\mathrm{XY}$ & $15 / 17$ & 1 & $22 / 23$ & $13 / 14 / 16$ & 29 & 13 & 11 & 1 & $10 / 11$ & Z1 23.41 & 13 & 13 & 1 & 25 \\
\hline Z1 23.40 & $X Y$ & $15 / 17$ & 19 & 22 & 14 & 29 & 1 & $11 / 13$ & 10 & 1 & Z1 23.47a & 13 & 13 & 1 & 25 \\
\hline Z1 23.42 & $\mathrm{XY}$ & $15 / 17$ & $15 / 19$ & 23 & $14 / 16$ & 29 & 15 & $11(12) 13$ & $11 / 13$ & 10 & Z1 23.47b & 1 & 13 & 31 & 25 \\
\hline Z1 32.49 & 1 & 1 & 1 & 1 & 1 & 1 & 1 & 1 & 1 & 1 & Z2 38.109 & 1 & 1 & 1 & 1 \\
\hline Z2 38.58 & $\mathrm{XY}$ & $15 / 17$ & 19 & $22 / 23$ & $14 / 16$ & 29 & 1 & $11 / 13$ & $(10) / 11$ & 11 & & & & & \\
\hline Z2 53.72 & $x$ & 1 & 17 & 23 & 16 & 1 & 14 & 13 & 13 & 1 & & & & & \\
\hline Z2 54.74 & 1 & $15 / 17$ & 1 & 1 & 1 & 1 & 1 & 1 & 1 & $\frac{1}{1}$ & & & & & \\
\hline Genotyp & $\mathbf{X Y}$ & $15 / 17$ & 19/(19) & $22 / 23$ & $14 / 16$ & $29 / 29$ & 15 & $11 / 13$ & 10/11/13 & $10 / 11$ & Haplotyp & 13 & 13 & 31 & 25 \\
\hline \multicolumn{16}{|c|}{ WG 485 (Zahn 13) } \\
\hline Ex/PCR & Amelo. & 10.107 .2 & VWA & FGA & D8S1179 & $10.108 \mathrm{D}$ & D18S51 & 10.108 .1 & D13S317 & D7S820 & Ex/PCR & DYS19 & DYS389| & DYS389II & DYS390 \\
\hline Z1 42.60 & 1 & 1 & 1 & 1 & 1 & 1 & 1 & 1 & 1 & 1 & & & & & \\
\hline Genotyp & $I$ & 1 & $I$ & $I$ & $I$ & $I$ & $I$ & 1 & $I$ & 1 & Haplotyp & & & & \\
\hline \multicolumn{16}{|c|}{ WG 487 (Zahn) } \\
\hline Ex/PCR & Amelo. & 10.108 .2 & VWA & FGA & D8S1179 & $10.109 \mathrm{D}$ & D18S51 & 10.109 .1 & D13S317 & D7S820 & & & & & \\
\hline Z1 91.101 & $x$ & 1 & 1 & 19 & 13 & 1 & 16 & 1 & 1 & 1 & & & & & \\
\hline Z1 95.103 & $\mathrm{X}$ & 15 & 1 & 1 & 13 & 1 & 1 & 10 & 1 & 1 & & & & & \\
\hline Z1 104.112 & $x$ & 1 & 1 & 1 & 1 & 1 & 1 & 1 & 1 & 1 & & & & & \\
\hline Z1 111.119 & $x$ & 1 & 1 & 1 & 1 & 1 & 1 & 1 & 1 & 1 & & & & & \\
\hline Genotyp & $x x$ & 1 & 1 & 1 & $I$ & $I$ & $I$ & 1 & $I$ & 1 & & & & & \\
\hline \multicolumn{16}{|c|}{ WG 488 (Zahn 16) } \\
\hline Ex/PCR & Amelo. & 10.109 .2 & VWA & FGA & D8S1179 & $10.110 \mathrm{D}$ & D18S51 & 10.110 .1 & D13S317 & D7S820 & Ex/PCR & DYS19 & DYS389I & DYS389II & DYS390 \\
\hline Z1 42.60 & $\mathrm{x}$ & 15 & 1 & 24 & $13 / 14$ & 1 & 1 & 12 & $11 / 12$ & 1 & Z1 91.110 & 1 & 1 & 1 & 1 \\
\hline Z1 91.101 & $\mathrm{Y}$ & 1 & 1 & 1 & 15 & 29 & 1 & 12 & 1 & 1 & Z1 96.110 & 1 & 1 & 1 & 1 \\
\hline Z1 96.103 & $X Y$ & $(16) / 17$ & 17 & 1 & 13 & $28 / 30$ & 13 & 12 & 11 & 11 & & & & & \\
\hline Genotyp & $\mathrm{XY}$ & 1 & 1 & $I$ & 13 & 1 & 1 & $12 / 12$ & 11 & 1 & Haplotyp & 1 & 1 & $\frac{1}{1}$ & 1 \\
\hline \multicolumn{16}{|c|}{ WG 491 (Zahn 36) } \\
\hline Ex/PCR & Amelo. & 10.110 .2 & VWA & FGA & D8S1179 & $10.111 \mathrm{D}$ & D18S51 & 10.111 .1 & D13S317 & D7S820 & Ex/PCR & DYS19 & DYS3891 & DYS389II & DYS390 \\
\hline Z1 91.101 & 1 & 1 & 1 & 1 & 1 & 1 & 1 & 1 & 1 & 1 & & & & & \\
\hline Genotyp & $I$ & 1 & $I$ & 1 & $I$ & $I$ & I & $I$ & 1 & $I$ & Haplotyp & & & & \\
\hline \multicolumn{16}{|c|}{ WG 500 (Zahn 45, Zahn 46) } \\
\hline Ex/PCR & Amelo. & $\begin{array}{l}0.111 .2 \\
\end{array}$ & VWA & FGA & D8S1179 & $10.112 \mathrm{D}$ & D18S51 & 10.112 .1 & D13S317 & D7S820 & Ex/PCR & DYS19 & DYS3891 & DYS389II & DYS390 \\
\hline Z1 43.66 & 1 & 1 & 1 & 1 & 1 & 1 & 1 & 1 & 1 & 1 & & & & & \\
\hline Z1 80.93 & 1 & I & 1 & 1 & 1 & 1 & 1 & 1 & 1 & 1 & & & & & \\
\hline Genotyp & 1 & 1 & 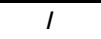 & 1 & 1 & $t$ & 1 & 1 & 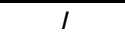 & 1 & Haplotyp & & & & \\
\hline
\end{tabular}




\begin{tabular}{|c|c|c|c|c|c|c|c|c|c|c|c|c|c|c|c|}
\hline \multicolumn{16}{|c|}{ WG 505 (Zahn 47, Zahn 46) } \\
\hline Ex/PCR & Amelo. & 10.112 .2 & VWA & FGA & D8S1179 & $10.113 \mathrm{D}$ & D18S51 & 10.113 .1 & D13S317 & D7S820 & Ex/PCR & DYS19 & DYS3891 & DYS389II & DYS390 \\
\hline Z1 31.49 & $\mathrm{XY}$ & 15 & $16 / 17$ & $21 / 24$ & 14 & $30 / 31.2$ & $12 / 13$ & $12 / 13$ & $9 / 13$ & $9 / 11$ & Z1 31.55 & 1 & 1 & 1 & 1 \\
\hline Z1 31.51 & $\mathrm{XY}$ & 15 & $16 / 17$ & $21 / 23$ & 14 & $30 / 31.2$ & $12 / 13$ & $12 /(13)$ & $9 / 13$ & 9 & & & & & \\
\hline Z1 43.60 & 1 & 1 & 1 & 1 & 1 & 1 & 1 & 1 & 1 & 1 & & & & & \\
\hline Z1 48.67 & $\mathrm{x}$ & 16 & 1 & 24 & 1 & 1 & 1 & 1 & 1 & 1 & & & & & \\
\hline Z1 80.93 & $x$ & $15 / 16 / 17$ & 1 & 1 & 1 & 1 & 1 & 1 & 1 & $\frac{1}{1}$ & & & & & \\
\hline Z2 80.93 & $x$ & 1 & 1 & 1 & 1 & 1 & 1 & 1 & 1 & 1 & & & & & \\
\hline Z2 91.101 & $\frac{1}{1}$ & $\frac{1}{1}$ & 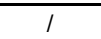 & $\frac{1}{1}$ & 1 & 1 & 1 & 1 & 1 & 1 & & & & & \\
\hline Genotyp & $\overline{X(Y)}$ & $15 / 16$ & $(16 / 17)$ & $(21) / 24$ & $(14 / 14)$ & $(30 / 31.2)$ & $(12 / 13)$ & (12) & $(9 / 13)$ & (9) & Haplotyp & 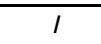 & 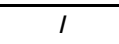 & $T$ & $T$ \\
\hline \multicolumn{16}{|c|}{ WG 507 (Zahn 47) } \\
\hline Ex/PCR & Amelo. & 10.113 .2 & VWA & FGA & D8S1179 & $10.114 \quad \mathrm{D}$ & D18S51 & 10.114 .1 & D13S317 & D7S820 & & & & & \\
\hline Z1 97.104 & $\mathrm{x}$ & 16 & 15.2 & 22 & 14 & 32.2 & 1 & 11 & 12 & 1 & & & & & \\
\hline Z1 98.104 & $x$ & 1 & 1 & 1 & 1 & 1 & 1 & 1 & 1 & 1 & & & & & \\
\hline Z1 111.119 & $\bar{x}$ & 15 & 19 & 23 & 13 & 1 & 1 & 11 & 1 & $\frac{1}{1}$ & & & & & \\
\hline Genotyp & $x x$ & 1 & 1 & 1 & $I$ & 1 & 1 & 1 & 1 & 1 & & & & & \\
\hline \multicolumn{16}{|c|}{ WG 517 (Zahn 16, Femur) } \\
\hline Ex/PCR & Amelo. & 10.114 .2 & VWA & FGA & D8S1179 & $10.115 \quad \mathrm{D}$ & D18S51 & \begin{tabular}{|l|}
10.115 .1 \\
\end{tabular} & D13S317 & D7S820 & Ex/PCR & DYS19 & DYS389| & DYS389II & DYS390 \\
\hline Z1 43.60 & $X Y$ & $16 / 17$ & 17 & $20 / 25$ & 12 & 32 & $15 / 18$ & 12 & $8 / 12$ & 1 & Z1 43.85 & 1 & 1 & 1 & 1 \\
\hline Z1 45.61 & $\overline{X Y}$ & $16 / 17$ & $(17) / 18$ & $24 / 25$ & $12 / 13$ & $30 / 32$ & 13 & 12 & 8 & 10 & Z1 44.65 & 14 & 13 & 29 & 24 \\
\hline Z1 46.64 & $X Y$ & $16 / 17$ & $(17) / 18$ & 25 & $12 / 13$ & $30 / 32$ & 1 & 12 & 8 & 10 & Z1 46.68 & 14 & 13 & 1 & I \\
\hline Z1 80.93 & 1 & 1 & 1 & 1 & 1 & 1 & 1 & 1 & 1 & 1 & Z1 46.85 & 1 & 13 & 1 & 24 \\
\hline K 115.127 & $x$ & 15 & 17 & 25 & 1 & 1 & 14/18 & 12 & 12 & 10 & K 108.126 & 1 & 1 & 1 & 1 \\
\hline K 117.131 & $x$ & 17 & 16 & 1 & 16 & 1 & 1 & $11 / 12$ & 1 & 1 & & & & & \\
\hline Genotyp & $X Y$ & $16 / 17$ & $17 / 18$ & 25 & $12 / 13$ & $30 / 32$ & 18 & $12 / 12$ & $8 / 12$ & $10 / 10$ & Haplotyp & 14 & 13 & 1 & 24 \\
\hline \multicolumn{16}{|c|}{ WG 551 (Zahn 27) } \\
\hline Ex/PCR & Amelo. & 10.115 .2 & VWA & FGA & D8S1179 & 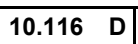 & D18S51 & 10.116 .1 & D13S317 & D7S820 & Ex/PCR & DYS19 & DYS389| & DYS389II & DYS390 \\
\hline Z1 97.104 & 1 & 1 & 14 & 1 & 1 & 1 & 1 & 1 & 1 & 1 & & & & & \\
\hline Z1 98.104 & 1 & 1 & 1 & 1 & 1 & 1 & 1 & 1 & 1 & 1 & & & & & \\
\hline Z1 104.112 & 1 & 17 & 1 & 21 & $10 / 15$ & 1 & 1 & 1 & 1 & 1 & & & & & \\
\hline Genotyp & $I$ & 1 & 1 & 1 & 1 & I & $I$ & 1 & I & I & Haplotyp & & & & \\
\hline \multicolumn{16}{|c|}{ WG 556 (Zahn 37) } \\
\hline Ex/PCR & Amelo. & 10.116 .2 & VWA & FGA & D8S1179 & \begin{tabular}{ll|}
$10.117 \quad \mathrm{D}$ \\
\end{tabular} & D18S51 & 10.117 .1 & D13S317 & D7S820 & Ex/PCR & DYS19 & DYS389| & DYS389II & DYS390 \\
\hline Z197.104 & 1 & 1 & 1 & 1 & 1 & 1 & 1 & 1 & 1 & 1 & & & & & \\
\hline Z1 98.104 & 1 & 1 & 1 & 1 & 1 & 1 & 1 & 1 & 1 & 1 & & & & & \\
\hline Z1 104.112 & $x$ & $15 / 19$ & $16 / 19$ & 1 & $12 / 15$ & 1 & 1 & $9 / 12$ & 1 & 1 & & & & & \\
\hline
\end{tabular}




\begin{tabular}{|c|c|c|c|c|c|c|c|c|c|c|c|c|c|c|c|}
\hline Genotyp & 1 & 1 & 1 & 1 & I & $I$ & I & 1 & 1 & 1 & Haplotyp & & & & \\
\hline \multicolumn{16}{|c|}{ WG 562 (Zahn 37, Zahn 47) } \\
\hline Ex/PCR & Amelo. & $\begin{array}{l}0.117 .2 \\
\end{array}$ & VWA & FGA & D8S1179 & \begin{tabular}{|l|}
$10.118 \quad D$ \\
\end{tabular} & D18S51 & \begin{tabular}{|l|}
10.118 .1 \\
\end{tabular} & $\begin{array}{l}\text { D13S317 } \\
\end{array}$ & D7S820 & Ex/PCR & DYS19 & DYS3891 & DYS389II & DYS390 \\
\hline Z1 1.1a & 1 & 1 & 1 & 1 & 1 & 1 & 1 & 1 & 1 & 1 & Z1 3.4a & 1 & 12 & 30 & 1 \\
\hline Z1 1.1b & 1 & 1 & 1 & 1 & 1 & 29 & 1 & 1 & 1 & 1 & Z1 3.4b & 1 & 1 & 1 & 1 \\
\hline Z1 3.2a & $x$ & 1 & 19 & $21 / 23$ & 1 & 1 & 1 & 11 & 1 & 1 & & & & & \\
\hline $\mathrm{Z1} 3.2 \mathrm{~b}$ & $\overline{X Y}$ & 16 & 1 & 1 & 14 & 1 & 1 & 11 & $10 / 11$ & 10 & & & & & \\
\hline Z1 3.3a & $\mathrm{x}$ & 15/18 & 19 & 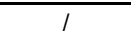 & 14 & 31.2 & 1 & $10 /(11) / 12$ & 13 & 10 & & & & & \\
\hline Z1 3.3b & 1 & $14 / 15$ & 16 & 1 & 13 & 30 & 1 & 1 & 1 & 1 & & & & & \\
\hline Z1 22.39 & 1 & 1 & 1 & 1 & 1 & 1 & 1 & 1 & 1 & 1 & & & & & \\
\hline Z2 23.40 & $x$ & 16 & 1 & 1 & 13 & 1 & 1 & 1 & 1 & 10 & & & & & \\
\hline Z2 112.124 & $X Y$ & 1 & 1 & 1 & 1 & 1 & 1 & 10 & 1 & 1 & & & & & \\
\hline Genotyp & $X Y$ & 1 & 1 & 1 & 1 & 1 & 1 & 1 & 1 & 1 & Haplotyp & 1 & 1 & I & 1 \\
\hline \multicolumn{16}{|c|}{ WG 565 (Zahn) } \\
\hline Ex/PCR & Amelo. & 10.118 .2 & VWA & FGA & D8S1179 & \begin{tabular}{|l|}
$10.119 \quad D$ \\
\end{tabular} & D18S51 & \begin{tabular}{|l|}
10.119 .1 \\
\end{tabular} & D13S317 & D7S820 & Ex/PCR & DYS19 & DYS3891 & DYS389II & DYS390 \\
\hline Z1 43.60 & $\mathrm{x}$ & 1 & 15 & 21 & 1 & 1 & 1 & 1 & 1 & 1 & & & & & \\
\hline Genotyp & 1 & $I$ & 1 & 1 & 1 & 1 & 1 & 1 & 1 & 1 & Haplotyp & & & & \\
\hline \multicolumn{16}{|c|}{ WG 567 (Zahn 16, Zahn 17) } \\
\hline Ex/PCR & Amelo. & 10.119 .2 & VWA & FGA & D8S1179 & $10.120 \mathrm{D}$ & D18S51 & 10.120 .1 & D13S317 & D7S820 & & & & & \\
\hline Z1 31.49 & 1 & 16 & $14 / 15 / 16$ & $24 / 25$ & 15 & $30 / 32.2$ & 18 & $9 / 11 / 12$ & 12 & $9 /(10)$ & & & & & \\
\hline Z1 31.51 & $\mathrm{Y}$ & 18 & $14 / 15 /(16)$ & 24 & $10 / 14 / 15$ & $28 / 32.2$ & 17 & $9 / 11$ & $(11) / 12$ & $9 /(10)$ & & & & & \\
\hline Z1 48.67 & $\mathrm{X}$ & 1 & 1 & 1 & 1 & 1 & 1 & 1 & 1 & 1 & & & & & \\
\hline Z1 49.69 & $\mathrm{X}$ & 17 & 19 & $21 / 23$ & 14 & 30 & 1 & $11 / 12 / 13$ & 13 & 1 & & & & & \\
\hline Z2 56.76 & $\mathrm{x}$ & 17 & 1 & 1 & 1 & 1 & 1 & 1 & 1 & 1 & & & & & \\
\hline Z2 80.93 & $x$ & 1 & 16 & $22 / 23$ & 14 & 1 & 1 & 1 & 1 & 1 & & & & & \\
\hline Z2 91.101 & $\mathrm{x}$ & 18 & 19 & 21 & $11 / 14$ & $30 / 32.2$ & 1 & 1 & 1 & 1 & & & & & \\
\hline Genotyp & $\mathbf{x X}$ & $17 / 18$ & $(14)(15) 16$ & $21 / 23 /(24)$ & $14 /(15)$ & $30 / 32.2$ & 1 & $(9 /) 11 / 12$ & (12) & (9) & & & & & \\
\hline \multicolumn{16}{|c|}{ WG 568 (Zahn) } \\
\hline Ex/PCR & Amelo. & 10.120 .2 & VWA & FGA & D8S1179 & $10.121 \quad D$ & D18S51 & 10.121 .1 & D13S317 & D7S820 & Ex/PCR & DYS19 & DYS3891 & DYS389II & DYS390 \\
\hline Z192.101 & $X Y$ & 15 & 1 & 1 & 1 & 1 & 1 & 1 & 1 & 1 & & & & & \\
\hline Genotyp & 1 & 1 & 1 & 1 & 1 & 1 & I & 1 & I & 1 & Haplotyp & & & & \\
\hline \multicolumn{16}{|c|}{ WG 577 (Zahn 44) } \\
\hline Ex/PCR & Amelo. & 10.121 .2 & VWA & FGA & D8S1179 & $10.122 \mathrm{D}$ & D18S51 & 10.122 .1 & D13S317 & D7S820 & Ex/PCR & DYS19 & DYS3891 & DYS389II & DYS390 \\
\hline Z1 12.27a & 1 & 1 & 15 & 22 & 1 & 26 & 1 & 11 & 1 & 1 & $12.28 a$ & 1 & 1 & 1 & 1 \\
\hline
\end{tabular}




\begin{tabular}{|c|c|c|c|c|c|c|c|c|c|c|c|c|c|c|c|}
\hline Z1 12.27b & 1 & (13)/14 & 1 & 1 & 1 & $29 / 30$ & 1 & 1 & 1 & 1 & $12.28 \mathrm{~b}$ & 1 & 1 & 1 & 1 \\
\hline Z1 12.31a & $\mathrm{XY}$ & 1 & 1 & 1 & 1 & 1 & 1 & 1 & 1 & 1 & & & & & \\
\hline Z1 12.31b & $\mathrm{Y}$ & 16 & 1 & 23 & 11 & 1 & 1 & $8 / 12$ & 1 & 1 & & & & & \\
\hline Genotyp & $(X Y)$ & 1 & $I$ & 1 & 1 & 1 & 1 & 1 & I & I & Haplotyp & 1 & 1 & I & 1 \\
\hline \multicolumn{16}{|c|}{ WG 580 (Zahn 37) } \\
\hline Ex/PCR & Amelo. & 10.122 .2 & VWA & FGA & D8S1179 & $10.123 \mathrm{D}$ & D18S51 & 10.123 .1 & D13S317 & D7S820 & & & & & \\
\hline Z1 1.1a & $\mathrm{x}$ & 1 & 1 & 1 & 13 & 1 & 1 & 1 & 12 & 1 & & & & & \\
\hline Z11.1b & 1 & 1 & 1 & 1 & 1 & 1 & 1 & 1 & 1 & 1 & & & & & \\
\hline Z1 3.2a & 1 & 1 & 1 & 1 & 15 & 1 & 1 & 12 & 1 & 1 & & & & & \\
\hline $\mathrm{Z1} \mathrm{3.2b}$ & 1 & 15 & 1 & 22 & 1 & 1 & 15 & 1 & 11 & 1 & & & & & \\
\hline Z1 3.3.a & 1 & 1 & 18 & 1 & 14 & 1 & 1 & 1 & 1 & 10 & & & & & \\
\hline Z1 3.3b & 1 & 1 & 1 & 1 & 15 & 28 & 15 & $10 /(11) / 12$ & 1 & 10 & & & & & \\
\hline Z1 3.5a & 1 & 1 & 1 & 1 & 1 & 1 & 1 & 1 & 1 & 1 & & & & & \\
\hline$Z 13.5 b$ & $x$ & 16 & 1 & 22 & 1 & 1 & 1 & 12 & 1 & 11 & & & & & \\
\hline Z1 9.19 & 1 & $13 / 16$ & 17 & 1 & $8 /(10) / 11$ & 30 & 1 & 1 & 1 & 1 & & & & & \\
\hline Z1 9.23a & $x$ & 18 & 19 & 1 & $8 / 11$ & 1 & 15 & 8 & 13 & 1 & & & & & \\
\hline Z1 9.23b & $x$ & $13 / 16$ & 1 & 1 & 14 & 1 & 1 & 1 & 1 & 1 & & & & & \\
\hline Z1 9.25a & 1 & 1 & 1 & I & 1 & 1 & 1 & 1 & 1 & I & & & & & \\
\hline Z1 9.25b & $\mathrm{x}$ & 1 & 16 & 1 & 1 & 1 & 15 & 1 & 1 & 1 & & & & & \\
\hline Genotyp & $\mathrm{XX}$ & 1 & 1 & 1 & 1 & 1 & 1 & 1 & 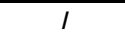 & 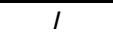 & & & & & \\
\hline \multicolumn{16}{|c|}{ WG 586 (Zahn) } \\
\hline Ex/PCR & Amelo. & 10.123 .2 & VWA & FGA & D8S1179 & $10.124 \quad \mathrm{D}$ & D18S51 & \begin{tabular}{|l|}
10.124 .1 \\
\end{tabular} & D13S317 & D7S820 & Ex/PCR & DYS19 & DYS3891 & DYS389II & DYS390 \\
\hline Z1 59.79 & $X Y$ & 1 & 1 & 1 & 1 & 1 & 14 & 1 & 1 & 10 & & & & & \\
\hline Z1 79.93 & $X Y$ & 1 & 1 & 1 & 1 & 1 & 1 & 1 & 1 & 1 & & & & & \\
\hline Genotyp & $\mathbf{X Y}$ & 1 & 1 & 1 & $I$ & 1 & 1 & 1 & I & 1 & Haplotyp & & & & \\
\hline \multicolumn{16}{|c|}{ WG 590 (Zahn 17, Zahn 13) } \\
\hline Ex/PCR & Amelo. & 10.124 .2 & VWA & FGA & D8S1179 & $10.125 \mathrm{D}$ & D18S51 & 10.125 .1 & D13S317 & D7S820 & Ex/PCR & DYS19 & DYS3891 & DYS389II & DYS390 \\
\hline Z1 43.60 & 1 & 1 & 17 & 1 & 1 & 1 & 1 & 1 & 1 & 1 & Z2 102.102 & 1 & 1 & 1 & 1 \\
\hline Z159.79 & $x$ & 1 & 17 & 22 & $11 / 14$ & $31.2 / 32.2$ & 1 & 1 & 1 & 1 & & & & & \\
\hline Z1 77.92 & $X Y$ & 1 & 1 & 21 & $12 / 13$ & 30.2 & 16 & 11 & 1 & 1 & & & & & \\
\hline Z2 95.103 & $X Y$ & 15 & 17 & $19 / 21$ & 14 & 31 & 1 & $11 / 12$ & 1 & 1 & & & & & \\
\hline Z2 102.111 & $\mathrm{XY}$ & 18 & 17 & 1 & 14 & 28 & 1 & \begin{tabular}{|l}
$(10) / 11 / 12$ \\
\end{tabular} & 1 & 11 & & & & & \\
\hline Genotyp & $X Y$ & 1 & $17 / 17$ & 1 & 14 & 1 & 1 & $11 / 12$ & I & 1 & Haplotyp & 1 & 1 & 1 & 1 \\
\hline \multicolumn{16}{|c|}{ WG 610 (Zahn 26) } \\
\hline Ex/PCR & Amelo. & 10.125 .2 & VWA & FGA & D8S1179 & $10.126 \quad \mathrm{D}$ & D18S51 & \begin{tabular}{|l|}
10.126 .1 \\
\end{tabular} & D13S317 & D7S820 & Ex/PCR & DYS19 & DYS3891 & DYS389II & DYS390 \\
\hline Z1 43.60 & $X Y$ & 14 & $15 / 16$ & $19 / 26$ & $10 / 11$ & $30 / 31.2$ & 1 & 11 & 11 & 10 & Z1 43.85 & 1 & 1 & 1 & 1 \\
\hline
\end{tabular}




\begin{tabular}{|c|c|c|c|c|c|c|c|c|c|c|c|c|c|c|c|}
\hline Z1 53.72 & $X Y$ & $14 / 18$ & 15 & 24 & $10 / 11$ & 29 & 1 & $8 / 11$ & 1 & 1 & Z1 51.77 & 1 & 1 & 1 & 1 \\
\hline Z1 54.74 & $\mathrm{XY}$ & 14/18 & (15)/16 & $24 / 26$ & 10 & $29 / 32.2$ & 1 & 11 & 14 & 9 & Z1 56.110 & 1 & 1 & 1 & 1 \\
\hline Z156.76 & $\mathrm{Y}$ & $14 / 18$ & 1 & 26 & 1 & 29 & 1 & 1 & $10 / 14$ & 1 & & & & & \\
\hline Z1 51.76 & $X Y$ & 14 & 1 & 22 & $10 / 11$ & 30 & 1 & 1 & 1 & 1 & & & & & \\
\hline Z1 102.111 & $\mathrm{XY}$ & 14 & 14 & 24 & 10 & 1 & 1 & 11 & 1 & 1 & & & & & \\
\hline Genotyp & $X Y$ & $14 / 18$ & $15 / 16$ & $24 / 26$ & 10/11 & $29 / 30$ & 1 & $11 / 11$ & 14 & 1 & Haplotyp & 1 & 1 & 1 & 1 \\
\hline \multicolumn{16}{|c|}{ WG 612 (Zahn 36) } \\
\hline Ex/PCR & Amelo. & $\begin{array}{l}10.126 .2 \\
\end{array}$ & VWA & FGA & D8S1179 & \begin{tabular}{ll|}
10.127 & $\mathrm{D}$ \\
\end{tabular} & D18S51 & 10.127 .1 & D13S317 & D7S820 & Ex/PCR & DYS19 & DYS3891 & DYS389II & DYS390 \\
\hline Z1 18.35a & $\mathrm{x}$ & 1 & 16 & 1 & 1 & 1 & $15 / 19$ & 9 & 1 & 1 & Z1 18.36 & 1 & 1 & 1 & 1 \\
\hline Z1 18.35b & 1 & 15 & $14 / 15$ & 21 & 12 & 1 & 15 & 12 & 11 & 1 & & & & & \\
\hline Z1 59.79 & $x$ & $(14) / 15 / 18$ & 18 & 1 & 1 & 32.2 & 12 & 12 & 11 & 1 & & & & & \\
\hline Z1 77.92 & 1 & 1 & 1 & 1 & 1 & 1 & 1 & 1 & 1 & 1 & & & & & \\
\hline Genotyp & $x X$ & 1 & 1 & 1 & 1 & 1 & 1 & 1 & $I$ & $I$ & Haplotyp & 1 & 1 & 1 & 1 \\
\hline \multicolumn{16}{|c|}{ WG 615 (Zahn 27) } \\
\hline Ex/PCR & Amelo. & 10.127 .2 & VWA & FGA & D8S1179 & $10.128 \quad \mathrm{D}$ & D18S51 & 10.128 .1 & D13S317 & D7S820 & Ex/PCR & DYS19 & DYS3891 & DYS389II & DYS390 \\
\hline Z1 13.29a & $\mathrm{x}$ & 1 & 1 & 1 & $10 / 12$ & 1 & 1 & 1 & 1 & 1 & Z1 13.28a & 1 & 1 & 1 & 1 \\
\hline Z1 13.29b & $\mathrm{X}$ & 1 & 1 & 22 & $12 / 14$ & 1 & 1 & 1 & 1 & 11 & Z1 13.28b & 1 & 1 & 1 & 1 \\
\hline Genotyp & (XX) & 1 & 1 & I & 1 & 1 & 1 & 1 & 1 & 1 & Haplotyp & 1 & 1 & 1 & I \\
\hline \multicolumn{16}{|c|}{ WG 616 (Zahn 23) } \\
\hline Ex/PCR & Amelo. & 10.128 .2 & VWA & FGA & D8S1179 & \begin{tabular}{ll|}
10.129 & $\mathrm{D}$
\end{tabular} & D18S51 & 10.129 .1 & D13S317 & D7S820 & Ex/PCR & DYS19 & DYS3891 & DYS389II & DYS390 \\
\hline $\mathrm{Z1} 12.27 a$ & $x$ & 1 & 1 & 1 & 1 & 1 & 1 & 1 & 1 & 1 & Z1 12.28a & 1 & 1 & 1 & 1 \\
\hline Z1 12.27 & 1 & 1 & 1 & 21 & 16 & 35 & 1 & 13 & 1 & 1 & Z1 12.28b & 1 & 1 & 1 & 1 \\
\hline Z1 12.31a & $x$ & 1 & 1 & 1 & 14 & 1 & 1 & 11 & 1 & 1 & & & & & \\
\hline Z1 12.31b & $\mathrm{X}$ & 1 & 14 & 1 & 1 & 29 & 1 & 12 & 11 & $9 / 10$ & & & & & \\
\hline Z1 59.76 & 1 & 1 & 1 & 1 & 1 & 1 & 1 & 1 & 1 & 1 & & & & & \\
\hline Genotyp & $(\mathrm{XX})$ & $I$ & $I$ & 1 & 1 & 1 & 1 & 1 & $I$ & $I$ & Haplotyp & 1 & 1 & 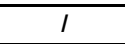 & 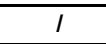 \\
\hline \multicolumn{16}{|c|}{ WG 619 (Zahn 46, Zahn 47) } \\
\hline Ex/PCR & Amelo. & 10.129 .2 & VWA & FGA & D8S1179 & $10.130 \mathrm{D}$ & D18S51 & \begin{tabular}{|l|}
10.130 .1 \\
\end{tabular} & D13S317 & D7S820 & Ex/PCR & DYS19 & DYS3891 & DYS389II & DYS390 \\
\hline Z1 1.1a & 1 & 1 & 1 & 1 & 1 & 1 & 1 & 1 & 1 & 1 & Z1 3.4a & 16 & 12 & 1 & 22 \\
\hline Z1 1.1b & 1 & 1 & 1 & 1 & 1 & 1 & 1 & 1 & 1 & 1 & Z1 3.4a & 16 & 12 & 1 & 22 \\
\hline Z1 3.2a & $X Y$ & $14 / 18$ & $17 / 19$ & $20 / 22$ & $12 / 14$ & $26 / 30$ & 13 & \begin{tabular}{|c|}
$9 /(10) /(11)$ \\
\end{tabular} & 1 & 1 & Z1 9.22a & 16 & 12 & 1 & 22 \\
\hline $\mathrm{Z1} \mathrm{3.2b}$ & $\overline{X Y}$ & $14 / 18$ & $17 / 19$ & $20 / 22$ & $12 / 14$ & 30 & 1 & \begin{tabular}{|c|}
$9 /(10)$ \\
\end{tabular} & $(10) / 11$ & 1 & $Z 19.22 b$ & 16 & 12 & 30 & 22 \\
\hline Z1 3.3a & $X Y$ & $14 / 18$ & $17 / 19$ & 22 & $12 / 14$ & 30 & $13 / 17$ & $9 / 10$ & 11 & $(10) / 11$ & Z1 9.22a & 16 & 12 & 30 & 22 \\
\hline Z1 3.3b & $X Y$ & $14 / 18$ & $17 / 19$ & $20 / 22$ & $12 / 14$ & 30 & $13 / 17$ & $(9) / 10$ & 11 & 11 & & & & & \\
\hline Z1 9.25a & Ü.a. & $14 / 18$ & 17 & 20 & Ü.a. & 30 & $15 / 17$ & Ü.a. & 10 & 10 & & & & & \\
\hline Z1 9.25b & Ü.a. & $14 / 18$ & $17 / 19$ & $20 / 22$ & $12 / 14$ & 30 & 1 & $9 / 10$ & 10 & 11 & & & & & \\
\hline
\end{tabular}




\begin{tabular}{|c|c|c|c|c|c|c|c|c|c|c|c|c|c|c|c|}
\hline Z1 17.S1 & $X Y$ & $14 / 18$ & 17 & 22 & $12 / 14$ & 30 & 1 & 9 & 10 & 1 & & & & & \\
\hline Z1 17.S2 & $\mathrm{XY}$ & 14/18 & $17 / 19$ & $20 / 22$ & $12 / 14$ & 30 & 1 & $9 /(10)$ & $10 / 11$ & 1 & & & & & \\
\hline Z2 38.58 & $X Y$ & $14 / 18$ & $17 / 19$ & $20 / 22$ & $12 / 14$ & 30 & 1 & $9 / 10$ & $10 / 11$ & 1 & & & & & \\
\hline Z2 30.63 & $X Y$ & $14 / 18$ & $17 / 19$ & 1 & $11 / 12 / 14$ & 30 & 1 & $(9) / 10$ & 10 & 1 & & & & & \\
\hline Genotyp & $\mathrm{XY}$ & $14 / 18$ & $17 / 19$ & $20 / 22$ & $12 / 14$ & $30 / 30$ & $(13) / 17$ & $9 / 10$ & $10 / 11$ & $(10) / 11$ & \begin{tabular}{|l|} 
Haplotyp \\
\end{tabular} & 16 & 12 & 30 & 22 \\
\hline \multicolumn{16}{|c|}{ WG 620 (Zahn 35) } \\
\hline Ex/PCR & Amelo. & 10.130 .2 & VWA & FGA & D8S1179 & $10.131 \quad \mathrm{D}$ & D18S51 & 10.131 .1 & D13S317 & D7S820 & Ex/PCR & DYS19 & DYS3891 & DYS389II & DYS390 \\
\hline Z1 60.80 & $X Y$ & $16 / 18$ & $16 / 18$ & $(21) / 22 / 25$ & $10 / 13$ & $28 / 30$ & 12 & $11 / 12$ & 1 & $10 / 11$ & Z160.85a & 1 & 1 & 1 & 1 \\
\hline Z192.101 & $x$ & 1 & $14 / 16$ & 24 & 12 & 1 & 1 & 1 & 12 & 1 & $\mathrm{Z1}$ 60.83b & 1 & 1 & 1 & $23 / 25$ \\
\hline Z1 96.103 & $x$ & 18 & 16 & 24 & 16 & 1 & 1 & 10 & 1 & 1 & & & & & \\
\hline Genotyp & 1 & 18 & 16 & 24 & 1 & 1 & 1 & 1 & 1 & 1 & Haplotyp & 1 & 1 & 1 & 1 \\
\hline \multicolumn{16}{|c|}{ WG 625 (Zahn 37; Femur) } \\
\hline Ex/PCR & Amelo. & 10.131 .2 & VWA & FGA & D8S1179 & $10.132 \mathrm{D}$ & D18S51 & 10.132 .1 & D13S317 & D7S820 & Ex/PCR & DYS19 & DYS389I & DYS389II & DYS390 \\
\hline Z1 9.19 & 1 & 15 & 1 & 22.2 & 11 & $30.2 / 31.2$ & 1 & 1 & 1 & 9 & Z19.21 a & 1 & 1 & 1 & 22 \\
\hline Z1 9.23 & $\mathrm{X}$ & (15)/16 & 17 & 1 & 11 & 30 & 1 & 12 & 1 & 1 & Z1 9.21 b & 1 & 1 & 1 & 1 \\
\hline Z1 9.23 & $\mathrm{Y}$ & 16 & 16 & 1 & 13 & 1 & 1 & 10 & 1 & 1 & Z1 $9.24 \mathrm{a}$ & 1 & 1 & 1 & 1 \\
\hline $\mathrm{Z1} 60.80$ & $x$ & $14 / 16$ & 17 & $22 / 24$ & 11 & 31 & $12 / 16$ & $8 / 10$ & $10 / 17$ & 1 & Z1 60.85 & 1 & 14 & 1 & 1 \\
\hline K 114.128 & 1 & 1 & 1 & 1 & 1 & 1 & 1 & 1 & 1 & 1 & & & & & \\
\hline Genotyp & 1 & $I$ & 1 & 1 & 1 & 1 & 1 & & $I$ & 1 & Haplotyp & 1 & 1 & 1 & 1 \\
\hline \multicolumn{16}{|c|}{ WG 631 (Zahn 26; Femur) } \\
\hline Ex/PCR & Amelo. & 10.132 .2 & VWA & FGA & D8S1179 & $10.133 \quad \mathrm{D}$ & D18S51 & 10.133 .1 & D13S317 & D7S820 & Ex/PCR & DYS19 & DYS389| & DYS389II & DYS390 \\
\hline Z1 18.35a & $X Y$ & $15 / 18$ & $(15) / 16 / 18$ & 20 & $(11) / 12 / 14$ & $26 / 29$ & 1 & 12 & 12 & 1 & Z1 18.36 & 1 & 1 & 1 & 1 \\
\hline$Z 1$ 18.35b & $X Y$ & 15 & $15 / 19$ & 19/22 & 11 & 29 & 1 & 12 & $8 / 12$ & 1 & Z1 47.85 & 13 & 13 & 30 & 1 \\
\hline Z1 47.66 & $X Y$ & $15 / 18$ & 16 & $19 / 20$ & $11 / 12$ & 29 & 1 & $8 / 12$ & 8 & 1 & Z1 60.85 & 13 & 13 & 1 & 25 \\
\hline $\mathrm{Z1} 60.80$ & $X Y$ & $15 / 18 / 19$ & 1 & 20 & 15 & 29 & 1 & 1 & 12 & 1 & Z177.110 & 1 & 1 & 30 & 25 \\
\hline Z1 77.92 & $\mathrm{XY}$ & 15 & $15 / 16 / 17$ & 20 & $11 / 12$ & 29 & 1 & 1 & 1 & 1 & K 108.126 & 1 & 1 & 1 & 1 \\
\hline K 113.124 & $\mathrm{x}$ & $15 / 17$ & 18 & $19 / 20$ & 1 & $29 / 31$ & $16 / 17$ & & $12 / 13$ & 10 & K 113.126 & 1 & 1 & 1 & 1 \\
\hline K 114.125 & $x$ & 15 & 18 & 24 & 1 & 29 & 1 & 12 & 1 & 9 & K 114.126 & 1 & 1 & 1 & 1 \\
\hline Genotyp & $\overline{X Y}$ & $15 / 18$ & $15 / 16$ & $19 / 20$ & $11 / 12$ & $29 / 29$ & I & $12 / 12$ & $8 / 12$ & 1 & Haplotyp & 13 & 13 & 30 & 25 \\
\hline \multicolumn{16}{|c|}{ WG 636 (Zahn 16) } \\
\hline Ex/PCR & Amelo. & 10.133 .2 & VWA & FGA & D8S1179 & $10.134 \quad \mathrm{D}$ & D18S51 & 10.134 .1 & D13S317 & D7S820 & Ex/PCR & DYS19 & DYS3891 & DYS389II & DYS390 \\
\hline Z1 60.80 & $x$ & 15 & 1 & 1 & 11 & 1 & 1 & 1 & 1 & 1 & & & & & \\
\hline Z1 92.101 & 1 & 1 & 1 & 1 & 1 & 1 & 1 & 1 & 1 & 1 & & & & & \\
\hline Genotyp & $I$ & 1 & 1 & $I$ & 1 & 1 & $I$ & 1 & $I$ & 1 & Haplotyp & & & & \\
\hline \multicolumn{16}{|c|}{ WG 641 (Zahn 43) } \\
\hline Ex/PCR & Amelo. & 10.134 .2 & VWA & FGA & D8S1179 & $10.135 \mathrm{D}$ & D18S51 & 10.135 .1 & D13S317 & D7S820 & Ex/PCR & DYS19 & DYS3891 & DYS389II & DYS390 \\
\hline
\end{tabular}




\begin{tabular}{|c|c|c|c|c|c|c|c|c|c|c|c|c|c|c|c|}
\hline Z1 60.80 & $\mathrm{Y}$ & 1 & 1 & 1 & 1 & 1 & $15 / 17$ & 1 & 1 & 1 & & & & & \\
\hline Z1 92.101 & $x$ & 16 & 18 & 19 & $10 / 14$ & 32.2 & 1 & 1 & 12 & 1 & & & & & \\
\hline Genotyp & 1 & 1 & 1 & 1 & 1 & 1 & 1 & 1 & 1 & 1 & Haplotyp & & & & \\
\hline \multicolumn{16}{|c|}{ WG 644 (Zahn 38, Zahn 37) } \\
\hline Ex/PCR & Amelo. & 10.135 .2 & VWA & FGA & D8S1179 & $10.136 \quad D$ & D18S51 & 10.136 .1 & D13S317 & D7S820 & Ex/PCR & DYS19 & DYS3891 & DYS389II & DYS390 \\
\hline Z1 4.6a & $X Y$ & 15 & $16 / 20$ & 20 & 12 & $29 / 31.2$ & 1 & $9 / 12$ & $9 / 11$ & 11 & Z1 4.8 & 16 & 12 & 1 & 22 \\
\hline Z1 4.6b & $X Y$ & $15 / 18$ & 14 & 19/20/(21) & 12 & $29 / 31.2$ & 1 & $9 / 12$ & 9/11/13 & 11 & Z1 7.18a & 15 & 1 & 1 & 22 \\
\hline Z1 4.7a & ü.a & ü.a & (15)16/20 & $19 / 20$ & ü.a & $29 / 31.2$ & 1 & 12 & $9 / 11$ & 11 & $\mathrm{Z17.18b}$ & 1 & 12 & 1 & 22 \\
\hline Z1 4.7b & ü.a & ü.a & $(16) /(20)$ & 20 & ü.a & $29 / 31.2$ & 1 & 1 & 11 & 11 & $\mathrm{Z1} \mathrm{7.18c}$ & 16 & 12 & $\frac{T}{1}$ & 22 \\
\hline Z1 7.16a & $\mathrm{XY}$ & $15 / 17$ & $11 / 15 / 16$ & $19 / 20$ & $12 / 14$ & 31.2 & 19 & 1 & 9 & $10 / 11$ & Z1 15.33a & 16 & 12 & 7 & 22 \\
\hline Z1 7.16b & $X Y$ & 18 & $(15) / 16$ & 19 & $12 / 14$ & $30.2 / 31.2$ & 15 & $9 / 12$ & 11 & 10 & Z1 15.33b & 16 & 1 & 1 & \\
\hline Z17.17a & $X Y$ & 16 & $14 / 16 / 20$ & 1 & $12 / 13$ & $29 / 31.2$ & 18 & 12 & $11 / 13$ & $10 / 11$ & \begin{tabular}{|l|}
$Z 276.122$ \\
\end{tabular} & 1 & 12 & 7 & 22 \\
\hline Z1 7.17b & $X Y$ & $15 / 18$ & 20 & 20 & 12 & $29 / 31.2$ & 1 & 12 & 9 & 1 & & & & & \\
\hline Z2 33.52 & $\mathrm{XY}$ & $15 / 18$ & 16 & 1 & $12 / 15$ & 31.2 & 17 & 9 & 11 & 1 & & & & & \\
\hline Z2 35.54 & $\overline{X Y}$ & $15 / 18$ & $16 / 20$ & $19 / 20$ & 12 & 1 & 1 & $9 / 12$ & $9 / 11$ & 11 & & & & & \\
\hline Genotyp & $\mathrm{XY}$ & 15/18 & $16 / 20$ & $19 / 20$ & 12 & $29 / 31.2$ & I & 9/12 & 9/11 & 10/11 & Haplotyp & 16 & 12 & I & 22 \\
\hline \multicolumn{16}{|c|}{ WG 647 (Zahn 36, Zahn 26) } \\
\hline Ex/PCR & Amelo. & 10.136 .2 & VWA & FGA & D8S1179 & $10.137 \quad \mathrm{D}$ & D18S51 & 10.137 .1 & D13S317 & D7S820 & & & & & \\
\hline $\mathrm{Z1} 60.80$ & $\mathrm{x}$ & $16 / 17$ & 1 & 1 & 12 & 1 & 1 & 12 & 1 & 1 & & & & & \\
\hline Z177.92 & $x$ & $(15) / 16$ & $16 / 18$ & 1 & 1 & 1 & 1 & 1 & 1 & 1 & & & & & \\
\hline Z2 92.101 & $\mathrm{x}$ & $14 / 16$ & 1 & 23 & 1 & 1 & 1 & 1 & 1 & 1 & & & & & \\
\hline Z2 96.103 & $x$ & $16 / 17$ & 1 & 23 & 1 & 1 & 12 & 1 & 1 & 1 & & & & & \\
\hline Genotyp & $x X$ & 1 & 1 & 23 & 1 & 1 & 1 & 1 & 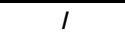 & 1 & & & & & \\
\hline \multicolumn{16}{|c|}{ WG 655 (Zahn 46) } \\
\hline Ex/PCR & Amelo. & 10.137 .2 & VWA & FGA & D8S1179 & \begin{tabular}{ll|}
$10.138 \quad \mathrm{D}$ \\
\end{tabular} & D18S51 & 10.138 .1 & D13S317 & D7S820 & Ex/PCR & DYS19 & DYS3891 & DYS389II & DYS390 \\
\hline Z1 7.16a & $\mathrm{Y}$ & 1 & 18 & 1 & 1 & $26 / 29 / 30$ & 1 & 1 & 11 & 1 & Z1 7.18a & 1 & 1 & 1 & 1 \\
\hline Z1 7.16b & $\bar{Y}$ & $13 / 16$ & $16 / 17$ & 1 & $11 / 14$ & 1 & 1 & 12 & 10 & 1 & $\mathrm{Z17.18b}$ & 1 & 12 & 30 & 1 \\
\hline Z1 7.17a & 1 & 1 & 1 & 1 & 1 & 30 & 1 & 1 & 1 & 1 & $\mathrm{Z1} \mathrm{7.18c}$ & 1 & 12 & 30 & 1 \\
\hline $\mathrm{Z17.17b}$ & $\bar{Y}$ & $12 / 15$ & 17 & 21 & 1 & 30 & 1 & 12 & 1 & 1 & Z19.21a & 1 & 1 & 1 & 1 \\
\hline Z1 9.19 & $X Y$ & $13 / 16$ & 1 & 1 & 14 & 1 & 19 & 1 & 1 & 1 & Z1 9.21b & 14 & 12 & 1 & 1 \\
\hline Z1 9.23a & $\mathrm{Y}$ & $16 / 17$ & $14 / 18$ & 1 & 1 & 1 & 1 & 12 & 1 & 1 & Z1 9.22 & 1 & 13 & 1 & 23 \\
\hline Z1 9.23b & 1 & 13/16/17 & 16 & 1 & $10 / 13$ & 1 & 19 & $10 / 11$ & 1 & 1 & Z1 40.85 & 14 & 12 & 1 & 1 \\
\hline Z1 40.59 & $Y$ & 16 & 16/17/18 & 1 & 13 & 1 & 1 & 10 & 1 & 1 & & & & & \\
\hline Z1 47.66 & 1 & 18 & 1 & 22 & 10 & 1 & 1 & 1 & 1 & 1 & & & & & \\
\hline K 118.131 & $X Y$ & 13/15/17 & $17 / 18$ & 21 & 13/14/15 & $29 / 31.2$ & 1 & $11 / 12$ & $10 / 13$ & 1 & & & & & \\
\hline Genotyp & $X Y$ & 13/16/17 & 16/17/18 & 21 & $13 / 14$ & 30 & (19) & 12 & 1 & 1 & Haplotyp & 14 & 12 & 30 & I \\
\hline
\end{tabular}




\begin{tabular}{|c|c|c|c|c|c|c|c|c|c|c|c|c|c|c|c|}
\hline \multicolumn{16}{|c|}{ WG 658 (Zahn 36) } \\
\hline Ex/PCR & Amelo. & 10.138 .2 & VWA & FGA & D8S1179 & $10.139 \mathrm{D}$ & D18S51 & 10.139 .1 & D13S317 & D7S820 & Ex/PCR & DYS19 & DYS3891 & DYS389II & DYS390 \\
\hline Z1 47.66 & $x$ & 18 & 19 & $22 / 23$ & 1 & 1 & 16 & 1 & 10 & 10 & Z1 61.83 & 1 & 12 & 1 & 1 \\
\hline Z1 61.80 & $X Y$ & 18 & $16 / 17$ & $22 / 23$ & $12 / 13$ & 29 & 1 & $8 / 9 / 10$ & 1 & 1 & Z1 61.85 & 1 & 13 & 1 & 23 \\
\hline Z1 77.92 & $\mathrm{XY}$ & 14/18 & $16 / 19$ & 1 & $(11) / 13$ & 1 & 1 & 12 & 1 & 1 & Z1 77.122 & 1 & 13 & 1 & 23 \\
\hline Z1 92.101 & 1 & 1 & 1 & 1 & 1 & 1 & 1 & 1 & 1 & 1 & & & & & \\
\hline Genotyp & $X Y$ & $18 /(18)$ & $16 / 19$ & $22 / 23$ & 13 & 1 & 1 & 1 & 1 & 1 & Haplotyp & 1 & 13 & $I$ & 23 \\
\hline \multicolumn{16}{|c|}{ WG 668 (Zahn 17) } \\
\hline Ex/PCR & Amelo. & 10.139 .2 & VWA & FGA & D8S1179 & \begin{tabular}{ll|}
$10.140 \quad \mathrm{D}$ \\
\end{tabular} & D18S51 & 10.140 .1 & D13S317 & D7S820 & & & & & \\
\hline Z1 97.104 & $x$ & $14 / 15$ & $16 / 17$ & $21 / 22$ & $12 / 13$ & 1 & $10 / 13$ & 13 & 15 & 10 & & & & & \\
\hline Z1 98.104 & $x$ & $14 / 15$ & 1 & 21 & 16 & 1 & 1 & 13 & 1 & 11 & & & & & \\
\hline Z1 104.112 & $\bar{x}$ & $14 / 15$ & 16 & 22 & $12 / 13$ & 28 & 7 & 13 & 13 & $\frac{1}{1}$ & & & & & \\
\hline Genotyp & $x x$ & $14 / 15$ & 16 & $21 / 22$ & $12 / 13$ & 1 & 1 & $13 / 13$ & 1 & 1 & & & & & \\
\hline \multicolumn{16}{|c|}{ WG 689 (Zahn 18) } \\
\hline Ex/PCR & Amelo. & 10.140 .2 & VWA & FGA & D8S1179 & \begin{tabular}{|l|l|}
$10.141 \quad \mathrm{D}$ & \\
\end{tabular} & D18S51 & \begin{tabular}{|l|}
10.141 .1 \\
\end{tabular} & D13S317 & D7S820 & Ex/PCR & DYS19 & DYS389| & DYS389II & DYS390 \\
\hline Z1 45.61 & $\mathrm{Y}$ & 17 & $(17) / 18$ & 1 & 10 & 28 & 1 & 1 & 1 & 1 & Z1 46.68 & 1 & 13 & 1 & 1 \\
\hline Z1 46.64 & $\mathrm{Y}$ & 1 & 1 & 22.2 & 14 & 30 & 1 & 12 & 8 & 9 & Z1 52.77 & 1 & 1 & 1 & 1 \\
\hline Z1 53.72 & $X Y$ & 15 & 1 & 1 & 8 & 1 & 1 & 1 & 1 & 1 & & & & & \\
\hline Z1 52.70 & 1 & 1 & 1 & 1 & 1 & 1 & 1 & 1 & 1 & 1 & & & & & \\
\hline Z1 52.76 & 1 & 1 & 1 & 1 & 1 & 1 & 1 & 1 & 1 & 1 & & & & & \\
\hline Z1 77.92 & $x$ & 1 & 19 & 1 & 1 & 1 & 1 & 1 & 1 & 1 & & & & & \\
\hline Genotyp & $\overline{X Y}$ & I & 1 & I & $I$ & I & 1 & 1 & $I$ & I & Haplotyp & $T$ & $T$ & $T$ & $T$ \\
\hline \multicolumn{16}{|c|}{ WG 696 (Zahn 46, Femur) } \\
\hline Ex/PCR & Amelo. & 10.141 .2 & VWA & FGA & D8S1179 & $10.142 \mathrm{D}$ & D18S51 & 10.142 .1 & D13S317 & D7S820 & Ex/PCR & DYS19 & DYS3891 & DYS389II & DYS390 \\
\hline Z1 45.61 & $\mathrm{XY}$ & 17 & $16 / 18$ & $19 / 23$ & $10 / 12 / 15$ & 33 & 1 & 11 & 12 & 1 & Z1 45.68 & 1 & 13 & 1 & 1 \\
\hline Z1 46.64 & $\mathrm{XY}$ & 17 & $17 /(18)$ & $19 / 23$ & $13 / 15$ & 28 & 1 & 11 & 1 & 1 & Z1 46.68 & 14 & & & \\
\hline Z1 53.72 & $\overline{X Y}$ & $15 / 17$ & $15 / 17$ & 19 & $11 / 13$ & $28 / 29$ & 18 & $(11) / 12$ & $8 / 13$ & 9 & Z1 46.85 & 1 & I & 1 & 1 \\
\hline Z154.74 & $X Y$ & 17 & 17 & $19 / 23$ & 13 & $28 / 29$ & $13 / 14$ & $11 / 13$ & $13 / 14$ & 8 & Z1 52.77 & 1 & 1 & 1 & 1 \\
\hline Z1 52.70 & $\overline{X Y}$ & 17 & 18 & 19 & 1 & 31 & 1 & 11 & 1 & 1 & K 109.126 & 1 & 1 & 1 & 1 \\
\hline Z1 52.76 & 1 & 18 & 1 & 1 & 1 & 1 & 1 & 1 & 1 & 1 & & & & & \\
\hline K 115.127 & $x$ & 15 & 16 & 1 & 10 & 33.2 & 1 & 1 & 11 & 10 & & & & & \\
\hline K 118.131 & $\overline{X Y}$ & $13 / 15 / 16$ & 16 & $21 / 22 / 26$ & $13 / 14$ & $27 / 28 / 29$ & 19 & $(11) / 12$ & 12 & 11 & & & & & \\
\hline Genotyp & $X Y$ & 17 & $17 / 18$ & $19 / 23$ & $13 / 15$ & $28 / 29$ & 1 & $11 /(11)$ & 13 & 1 & Haplotyp & $I$ & 1 & 1 & $I$ \\
\hline \multicolumn{16}{|c|}{ WG 697 (Zahn 46, Zahn 24) } \\
\hline Ex/PCR & Amelo. & 10.142 .2 & VWA & FGA & D8S1179 & $10.143 \quad \mathrm{D}$ & D18S51 & 10.143 .1 & D13S317 & D7S820 & & & & & \\
\hline Z1 16.34a & $x$ & $15 / 18$ & 16 & $22 / 23$ & $13 / 14$ & $26 / 30$ & 1 & $9 /(11) / 12$ & 1 & 1 & & & & & \\
\hline
\end{tabular}




\begin{tabular}{|c|c|c|c|c|c|c|c|c|c|c|c|c|c|c|c|}
\hline Z1 16.34b & $\mathrm{x}$ & 15 & 16 & $22 / 23$ & 13 & 26 & 1 & 9 & 1 & 1 & & & & & \\
\hline Z1 26.44 & $x$ & $15 / 17 / 18$ & $15 / 16$ & 22 & $11 / 13$ & 30 & $13 / 19$ & 1 & 11 & 1 & & & & & \\
\hline Z1 48.67 & $\mathrm{XY}$ & 18 & 1 & 24 & $11 / 13$ & 30 & 1 & $11 / 12$ & 1 & 1 & & & & & \\
\hline Z2 61.80 & 1 & 1 & 1 & 1 & 1 & 1 & 1 & 1 & 1 & 1 & & & & & \\
\hline Z2 77.92 & $x$ & 14 & 16 & 22 & 13 & 1 & 1 & 10 & 1 & 8 & & & & & \\
\hline Genotyp & $x x$ & 15/18 & $16 / 16$ & $22 /(23)$ & $11 / 13$ & $(26) / 30$ & 1 & $(9) / 12$ & 1 & 1 & & & & & \\
\hline \multicolumn{16}{|c|}{ WG 699 (Zahn 38) } \\
\hline Ex/PCR & Amelo. & 10.143 .2 & VWA & FGA & D8S1179 & $10.144 \quad \mathrm{D}$ & D18S51 & 10.144 .1 & D13S317 & D7S820 & Ex/PCR & DYS19 & DYS3891 & DYS389II & DYS390 \\
\hline$\overline{Z 116.34 a}$ & $x$ & 1 & 1 & 1 & 14 & 1 & 19 & 13 & 1 & 1 & & & & & \\
\hline Z1 16.34b & 1 & 1 & 16 & 1 & 13 & 29 & 1 & 1 & 8 & 8 & & & & & \\
\hline Z1 61.80 & $\mathrm{XY}$ & 17 & 1 & 1 & 10 & 1 & 1 & 1 & 1 & 1 & & & & & \\
\hline Genotyp & 1 & 1 & 1 & 1 & 1 & 1 & 1 & 1 & I & 1 & Haplotyp & & & & \\
\hline \multicolumn{16}{|c|}{ WG 702 (Zahn 84) } \\
\hline Ex/PCR & Amelo. & 10.144 .2 & VWA & FGA & D8S1179 & $10.145 \quad \mathrm{D}$ & D18S51 & 10.145 .1 & D13S317 & D7S820 & Ex/PCR & DYS19 & DYS3891 & DYS389II & DYS390 \\
\hline Z1 61.80 & 1 & 1 & 1 & 1 & 1 & 1 & 1 & 1 & 1 & 1 & & & & & \\
\hline Genotyp & 1 & 1 & 1 & 1 & 1 & 1 & 1 & 1 & 1 & 1 & Haplotyp & & & & \\
\hline \multicolumn{16}{|c|}{ WG 704 (Zahn 48) } \\
\hline Ex/PCR & Amelo. & 10.145 .2 & VWA & FGA & D8S1179 & $10.146 \mathrm{D}$ & D18S51 & 10.146 .1 & D13S317 & D7S820 & Ex/PCR & DYS19 & DYS389I & DYS389II & DYS390 \\
\hline Z1 12.27a & $\mathrm{Y}$ & 1 & 14 & 22 & 13 & 1 & 1 & 10 & 15 & 1 & Z1 12.28a & 1 & 1 & 1 & 23 \\
\hline Z1 12.27b & $\overline{X Y}$ & $15 / 16$ & 1 & 1 & 13 & 1 & 1 & 10 & 1 & 1 & Z1 12.28b & 15 & 12 & 1 & 1 \\
\hline Z1 12.31a & $\mathrm{Y}$ & 14 (kl.) & 14 & 20 & 13 & 1 & 1 & 11 & 1 & 10 & Z1 22.41 & 14 & 12 & 27 & 23 \\
\hline Z1 12.31b & $\mathrm{Y}$ & 15 & $14 / 16 / 18$ & 22 & $13 / 14$ & $30 / 31.2$ & 1 & 12 & 13 & 8 & Z1 23.41 & 1 & 12 & 1 & 23 \\
\hline Z1 22.39 & $\mathrm{XY}$ & $15 / 16$ & 14/15/16 & $20 / 22$ & $13 / 15$ & $31 / 31.2$ & 14 & $12 / 13$ & 12 & 12 & Z1 22.43 & 14 & 12 & 1 & 23 \\
\hline Z1 22.40 & $X Y$ & $15 / 16$ & $14 / 16$ & $20 / 22$ & $13 / 15$ & 31.2 & 14 & $12 / 13$ & 11 & 1 & Z1 23.47a & 14 & 12 & 1 & 23 \\
\hline Z1 23.42 & $X Y$ & $15 / 16$ & $14 / 16$ & 1 & $13 / 15$ & $29 / 31$ & 1 & $(12) / 13$ & 1 & 12 & Z1 23.47b & 14 & 12 & 1 & 23 \\
\hline Z1 52.70 & $\mathrm{Y}$ & 16 & 1 & 1 & $13 / 15$ & 1 & 14 & 1 & 1 & 1 & & & & & \\
\hline Z1 61.80 & $X Y$ & $15 / 16$ & $14 / 18$ & 1 & 13 & 1 & 1 & 13 & 1 & 1 & & & & & \\
\hline Genotyp & $\mathrm{XY}$ & $15 / 16$ & $14 / 16$ & $20 / 22$ & $13 / 15$ & $31 / 31.2$ & $14 / 14$ & $12 / 13$ & 1 & 12 & Haplotyp & 14 & 12 & 1 & 23 \\
\hline \multicolumn{16}{|c|}{ WG 705 (Zahn 64) } \\
\hline Ex/PCR & Amelo. & 10.146 .2 & VWA & FGA & D8S1179 & $10.147 \quad \mathrm{D}$ & D18S51 & 10.147 .1 & D13S317 & D7S820 & Ex/PCR & DYS19 & DYS3891 & DYS389II & DYS390 \\
\hline Z1 61.80 & 1 & 1 & 1 & 1 & 1 & 1 & 1 & 1 & 1 & 1 & & & & & \\
\hline Genotyp & I & 1 & $I$ & 1 & $I$ & $I$ & I & 1 & 1 & 1 & Haplotyp & & & & \\
\hline \multicolumn{16}{|c|}{ WG 715 (Zahn 54) } \\
\hline Ex/PCR & Amelo. & 10.147 .2 & VWA & FGA & D8S1179 & $10.148 \quad \mathrm{D}$ & D18S51 & 10.148 .1 & D13S317 & D7S820 & Ex/PCR & DYS19 & DYS3891 & DYS389II & DYS390 \\
\hline Z1 78.92 & $X Y$ & 1 & 1 & 21 & 1 & 1 & 1 & 1 & 1 & 1 & & & & & \\
\hline Genotyp & 1 & 1 & 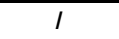 & 1 & 1 & $t$ & 1 & 1 & $t$ & 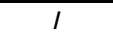 & Haplotyp & & & & \\
\hline
\end{tabular}




\begin{tabular}{|c|c|c|c|c|c|c|c|c|c|c|c|c|c|c|c|}
\hline \multicolumn{16}{|c|}{ WG 724 (Zahn 62) } \\
\hline Ex/PCR & Amelo. & 10.148 .2 & VWA & FGA & D8S1179 & $10.149 \mathrm{D}$ & D18S51 & 10.149 .1 & D13S317 & D7S820 & Ex/PCR & DYS19 & DYS3891 & DYS389II & DYS390 \\
\hline Z1 78.92 & 1 & 1 & 15 & 1 & 1 & 28 & 1 & 1 & 1 & 1 & & & & & \\
\hline Z1 92.101 & 1 & 1 & 1 & 1 & 1 & 1 & 1 & 1 & 1 & 1 & & & & & \\
\hline Genotyp & $I$ & 1 & 1 & 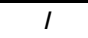 & 1 & 1 & I & 1 & 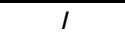 & 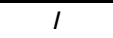 & Haplotyp & & & & \\
\hline \multicolumn{16}{|c|}{ WG 748 (Zahn 46, Femur) } \\
\hline Ex/PCR & Amelo. & 10.149 .2 & VWA & FGA & D8S1179 & $10.150 \mathrm{D}$ & D18S51 & 10.150 .1 & D13S317 & D7S820 & Ex/PCR & DYS19 & DYS3891 & DYS389II & DYS390 \\
\hline Z1 45.61 & $\mathrm{XY}$ & $18 / 19$ & 16 & $20 / 24$ & $10 / 13$ & $28 / 31$ & $15 / 16$ & $11 / 14$ & $\begin{array}{ll}(11) / 12 \\
\end{array}$ & 12 & Z1 45.65 & 16 & 13 & 1 & 25 \\
\hline Z1 46.64 & $X Y$ & 18 & 17 & $20 / 24$ & $10 / 13$ & $28 / 30$ & 1 & $11 / 14$ & $11 / 12$ & $10 / 12$ & Z1 46.68 & 16 & 13 & 7 & 25 \\
\hline Z1 52.70 & $\overline{X Y}$ & $17 / 18$ & $16 / 17$ & 20 & $10 / 13$ & 1 & 1 & 11 & 1 & 1 & Z1 52.77 & 1 & 1 & 1 & 1 \\
\hline Z1 52.76 & $\mathrm{XY}$ & 17 & 1 & 1 & 1 & I & 1 & 1 & 1 & 1 & Z1 46.109 & 1 & 1 & 33 & 25 \\
\hline Z1 54.74 & 1 & 1 & 7 & $20 / 24$ & 7 & 7 & $14 / 16$ & 1 & 1 & $9 / 10$ & \begin{tabular}{|l|} 
K 109.126 \\
\end{tabular} & 7 & 7 & 1 & 1 \\
\hline Genotyp & $X Y$ & 17/18 & $16 / 17$ & $20 / 24$ & $10 / 13$ & 28 & 16 & 11/14 & $(11) / 12$ & $(10) / 12$ & Haplotyp & 16 & 13 & 1 & 25 \\
\hline \multicolumn{16}{|c|}{ WG 757 (Zahn 37, Zahn 38; Femur) } \\
\hline Ex/PCR & Amelo. & 10.150 .2 & VWA & FGA & D8S1179 & $\begin{array}{|ll|}10.151 \quad \mathrm{D} \\
\end{array}$ & D18S51 & 10.151 .1 & D13S317 & D7S820 & Ex/PCR & DYS19 & DYS389| & DYS389II & DYS390 \\
\hline Z1 16.34a & $X Y$ & 16 & 16 & 22 & 1 & 1 & 1 & 1 & 1 & 11 & Z1 16.36 & 1 & 1 & 1 & 1 \\
\hline Z1 16.34b & 1 & 15 & 16 & 22 & $12 / 14 / 18$ & 31.2 & 16 & l & 11 & 1 & Z2 40.65 & 16 & 12 & 1 & 1 \\
\hline Z1 27.46 & $X Y$ & $15 / 18$ & 16/18 & 21 & $13 / 14$ & 1 & $13 / 17$ & 1 & 1 & 11 & Z2 46.68 & 1 & 1 & 1 & 1 \\
\hline Z1 35.54 & $X Y$ & 18 & 15/16/18 & 21 & 13 & 31.2 & 1 & 11 & 11 & 11 & Z2 47.85 & 1 & 1 & 1 & 26 \\
\hline Z2 40.59 & $\mathrm{XY}$ & $15 / 18$ & $(15) / 16 / 18$ & $21 / 22$ & $(13) / 14$ & $28 / 30.2$ & l & 11 & 1 & 1 & Z2 51.77 & l & 1 & 1 & l \\
\hline Z2 46.64 & 1 & 1 & 1 & 1 & 1 & 32.2 & 1 & 14 & 1 & 1 & \begin{tabular}{|l|} 
Z2 47.110 \\
\end{tabular} & 16 & 12 & 1 & 1 \\
\hline Z2 47.66 & $\overline{X Y}$ & $15 / 18$ & 18 & 21 & $12 / 13 / 14$ & 31.2 & 13 & 1 & 10 & 11 & \begin{tabular}{|l|} 
Z2 40.109 \\
\end{tabular} & 1 & 1 & 1 & 1 \\
\hline Z2 53.72 & $\mathrm{x}$ & I & 1 & 22 & 13 & 1 & 13 & 1 & 1 & 1 & & & & & \\
\hline Z2 51.76 & $\bar{x}$ & 1 & 1 & 1 & 1 & 1 & 1 & 1 & 1 & 1 & & & & & \\
\hline K 116.128 & 1 & 1 & 1 & 1 & 1 & 1 & 1 & 1 & 1 & 1 & & & & & \\
\hline Genotyp & $X Y$ & 15/18 & $16 / 18$ & $21 / 22$ & $13 / 14$ & 31.2 & 13 & 11 & 11 & 11/11 & Haplotyp & 16 & 12 & 1 & 1 \\
\hline \multicolumn{16}{|c|}{ WG 758 (Zahn 45) } \\
\hline Ex/PCR & Amelo. & 10.151 .2 & VWA & FGA & D8S1179 & $10.152 \quad \mathrm{D}$ & D18S51 & 10.152 .1 & D13S317 & D7S820 & Ex/PCR & DYS19 & DYS3891 & DYS389II & DYS390 \\
\hline Z1 16.34a & $\mathrm{Y}$ & 1 & 16 & 1 & 1 & 1 & 1 & 12 & 1 & 1 & & & & & \\
\hline Z1 16.34b & $X Y$ & 17 & 17 & 1 & 12 & 30 & 1 & 1 & 1 & 1 & & & & & \\
\hline Z1 61.80 & 1 & 1 & 1 & 1 & 1 & 1 & 1 & 1 & 1 & 1 & & & & & \\
\hline Genotyp & $(\mathrm{XY})$ & $I$ & I & 1 & $I$ & $I$ & 1 & $I$ & 1 & 1 & Haplotyp & & & & \\
\hline \multicolumn{16}{|c|}{ WG 763 (Zahn) } \\
\hline Ex/PCR & Amelo. & 10.152 .2 & VWA & FGA & D8S1179 & \begin{tabular}{ll|}
$10.153 \quad \mathrm{D}$ \\
\end{tabular} & D18S51 & 10.153 .1 & D13S317 & D7S820 & Ex/PCR & DYS19 & DYS3891 & DYS389II & DYS390 \\
\hline Z1 62.80 & 1 & 1 & 1 & 1 & 1 & 1 & 1 & 1 & 1 & 1 & & & & & \\
\hline Genotyp & 1 & 1 & 1 & 1 & 1 & 1 & 1 & 1 & 1 & 1 & Haplotyp & & & & \\
\hline
\end{tabular}




\begin{tabular}{|c|c|c|c|c|c|c|c|c|c|c|c|c|c|c|c|}
\hline \multicolumn{16}{|c|}{ WG 775 (Zahn 85) } \\
\hline Ex/PCR & Amelo. & 10.153 .2 & VWA & FGA & D8S1179 & $10.154 \quad D$ & D18S51 & 10.154 .1 & D13S317 & D7S820 & Ex/PCR & DYS19 & DYS3891 & DYS389II & DYS390 \\
\hline Z1 16.34a & $x$ & 17 & 16 & 1 & 1 & 26 & 1 & 1 & 1 & 1 & & & & & \\
\hline Z1 16.34b & 1 & 15 & 14 & 1 & 1 & 1 & 1 & 1 & 1 & 1 & & & & & \\
\hline Z1 62.80 & 1 & 1 & 1 & 1 & 1 & 1 & 1 & 1 & 1 & 1 & & & & & \\
\hline Genotyp & 1 & 1 & 1 & 1 & 1 & 1 & 1 & 1 & 1 & 1 & Haplotyp & & & & \\
\hline \multicolumn{16}{|c|}{ WG 778 (Zahn 36) } \\
\hline Ex/PCR & Amelo. & 10.154 .2 & VWA & FGA & D8S1179 & $10.155 \mathrm{D}$ & D18S51 & 10.155 .1 & D13S317 & D7S820 & Ex/PCR & DYS19 & DYS3891 & DYS389II & DYS390 \\
\hline Z1 9.19 & $x$ & 17 & 1 & 1 & 1 & 1 & 1 & 12 & 1 & 1 & Z19.21a & 1 & 14 & 1 & 24 \\
\hline Z1 9.23a & $\mathrm{XY}$ & 1 & 1 & 1 & 1 & 1 & 1 & $\frac{1}{1}$ & 1 & 1 & Z1 9.21b & 1 & 1 & 7 & 24 \\
\hline Z1 9.23b & 1 & 1 & 1 & 1 & 1 & 1 & 1 & 1 & 1 & 1 & Z1 9.22 & 1 & 1 & 1 & 1 \\
\hline Z162.80 & $\bar{x}$ & 7 & 7 & 1 & 7 & 7 & 7 & 7 & 7 & 7 & & & & & \\
\hline Genotyp & 1 & 1 & $I$ & 1 & $I$ & 1 & 1 & 1 & I & I & Haplotyp & $I$ & 1 & I & I \\
\hline \multicolumn{16}{|c|}{ WG 779 (Zahn 83) } \\
\hline Ex/PCR & Amelo. & 10.155 .2 & VWA & FGA & D8S1179 & $10.156 \quad \mathrm{D}$ & D18S51 & 10.156 .1 & D13S317 & D7S820 & Ex/PCR & DYS19 & DYS389| & DYS389II & DYS390 \\
\hline Z1 62.80 & 1 & 1 & 1 & 1 & 1 & 1 & 1 & 1 & 1 & 1 & & & & & \\
\hline Genotyp & 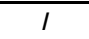 & 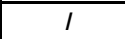 & 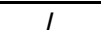 & 1 & 1 & 1 & 1 & 1 & 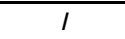 & $\frac{1}{1}$ & Haplotyp & & & & \\
\hline \multicolumn{16}{|c|}{ WG 781 (Zahn 16, Zahn 14, Femur) } \\
\hline Ex/PCR & Amelo. & 10.156 .2 & VWA & FGA & D8S1179 & $10.157 \quad \mathrm{D}$ & D18S51 & 10.157 .1 & D13S317 & D7S820 & Ex/PCR & DYS19 & DYS3891 & DYS389II & DYS390 \\
\hline Z1 45.61 & $\mathrm{XY}$ & 15 & 1 & $20 / 21$ & $13 / 14$ & 30 & 15 & 12 & 11 & 8 & Z1 45.77 & 1 & 12 & 28 & 22 \\
\hline Z1 52.70 & $\mathrm{x}$ & 1 & 1 & 1 & 1 & 1 & 1 & 1 & 1 & 1 & Z1 78.110 & 1 & 1 & 1 & 1 \\
\hline Z1 52.76 & 1 & 1 & 1 & 1 & 1 & 1 & 1 & 1 & 1 & 1 & & & & & \\
\hline Z1 78.92 & $X Y$ & $(15) / 16$ & 1 & 21 & 15 & 29 & 15 & 13 & 11 & 1 & & & & & \\
\hline Z2 95.103 & $x$ & 1 & 1 & 1 & 1 & 1 & 1 & 1 & 11 & 1 & & & & & \\
\hline K 116.128 & 1 & 1 & 1 & 1 & 1 & 1 & 1 & 1 & 1 & 1 & & & & & \\
\hline K 118.131 & 1 & 1 & 1 & 1 & 1 & 1 & 1 & 1 & 1 & 1 & & & & & \\
\hline Genotyp & $X Y$ & 1 & 1 & 21 & 1 & 1 & 15 & 1 & 11 & 1 & Haplotyp & 1 & 1 & 1 & 1 \\
\hline \multicolumn{16}{|c|}{ WG 785 (Zahn 48, Femur) } \\
\hline Ex/PCR & Amelo. & 10.157 .2 & VWA & FGA & D8S1179 & $10.158 \quad \mathrm{D}$ & D18S51 & 10.158 .1 & D13S317 & D7S820 & Ex/PCR & DYS19 & DYS3891 & DYS389II & DYS390 \\
\hline Z1 45.61 & $\mathrm{XY}$ & $(15) / 16$ & 14 & $22 / 23.2$ & $12 / 14$ & 32.2 & 1 & $9 / 12$ & 13 & 9 & Z1 45.85 & 1 & 1 & 1 & 1 \\
\hline Z1 46.64 & $X Y$ & 16 & 14 & $21 / 24$ & $17 / 18$ & 32.2 & 1 & 9 & 11 & 1 & Z1 46.85 & 14 & 1 & 1 & 26 \\
\hline Z151.76 & $\mathrm{XY}$ & $15 / 16$ & 1 & 1 & 1 & 1 & 1 & 12 & 11 & & Z151.77 & 1 & 15 & 1 & 22 \\
\hline Z1 78.92 & $X Y$ & 16 & $(13) / 14$ & 1 & 1 & 1 & 1 & 1 & 1 & 1 & Z1 78.122 & 1 & 1 & 1 & 22 \\
\hline K 116.128 & 1 & 1 & 1 & 1 & 1 & 1 & 1 & 1 & 1 & 1 & Z1 78.110 & 1 & 1 & 1 & 22 \\
\hline K 118.131 & 1 & 1 & 1 & 1 & 1 & 1 & 1 & 1 & 1 & 1 & & & & & \\
\hline Genotyp & $\mathrm{XY}$ & $15 / 16$ & $14 / 14$ & 1 & 1 & 32.2 & 1 & $9 / 12$ & 11 & 1 & Haplotyp & 1 & 1 & 1 & 22 \\
\hline
\end{tabular}


WG 790 (Zahn 26)

\begin{tabular}{|c|c|c|c|c|c|c|c|c|c|c|c|c|c|c|c|}
\hline \multicolumn{16}{|c|}{ WG 790 (Zahn 26) } \\
\hline Ex/PCR & Amelo. & 10.158 .2 & VWA & FGA & D8S1179 & $10.159 \mathrm{D}$ & D18S51 & 10.159 .1 & D13S317 & D7S820 & Ex/PCR & DYS19 & DYS389I & DYS389II & DYS390 \\
\hline Z1 29.48 & $X Y$ & 17 & 16 & 23 & 1 & 32.2 & 1 & 1 & 1 & 9 & Z1 29.55 & 1 & 1 & 1 & 1 \\
\hline Z1 29.51 & $\mathrm{x}$ & 18 & 17 & 19 & $13 / 14$ & 1 & 1 & 11 & 12 & 9 & & & & & \\
\hline Z1 34.53 & 1 & 1 & 1 & 1 & 1 & I & 1 & l & 1 & 1 & & & & & \\
\hline Genotyp & 1 & 1 & 1 & 1 & I & I & I & 1 & 1 & (9) & Haplotyp & 1 & 1 & 1 & 1 \\
\hline \multicolumn{16}{|c|}{ WG 796 (Zahn 36) } \\
\hline Ex/PCR & Amelo. & 10.159 .2 & VWA & FGA & D8S1179 & $10.160 \mathrm{D}$ & D18S51 & 10.160 .1 & D13S317 & D7S820 & & & & & \\
\hline Z1 62.80 & $\mathrm{x}$ & 15 & 1 & 1 & 1 & 1 & I & 10 & 1 & I & & & & & \\
\hline Z1 78.92 & $\mathrm{X}$ & 1 & 1 & 1 & 1 & 1 & 1 & 1 & 1 & 1 & & & & & \\
\hline Genotyp & $x x$ & 1 & 1 & 1 & 1 & 1 & I & 1 & 1 & 1 & & & & & \\
\hline \multicolumn{16}{|c|}{ WG 799 (Zahn 47) } \\
\hline Ex/PCR & Amelo. & 10.160 .2 & VWA & FGA & D8S1179 & $10.161 \mathrm{D}$ & D18S51 & 10.161 .1 & D13S317 & D7S820 & Ex/PCR & DYS19 & DYS389I & DYS389II & DYS390 \\
\hline Z1 47.66 & $\mathrm{XY}$ & 18 & 17 & 22 & 13 & 1 & 14 & 1 & $11 / 12$ & 1 & Z1 47.85 & 1 & 15 & 1 & 23 \\
\hline Z1 62.80 & $\mathrm{x}$ & 1 & 1 & 1 & 17 & $29 / 30$ & 1 & 1 & 1 & 9 & Z1 47.110 & 1 & 1 & 1 & 1 \\
\hline Z1 78.92 & $\mathrm{X}$ & $(14) / 15$ & 1 & 19 & 1 & 1 & 1 & 1 & $9 / 12$ & 1 & & & & & \\
\hline Genotyp & 1 & 1 & 1 & 1 & 1 & 1 & 1 & 1 & 1 & I & Haplotyp & 1 & $I$ & 1 & 1 \\
\hline
\end{tabular}


Tabelle 10.4: Haplotypisierungsergebnisse der mt-DNA-Multiplex-PCR der analysierten Weingartener Individuen. Angegeben sind die Abweichungen zur Anderson-Referenz Sequenz (Anderson et al. 1981) für die Abschnitte aus der mitochondrialen Kontrollregion, die hier HVRI A, HVRI B und HVRII C genannt werden. Ein „. “ “ bedeutet, daß kein Unterschied vorliegt. Ein „, “ “ zeigt an, daß die Position nicht lesbar war. Die Bezeichnung „I “ steht für die Insertion einer Base. Bei dem Nachweis mehrerer Basen an einer Position wurden die IUB-Codes verwendet.

\begin{tabular}{|c|c|c|c|c|c|c|c|c|c|c|c|c|c|c|c|c|c|c|c|c|c|c|c|c|c|c|c|c|c|c|c|c|c|c|c|c|c|c|c|c|c|c|c|c|c|c|c|c|}
\hline & & \multicolumn{18}{|c|}{$\begin{array}{c}\text { HVR1 A } \\
\text { (Pos. 16234-16316) }\end{array}$} & \multicolumn{14}{|c|}{$\begin{array}{c}\text { HVR1 B } \\
\text { (Pos. 16049 - 16172) }\end{array}$} & \multicolumn{15}{|c|}{$\begin{array}{c}\text { HVR2 C } \\
\text { (Pos. 150-322) }\end{array}$} \\
\hline $\begin{array}{l}\text { Ind. } \\
\text { Nr. }\end{array}$ & & & $\begin{array}{l}1 \\
6 \\
2 \\
4 \\
9\end{array}$ & $\begin{array}{l}1 \\
6 \\
2 \\
5 \\
6\end{array}$ & $\begin{array}{l}1 \\
6 \\
2 \\
6 \\
1\end{array}$ & $\begin{array}{l}1 \\
6 \\
2 \\
6 \\
5\end{array}$ & $\begin{array}{l}1 \\
6 \\
2 \\
6 \\
6\end{array}$ & $\begin{array}{l}1 \\
6 \\
2 \\
7 \\
0\end{array}$ & $\begin{array}{l}1 \\
6 \\
2 \\
7 \\
8\end{array}$ & $\begin{array}{l}1 \\
6 \\
2 \\
8 \\
8\end{array}$ & $\begin{array}{l}1 \\
6 \\
2 \\
9 \\
2\end{array}$ & $\begin{array}{l}1 \\
6 \\
2 \\
9 \\
4\end{array}$ & $\begin{array}{l}1 \\
6\end{array}$ & $\begin{array}{l}1 \\
6 \\
2 \\
9 \\
6\end{array}$ & $\begin{array}{l}1 \\
6 \\
2 \\
9 \\
8\end{array}$ & $\begin{array}{l}1 \\
6 \\
3 \\
0 \\
1\end{array}$ & $\begin{array}{l}1 \\
6 \\
3 \\
0 \\
2\end{array}$ & $\begin{array}{l}1 \\
6 \\
3 \\
0 \\
4\end{array}$ & $\begin{array}{l}1 \\
6\end{array}$ & & $\begin{array}{l}1 \\
6 \\
0 \\
9 \\
2\end{array}$ & $\begin{array}{l}1 \\
6 \\
0 \\
9 \\
3\end{array}$ & $\begin{array}{l}1 \\
6 \\
1 \\
1 \\
1\end{array}$ & $\begin{array}{l}1 \\
6 \\
1 \\
2 \\
4\end{array}$ & $\begin{array}{l}1 \\
6 \\
1 \\
2 \\
6\end{array}$ & $\begin{array}{l}1 \\
6 \\
1 \\
2 \\
9\end{array}$ & $\begin{array}{l}1 \\
6 \\
1 \\
3 \\
4\end{array}$ & $\begin{array}{l}1 \\
6 \\
1 \\
4 \\
5\end{array}$ & $\begin{array}{l}1 \\
6 \\
1 \\
6 \\
2\end{array}$ & $\begin{array}{l}1 \\
6 \\
1 \\
6 \\
3\end{array}$ & $\begin{array}{l}1 \\
6 \\
1 \\
6 \\
4\end{array}$ & $\begin{array}{l}1 \\
6 \\
1 \\
6 \\
8\end{array}$ & $\begin{array}{l}1 \\
6 \\
1 \\
7 \\
2\end{array}$ & $\begin{array}{l}1 \\
8 \\
5\end{array}$ & $\begin{array}{l}1 \\
8 \\
8\end{array}$ & $\begin{array}{l}1 \\
8 \\
9\end{array}$ & $\begin{array}{l}1 \\
9 \\
5\end{array}$ & $\begin{array}{l}2 \\
0 \\
0\end{array}$ & $\begin{array}{l}2 \\
0 \\
4\end{array}$ & $\begin{array}{l}2 \\
0 \\
7\end{array}$ & $\begin{array}{l}2 \\
1 \\
7\end{array}$ & $\begin{array}{l}2 \\
2 \\
8\end{array}$ & & $\begin{array}{l}2 \\
6 \\
3\end{array}$ & $\begin{array}{l}2 \\
8 \\
5\end{array}$ & $\begin{array}{l}2 \\
9 \\
5\end{array}$ & $\begin{array}{l}3 \\
0 \\
9 \\
1\end{array}$ & \\
\hline Anderson & & C & $\mathrm{T}$ & G & C & A & C & C & C & $\mathrm{T}$ & C & C & C & C & $\mathrm{T}$ & C & A & $\mathrm{T}$ & $\mathrm{T}$ & C & $\mathrm{T}$ & $\mathrm{T}$ & $\mathrm{T}$ & $\mathrm{T}$ & $\mathrm{T}$ & G & C & G & A & A & A & C & $\mathrm{T}$ & G & A & A & $\mathrm{T}$ & A & $\mathrm{T}$ & G & $\mathrm{T}$ & G & $\mathrm{T}$ & A & C & C & - & \\
\hline 52 & $\mathrm{mt} 1$ & & . & & . & . & & & . & & . & & . & . & . & . & & . & C & & . & & . & . & & & . & . & & & & & & & & & & . & . & & . & . & . & G & & & & \\
\hline 182 & $\mathrm{mt} 1$ & I & 1 & 1 & 1 & 1 & & & . & & . & & . & . & & . & & . & C & I & & & . & & & & . & . & & & & & & & & & . & . & . & & . & . & . & G & & & . & \\
\hline 221 & $\mathrm{mt1}$ & & . & . & . & . & & & . & . & . & & . & . & . & . & & . & P & & . & & . & & & & . & . & & & & & & & & & . & . & . & & . & . & . & G & & & & \\
\hline 256 & $\mathrm{mt} 1$ & . & & & & & . & & & & & . & & & & & & & C & & & . & & & & & & & & . & & & & & . & & & & & & & & & G & . & & . & \\
\hline 270 & $\mathrm{mt1}$ & & . & & & . & & . & & & . & & & & & & & . & C & & . & & & & & . & & & . & & . & & . & & & . & & & . & & . & & & G & & . & & C \\
\hline 298 & $\mathrm{mt1}$ & & . & . & . & . & & & . & . & . & & . & . & . & . & & . & C & & . & & . & . & & . & . & . & . & & . & & & & & & . & . & . & & . & . & . & G & & & & $\begin{array}{l}\text { I: } \\
\text { C }\end{array}$ \\
\hline 322 & $\mathrm{mt1}$ & . & & & & & & & & & & . & & & & & . & & ? & . & & . & & & & & & & & . & & & I & & . & & & & & . & & & & G & & & . & $\begin{array}{l}\text { I: } \\
\mathrm{C}\end{array}$ \\
\hline 397 & $\mathrm{mt} 1$ & & . & & & . & & . & & & . & & . & & & . & & . & C & & . & & . & . & & . & & & . & & . & & I & & & . & & & . & & . & & & G & & . & & $\begin{array}{l}\text { I: } \\
\text { c }\end{array}$ \\
\hline 715 & $\mathrm{mt} 1$ & & . & . & . & . & & & . & & . & & . & . & . & . & & . & $\mathrm{Y}$ & & . & & . & . & & & & . & . & & . & & . & & & & & . & . & & . & . & . & G & & & & C \\
\hline 111 & $\mathrm{mt} 2$ & & . & & & . & & & & & . & & . & & & . & & . & & $\mathrm{T}$ & . & & . & . & C & & & A & . & & . & & C & & & & & & C & & . & & & G & & . & . & C \\
\hline 115 & mt3 & & . & & & . & & & & & . & & . & . & & . & & . & & & . & & . & . & & & & . & . & & . & & & & & & & & . & & . & & & G & & . & I: & I: \\
\hline 125 & $\mathrm{~m}+3$ & & . & & . & . & & & . & & . & & . & . & . & . & & . & . & & . & & . & . & & & & . & . & & . & & & & & & & . & . & & . & . & . & G & & & I: & I: \\
\hline 704 & $\mathrm{mt3}$ & & . & & & . & & & & & . & & & & & . & & . & & & . & & . & . & & . & & & . & & . & & & & & & & & . & & . & & & G & & . & $\begin{array}{l}\text { l: } \\
\mathrm{C}\end{array}$ & C \\
\hline 130 & $\mathrm{~m} t 4$ & & . & & & . & & . & . & & . & & . & . & & . & & . & & & . & & . & . & & . & & . & . & & . & & & & & & & . & . & & . & . & . & G & & . & . & $\begin{array}{l}\text { l: } \\
\mathrm{C}\end{array}$ \\
\hline 199 & $\mathrm{mt4}$ & & . & & . & . & & & . & & . & & . & . & . & . & & . & . & & . & & . & . & & & & . & . & & . & & & & & & & . & . & & . & . & . & G & & . & & $\begin{array}{l}\text { I: } \\
\text { c }\end{array}$ \\
\hline 257 & $\mathrm{mt} 4$ & & . & & & . & & & & & . & & & & & . & & & & & . & & & & & & & & 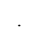 & & . & & & & & & & & . & & & & & G & & . & & $\begin{array}{l}\text { li: } \\
\mathrm{c}\end{array}$ \\
\hline 282 & $\mathrm{mt} 4$ & . & & & & & & & & & & . & & & & & & & & & & . & & & & & & & & . & & & & & . & & & & & . & & & & G & . & & . & I: \\
\hline 395 & $\mathrm{mt4}$ & & . & & . & . & & . & . & & . & & . & . & . & . & & . & . & & . & & . & . & & & . & . & . & & . & & 1 & & & & & . & . & & . & . & . & G & & & · & C \\
\hline 464 & $\mathrm{mt4}$ & & & & & & & . & & & & & & & & & & & & & & & & & & & & & . & & & & & & & , & & & . & & & & & G & & & & $\begin{array}{l}\text { I: } \\
\text { c }\end{array}$ \\
\hline 568 & $\mathrm{mt} 4$ & . & & & & & & & & & & . & & & & & . & & & . & & . & & & & & & & & . & & & 1 & & . & & & & & . & & & & G & . & & 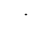 & $\begin{array}{l}\text { I: } \\
\text { C: }\end{array}$ \\
\hline 590 & $\mathrm{mt} 4$ & & . & & . & . & & & . & . & . & & . & . & . & . & & . & . & & . & & . & . & & & . & . & . & & & & & & & & . & . & . & & . & . & . & G & & . & . & o. \\
\hline 612 & $\mathrm{mt} 4$ & & & & & & & & & & & & & & & & . & & & & & & & & & & & & & & & . & & & & & & & & . & & & & G & & & & \\
\hline 631 & $\mathrm{mt} 4$ & . & & & & & . & & & & & . & & & & & & & & & & & & & & & & & & & & & & & . & & & & & & & & & G & . & & & \\
\hline
\end{tabular}




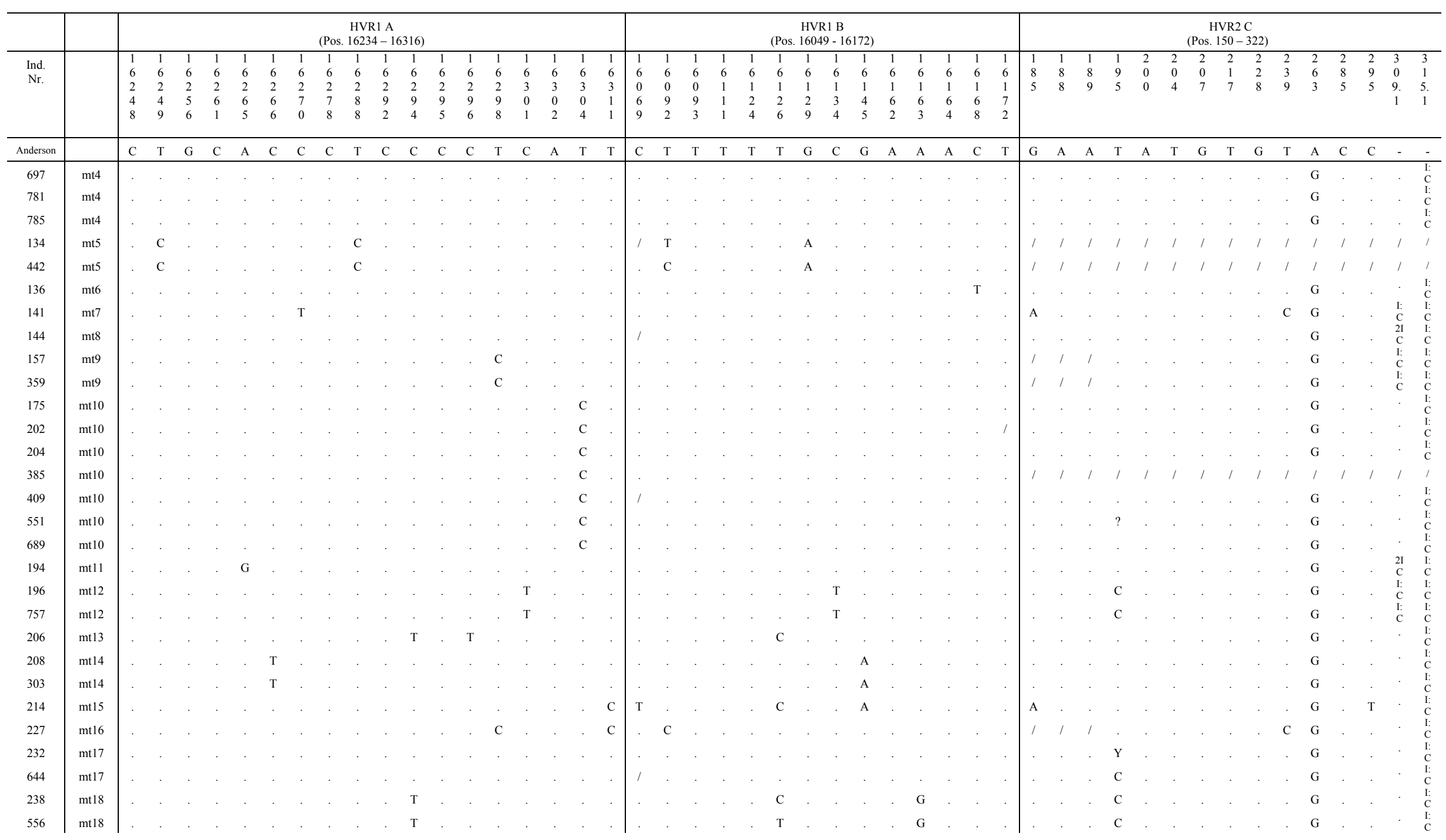




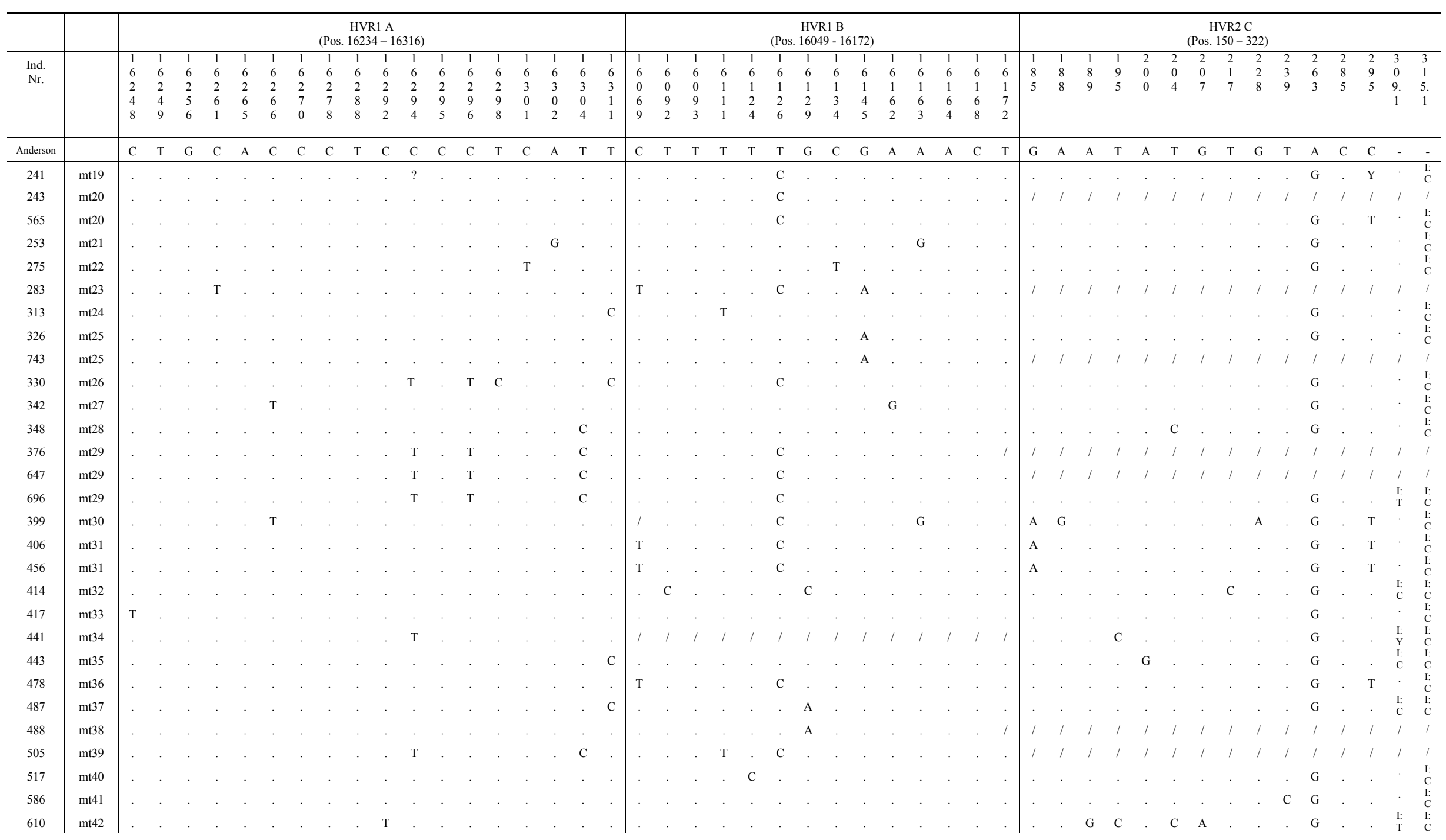




\begin{tabular}{|c|c|c|c|c|c|c|c|c|c|c|c|c|c|c|c|c|c|c|c|c|c|c|c|c|c|c|c|c|c|c|c|c|c|c|c|c|c|c|c|c|c|c|c|c|c|c|c|c|}
\hline \multirow[b]{2}{*}{$\begin{array}{l}\text { Ind. } \\
\text { Nr. }\end{array}$} & & \multicolumn{18}{|c|}{$\begin{array}{c}\text { HVR1 A } \\
\text { (Pos. 16234-16316) }\end{array}$} & \multicolumn{14}{|c|}{$\begin{array}{c}\text { HVR1 B } \\
\text { (Pos. 16049- - 16172) } \\
\end{array}$} & \multicolumn{15}{|c|}{$\begin{array}{c}\text { HVR2 C } \\
\text { (Pos. 150-322) }\end{array}$} \\
\hline & & & & $\begin{array}{l}1 \\
6 \\
2 \\
5 \\
6\end{array}$ & $\begin{array}{l}1 \\
6 \\
2 \\
6 \\
1\end{array}$ & $\begin{array}{l}1 \\
6 \\
2 \\
6 \\
5\end{array}$ & $\begin{array}{l}1 \\
6 \\
2 \\
6 \\
6\end{array}$ & $\begin{array}{l}1 \\
6 \\
2 \\
7 \\
0\end{array}$ & $\begin{array}{l}1 \\
6 \\
2 \\
7 \\
8\end{array}$ & $\begin{array}{l}1 \\
6 \\
2 \\
8 \\
8\end{array}$ & $\begin{array}{l}1 \\
6 \\
2 \\
9 \\
2\end{array}$ & $\begin{array}{l}1 \\
6 \\
2 \\
9 \\
4\end{array}$ & $\begin{array}{l}1 \\
6 \\
2 \\
9 \\
5\end{array}$ & $\begin{array}{l}1 \\
6 \\
2 \\
9 \\
6\end{array}$ & $\begin{array}{l}1 \\
6 \\
2 \\
9 \\
8\end{array}$ & $\begin{array}{l}1 \\
6 \\
3 \\
0 \\
1\end{array}$ & $\begin{array}{l}1 \\
6 \\
3 \\
0 \\
2\end{array}$ & $\begin{array}{l}1 \\
6 \\
3 \\
0 \\
4\end{array}$ & $\begin{array}{l}1 \\
6 \\
3 \\
1 \\
1\end{array}$ & $\begin{array}{l}1 \\
6 \\
0 \\
6 \\
9\end{array}$ & $\begin{array}{l}1 \\
6 \\
0 \\
9 \\
2\end{array}$ & $\begin{array}{l}1 \\
6 \\
0 \\
9 \\
3\end{array}$ & $\begin{array}{l}1 \\
6 \\
1 \\
1 \\
1\end{array}$ & $\begin{array}{l}1 \\
6 \\
1 \\
2 \\
4\end{array}$ & $\begin{array}{l}1 \\
6 \\
1 \\
2 \\
6\end{array}$ & $\begin{array}{l}1 \\
6 \\
1 \\
2 \\
9\end{array}$ & $\begin{array}{l}1 \\
6 \\
1 \\
3 \\
4\end{array}$ & $\begin{array}{l}1 \\
6 \\
1 \\
4 \\
5\end{array}$ & $\begin{array}{l}1 \\
6 \\
1 \\
6 \\
2\end{array}$ & $\begin{array}{l}1 \\
6 \\
1 \\
6 \\
3\end{array}$ & $\begin{array}{l}1 \\
6 \\
1 \\
6 \\
4\end{array}$ & & $\begin{array}{l}1 \\
6 \\
1 \\
7 \\
2\end{array}$ & $\begin{array}{l}1 \\
8 \\
5\end{array}$ & $\begin{array}{l}1 \\
8 \\
8\end{array}$ & $\begin{array}{l}1 \\
8 \\
9\end{array}$ & $\begin{array}{l}1 \\
9 \\
5\end{array}$ & $\begin{array}{l}2 \\
0 \\
0\end{array}$ & $\begin{array}{l}2 \\
0 \\
4\end{array}$ & $\begin{array}{l}2 \\
0 \\
7\end{array}$ & & & $\begin{array}{l}2 \\
3 \\
9\end{array}$ & $\begin{array}{l}2 \\
6 \\
3\end{array}$ & $\begin{array}{l}2 \\
8 \\
5\end{array}$ & & & $\begin{array}{l}3 \\
1 \\
5 . \\
1\end{array}$ \\
\hline Anderson & & $\mathrm{C}$ & $\mathrm{T}$ & G & $\mathrm{C}$ & A & $\mathrm{C}$ & $\mathrm{C}$ & $\mathrm{C}$ & $\mathrm{T}$ & C & $\mathrm{C}$ & $\mathrm{C}$ & $\mathrm{C}$ & $\mathrm{T}$ & C & $\mathrm{A}$ & $\mathrm{T}$ & $\mathrm{T}$ & $\mathrm{C}$ & $\mathrm{T}$ & $\mathrm{T}$ & $\mathrm{T}$ & $\mathrm{T}$ & $\mathrm{T}$ & G & $\mathrm{C}$ & G & A & A & $\mathrm{A}$ & C & $\mathrm{T}$ & $\mathrm{G}$ & A & $\mathrm{A}$ & $\mathrm{T}$ & $\mathrm{A}$ & $\mathrm{T}$ & $\mathrm{G}$ & $\mathrm{T}$ & G & $\mathrm{T}$ & $\mathrm{A}$ & $\mathrm{C}$ & $\mathrm{C}$ & - & - \\
\hline 724 & $\mathrm{mt} 42$ & & . & . & . & . & . & . & . & . & $\mathrm{T}$ & . & . & . & . & . & . & . & . & & . & . & . & . & . & . & . & . & . & . & . & . & . & 1 & 1 & 1 & 1 & 1 & 1 & 1 & 1 & 1 & 1 & 1 & 1 & 1 & 1 & \\
\hline 748 & $\mathrm{mt} 42$ & & & & & & & & & . & $\mathrm{T}$ & & & & & & & & & & & & . & & 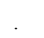 & & & & & . & & & & & . & G & C & . & $\mathrm{C}$ & A & & & & G & & & $\begin{array}{l}\text { I: } \\
\text { C }\end{array}$ & I: \\
\hline 619 & $\mathrm{mt} 43$ & & . & . & . & & . & $\mathrm{T}$ & & . & & . & . & & . & & . & . & . & & & . & . & & & & . & . & & . & & . & . & & . & & . & . & & . & . & & . & G & . & . & $\begin{array}{l}\text { I: } \\
\text { C }\end{array}$ & \\
\hline 620 & $\mathrm{~m}+43$ & & & . & . & & . & $\mathrm{T}$ & & . & & . & . & . & . & & . & . & . & & & . & . & . & . & & . & . & . & . & & . & & 1 & I & 1 & 1 & 1 & I & 1 & 1 & 1 & 1 & 1 & 1 & 1 & 1 & I \\
\hline 625 & $\mathrm{mt} 44$ & & & & & & & & & . & & $\mathrm{T}$ & & $\mathrm{T}$ & & & & & & & & & & & & & & & & . & & & & & . & & & . & & . & & & & G & . & & & $\begin{array}{l}\text { l: } \\
\text { c }\end{array}$ \\
\hline 658 & $\mathrm{~m}+45$ & & & & & . & & & & & $\mathrm{T}$ & $\mathrm{T}$ & & & & . & & & & & & & & . & $\mathrm{Y}$ & & & & & & & & & . & & & & & . & & & & & G & & & . & \\
\hline 668 & $\mathrm{mt} 46$ & & . & . & . & & . & . & & . & & . & . & & . & & . & . & C & & & C & . & & . & . & . & . & & . & . & . & . & & . & & . & . & & . & . & . & . & G & . & . & $\begin{array}{l}\text { I: } \\
\text { C }\end{array}$ & \\
\hline 699 & $\mathrm{mt} 47$ & & & & & & & $\mathrm{Y}$ & & & & & & & & & & & & & & & . & & & & & & & & & & & & & & & & & & & & & G & & $\mathrm{Y}$ & & \\
\hline 796 & $\mathrm{mt} 48$ & & & & $\mathrm{~T}$ & . & & & & & & & & & & & & & & & & & & . & & & & & . & & & & & . & & & & & . & & & & & G & & & . & $\begin{array}{l}\text { l: } \\
\text { C }\end{array}$ \\
\hline 799 & $\mathrm{mt}+49$ & & . & . & . & & . & . & & . & & $\mathrm{T}$ & . & & . & & . & C & . & & & . & . & & C & & . & . & & . & . & . & . & & . & & $\mathrm{Y}$ & . & & . & . & . & . & G & . & . & . & $\begin{array}{l}\text { I: } \\
\text { c }\end{array}$ \\
\hline 164 & $\mathrm{~m} t 50$ & & . & . & . & & . & . & . & . & & $\mathrm{T}$ & . & $\mathrm{T}$ & C & & . & . & . & & & . & . & & C & & . & . & & . & . & . & . & & . & G & C & . & & . & . & . & . & G & . & . & & \\
\hline 179 & $\mathrm{~m} t 50$ & & & & & . & & & & & & $\mathrm{T}$ & & $\mathrm{T}$ & C & . & & & & & & & & . & C & & & & . & & & & & . & & & C & & . & & & & & G & & & & $\begin{array}{l}\text { I: } \\
\text { C }\end{array}$ \\
\hline 344 & $\mathrm{~m}+50$ & & & . & . & & . & . & . & . & & $\mathrm{T}$ & & $\mathrm{T}$ & C & & . & . & . & & & . & . & . & C & & . & . & . & . & & . & . & 1 & 1 & 1 & 1 & 1 & 1 & 1 & 1 & 1 & 1 & 1 & 1 & 1 & 1 & 1 \\
\hline 66 & $?$ & & . & . & . & & . & . & . & . & & . & . & . & . & & . & . & C & & & . & . & & . & & . & . & & . & & & . & 1 & 1 & I & 1 & 1 & 1 & 1 & 1 & 1 & 1 & I & 1 & 1 & 1 & I \\
\hline 119 & ? & & & & & . & & $\mathrm{T}$ & & & . & & & & & & & & & & . & & & & & & & & & & . & & & 1 & I & I & 1 & 1 & 1 & 1 & 1 & 1 & 1 & 1 & 1 & 1 & 1 & 1 \\
\hline 153 & ? & & & & & & & & & & & & & & & & . & & & & & & & & & & & & & & & & & 1 & I & I & 1 & 1 & 1 & 1 & 1 & 1 & 1 & 1 & 1 & 1 & 1 & I \\
\hline 231 & ? & & . & . & . & & . & . & . & . & & . & . & . & . & & . & . & . & & & . & . & . & . & & . & . & . & . & & & 1 & 1 & 1 & 1 & 1 & 1 & 1 & 1 & 1 & 1 & 1 & 1 & 1 & 1 & 1 & 1 \\
\hline 260 & ? & & & . & . & & . & . & . & . & & . & & . & . & & . & & C & 1 & & . & . & & . & & . & & & . & & . & & 1 & 1 & 1 & 1 & 1 & 1 & 1 & 1 & 1 & 1 & 1 & 1 & 1 & 1 & 1 \\
\hline 278 & ? & 1 & I & 1 & 1 & 1 & 1 & 1 & 1 & 1 & I & 1 & 1 & 1 & 1 & 1 & 1 & 1 & 1 & 1 & 1 & 1 & 1 & 1 & 1 & 1 & 1 & 1 & 1 & 1 & 1 & 1 & 1 & 1 & 1 & 1 & 1 & 1 & 1 & 1 & 1 & 1 & 1 & 1 & 1 & 1 & 1 & 1 \\
\hline 363 & ? & & . & . & . & & . & . & . & . & & . & & . & . & & . & . & . & & & . & . & . & . & & . & . & . & . & & . & 1 & 1 & 1 & 1 & 1 & 1 & 1 & 1 & 1 & 1 & 1 & 1 & 1 & 1 & 1 & 1 \\
\hline 411 & ? & 1 & & . & . & & . & . & & . & & . & & . & . & & & . & . & 1 & & . & . & & . & & . & & & . & & . & & 1 & 1 & 1 & 1 & 1 & 1 & 1 & 1 & 1 & 1 & 1 & 1 & 1 & 1 & I \\
\hline 480 & ? & & & & . & & & & & . & & & & & & & . & & C & . & & & & & . & & . & & & . & & . & & 1 & 1 & 1 & 1 & 1 & 1 & 1 & 1 & 1 & 1 & 1 & 1 & 1 & 1 & I \\
\hline 507 & ? & & & . & . & & . & . & . & . & $\mathrm{T}$ & $\mathrm{T}$ & $\mathrm{T}$ & C & . & & . & & . & 1 & 1 & 1 & I & 1 & 1 & 1 & 1 & 1 & 1 & 1 & 1 & 1 & 1 & 1 & 1 & 1 & 1 & 1 & 1 & 1 & I & 1 & 1 & 1 & 1 & 1 & 1 & I \\
\hline 567 & ? & & & . & . & & . & & & . & & . & & . & . & & & & . & & & . & . & & . & & . & & & . & & & & 1 & I & 1 & 1 & 1 & 1 & 1 & 1 & 1 & 1 & 1 & 1 & 1 & 1 & I \\
\hline 655 & ? & & & & . & & . & & & & & . & & & & & . & & & & & & & & & & & & ? & & & & & 1 & I & 1 & 1 & 1 & 1 & 1 & 1 & 1 & 1 & 1 & 1 & 1 & 1 & 1 \\
\hline 733 & ? & & & & & & & & 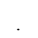 & & & & & . & & & & 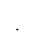 & & & & & 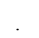 & & & & & & G & & & & & 1 & 1 & 1 & 1 & 1 & 1 & 1 & 1 & 1 & 1 & 1 & 1 & 1 & 1 & 1 \\
\hline
\end{tabular}




\section{Danksagung}

Bedanken möchte ich mich bei Prof. Dr. Bernd Herrmann für die Bereitstellung des Themas, des Arbeitsplatzes und insbesondere für seine Langmut in der Endphase der Arbeit.

Mein besonderer Dank gilt außerdem Frau Dr. Susanne Hummel für ihre Unterstützung und Ratschläge während des gesamten Verlaufs der Arbeit. Darüber hinaus bin ich ihr, wie auch Frau Dr. Cadja Lassen, für die Konzipierung des Weingarten-Projekts zu Dank verpflichtet.

Der Stadt Weingarten und Herrn Dr. Joachim Wahl, Landesdenkmalamt BadenWürttemberg, sei für die freundliche Überlassung der Probenmaterials gedankt.

Bedanken möchte ich mich bei den studentischen Hilfskräften: Marielle Heinrich, Frauke Güntzler, Long-Xiang Lee, Jan Stindt, Vera Stankow und Eva Czirr. Großer Dank für die Laborarbeit gilt auch Annegret Becker.

Großer Dank gilt vielen weiteren Kollegen und Freunden, insbesondere aber Dr. Tobias Schultes, Dr. Joachim Burger, Dr. Barbara Bramanti, Dr. Holger Schutkowski, Svenja Weise, Andrea Bartels, Birgit Großkopf, Holger Zierdt, Diane Schmidt, Sabine Becker, Ed George, Gerlinde Tavakolian, Sybille Hourticolon, Karin Haack, Uta Immel, Ruth Bollongino, Nicole Weber, Birgit Zeike, Boris Müller, Dr. Odile Loreille. Allergrößter Dank gilt natürlich Sascha Fabig.

Darüberhinaus möchte ich mich ganz herzlich bei meiner Mutter bedanken.

Diese Arbeit wurde aus Mitteln der Deutschen Forschungsgemeinschaft finanziert. 


\section{Lebenslauf}

Julia Gerstenberger

Staatsangehörigkeit: deutsch

02.05 .1971

geboren in Osnabrück

1977 - 1981

Grundschule in Gaste

$1981-1983$

Orientierungsstufe in Hasbergen

$1988-1989$

Auslandsschuljahr in San Antonio, Texas, USA

$1983-1991$

Ratsgymnasium in Osnabrück

14.05.1991

$1991-1992$

$1992-1998$

20.10 .1994

$1997-1998$

28.12.1998

$01.10 .98-30.06 .99$

Erlangen der Allgemeinen Hochschulreife

Studium der Geschichte/Politikwissenschaft, Universität Osnabrück

Studium der Biologie an der Georg-August-Universität Göttingen

Biologie-Vordiplomsprüfung in den Fächern Zoologie, Mikrobiologie, Chemie, Physikalische Chemie

Mündliche Prüfungen zum Diplom in den Fächern Anthropologie, Mikrobiologie, Psychologie

Diplomarbeit am Institut für Zoologie und Anthropologie, Abt. Historische Anthropologie und Humanökologie mit dem Titel: „Rekonstruktion familiärer Verwandtschaft durch autosomale STR und Y-Haplotypen Analyse von alter DNA“

Absolvierung des Diploms in Biologie

Wissenschaftliche Hilfskraft im Dekanat der Biologischen Fakultät, Universität Göttingen

15.04.99 - 15.06.99 Werksvertrag mit der Universität Göttingen am Institut für Zoologie und Anthropologie, Abt. Historische Anthropologie und Humanökologie für das Projekt: „Extraktion und Amplifikation von Proben aus dem Fundkomplex Wremen zur molekularen Geschlechtsdeterminierung und STRTypisierung“.

01.07.99-31.12.01 Wissenschaftliche Angestellte am Institut für Zoologie und Anthropologie, Abt. für Anthropologie und Humanökologie der Universität Göttingen und Beginn des Promotionsvorhabens „Analyse alter DNA zur Ermittlung von Heiratsmustern in einer frühmittelalterlichen Bevölkerung“ im Rahmen des DFG-Projekts „Rekonstruktion von Heiratsmustern durch genetische Typisierungen von Skeletten einer frühmittelalterlichen, sozial stratifizierten Bevölkerung“. 